“KISS TODAY GOODBYE, AND POINT ME TOWARD TOMORROW”:

REVIVING THE TIME-BOUND MUSICAL, 1968-1975

A Dissertation

Presented to

The Faculty of the Graduate School

At the University of Missouri

In Partial Fulfillment

Of the Requirements for the Degree

Doctor of Philosophy

\author{
By \\ BRYAN M. VANDEVENDER \\ Dr. Cheryl Black, Dissertation Supervisor
}

July 2014 
(C) Copyright by Bryan M. Vandevender 2014

All Rights Reserved 
The undersigned, appointed by the dean of the Graduate School, have examined the dissertation entitled

“KISS TODAY GOODBYE, AND POINT ME TOWARD TOMORROW":

REVIVING THE TIME-BOUND MUSICAL, 1968-1975

Presented by Bryan M. Vandevender

A candidate for the degree of

Doctor of Philosophy

And hereby certify that, in their opinion, it is worthy of acceptance.

Dr. Cheryl Black

Dr. David Crespy

Dr. Suzanne Burgoyne

Dr. Judith Sebesta 


\section{ACKNOWLEDGEMENTS}

I incurred several debts while working to complete my doctoral program and this dissertation. I would like to extend my heartfelt gratitude to several individuals who helped me along the way. In addition to serving as my dissertation advisor, Dr. Cheryl Black has been a selfless mentor to me for five years. I am deeply grateful to have been her student and collaborator. Dr. Judith Sebesta nurtured my interest in musical theatre scholarship in the early days of my doctoral program and continued to encourage my work from far away Texas. Her graduate course in American Musical Theatre History sparked the idea for this project, and our many conversations over the past six years helped it to take shape. The other members of my dissertation committee, Dr. David Crespy and Dr. Suzanne Burgoyne, also deserve recognition as they have been thoughtful readers and vocal advocates of my work. My friends and graduate student colleagues at the University of Missouri, particularly Ron Zank, Emily Rollie, and Milbre Burch, have challenged me, encouraged me, and been wonderful traveling companions on my academic journey. Because my dissertation required that I spend time in archives, I would not have been able to complete this project without the assistance of the curators and research librarians at the New York Public Library for the Performing Arts and the Howard Gotlieb Archival Research Center at Boston University. Finally, I would be remiss if I did not acknowledge my parents, Steve and Gail, and my sister, Emily. Thank you for your love and support throughout my graduate education. 


\section{TABLE OF CONTENTS}

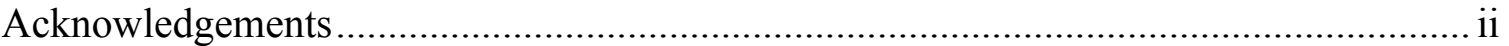

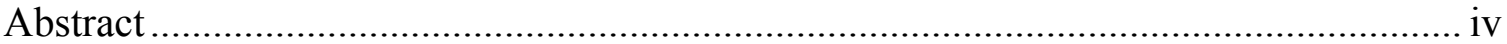

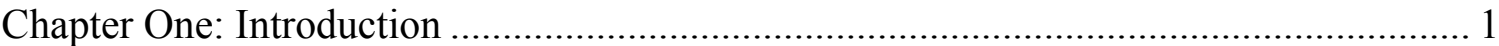

Chapter Two: "It's What's Happening": Hair ................................................................. 28

Chapter Three: "Everything's Different, Nothing's Changed": Company ........................ 98

Chapter Four: "Love's What We'll Remember": A Chorus Line ................................... 161

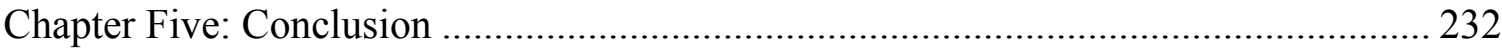

Appendix A: The Most Frequently Revived Musicals in Broadway History ................ 250

Appendix B: The Longest Running Musical Revivals in Broadway History ................. 252

Appendix C: Production Information for Hair - 1968 Broadway Production................ 254

Appendix D: Production Information for Hair - 1977 Broadway Revival.................... 256

Appendix E: Production Information for Hair - 2009 Broadway Revival .................... 258

Appendix F: Production Information for Company - 1970 Broadway Production ........ 260

Appendix G: Production Information for Company - 1995 Broadway Revival............ 262

Appendix H: Production Information for Company - 2006 Broadway Revival............ 264

Appendix I: Production Information for A Chorus Line - 1975 Broadway Production . 266

Appendix J: Production Information for A Chorus Line - 2006 Broadway Revival ...... 268

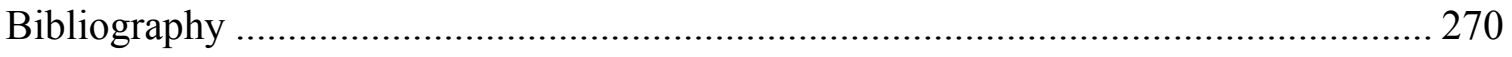

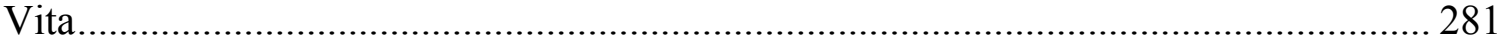




\begin{abstract}
As musical theatre scholars Stacy Wolf, Sheldon Patinkin, and John Bush Jones have argued, American musicals are among our country's most valuable social documents as they depict the dominant discourses and reigning values of the cultural moment from which they first emerged through song, dance, and story. Consequently, all works are innately tied to the era that produced them. Some musicals, however, feature ties to the past are stronger and markedly more visible than others. When the vestiges of the past are so numerous that a given musical says more about the prevailing paradigms of art and thought at a specific moment in American history than it does about the universality of the human condition, then the work might be identified as time-bound. A musical's propensity for time-boundedness is perhaps never more evident than when it is revived years after its original production. When the era that occasioned the piece has passed and the attitudes that it first espoused have changed, a musical that was once fresh and timely can appear quaint, absurd, impolitic, or even myopic to a contemporary audience. Moreover, if the forms of song and dance first employed by that musical are outmoded, and not altered or updated in some way, then the work may read aesthetically as well as socially obsolete. This study offers a systematic investigation of the ways in which theatre artists - directors, designers, composers, librettists, and choreographershave approached the task of reviving significantly time-bound musicals on Broadway. Through an examination of three representative case studies-Hair (1968), Company (1970), and A Chorus Line (1975) — this project identifies the various ways in which the musicals are anchored to their original era, how those bonds have been negotiated in revivals, and to what effect.
\end{abstract}




\section{CHAPTER ONE}

\section{INTRODUCTION}

What does a geist do when the zeit has moved on? ${ }^{1}$

\section{PURPOSE/RATIONALE}

In an April 1995 article for The New York Times, theatre critic Margo Jefferson somewhat caustically described the current theatrical landscape on Broadway as "a museum of the American Musical staffed by busy curator-directors eager to put their stamp on every show they mount."2 Sarcasm notwithstanding, Jefferson's assessment was both fair and particularly apt, as a surfeit of musical revivals had taken residence in New York theatres over the previous five years. In response to rising production costs and increased financial risk, Broadway producers slowly shifted their attention away from newer, untested works and instead focused more readily on mounting new productions of previously successful musicals, hoping to draw audiences through appeals to nostalgia and the promise of familiar, time-tested fare. What began as a commercially cautious pattern, however, had become a popular and profitable trend at the time of Jefferson's writing. The 1995 Broadway season featured seven such re-stagings, bringing the total number of musical revivals produced on the Great White Way since 1989 to twenty-two. These figures, while relatively common by today's standards, were quite staggering given that several seasons immediately prior to 1989 failed to produce more than one musical revival. Even more remarkable was the fact that a significant number of these productions

\footnotetext{
${ }^{1}$ Clive Barnes, "The Roots of Hair's Brush With Fame," review of Hair by James Rado,

${ }^{2}$ Margo Jefferson, “Strolling Along Broadway's Museum Mile,” New York Times, April 2, 1995.
} 
were commercially successful. Very few revived musicals since the 1971 Broadway remounting of Vincent Youmans's 1925 musical comedy No, No Nanette-famously supervised by Busby Berkeley and heavily revised to good effect by Burt Shevelovehad been able to capture the attention and favor of New York theatregoers. The new Nanette was an achievement, but also an anomaly, and while many musical theatre historians credit its success with re-igniting the Broadway producing community's interest in revivals, thereby creating something of a revival craze on Broadway throughout the 1970s, the majority of like productions that followed-such as Irene (1973), Good News (1974), Where's Charley? (1974), Can-Can (1981), and Little Johnny Jones (1982) — were marked by brief runs and financial losses. By comparison, the musical revival seemed to receive a much warmer welcome in the 1990s. Several of the revivals running on Broadway when Jefferson's article went into print—-such as Jerry Zak's critically lauded treatment of Guys and Dolls (1992), Harold Prince's dramaturgically retooled Show Boat (1994), and Jeff Calhoun's celebrity-studded Grease (1994) — proved exceptionally popular with audiences. Steady and enthusiastic attendance kept these revivals and many of those that would appear in subsequent seasons lucrative and running well past their initial premiere. ${ }^{3}$

Lending further credence to Jefferson's museum metaphor was the fact that the years that witnessed this revival phenomenon did not boast a significant number of successful new American musicals. Between 1989 and 1994, only thirty-five original

\footnotetext{
${ }^{3}$ A few of these later long-running revivals would include Walter Bobbie's Chicago (1996), Christopher Renshaw's The King and I (1996), Sam Mendes's Cabaret (1998), Graciela Daniele's Annie Get Your Gun (1999), and Michael Blakemore's Kiss Me Kate (1999).
} 
book musicals opened on Broadway—seven of which were imports from Europe. ${ }^{4}$ According to Larry Stempel, author of Showtime: A History of the Broadway Musical Theater, the prevalence of musical revivals during these years was not just merely a "fact of life [on Broadway] in the 1990s," but rather an indication that revived musicals "took on a level of importance comparable to the production of new ones." ${ }^{, 5}$ By the close of the 1993-1994 season, the seven musical revivals that had opened on Broadway effectively outnumbered the year's new musical offerings. The American Theatre Wing, in an effort to accommodate the unprecedented swell of musicals marked as revivals, created a new category of Tony Award specifically for revivals of musicals. Prior to 1994, any new production of a theatrical work previously produced on Broadway-either a play or a musical—had been eligible for the Wing's lone award for revivals. From the category's inception in 1977 to 1979 , this award was referred to as Most Innovative Production of a Revival. In 1980, the American Theatre Wing changed the award's name to Best Reproduction of a Play or Musical. This somewhat significant alteration of the award's name seems to denote a change in the evaluative criteria used to select a winner-an initial interest in productions that employed more revisionist methods and a gradual movement toward favoring productions that appeared to be more reverential re-stagings of a play's original production. In 1986, the American Theatre Wing once again changed the award's name to Best Revival of a Play or Musical, a designation that it retained until 1994 when the revivals of musicals received its own category. While the name of the award no longer connotes a particular method of revival, its earlier designations serve to

\footnotetext{
${ }^{4}$ Aspects of Love (1990), Buddy (1990), Miss Saigon (1991), Blood Brothers (1993), and Sunset Boulevard (1994) all came to Broadway from Great Britain's West End. Metro (1992) arrived in New York by way of Poland and Cyrano (1993) originally hailed from Holland.

${ }^{5}$ Larry Stempel, Showtime: A History of the Broadway Musical Theater (New York: W.W. Norton and Company, 2010), 653.
} 
illuminate the relatively recent history of revivalist practice. Representing two diametrically opposed approaches to revival, creative innovation and faithful recreation form the poles of a methodological continuum - the range of practices that directors use to revive a theatrical work.

In addition to evincing the significance of musical revivals, the establishment and continued presentation of the Best Musical Revival award also surely has helped to ensure that revivals remain a mainstay of the Broadway season. On average, fifteen musicals open on Broadway each year. With the exception of 2002, every season between 1995 and 2009 has featured three to six musical revivals. The 2009-2010 season saw the opening of thirteen musicals, seven of which were revivals. As Stempel reminds us, the practice of re-staging musical entertainments years after their first premiere is not itself new, and in fact, dates back to the eighteenth and nineteenth centuries when rival stock companies would produce and then re-produce previously successful melodramas such as Charles M. Barras's The Black Crook and operettas such as Franz Lehar's The Merry Widow, and W.S. Gilbert and Arthur Sullivan's H.M.S. Pinafore. ${ }^{6}$ However, it has only been within the past twenty years or so that the musical revival became the veritable commodity and undeniable trend that it is today —a trend that composer Stephen Sondheim has likened to kudzu. In his estimation, the preponderance of musical revivals can be attributed to the fact that "revivals encourage more revivals." Stempel, however, offers a relatively more thoughtful explanation: "The current trend goes beyond the perennial exercises in caution of audiences choosing a show on name recognition, or

\footnotetext{
${ }^{6}$ Stempel, 647.

${ }^{7}$ Quoted in Anthony Thomassini, "Investing in the Past May Be Safe, but at the Risk of Broadway’s Future,” New York Times, August 16, 1998.
} 
producers investing in a safe bet. It rests also on the cultural capital that has accrued to a certain repertoire of musicals in the recent past."

The repertoire to which Stempel refers-that collection of musicals that have enjoyed a healthy afterlife on Broadway—is composed chiefly of works perceived as classic or timeless. In theory, their ability to be revived stems in part from the strength of their textual materials - libretto, lyrics, and score—as well as their proven past success. More importantly, these musicals also seem to demonstrate an innate capacity for resonating with audiences long after their original production. Representing some of the form's most landmark achievements, the majority of these properties come from the Golden Age of Musical Theatre or share an important characteristic endemic to musicals of that period. ${ }^{9}$ In No Legs, No Jokes, No Chance: A History of the American Musical Theater, Sheldon Patinkin characterizes Golden Age musicals as "retreats from the present" and suggests that the majority of these works maintained a marked distance from the historical moment that produced them by featuring settings that were erstwhile or ahistorical. ${ }^{10}$ Popular musicals of the period such as Oklahoma! (1943), Annie Get Your Gun (1946), The Music Man (1957), and Hello, Dolly! (1964) were set within a heavily romanticized American past while other titles, such as Brigadoon (1947) and Camelot (1960), occupied the world of fantasy and myth. Those musicals that did depict their

${ }^{8}$ Stempel, 647.

${ }^{9}$ Musical theatre historians frequently refer to the period of time in which the model of the integrated musical was the norm on Broadway as the Golden Age of Musical Theatre. While scholars frequently debate the precise dates of the era, Corrine J. Nadden, author of The Golden Age of Musical Theatre, charges that the period lasted for twenty-two years, beginning with the premiere of Richard Rodgers and Oscar Hammerstein II's Oklahoma! (1943) and concluding with Alan Jay Lerner and Burton Lane's On a Clear Day You Can See Forever (1965). Her timeline ends just three year prior to the Broadway premiere of Hair (1968) - a musical that she sees as triggering a climate change on Broadway.

${ }^{10}$ Sheldon Patinkin, No Legs, No Jokes, No Chance: A History of the American Musical Theater (Evanston, IL: Northwestern University Press, 2008), 267. 
present day—such as On the Town (1944) or The Pajama Game (1954)—offered a significantly simplified, idealized, or even whimsical portrait of American life. In each of these cases, the nature of a given work's temporal setting kept it from becoming too encumbered by the realities of its day, and as Patinkin alludes, offered theatergoers an opportunity to depart from their current era. The vast majority of musicals contained within the revival repertoire share this detached or pliable relationship with history, and thus, appear to be relatively unfettered by time. ${ }^{11}$ Consequently, these properties seem to continuously transcend their eras and give credence to Rebecca Ann Rugg's claim that nostalgia — fondness for a distant past that might not have existed —is "the prime dramaturgical mode of musical theatre." 12

To this conversation, conductor and theorist Lehman Engel adds that a musical's endurance across time also corresponds to the universality of its subjects or themes. In Words With Music: Creating the Broadway Musical Libretto, he asserts that a truly enduring musical has "the power to impart its meanings as well as its mysteries to people at all times and in all places. ${ }^{, 13}$ Musicologist Bruce Kirle offers a slightly more nuanced explanation of this process with his claim that timelessness is not an innate quality that a musical possesses, but rather an indication of congruence between its original zeitgeist and the concerns of future audiences. In Unfinished Show Business: Broadway Musicals as Works-in-Process, he asserts that this correlation is predicated on a musical's ability to conform to such concerns: "Even the most popular of musicals is universal and timeless

${ }^{11}$ See Appendix A for a list of the most frequently revived American musicals in Broadway history. See Appendix B for a list of the longest running American musicals in Broadway history.

${ }^{12}$ Rebecca Ann Rugg, "What It Used to Be: Nostalgia and the State of the Broadway Musical," Theatre 32.2 (2002): 44-55.

${ }^{13}$ Lehman Engel, Words With Music: Creating the Broadway Musical Libretto, Rev. ed. (New York: Applause Theatre and Cinema Books, 2006), 216. 
only in its willingness to adapt to the values, anxieties, and tensions of new audiences in new cultural moments." 14 According to the author, the musicals that best demonstrate this flexibility are those that address and offer solutions to recurrent social problems - issues that were debated at the time of their original productions and continue to be contested in subsequent decades. A brief survey of Broadway's most frequently revived musicals would seem to support Kirle's claim. Richard Rodgers and Oscar Hammerstein II's highly celebrated Oklahoma! (1943), developed and produced during the Second World War, espouses the importance of community and nationalism. Likewise, Leonard Bernstein, Stephen Sondheim, and Arthur Laurents's West Side Story (1957), a musical adaptation of William Shakespeare's Romeo and Juliet, ran on Broadway amidst the American Civil Rights movement and warned its audiences of the dangers of racial prejudice. Laurents and Sondheim's later collaboration with Jule Styne, Gypsy (1959), premiered just prior to the start of feminism's second wave and chronicles a determined mother's attempts to create opportunities for her daughters within a male-dominated entertainment industry. Jerry Bock, Sheldon Harnick, and Joseph Stein's Fiddler On the Roof (1964) examines the roles that faith and tradition play in a rapidly changing culture. Under Kirle's rubric, similar claims of timelessness could also be made of some of Broadway's other routinely revived musicals: Show Boat (1927), Pal Joey (1940), Carousel (1945), Guys and Dolls (1950), and Man of La Mancha (1965). The concerns that these works address - racism, class difference, domestic violence, the reification of gender roles, and censorship — are relatively perennial, and while the musicals themselves

\footnotetext{
${ }^{14}$ Bruce Kirle, Unfinished Show Business: Broadway Musicals as Works-in-Process
} (Carbondale, IL: Southern Illinois University Press, 2005), 124. 
have not always recaptured their initial success in revival, they are securely canonized and often heralded as exemplars of the form.

There is, however, a host of other notable American musicals that are far less frequently revived, due to the fact that they are generally perceived to be less than lasting. Because of their initial accomplishment and relative import to musical theatre history, some of these properties have been re-staged on Broadway; however, they differ from the more enduring musicals mentioned above in that their form and content reflect the historical moment that produced them much more directly. Works such as Babes in Arms (1937), One Touch of Venus (1940), Call Me Madam (1950), Pipe Dream (1955), Bells Are Ringing (1956), Flower Drum Song (1958), No Strings (1962), and Applause (1970) depicted the world that waited for their original audience members when they exited the theatre doors. Other pieces such as Finian's Rainbow (1947), Kismet (1953), or Two Gentlemen of Verona (1971) may have featured historical or fantastic settings, but were so laden with beliefs, assumptions, values, and aesthetics of their era that the musicals themselves came to resemble the undeniable present. In both scenarios, the primary features of these works - their setting, plot, themes, depictions of race, gender, and ethnicity, political agenda, musical idioms, or staging requirements—arguably anchor them to their original zeitgeist, making these musicals seem comparatively time-bound. These close ties to a specific past appear to function as historical touchstones - artifacts that may remind viewers of a musical's age and era.

Kirle's observation regarding the need for accord between a musical's present and its future points to a fundamental paradox that underpins the project of reviving musicals. Musicals, chosen for revival because of their alleged timelessness, are always already 
products of the era that produced them. Consequently, no musical is ever completely liberated from the bonds of time. In his forward to John Bush Jones's Our Musicals Ourselves: A Social History of the American Musical, the prolific Broadway lyricist Sheldon Harnick contends that all musicals function as social documents, and thereby "convey the assumptions, biases, aspirations, and racial and sexual attitudes of the time in which they were first written and staged ... [they] tell us who we were and who we are as individuals, as members of a community, as citizens of a nation." ${ }^{.15}$ Under Harnick's credo, musicals — regardless of their historical setting —use song, dance, and story to depict the dominant discourses of the cultural moment from which they first emerged. The lyricist is not alone in his contention. As written histories of the musical have proliferated in recent years, writers such as John Bush Jones, Raymond Knapp, Jessica Sternfeld, Stacy Wolf, and Elizabeth Wollman have joined Kirle in eschewing a wholly formalist account of the genre in favor of examining the social and material conditions that have shaped the musical theatre over the course of the twentieth century. Since Harnick's notion of the musical as social document suggests that all works are innately tied to the cultural moment that produced them, it would stand to reason that all musicals (or, indeed, all cultural products) are to some extent time-bound. However, as some musicals' ties to the past are stronger and markedly more visible than others, it seems reasonable to perceive some musicals as more time-bound than others. In this sense, "time-boundedness" is not a categorical marker, but rather a quality germane to all musicals that exists on a continuum. When the vestiges of the past are so numerous that a given musical seems to have more to say about the prevailing paradigms of art and

\footnotetext{
${ }^{15}$ Sheldon Harnick, foreword to Our Musicals, Ourselves: A Social History of the American Musical Theatre, by John Bush Jones (Hanover, MA: Brandeis University Press, 2003), $x$.
} 
thought at a specific moment in American history than it does about the universality of the human condition, then the work might be identified as, more or less, fixed to its time. The stronger and more visible its ties, the more time-bound the musical is. The phenomenon of time-boundedness certainly extends to the non-musical theatre as well. Countless comedies and dramas of the American canon are teeming with the remains of their era and thereby appear dated by contemporary standards. Their time-bound nature occurs at the level of their textual materials such as dialogue, subject matter, and themes. The same holds true for musicals; however, a musical's composite text consists of more than its scripted libretto. In utilizing music, lyrics, and dance, in addition to a script, musicals generally feature more artistic and historical relics than their non-musical counterparts. Works of musical theatre, therefore, are arguably more time-bound than other forms of theatre.

Musicals overburdened with the remnants of yesteryear then present several discrete challenges to the theatre artist wishing to re-stage these works for modern audiences. Some critics, Thomas S. Hischak chief among them, have gone so far as to claim that musicals such as Pipe Dream (1955) and Company (1970) are "unrevivable" as they feature music "that sounds like the past" and "a libretto that speaks in a bygone tongue." " Bruce Kirle rejects terms such as "dated" or "unrevivable," but does recognize the obstacle that a musical's historical context can present—particularly for those works that precede or postdate the Golden Age - when being read or staged in the present day. As he states, "It is impossible to evaluate musicals of the past without examining the cultural moment that produced them ... not only do we live in a different time and

${ }^{16}$ Thomas S. Hischak, Boy Loses Girl: Broadway's Librettists (Lanham, MD: Scarecrow Press, 2002), 169. 
culture, but also it is difficult, if not impossible, to reconstruct the conditions of performance. It is certainly impossible to reconstruct the audience ... historical context not only influenced the texts of these musicals, but also helped shape the way these productions were performed and received by their audiences. ${ }^{117}$ Kirle later describes all musicals as fluid works-in-process that can and should be re-imagined in revival. As he states, musicals that we might classify as time-bound "are producible, but they must be made relevant to a different cultural moment if audiences are to accept them. Far from being closed, they are unfinished, which is why musicals in revival are often re-invented, rethought, and sometimes rewritten (and the music reworked) to conform to a new audience. ${ }^{" 18}$ The author notes how the specter of an original zeitgeist has been addressed in a handful of recent Broadway revivals; however, these mentions are generally brief, somewhat randomly organized, and presented as anecdotes rather than discrete objects of analysis. Kirle's book certainly advocates for the revival of ostensibly time-bound musicals, but the scope of his study does not include any systematic investigation of how such works have been revived. The practice of reviving musicals, time-bound or otherwise, has yet to be thoroughly examined.

This study aims to attend to this gap in current musical theatre scholarship by offering a systematic investigation of the ways in which theatre artists - directors, designers, composers, librettists, and choreographers - have approached the task of reviving a significantly time-bound musical. Through an examination of three representative case studies, I will attempt to identify the various ways in which these musicals are anchored to their original era, how those bonds have been negotiated in

\footnotetext{
${ }^{17}$ Kirle, xviii.

${ }^{18}$ Ibid., 14.
} 
revivals, and to what effect. Questions that drive this research include: What is the nature of these works' respective relationships to time? In what ways and to what degree are the musicals bound to their original cultural context? What are the exigencies of reviving these musicals? What is the relationship between the musicals and their respective revival contexts? What are the various methods of revival that theatre artists have employed in the re-staging of these three musicals? What are the results of their efforts? The musicals selected for this study come from a fixed seven-year period (1968-1975) and have received no more than two Broadway revivals, the majority of which have been mounted within the last twenty years. These musicals all come from the post-Golden Age era, were originally set in the same historical moment in which they were written, and are notable as landmark artistic achievements. They are all also generally perceived as significantly time-bound, and, despite their iconic status, have elicited skepticism from critics and scholars as to their suitability for revival at one time or another. These works are: James Rado, Gerome Ragni, and Galt MacDermot's Hair (1968; revived in 1977 and 2009), George Furth and Stephen Sondheim's Company (1970; revived in 1995 and 2006), and James Kirkwood, Nicholas Dante, and Marvin Hamlisch's A Chorus Line (1975; revived in 2006).

Where musical theatre historians such as Stempel, Patinkin, Jones, and Knapp have noted the comparatively indirect attachments that many Golden Age properties share with their original zeitgeist, they have also suggested that musicals written before and after the Golden Age were well known for engaging their cultural moment in a comparatively more forthright manner through present-day settings, topical references and themes, and the satirization or critique of current events. Additionally, almost all of 
these works employed the popular musical idioms of their original era. For all of these reasons, early musical comedies of the 1920s and 1930s along with rock and concept musicals of the 1960s and 1970s provide the best models for distinctively time-bound musicals. While revivals of works from either era are well suited for this project, notable new productions of Pre-Golden Age musicals have been a relatively rare occurrence on Broadway since the early 1970s, and particularly since the revival became an observable trend in the early 1990s. Historical masterworks such as Show Boat or perennial favorites such as Pal Joey and Anything Goes present exceptions to this rule, but might also be seen as prototypes for the integrated musical of the Golden Age more than representative of the musical entertainments produced during their own era. Moreover, primary research materials for many of these early musicals and their sporadic revivals are difficult to locate. As Rob Fisher, the Tony Award winning music director and conductor for the City Center's Great American Musicals in Concert Series, notes, "Back then, these shows were a more disposable product . . . like the entertainment of the week. The creator was not expecting us to come along at the end of the century and put this mosaic back together." ${ }^{, 19}$ David Savran has made similar observations in his scholarship on musical theatre historiography and describes those musicals that predate the 1943 premiere of Oklahoma! as "palimpsests in which the partially erased originals can be glimpsed—if they can be glimpsed at all — only through later accretions." 20 Therefore, the best representative case studies for this investigation come from the Post-Golden Age period. This era was extremely rich and witnessed a wide array of momentous historical events that triggered notable shifts in American culture including, but not limited to the Vietnam

\footnotetext{
${ }^{19}$ Quoted in Thomassini.

${ }^{20}$ David Savran, "Toward a Historiography of the Popular," Theatre Survey. 45, no. 2
} (2004): 211-217. 
War, the assassinations of Martin Luther King Jr. and Robert F. Kennedy, the sexual revolution, the impeachment of President Richard Nixon, and the dawning of the Me Decade. The struggles of the burgeoning civil rights, feminist, and gay rights movements also contributed to the tenor of the zeitgeist, making the extant social milieu notably more tempestuous than that of the comparatively peaceful Golden Age. John Bush Jones contends that musicals from this era absorbed the tensions of the cultural moment and became increasingly driven by social and political issues. ${ }^{21}$ Addressing these concerns presumably strengthened the musicals' ties to their zeitgeist and makes them strong exemplars of time-bound musicals.

In addition to being somewhat famously moored to their cultural moment, Hair, Company, and A Chorus Line are three of the era's most historically significant (and in some cases commercially successful) musicals of the era. The fact that their original productions are widely considered to be watershed events in musical theatre history presents an additional challenge to anyone attempting a revival of them. Those theatre artists who have staged these pieces have been required to confront not only the specter of time, but also their iconic status and the myth of their original productions.

The remarkable rate at which musicals of the past are remounted on Broadway suggests that the musical revival is ripe for scholarly investigation. Furthermore, the fact that the past several Broadway seasons have included revivals of Post-Golden Age musicals that could qualify as time-bound indicates that the revival repertoire is gradually expanding. An investigation into how certain theatre artists have worked to extricate time-bound musicals from their original eras could supply other artists with discrete models for how to approach these pieces. Though current parlance infers that revivals are

\footnotetext{
${ }^{21}$ Jones, 237.
} 
exclusive to Broadway, any new production of an original work that is not a world premiere is ostensibly a revival. Discovering how these musicals have been prepared for new productions on Broadway might help to encourage new, and possibly more successful, productions elsewhere. Additionally, because of the musical's ability to represent America's social history, this study increases our understanding of how American musicals manifest, reflect, and help to shape our cultural and national identity. It also contributes to the histories of the American musical penned by the likes of Kirle, Knapp, Jones, and Wolf and helps to expand the extant historical narrative by attending to three landmark musicals in revival.

\section{METHODS AND PROCEDURES}

A primary objective of this historical study is to examine the relationship between the chosen musicals' original productions, the cultural moments that produced them, and the musicals' later revivals - specifically attending to how directors and their creative teams prepared the musicals for performance and how their artistic choices, along with the musicals themselves, made meaning within a particular historical context. Each case study begins with an accounting of the historical events and cultural imperatives that influenced American life at the time of the given musical's creation, and is followed by an analysis of the given musical's original production - its libretto, lyrics, score, staging, design, casting, and choreography. The purpose of this analysis is to identify how and to what degree the musical's aesthetic features bind the work to its era, and which therefore might require alteration or reconsideration in revival. Cultural and intellectual histories of the United States during the 1960s and 1970s aid in the assessment of how each cultural 
moment manifests from within the selected musicals. Such studies include David Allyn's Make Love, Not War - The Sexual Revolution: An Unfettered History, Edward D. Berkowitz's Something Happened: A Political and Cultural Overview of the Seventies, Peter N. Carroll's It Seemed Like Nothing Happened, David Farber's The Age of Great Dreams: America in the 1960s, Todd Gitlin's The Sixties: Years of Hope, Days of Rage, and Bruce Schulman's The Seventies: The Great Shift In American Culture, Society, and Politics, as well as social histories of the musical such as John Bush Jones's Our Musicals Ourselves: A Social History of the American Musical, Raymond Knapp's The American Musical and the Formation of National Identity, Gerald Mast's Can't Help Singing': The American Musical on Stage and Screen, and Stacy Wolf's Changed for Good: A Feminist History of the Broadway Musical —accounts that examine the material conditions (both on and independent of Broadway) that have influenced the growth and development of the form.

After examining the selected musical's relationship to its original context, the focus of the chapter turns to how directors treated each piece in revival. Close reading and analysis of these new productions, within their revival contexts, helps to reveal how each revival's production team addressed the time-bound elements of its musical. As with the original contexts, I have relied on primary and secondary sources to understand the revival contexts. Textual materials (libretti and scores), cast recordings, and production photographs document the work as staged. Published interviews with or memoirs by creative team members illuminate how and why specific artistic choices were made. New York critics' reviews and box office records assist in evaluating the efficacy and impact of these choices by providing litmus for how the musicals, newly conceived, resonated 
with the larger theatergoing culture of their new historical moment.

There is scant, direct evidence for determining how audiences received and responded to these performances. Critics' reviews reveal the responses of a small, and uniquely informed cross-section of the theatergoing population, with occasional reference to how larger numbers of the audience responded. The length of a run and the number of tickets sold suggests whether or not a production attracted audiences, yet these figures do not necessarily indicate how the performance resonated with viewers. Any assumptions made or conclusions drawn regarding audience reception, therefore, will be subject to these limitations. Cultural context, however, helps me to draw reasonable, if not definitive conclusions by illuminating the predominant cultural perspectives at the time of these productions' presentation. Taken with critics' reviews and box office statistics, the artistic trends of the moment and the prevailing attitudes toward the social issues treated in the productions offer some insight regarding how audiences might have received the performances.

Of the eight productions surveyed in this study (three original and five revivals), I have reviewed the complete libretto and score for each staging save the 1977 Broadway revival of Hair as it is not held by any of the archives that currently maintain collections on the musical. The Tom O'Horgan Collection, currently housed at Boston University's Howard Gotlieb Archival Research Center, contains several excerpts of the production's libretto. These individual pages, along with published interviews with the production's creative team, provided the materials for my analysis of the revival. Additionally, I viewed video recordings of six of the productions at the Theatre on Film and Tape Archive at the New York Public Library for the Performing Arts. The only productions 
that I did not view in their entirety were the 1968 and 1977 Broadway productions of Hair as no complete recordings are held by any of the extant archives. However, the Howard Gotlieb Archival Research Center holds some raw video footage of Hair's various international companies. This footage combined with production photos, memoirs penned by original cast members, interviews with the members of the creative teams contributed to my understanding of these productions.

The primary method for this project is theatrical and cultural historiography, relying on evidence gathered from primary and secondary sources to investigate how cultural context has influenced the creation and development of three representative, time-bound musicals and the various ways in which new productions of those musicals made meaning in later cultural contexts. The culmination of this project is a historical narrative that documents and attempts to assess the significance of these efforts. In addition to the previously cited works of musical theatre history (Jones, Kirle, Wolf, et al.), methodological models for this project include Roger Bechtel's Past Performance: American Theatre and The Historical Imagination and David Román's Performance in America: Contemporary U.S. Culture and the Performing Arts, as they represent historical studies that address theatrical practice and its relationship with American culture at various moments in time. Bechtel advocates for this rather hybrid approach to historiographic research and contends that investigating past performance in this manner provides historians with a more nuanced understanding that works are "resolutely inseparable from their historical moments, yet connected, in often surprising ways, to our own" and activates a historical imagination that allows us to re-envision the past 
critically. ${ }^{22}$ In mirroring Bechtel and Román's methodologies, this study then addresses how theatrical practice engages with time on two fronts in an effort to illuminate the selected musicals' relationship with time.

The methods of investigation and procedures for analysis employed for this study are also influenced by the approaches and practices of New Historicism, a hybrid practice that integrates textual analysis and post-positivist historiography. The project of New Historicism, as it has been described by some of its chief practitioners-Stephen Greenblatt, Catherine Gallagher, Louis A. Montrose, and Elizabeth Fox-Genovese- is foregrounded by a belief that a text is not itself an autonomous or self-contained aesthetic object, but rather an artifact that reflects the culture from which it emerged. As H. Aram Veeser asserts in the introduction to his edited volume, The New Historicism Reader, one of the field's fundamental assumptions is that "every expressive act is embedded in a network of material practices. ${ }^{, 23}$ New Historicists are particularly interested in recognizing how history — in all of its material complexity_-might have played a role in the creation of a given object. As Veeser notes, "the world irresistibly contaminates the literary text." ${ }^{24}$ Determining the nature and significance of this contamination with respect to the selected musicals' texts and original productions is a primary aim of this project.

Discovering how my chosen musicals emerged from and contributed to their original eras is commensurate with the aims of post-positivist theatre historiography and New Historicism; however, it only represents one aspect of my project's methodology.

${ }^{22}$ Roger Bechtel, Past Performance: American Theatre and the Historical Imagination (Lewisburg, PA: Bucknell University Press, 2007), 23.

${ }^{23}$ H. Aram Veeser, "The New Historicism," The New Historicism Reader, ed. H. Aram Veeser (New York: Routledge, 1994), 2.

${ }^{24}$ Veeser, 17. 
Investigating how works from the past have been prepared for more contemporary audiences requires that the musicals be analyzed with respect to their original and revival contexts, which also requires an examination of how both the preparations and the musicals themselves were received. Doing so will help to determine if and how the chosen musicals found congruity with audiences during the eras in which they were revived. Beyond identifying the artistic features that have threatened to stymie these musicals to their original cultural moment, the goal of this project is to discover how theatre artists in later eras have addressed these features as they have prepared the works for contemporary audiences - how they have turned these musicals away from what was their today, and in doing so, pointed the works toward tomorrow.

The cohort of artists that comprise the production's creative team is a significant factor in accounting for the response to and impact of a revival. The director, as the chief creative force of and leader of the team, is arguably the most influential of these artists. Therefore, the analysis of each revival will include a brief evaluation of its director and his or her work in later years. Assessing a theatre artist's talent is a subjective game at best; however, the critical and commercial success of later directing projects along with peer accolades vis-à-vis awards help to shed light on their artistry and skill.

Several other theorists contribute to this study in helping to assess how the chosen musicals make meaning across time, particularly semioticians. As the prolific theatre historian and theorist Marvin Carlson has suggested, addressing a theatrical work's various signifiers is tantamount to the study of theatre history: "A major concern for the scholar of theatre history is the dynamic involved in the changing interpretations (or 
readings) of works in different historical periods." 25 Analyzing the production of a theatrical work in a later context necessarily imagines a future for that work, or what director and theorist Jonathan Miller refers to as the afterlife. In Subsequent Productions, Miller contends that great plays secure their place in the theatrical canon when they inspire new stagings. By his charge, a given play’s afterlife - the production history that follows the conclusion of its original production - determines its worth and import to the historical record:

As long as we recognize and accept the argument that performance is, necessarily, a limitation, then the destiny of a great play is to undergo a series of performances each of which is incomplete . . by submitting itself to the possibility of successive recreation, however, the play passes through the development that is its birthright, and its meaning begins to be fully appreciated only when it enters a period that I shall call its afterlife. ${ }^{26}$

Miller's afterlife rests upon Umberto Eco's notion of the “open text” and Roland Barthes's theory of the "writerly text." Both critics envision a dynamic literary work that invites numerous readings and defies a single, fixed interpretation. Displacing the primacy of the author, Barthes in particular delegates the construction of meaning to those who read (or view) the text. ${ }^{27}$ The afterlife, as Miller imagines it, is made possible not only through multiple productions, but also multiple interpretations of texts vis-à-vis directors who now function as discursive auteurs. As the work of directors - their aesthetic choices and their interpretive agenda - is fundamental to the afterlife, an

${ }^{25}$ Marvin Carlson, Theatre Semiotics: Signs of Life (Bloomington, IN: Indiana University Press, 1990), 13.

${ }^{26}$ Jonathan Miller, Subsequent Performances (New York: Faber and Faber, 1986), 23.

${ }^{27}$ See Umberto Eco, The Open Work, trans. Anna Cancogni (Cambridge, MA: Harvard University Press), 1989 and Roland Barthes, $S / Z$, trans. Richard Miller (New York: Hill and Wang), 1974. 
investigation of how directors revive time-bound musicals should provide insights into these works' durability in the afterlife.

\section{LITERATURE REVIEW}

Despite the popularity of the musical revival and its continued presence on Broadway, scholarship on the subject is relatively scant. Written histories of the musical tend to privilege original productions by overlooking or merely gesturing to a given musical's afterlife. Larry Stempel's Showtime: A History of the Broadway Musical and David H. Lewis's Broadway Musicals: A Hundred Year History, however, are notable exceptions. Both authors provide a brief accounting of the revival as a phenomenon, trace its rise as a discernable trend, and present explanations for the success and failure of certain recent revivals. Their assessments, however, are somewhat speculative and confined to a handful of pages. Even more neglected is scholarship that attends to the practice of reviving musicals. As mentioned earlier, Bruce Kirle's Unfinished Show Business: Broadway Musicals as Works-in-Process makes a very persuasive argument for why all musicals can be revived and recognizes, albeit briefly, a handful of noteworthy musical revivals that have been successfully re-imagined for modern audiences. Miranda Lundskaer-Nielsen's Directors and the New Musical Drama: British and American Musical Theatre in the 1980s and 90s and Ellen Marie Peck's recent article for Studies in Musical Theatre, "Artistic Freedom Through Subsidy: The British Model of Reviving American Musicals" offer a somewhat more focused examination of the revisionist methods employed by British directors in their re-staging of the American musical theatre canon for British theatre companies. Similarly, Jessica Hillman's 2010 
Theatre Topics article, "Tradition or Travesty?: Radical Reinterpretations of the Musical Theatre Canon," investigates how three directors from the American regional theatre utilized a postmodern deconstructionist aesthetic (somewhat contentiously because of legalities and licensing agreements) for productions of South Pacific, The Sound of Music, and Annie. The authors of these publications deal chiefly in revivals of arguably more "timeless" musicals and focus specifically on the contributions made by those revivals' directors; however, their close and careful readings of performance text make them useful methodological models for my own project. In addition to Miller's Subsequent Performances, several book-length studies address the notion of revival in non-musical works, including Marvin Carlson's The Haunted Stage, Susan Bennett's Performing Nostalgia: Shifting Shakespeare and the Contemporary Past, and Amy S. Green's The Revisionist Stage. Carlson's largely theoretical text claims that all theatre is a depository for personal as well as cultural memory. He further contends that the recollection of past productions (what he refers to as ghosts) will haunt the reception of all new performance events. While Miller's study deals exclusively with Shakespearean plays, his central argument and major claims - that a play's life extends beyond its first mounting only when it has been subjected to successive revisionist interpretationsclosely resemble those presented by Bruce Kirle. Green's project also addresses revisionist practice and examines the ways in which directors such as Andrei Serban, JoAnne Akalaitis, and Peter Sellars have "rewritten" canonized plays in performance by bringing contemporary anxieties to bear upon classic texts. While none of these books engage with questions of history directly, all three make strong cases for why classic or canonized plays should be revised when they are revived. 
At present, there is virtually no published scholarship on the Broadway revivals of Hair or A Chorus Line. Two short articles, John Olson's “Company - 25 Years Later” and Christa Skiles's “Company Turns 35," address some of the obstacles to revival that Company presents using the 1995 Roundabout Theatre Production and notable regional productions as cases in point. However, neither these articles nor any other attend to the 2006 Broadway revival of Company helmed by John Doyle. There is also little by way of focused scholarship on any of these musicals' original productions aside from Barbara Lee Horn's The Age of Hair: Evolution and Impact of Broadway's First Rock Musical, Elizabeth Wollman's The Theater Will Rock: A History of the Rock Musical, from Hair to Hedwig, and Ken Mandelbaum's A Chorus Line and the Musicals of Michael Bennett. Popular histories of these musicals, however, are ample. Eric Grode's Hair: The Story of the Show that Defined a Generation, Scott Miller's Let the Sunshine In: The Genius of Hair, Gary Stevens's The Longest Line: Broadway's Most Singular Sensation, and Denny Martin Flinn's What They Did for Love: The Untold Story Behind the Making of A Chorus Line offer an account of its given musical's inception and development. Memoirs penned by the artists involved in the creation of the musicals - such as Lorrie Davis's Letting down My Hair, Marvin Hamlisch's The Way I Was, Baayork Lee and Thommie Walsh's On the Line: The Creation of A Chorus Line, Donna McKechnie's Time Steps: My Musical Comedy Life, and Harold Prince's Contradictions: Notes on Twenty-Six Years in the Theatre - provide even more nuanced narratives. Additionally, critical biographies of the musicals' primary authors and critical assessments of their worksuch as Joanne Gordon's Art Isn't Easy: The Achievement of Stephen Sondheim, Martin Gottfried's Sondheim, Foster Hirsch's Harold Prince and the American Theatre, Carol 
Ilson's Harold Prince: A Director's Journey, and Meryl Secrest's Stephen Sondheim: A Life help us to better understand the creative choices that these artists made as they prepared their musicals for their first Broadway productions.

\section{CHAPTER SUMMARIES}

As stated earlier, each analytical chapter will begin with an overview of the selected musicals' original productions and their relationship to the larger cultural context before shifting to how the musicals were treated and received in revival. Chapter Two addresses Hair and begins with an analysis of the musical's indisputable ties to American culture during the turbulent and polarizing Vietnam War-particularly the hippie movement, anti-draft demonstrations, and New York City's burgeoning experimental theatre scene. While Hair's forthright reflection of the era is widely storied, questions of obsolescence and claims that the musical continues to lose its cultural relevance as time passes arguably threatens to compromise its afterlife. Even so, Hair has received two Broadway revivals. The first, mounted in 1977 and directed by Tom O'Horgan (who also helmed the musical's original production), opened amidst the comparatively peaceful and politically indifferent Me Decade. The second revival, directed by Diane Paulus in 2009, came to Broadway more than thirty-five years after the Vietnam War's end, but played to an American culture in crisis resulting from two foreign wars, a devastating financial crisis, a polarizing presidential election, and divisive debates on a variety of social issues, including marriage equality — a cause for which Paulus's cast advocated both on the stage and in the streets. 
Chapter Three attends to Company's examination of isolationism and critique of marriage — an assessment borne out of the sexual revolution of the 1960s and 1970s. Much like Hair, Sondheim and Furth's musical frequently encounters skepticism from critics and scholars who suggest that Company's decidedly unromantic depiction of modern marriage and urban relationships (which was disquieting at the time of its 1970 premiere) have become outmoded. The musical, however, has enjoyed a notable afterlife, which includes two Broadway revivals. Staged by Scott Ellis in 1995 and John Doyle in 2006, these productions represented decidedly different attempts to mitigate the musical's temporal setting through directorial concept and an approach to mise-en-scène. This chapter examines Ellis and Doyle's respective methods for re-conceptualizing Company - approaches that met with varied critical response.

Chapter Four reviews and assesses the attempts made by Bob Avian and Baayork Lee to replicate Michael Bennett's vision for A Chorus Line authentically in a Broadway revival staged in 2006. The widely mythologized original production's reflection of the Me Decade ethos resonated deeply with audiences and critics of the era and helped $A$ Chorus Line to play Broadway for an unprecedented fifteen years. The durability of the musical's message and myth would be tested, however, when A Chorus Line returned to Broadway during an era of reality television and YouTube stardom. The chapter investigates the manner in which critics and audiences received A Chorus Line's Me Decade rhetoric thirty-one years after the musical's original production, and how Avian and Lee's endeavors to resurrect the musical's original production affected that reception.

In the final chapter, I summarize the findings of the study, assess the efficacy and impact of the various efforts made by the teams who oversaw the revivals addressed in 
the study, and offer conclusions regarding the implications of these findings for future research and artistic practice. 


\title{
CHAPTER TWO
}

\section{IT'S WHAT'S HAPPENING: HAIR}

\author{
WE'RE ALL ENCASED IN SONIC ARMOR \\ BELTIN' IT OUT THROUGH CHROME GRENADES \\ MILES AND MILES OF MEDUSAN CHORD \\ THE ELECTRONIC SONIC BOOM \\ IT'S WHAT'S HAPPENING, BABY \\ IT'S WHERE IT'S AT DADDY ${ }^{28}$
}

\section{BROADWAY PRODUCTION}

Historians frequently cite 1968 as a watershed year in American culture, claiming that a series of harrowing domestic and international events propelled the societal unrest of earlier years to a critical mass. Irwin and Debi Unger, authors of Turning Point: 1968, describe the year as "calamitous" and point to the repeated appearance of eight-column headlines on the front page of The New York Times (twenty issues between April and December) as evidence of the year's tumult. ${ }^{29}$ A sizable portion of the events to receive attention from the press and the American populace pertained to the United States' involvement in the Vietnam War, which had reached its fourth year by 1968 . The American death toll totaled 11,363 at the close of 1967 and increased rapidly in late January after the Tet Offensive, which included the Battles of Huế and Khe Sanhn. ${ }^{30}$ Six weeks later, American soldiers murdered over five hundred unarmed Vietnamese

\footnotetext{
${ }^{28}$ Gerome Ragni and James Rado, Libretto to Hair: The American Tribal Love-Rock Musical, May 8, 1968, Tom O’Horgan Collection, Box 76, Howard Gotlieb Archival Research Center at Boston University, 53.

${ }^{29}$ Irwin Unger and Debi Unger, Prologue to Turning Point: 1968 (New York: Charles Scribner's Sons, 1988), 2.

${ }^{30}$ National Archives, "Statistical Information About Fatal Casualties of the Vietnam War," http://www.archives.gov/research/military/vietnam-war/casualty-statistics.html\#date (accessed April 4, 2014).
} 
civilians in the village of Son My. The Mỹ Lai Massacre, as journalists would label it the following year, quickly drew the indignation of the American anti-war movement. Student demonstrations protesting the war effort erupted at various colleges and universities throughout the year, most notably in April when members of the Students for a Democratic Society occupied several buildings at Columbia University—an act of defiance that ended with members of the New York City police removing the protesters from the university's campus by force. A similar event occurred on a much larger scale in August when 10,000 anti-war protesters confronted law enforcement officials outside of the 1968 Democratic National Convention in Chicago. Despite the anti-war movement's continued pleas for the United States to end its participation in the Vietnam conflict, the U.S. Department of Defense announced in October that both the Army and Marines would deploy approximately 24,000 troops to South Vietnam for involuntary second tours of duty by the year's end.

These aforementioned incidents combined with President Lyndon B. Johnson's withdrawal from the 1968 presidential election in March, the respective assassinations of Martin Luther King Jr. and Robert F. Kennedy in April and June, and Senator Richard Nixon's victory over Vice-President Hubert Humphrey and Alabama governor George Wallace for American presidency in November, are purported to have catalyzed the American youth culture - represented by the student activist movement as well as the hippie movement—and spurred their already strong antipathy for institutions of authority. Sociologist Todd Gitlin contends that the year's events incited a widespread disillusion and discontent, rooted in a belief that liberalism had failed and that the American government had deceived its citizenship - a vexation that aligned both the student 
reformers and the counterculture. In his celebrated first-hand account of the decade, The Sixties: Years of Hope, Days of Rage, Gitlin suggests that this intersection of views helped to forge a perceptible American youth identity guided by the following ethos: "To be young and American is to have been betrayed; to be alive is to be enraged." ${ }^{\prime 31}$ While the more militant reform tactics employed by the New Left, particularly Students for a Democratic Society (SDS), stood counter to the hippies' choice to withdraw from the dominant culture, both communities shared a similar spirit of rebellion that, according to Mark Kurlansky, would eventually extend beyond the youth culture and touch all aspects of American life by the end of $1968 .^{32}$

American youth repeatedly demonstrated their dissent by organizing in opposition to military conscription. While the peacetime draft initiated by Harry S. Truman's Selective Service Act of 1948 was still in effect at the start of the Vietnam War, the number of men called for military service in the first years of the conflict remained relatively low. However, the practice of drafting returned with new zeal in 1965 when President Johnson increased the number of American troops sent to South Vietnam from 9,000 per month to over 35,000 per month. ${ }^{33}$ Michael S. Foley identifies 1966 as the origin of the anti-draft movement, and suggests that draft resistance reached a volatile apex as 1967 ended. ${ }^{34}$ This marked rise in draft resistance also coincided with a dramatic surge in SDS membership and the diffusion of the hippie movement, which spread from its initial enclaves in San Francisco's Haight-Ashbury District and New York City's East

\footnotetext{
${ }^{31}$ Todd Gitlin, The Sixties: Years of Hope, Days of Rage, rev. trade ed. (New York: Bantam Books, 1993), 286.

${ }^{32}$ Mark Kurlansky, 1968: The Year That Rocked the World (New York: Random House, 2005), xvii.

${ }^{33}$ Michael S. Foley, Confronting the War Machine: Draft Resistance During the Vietnam War (Chapel Hill, NC: University of North Carolina Press, 2003), 35.

${ }^{34}$ Ibid., 9.
} 
Village and began to propagate throughout the United States. ${ }^{35}$ The rapid expansion of the student movement, the counterculture, and anti-draft protest over the course of a single year suggests that the discontent of America's youth was difficult to ignore by 1968, particularly given Gitlin's claim that "the zeitgeist screamed until it was hoarse."36 With vocal dissent as a defining characteristic of the historical moment, the voice of the youth movements would manifest throughout American culture in a variety of unlikely forms.

Amidst the din created by the year's turbulence, 1968 witnessed the Broadway premiere of Hair, the American Tribal Love-Rock Musical penned by James Rado, Gerome Ragni, and Galt MacDermot. Hair opened at the Biltmore Theatre on April 26 (the seventh day of the SDS occupation of Columbia University) and arrived on the Great White Way after two successive runs Off-Broadway in the final months of 1967: a sixweek limited engagement at Joseph Papp's Public Theatre and a forty-five performance run at a midtown discotheque known as the Cheetah. Directed by Tom O'Horgan, the musical garnered significant attention from audiences and critics alike for its depiction of the prevailing American zeitgeist, particularly the hippie movement. Set in New York City's East Village during the Vietnam era, Hair depicted a band of hippies known only as "The Tribe" as they advocated for peace, free love, clean air, long hair, communal living, psychedelics, and higher consciousness in an abandoned theatre space.

Throughout the musical's first act, various members of the tribe introduced themselves to the audience, catalogued the primary values of 1960s counterculture in song, and made preparations for the "Be-In," a protest event modeled after the "Human Be-In" held in

\footnotetext{
${ }^{35}$ Unger and Unger, 6-7.

${ }^{36}$ Gitlin, 287.
} 
San Francisco's Golden Gate Park on January 14, 1967 that preceded the city's widely mythologized Summer of Love. During Hair's fictional "Be-In," which occurred at the close of the musical's first act, the tribe voiced their opposition to the Vietnam War and the men of the group — save for the wistful and romantic Claude — burned their draft cards in a marked act of defiance. A sizable portion of the musical's second act attended to Claude's inner conflict regarding his conscription to military service in South Vietnam. Several members of the tribe begged Claude to dodge the draft and take refuge in Canada; however, a drug-fueled nightmare on the night before his scheduled induction prompted him to forsake both his friends and hippie life. The musical ended with Claude's death and the tribe's collective call for peace.

As members of the counterculture constituted a significant portion of Hair's dramatis personae, the primary assumptions, anxieties, and values that typified hippie life sat at the forefront of the musical's thirty-two songs and connective scenes. Hair's musical numbers addressed a wide array of counterculture concerns including astrology ("Aquarius"), drug use ("Hashish" and "Walking in Space"), sex ("Sodomy" and "The Bed"), protest (“Ain’t Got No"), the environment (“Air"), the generation gap (“Going Down" and "Hair"), eastern mysticism ("Hare Krishna"), race relations ("Colored Spade," and "Black Boys/White Boys"), war casualties ("Three-Five-Zero-Zero"), and peace ("Let the Sunshine In"). Furthermore, Rado and Ragni's libretto depicted the tribe's extreme distrust of and resistance to all forms of authority and presented a damning critique of the United States Government, the Selective Service System, and the Vietnam War. In an attempt to illustrate these various aspects of hippie culture, members of the tribe openly swore, mocked their elders, mocked government officials, manhandled 
an American flag, touched each other, touched themselves, consumed a wide array of legal and illegal pharmaceuticals, and —in what soon became the musical's most infamous scene - removed their clothing and stood naked before the audience.

At the same time, Hair espoused the importance of community and demonstrated the separatist rhetoric of the hippie movement. In The Hippies and American Values, Timothy S. Miller claims that wholesale rejection of the dominant culture, its metanarratives, and the status quo in order to create an alternate, more egalitarian society for themselves was a defining characteristic of the counterculture. ${ }^{37}$ Moreover, David Farber suggests that the impulse to create new communities is evidenced by the appearance of new hippie districts in cities such as Atlanta, Chicago, Austin, Lawrence, and Fayetteville: "The counterculture was about space, about taking over a few city blocks or a few acres of country side and trying to make a world out of it, a place where all the old rules were up for grabs and where, as the saying went, you could take a trip without a ticket." ${ }^{38}$

The notion of constructing a new domain of existence was integral to Hair as the musical's chief dramaturgical conceit concerned the tribe's occupation of an empty theatre. In repurposing the space as a site for their congregation, Claude and his friends not only fashioned a sanctuary from the dominant culture, but also attempted to design their own society with their own set of values and rules. The lyrics to "Aquarius," Hair's opening number, presented this task as the tribe's modus operandi. As Raymond Knapp has noted, "Aquarius" was an incantation whose melody and lyrics presented the tribe's

${ }^{37}$ Timothy S. Miller, Introduction to The Hippies and American Values, $2^{\text {nd }}$ ed. (Knoxville, TN: University of Tennessee Press, 2011), xvii.

${ }^{38}$ David Faber, The Age of Great Dreams: America in the 1960s (New York: Hill and Wang, 1994), 169. 
somewhat naïve belief that the approaching era would present a society malleable enough for them to sculpt. ${ }^{39}$ The Age of Aquarius as they imagined it would represent a time in which hippie values such as harmony, understanding, freedom, and love would steer the stars and the American populace. The entertainment that followed arguably presented spectators with a living portrait of what a world guided by the hippie conscience might look like. In an interview with Helen Lawrenson of Esquire, Michael Butler, the politician-turned producer who transferred the musical from the Public Theatre to Broadway, claimed that Hair's greatest achievement was that it "documented the flowering of a new society.. ${ }^{40}$ Butler's assessment concisely describes the musical's dramaturgical premise. From the opening vamp of "Aquarius" to the final strains of "Let the Sunshine In," the musical depicted the tribe's collective efforts to create their own civilization in the Biltmore Theatre-a community consciously removed from the dominant culture and supported by the reigning beliefs, assumptions, and values of the hippie movement.

Representing hippie culture as authentically as possible was of great concern to Rado and Ragni when they began to pen Hair's libretto. The counterculture, particularly its zest for life and its passionate response to war, fascinated both writers and compelled them to initiate the project despite the fact that neither of them had any playwriting experience. As Rado remembered, both he and Ragni identified with the hippie spirit and aimed to use the musical as a vehicle for sharing their message with mainstream audiences: "We were trying to capture the essence of a movement. We really believed in

${ }^{39}$ Raymond Knapp, The American Musical and the Formation of National Identity (Princeton, NJ: Princeton University Press, 2005), 157.

${ }^{40}$ Helen Lawresnon, "A Weekend with Chief Michael Butler and His Inner Tribe," Esquire, November 1971, 166. 
it—we really loved what was happening [in the streets]. ${ }^{.41}$ Taken as they were with hippie culture and its public promulgation of peace, love, and freedom, the musical's authors did not necessarily identify as hippies at the start of their collaboration. In an effort to learn more about the movement and its members, Rado and Ragni began to observe the longhaired denizens of New York City's Greenwich Village in 1965, monitoring the appearance, vernacular, and behavior of unwitting subjects-frequently at anti-war demonstrations, happenings, or be-ins. Documenting their surveillance over the course of these two years, the "field notes" of this ethnographic study became the raw material from which the authors would then fashion Hair's libretto and lyrics. ${ }^{42}$

Additionally, Rado, Ragni, and O'Horgan recruited several members of Hair's Broadway company directly from the streets of New York City. ${ }^{43}$ In an effort to endow the production with counterculture credibility, O'Horgan felt it best to forgo casting musical theatre professionals and instead invited members of youth culture who "looked right" and could convincingly interpret MacDermot's score to join the tribe. ${ }^{44}$ Consequently, ninety percent of the production's ensemble had no formal performance training or experience prior to their appearance in Hair. ${ }^{45}$ Many of these neophyte actors were not affiliated with the counterculture when they first joined the musical's tribe, but several later identified as hippies because of their participation in the production. As original cast member Walter Michael Harris attests, "I joined Hair as an actor and left as

${ }^{41}$ Quoted in Elizabeth Wollman, The Theatre Will Rock: A History of the Rock Musical, From Hair to Hedwig (Ann Arbor, MI: University of Michigan Press, 2006), 46.

${ }^{42}$ Barbara Lee Horn, The Age of Hair: Evolution and Impact of Broadway's First Rock Musical (New York: Greenwood Press, 1991), 24-25.

${ }^{43}$ See Appendix C for a complete list of the original production's cast and production team members.

${ }^{44}$ Ibid., 54-55.

${ }^{45}$ Lawrence Thelen, The Show Makers: Great Directors of the American Musical Theatre (New York: Routledge, 2004) 161. 
a hippie. Hair expanded my sense of mission, opened my eyes to the multi-layered universe and the political world ... the joy of life, the unity of the human family, and the need for people to transcend whatever keeps them apart. ${ }^{, 46}$ Lorrie Davis, another member of the original company who would later become Hair's chief historian, relates that many of the musical's performers approached their participation in the production as a mission rather than another professional stint and that disseminating the hippie message became — for some actors—-more important than a weekly paycheck. ${ }^{47}$

Hair's contemporaneity extended to not only its content, but also its form. Where a strong causal narrative supported most musicals of the Golden Age, Hair featured an episodic plot and a pliable libretto that relied heavily on improvisation and audience interaction. Furthermore, its rock-inspired songs did not emerge from or advance the central narrative, but rather divided the libretto into a series of discrete and sometimes wholly unrelated vignettes. Hair's structure then resembled a vaudeville or revue as opposed to the more integrated book musicals popularized by Rodgers and Hammerstein and further conventionalized by their contemporaries. Because these aforementioned aspects of the musical's dramaturgy represented a marked divergence from the Golden Age model, a portion of Hair's historical significance arguably derives from the fact that it stood counter to the standard musical theatre fare of the day on Broadway. Its divergence from tradition made the musical something of a novelty.

Hair's form was in fact more representative of theatrical offerings that were then burgeoning on Off-Broadway and Off-Off Broadway stages, presumably because two of

${ }^{46}$ Quoted in Jonathan Johnson, Good Hair Days: A Personal Journey With the American Tribal Love-Rock Musical (Lincoln, NE: iUniverse, 2004), 214.

${ }^{47}$ Lorrie Davis, Letting Down My Hair: Two Years With the Love Rock Tribe - From Dawning to Downing of Aquarius (New York: Arthur Fields Books, Inc., 1973), 39. 
its progenitors were active participants within New York City's experimental theatre scene throughout the early 1960s. Ragni learned improvisation and collaborative scriptwriting techniques as a member of Judith Malina and Julian Beck's Living Theatre from 1962 to 1963 and later during his tenure with Joseph Chaiken's Open Theatre from 1963 to 1966 . Director O'Horgan worked in avant-garde theatre for ten years prior to joining Hair's creative team and helmed over sixty productions for Ellen Stewart's Great Jones Repertory Company at La MaMa Experimental Theatre Club between 1963 and 1967. Theatre historian Stephen J. Bottoms further contends that Hair's use of song, spectacle, movement, and subdivided action resembled the performances that were presented at the Judson Poets Theatre, The Performing Garage, and Café Cino throughout the 1960s. Because Hair employed playwriting and staging practices borrowed from the foremost experimental theatre companies of the day, its presence on Broadway was notable and marked a break with tradition that would arguably alter the course of musical theatre history and cause the piece to become, in the words of John Bush Jones, "the unwitting prototype" for a rash of later musicals on Broadway that featured a decidedly more fragmented structure. ${ }^{48}$

With its form and content born of both the psyche and the aesthetics of the Vietnam era, Hair is arguably one of the most time-bound works in the American musical theatre canon. Several critics and scholars have identified the musical as a period piece and presented hypotheses for why Hair, a musical of great historical significance, has not enjoyed a more fruitful afterlife. New York Times theatre critic Charles Isherwood

${ }^{48}$ John Bush Jones, Our Musicals, Ourselves: A Social History of the American Musical Theatre, by John Bush Jones (Hanover, MA: Brandeis University Press, 2003), 273-274. 
conjectures that while the musical's ties to its cultural moment are among its most defining features, they have also thwarted the musical's chances for revival:

[Hair] is ... an interesting show that has retained its musical charm but is so deeply dyed in the sights, sounds, and smells of its era that it has also become a touchstone of $60 \mathrm{~s} \mathrm{kitsch}$. Hair crystallized the countercultural currents of its time with a tuneful innocence and exuberance that have assured its appeal as a popculture artifact. But those very qualities probably doomed its chances as an enduringly resonant work of art ... You can't pry Hair out of the 1960s, give it a new perm and make it speak of things timeless. Virtually every song, and much of the scattered book too, addresses quite specifically an attitude or an experience of the here and now, which is to say the there-and-then: draft dodging, fads like astrology, and be-ins, free love, newfangled drugs, and the Hare Krishna movement. ${ }^{49}$

Isherwood's assessment of Hair's innate time-boundedness suggests that the musical is not only a theatrical relic, but also a cultural curiosity when viewed in the present day. One could argue that the musical's transformation from pop-culture benchmark to historical remnant occurred in tandem with the end of its Broadway run. President Richard Nixon reduced the number of American soldiers in Vietnam by 70,000 in January of 1972 and officially suspended the draft one year later—an act that coincided with Henry Kissinger and Le Duc Tho's signing of a cease-fire agreement in Paris that would begin the process of bringing the Vietnam conflict to an end. When the first Broadway production of Hair closed on July 1, 1972, the era that produced it was on the verge of closing as well, making the musical somewhat obsolete before it officially entered its afterlife.

Attitudes such as Isherwood's might account for Hair's rather varied production history. Since 1972, the musical has enjoyed a handful of moderately successful regional

${ }^{49}$ Charles Isherwood, “The Aging of Aquarius," New York Times, September 16, 2007, A1. 
productions in Montreal (1985), Chicago (1988, 1996), Toronto (2006), and Los Angeles (2007), the majority of which were produced by Michael Butler. Butler also planned to organize a festival tour for Hair in 2000 that would travel to San Francisco, Seattle, Las Vegas, Denver, Washington, NYC, Boston, Chicago, Toronto, Atlanta, Miami, New Orleans, and culminate in a Broadway revival. Neither the tour nor the revival materialized. The producer's plans for another touring production in 2003 also floundered. Two additional attempts to revive Hair on Broadway were made in 2001 after the musical received successful concert performances by the Reprise Theatre Company in Los Angeles and New York's City Center Encores. Both productions preceded the attacks on the World Trade Center and never transferred to Broadway. To date, Hair has only received two Broadway revivals: one directed by Tom O'Horgan in 1977 and another helmed by Diane Paulus in 2009. Through their respective productions, both directors had to address the musical's relationship to its era, particularly with respect to its original libretto and score, which have arguably kept the musical tied to the late 1960s more than any of its other features.

While the Playbill to the original Broadway production of Hair never specified the musical's temporal setting, Rado and Ragni's libretto repeatedly confirmed the Vietnam era as Hair's moment in time with a surfeit of references to its present day. The musical's book and lyrics contained a total of forty-five allusions to American culture in late 1960s and included mentions of some of the foremost filmmakers, actors, musicians, politicians, religious leaders, visual artists, fictional characters, retailers, and household products of the day. Several of these references appeared in Rado and Ragni's lyrics. The final verse to the tribe's “Ain't Got No" contained a laundry list of pop culture 
references, including mentions of film stars Tuesday Weld, Richard Burton, Elizabeth Taylor, pop artist Andy Warhol, and President Lyndon B. Johnson. ${ }^{50}$ In the lyrics to "Manchester, England," Claude cited psychologist Timothy Leary and film directors Michelangelo Antonioni, Federico Fellini, and Roman Polanski as his chief role models. ${ }^{51}$ Crissy's anthem to lost love, "Frank Mills," made reference to the Hell's Angels, the Waverly Theatre, and The Beatles' lead guitarist, George Harrison. ${ }^{52}$ Additionally, in composing lyrics for “Three-Five-Zero-Zero," Ragni borrowed several lines of verse from the second movement of Alan Ginsberg's "Wichita Vortex Sutra," a 1966 anti-war poem that chronicled not only the American death toll, but also the numerous ways in which both American and South Vietnamese soldiers might die in combat:

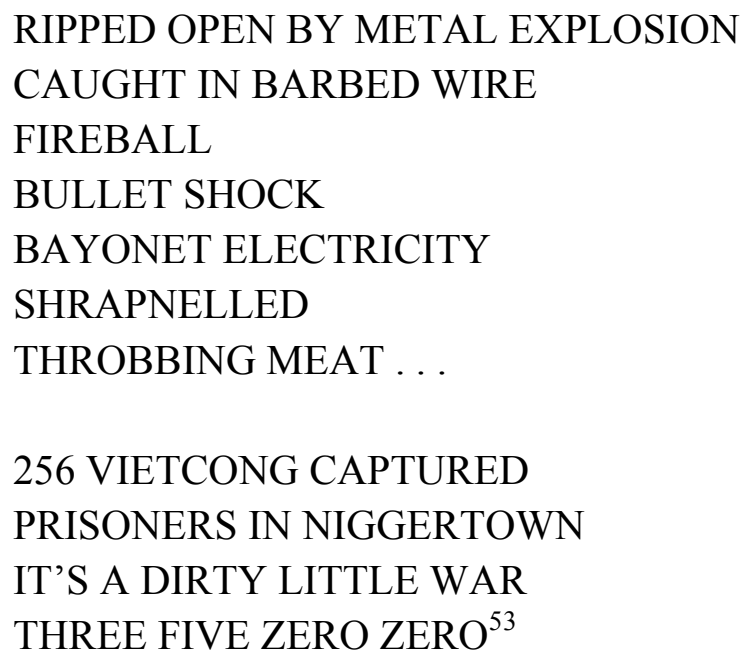

Other period references scattered through the text included: Vice President Hubert Humphrey, recording artists James Brown, The Grateful Dead, Mick Jagger, and Aretha Franklin, Rinso Detergent, King Korn Stamps, Halo Shampoo, The Mormon Tabernacle

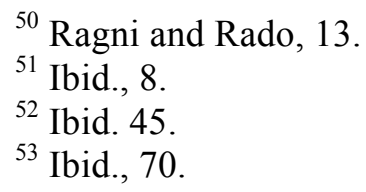


Choir, Orange Julius, and burgeoning computer manufacturer IBM. ${ }^{54}$ Berger, the selfappointed leader of the Tribe, identified Rabbi Benjamin Schultz, Pope Paul VI, George Wallace, and Richard Nixon as political figures with whom he would like to share his drugs. ${ }^{55}$ Pregnant tribe member Jeanie urged Claude to read Ophiel's 1961 book, The Art and Practice of Astral Projection. ${ }^{56}$ Furthermore, a scene that prefaced the musical's title song featured one of the tribe's male members impersonating Margaret Mead ${ }^{57}$ While Mead's most celebrated publications were forty years old at the time of Hair's premiere, the cultural anthropologist continued to author new studies throughout the 1960s including Continuities in Cultural Evolution (1964) and The Wagon and the Star: A Study of American Community Initiative (1966).

Rado and Ragni also scattered fourteen allusions to recognizable figures from previous decades - particularly the 1930s and 1940s—-throughout the libretto. These mentions of the past served to highlight the growing generation gap between Hair's hippie enclave and their elders. Among the cultural figures mentioned were Betty Crocker, Tonto, Buckwheat, Mary Pickford, Calvin Coolidge, Clark Gable, and Scarlett O'Hara. ${ }^{58}$ References to the recent past worked in concert with mentions of the current historical moment to situate the musical within the present cultural landscape and project the musical's action as immediate. One of the most notable instances of extant and erstwhile allusion occurred midway through the musical's first act when Hubert, traveling companion to the faux Margaret Mead, asked various members of the tribe to name their personal heroes. The hippies then cited a range of cultural figures known for their

\footnotetext{
${ }^{54}$ Ibid., 23, 31, 41, 64, 8, 16, 41, 33, 40, 73.

${ }^{55}$ Ibid., 23.

${ }^{56}$ Ibid., 35.

${ }^{57}$ Ibid., 35.

${ }^{58}$ Ibid., 16, 19, 30, 43, 68.
} 
signature hairstyles. Among the most current figures were Doris Day and Annette Funicello, film actresses who cultivated a public image of wholesome femininity throughout the 1960s vis-à-vis a series of successful romantic comedies and beach party movies respectively. The hippies' other stated heroes-Wonder Woman, Veronica Lake, Little Orphan Annie, and Buckwheat—all came into the public consciousness between 1924 and 1941; however, it is more than reasonable to assume that these figures were still recognizable to the American populace at the time of Hair's Broadway premiere as they had become American cultural icons. ${ }^{59}$ The overabundance of period references interspersed throughout Rado and Ragni's libretto, fifty-nine in total, suggests that the authors sought to align the world of their musical with the world outside of the Biltmore Theatre. By continuously remarking time with cultural allusions, Hair's authors performed the important dramaturgical task of establishing the musical's temporal setting.

Further certifying Hair's moment in time was the fact that Claude and the tribe cited the current year four times in one scene. An extended episode that preceded Claude's ode to personal freedom, "I Got Life," depicted the free-spirited youth engaged in a verbal altercation with his conservative parents. Six members of the tribe dressed in bathrobes helped Claude to recreate the argument with one trio representing his father and another trio impersonating his mother. Both sets of parents berated Claude for his lack of direction and drive, his lack of employment, and his unpatriotic attitude toward the war effort. His physical appearance was also a source of contention, particularly his dirty trousers, unkempt hair, and his choice to wear his mother's beads around his neck. Claude countered these grievances with an accusation that his parents' expectations were
${ }^{59}$ Ibid., 30. 
outdated, and therefore, invalid: "This is 1968, dearies. Not 1948." ${ }^{60}$ Claude's rebuttal not only alerted viewers to the musical's present day setting, but also drew attention to the incongruity between his values and those held by his parents, further suggesting that 1948 standards of living were no longer tenable in the late 1960s. The scene continued to highlight the generation gap as the parent chorus began to refer to Claude as 1968, insinuating that he embodied the spirit of the times:

MOM I: What have you got ...

MOM III: . . 1968 . . .

MOM II: . . may I ask?

DAD III: What have you got, $1968 \ldots$

DAD I: ... that makes you so damn superior ...

DAD II: . . . and gives me such a headache? ${ }^{61}$

The remaining members of the tribe watched Claude's scene unfold from the sidelines and responded to the parents' invocation of the current year by chanting " 1968 " in the background. This spoken underscore arguably supported Claude's defense of hippie culture and further confirmed the musical's temporal setting. For the duration of Hair's run on Broadway, the year cited by Claude and his parents in this scene changed each year so that the musical would continue to correspond to the current historical moment. Altering the musical's temporal setting in this manner each year allowed Hair's creative team to present the work as an immediate, real-time event.
${ }^{60}$ Ibid. 19.
${ }^{61}$ Ibid., 19-20. 
The fluidity of Hair's libretto extended beyond its stated temporal setting as improvisation played a central role in the musical's development and rehearsal process, presumably due to the creative team's experimental theatre roots. Lorrie Davis reports that Rado and Ragni gave director O'Horgan license to incorporate moments of extemporaneous dialogue that company members generated into Hair's book. This dialogue often took the form of comic bits that frequently made reference to the current popular culture. However, because actor improvisation was a regular feature of rehearsals, the company's contributions to the ever-expanding script were often jettisoned in favor of newer material. As a result of O'Horgan's instinctive and offhand rehearsal process, the first complete version of the Broadway libretto was not transcribed until days after the musical's official Broadway opening. ${ }^{62}$ The director also encouraged his actors to embrace the spirit of improvisation regularly throughout the musical's run. Consequently, members of the tribe frequently abandoned the musical's established text and contrived new dialogue during performances. The director's blanket authorization of actor ad-libbing meant that Hair was never frozen—a fact that the production's technicians and backstage crew frequently bemoaned as improvisation frequently forced them to ignore the cues dictated by the established book and respond instead to the unpredictable caprices of the musical's actors. ${ }^{63}$ Thus, Hair was a musical without a stable performance text. Performances could, and frequently did, change on a nightly basis due to a given tribe member's demeanor, creative instinct, or intemperance. As drug use was a common feature of Hair's backstage culture, intoxicated actors routinely went off script and improvised their performances, requiring their more sober colleagues to

\footnotetext{
${ }^{62}$ Davis, $109-110$.

${ }^{63}$ Ibid., 70.
} 
alter dialogue or even the order of songs in order to accommodate their delirious colleagues. In the event that a leading actor was too potted to perform, ensemble members divided the given actor's lines or songs among themselves. Consequently, all the musical's featured characters did not appear in every performance. ${ }^{64}$

In addition to the overabundance of period references found in its libretto, Hair's rootedness in 1960s culture can also be attributed to Galt MacDermot's score. MacDermot had never composed music for the theatre prior to his collaboration with Rado and Ragni. Furthermore, he was a formally trained musician who received his education at the University of Capetown where he concentrated his studies on African music. MacDermot began his composing career working in jazz, pop, blues, country and western, and rock, and earned a Grammy Award in 1960 for his “African Waltz,” a jazz piece composed for saxophonist Cannonball Adderly that recalled the popular AfroCuban jazz sounds of the day. ${ }^{65}$ For the score to Hair, MacDermot utilized several timely musical idioms including pop, rock, soul, and folk. The composer consciously modeled his songs after the popular tunes of the day recorded by such artists as Aretha Franklin, The Rolling Stones, and The Beatles. ${ }^{66}$

While musicologists such as Scott Warfield, Elizabeth Wollman, and Raymond Knapp contend that Hair was not the first Broadway musical to feature rock music, they do acknowledge that its score contained more rock idioms than any of its predecessorsmost notably Charles Strouse's Bye Bye Birdie (1960)—and that MacDermot's songs employed a more authentic rock modality that was consistent with the popular music of the time. In her assessment of Hair's score for The Theatre Will Rock: A History of the

\footnotetext{
${ }^{64}$ Horn, 91.

${ }^{65}$ Ibid., 27.

${ }^{66}$ Stanley Dance, “Galt MacDermot: Heir to Hair,” Downbeat, November 9, 1972, 14.
} 
Rock Musical, From Hair to Hedwig, Wollman contends that the historical significance

of MacDermot's songs stem from the fact that they represent a wide range of rock styles:

A rich array of maturing popular American musical styles are woven into the musical's score, from the funky, soul-infused "Aquarius," to the Motown-inspired "Black Boys/White Boys," too the free-form jam of "Walking in Space," to the psychedelia-tinged "Donna" and "Be-In." MacDermot's use of a variety of styles distinguishes his score from previous composers' attempts at bringing rock music to the Broadway stage by simply featuring recurring bass-lines or repetitive lyrics that parodied rock 'n' roll. ${ }^{67}$

Warfield claims that MacDermot's songs do not demonstrate a particularly innovative use of rock; however, his arrangements employed the harmonic vocabulary of 1960s rock music and his orchestrations (which relied heavily on amplified instruments) demonstrated an unambiguous rock sound. ${ }^{68}$ Hair's orchestrations called for a baritone saxophone, three trumpets, a drum set, eighteen percussion instruments, an electric bass, an electric piano, and two electric guitars. Due to the score's reliance on amplified instruments, members of the tribe used four handheld microphones when singing. Another five shotgun microphones and eight loudspeakers helped to amplify the actors' voices over the clamor of the onstage band. Wollman contends that the actor's need for amplification helped to earn Hair the designation of Broadway's first rock musical. ${ }^{69}$

In his appraisal of MacDermot's score for The American Musical and the Formation of National Identity, Knapp proposes that Hair's songs were evocative of their era not only because of the idiom in which they were composed, but also because of the dramaturgical function their lyrics performed throughout the musical. Several of the

${ }^{67}$ Wollman, 52.

${ }^{68}$ Scott Warfield, "From Hair to Rent: Is 'Rock' a Four-Letter Word on Broadway," The Cambridge Companion to the Musical, $2^{\text {nd }}$ ed., ed. William A. Everett and Paul R. Laird (Cambridge: Cambridge University Press, 2008) 238.

${ }^{69}$ Wollman, 54. 
numbers presented in Hair's first act, including "Hashish," "Sodomy," "Colored Spade," "Ain't Got No," "Air," and "I Got Life," presumably functioned to instruct otherwise uninformed audience members about the mission and values of the counterculture. These songs presented extensive lists of drugs, sexual acts, racial epithets, and hippie vernacular and arguably worked to acclimate spectators to hippie custom (often through shocking parlance) before introducing the central conflict of Claude's conscription. According to Knapp, "In the sixties, playing to a mixed audience of insiders, outsiders, and wannabe's, these lists were an essential exposition, part of the show's implicit mission to serve as a kind of teach-in." ${ }^{70}$ The musicologist goes on to argue that the overt pedagogical function of these songs has become redundant since the dissolution of the hippie movement, insinuating that present day audiences no longer require such explicit instruction about the hippie movement and that the songs' implicit didacticism has rendered the musical timeworn. However, the songs' capacity for instructing viewers is perhaps even more useful, if not necessary, years after the hippies' heyday. By familiarizing spectators with the movement's central tenets and primary concerns, Hair's numbers provide current audiences with a kind of historical context that will inform and orient their viewership. The songs certainly reify the musical's ties to the late 1960s but have not lost their narrative usefulness as Knapp has proposed.

The design team for Hair - composed of scenic designer Robin Wagner, costume designer Nancy Potts, and lighting designer Jules Fisher-further projected the Vietnam era as the musical's milieu by utilizing the aesthetics of the current zeitgeist. O'Horgan wanted the musical's spectators to engage with the hippie ensemble directly and feel as if they were attending a happening; consequently, he requested an environment for Hair in

\footnotetext{
${ }^{70}$ Knapp, 161.
} 
which the theatrical conventions or devices traditionally used to separate the audience from the actors on stage were diminished if not eliminated entirely. In order to honor the director's wishes, Wagner removed the Biltmore Theatre's grand drape and masking curtains, revealing its wings, fly rail, radiator pipes, electrics, and backstage crew to the audience. He also raised the upstage cyclorama, exposing the large, bare brick wall behind it. In an effort to minimize theatrical artifice, Wagner kept the stage relatively bare, giving the tribe ample room to dance, stage political demonstrations, and as Farber suggested previously, create its own world according to hippie ideals. This world extended beyond the stage as tribe members frequently broke the fourth wall and entered the house in order to address, sing to, and dance with audience members. Direct engagement with the audience became a hallmark of Hair, with tribe members wandering the house and mingling with patrons prior to the musical's start, and entreating spectators to join them onstage for a communal dance of celebration just after its conclusion. ${ }^{71}$

While minimalist in nature, Wagner's design called for two significant pieces of set dressing, the first of which was a hollowed out pickup truck stationed at stage left. Members of the musical's band sat in or around the truck's bed during performances and played their instruments in full view of the audience. Rather than hiding the musicians in the orchestra pit, Wagner featured them in his design, making them a discernable element of Hair's mise-en-scène. By placing the band onstage, Wagner further demonstrated the important role that rock music played in the musical's dramaturgy and suggested that the musicians (dressed in the same hippie attire as the actors) were members of the tribe as well. The second set piece was a multi-leveled scaffolding unit, positioned upstage and adorned with objects that members of the tribe might have collected off the street: a

\footnotetext{
${ }^{71}$ Horn, 66, 80.
} 
birdcage, a bicycle wheel, a stop sign, a hubcap, a flying horse, the face of Jesus Christ, a statue of Santa Claus, a rubber tire, an umbrella, a kite, and a cello. Meant to invoke the image of a Native American totem pole, the unit also displayed signifiers of American culture (such as a Coca-Cola bottle, the visage of Uncle Sam, star-spangled bunting, and a statue of Elvis Presley) as well as totems of the counterculture (including a neon sign for the Waverly Theatre, Lyndon B. Johnson's face mounted on a dartboard, and the Rolling Stones' signature “tongue and lips" logo). Rado and Ragni's initial libretto to Hair - the draft used for the Public Theatre's production—called for an overtly Native American totem pole; however, Wagner elected to construct a more abstract structure with cultural artifacts in order to further evoke the current zeitgeist:

The script calls for a totem pole on stage, but I felt that just as the play billed itself as 'American Tribal Love Rock Musical,' but wasn't about Indians at all, so should the totem pole not really be an Indian totem pole either. Instead we made it as contemporary as the play, building it up out of advertisements, signs, and other modern objects, which are the totems and taboos of our society today. ${ }^{72}$

Because of Wagner's design rationale, emblems of the current cultural moment faced the audience and worked in concert with the musical's book and music to remind spectators of Hair's present day setting.

In addition to transforming the Biltmore Theatre into a counterculture rumpus room, Wagner fashioned a series of handheld signs for the tribe to use during their more overt moments of protest. These placards, constructed from poster board and pieces of wood scrap, bore several different hippie slogans, including "Lay Don't Slay," "Let 1,000 Parks Bloom," and "Sit-Ins Cause Piles." While any of these expressions could have served as a rallying cry for real life hippies, one of Wagner's signs featured a phrase that

\footnotetext{
72 "Interview with Robin Wagner," Souvenir Program for Hair: The American Tribal Love-Rock Musical, Natoma Productions Inc., 1968, 8.
} 
was slightly more ironic and self-referential: "See Ethel Merman in Hair." At the time of Hair's premiere, Merman was a confirmed musical theatre legend whose star rose during the 1930s. Though she worked steadily throughout the Golden Age, Merman had not appeared in a Broadway production since her career-defining turn as Madame Rose in Jule Styne's Gypsy (1961). Wagner's slogan, suggesting that Merman had joined Hair's tribe, was something of a wisecrack acknowledging that the star's highly presentational acting style and signature belt, cultivated from years of headlining musical comedies, harkened a bygone era that stood in stark contrast to Hair's contemporaneity.

Furthermore, it insinuated, somewhat cheekily, that the current Broadway landscape was no longer amenable for the star's distinct performance persona. This witticism was disproven two year into Hair's Biltmore run, however, when Merman joined the Broadway cast of Jerry Herman's smash hit, Hello, Dolly! (1966), then running at the St. James Theatre. Though Merman's performance as Dolly Gallagher Levi would mark her final star turn in a Broadway musical, her presence on the Great White Way, just three blocks away from the Biltmore Theatre, helped to make Hair even more of an immediate event.

Hair's costumer, Nancy Potts, modeled many of the tribe's garments on the street clothes that company members wore to rehearsals. The designer attended rehearsals regularly and looked to the ensemble's self-identified hippies for inspiration, incorporating their bandanas, beads, feathers, fringe, and distressed denim into the looks that she created for the musical's principal characters. After procuring clothes from shops in Greenwich Village and the St. Mark's Place corridor (particularly vintage, thrift, and military surplus stores), Potts allowed tribe members to select their own garments and 
compose a highly idiosyncratic hippie ensemble. ${ }^{73}$ In justifying this choice, the designer alleged, "They have a firm understanding of themselves, emotionally and visually, and it would have been against all the show stands for to force on them hackneyed Broadway costuming techniques. ${ }^{, 74}$ Additionally, Lorrie Davis reports that cast members periodically wore their own clothes on stage. Whether from their own closet or Potts's collection of stock pieces, the tribe sported attire consistent with the current cultural moment, and in most cases, the counterculture aesthetic.

Utilizing vibrant colors and multiple strobe effects, lighting designer Jules Fisher sought to craft a visual complement for the rock idioms of MacDermot's score. The designer took inspiration from the psychedelic lighting he observed while attending concerts at Fillmore East, a rock venue adjacent to Manhattan's East Village that opened just six weeks prior to Hair's Broadway bow. ${ }^{75}$ As the designer alleged, "In Hair, the light, its color, drama and intensity are based on the tempo and temper of the music — and the motions of what is happening ... lights blink, change color, project up from the floor, down from the ceiling — take on a psychedelic life of their own." ${ }^{, 76}$ Fisher did not see his design as particularly groundbreaking given that colored lights and flashing strobes were a common feature of most rock clubs and discos; however, he did take pride in his use of projections during the musical's nude scene and battle montage. For the former, a single lighting instrument projected the image of a bed of flowers onto a large sheet of white muslin while members of the tribe removed their clothes from underneath it. In the final

\footnotetext{
${ }^{73}$ Davis, 58.

74 "Interview with Nancy Potts," Souvenir Program for Hair: The American Tribal LoveRock Musical, Natoma Productions Inc., 1968, 8.

${ }^{75}$ Myrna Katz Frommer and Harvey Frommer, It Happened on Broadway: An Oral History of the Great White Way (New York: Harcourt Brace \& Company, 1998), 244.

76 "Interview with Jules Fisher," Souvenir Program for Hair: The American Tribal LoveRock Musical, Natoma Productions Inc., 1968, 7.
} 
moments of Hair's first act, the tribe slowly emerged from the muslin, as if they were rising from the flowerbed, and stood naked along the stage's periphery, illuminated only by the shadows cast by the lone light. The battle scene, which occurred during Claude's second-act nightmare, included a collage of photographs from several American wars projected by a strobe light. While a collection of tribe members sang strains of "ThreeFive-Zero-Zero" and denounced the atrocities of war, a second faction recreated moments of the Vietnam conflict through pantomime, forecasting the violence that Claude would encounter after arriving in the war zone. According to Fisher, the choice to juxtapose photos of historic war battles onto the tribe's performance of war resulted in a harrowing experience for some spectators as "images of brutality were thrust into the audiences' face ten times a second." 77

The original Broadway production of Hair received six positive notices, six mixed reviews, and one pan from the major New York critics. Those reviewers who debated the musical's merits took umbrage with its episodic libretto, thin plot, and underdeveloped characters - those qualities that separated Hair from earlier Golden Age musicals. MacDermot's score received unanimous praise; however, several critics complained about the production's reliance on amplification, claiming that the on-stage rock band and use of personal microphones overwhelmed the Biltmore Theatre's acoustics. Likewise, Hair's cast earned favorable remarks for the "zestful abandon" of their performances, but also condemnation for their characters' "cheap, vulgar, foulmouthed, and tasteless" onstage behavior. ${ }^{78}$ Though assessments of the musical's virtues

${ }^{77}$ Frommer and Frommer, 244.

${ }^{78}$ John Chapman, "Hair Is Itchy, Twitchy, and Dirty; The Company Dances With Zest," Daily News, April 30, 1968, in New York Critics' Theatre Reviews. Vol. 29, ed. Joan Marlow and Betty Blake (New York: Critics’ Theatre Reviews Inc., 1968), 288. 
varied greatly, reviewers uniformly remarked Hair's contemporaneity. Those critics who defended the musical identified its congruence of form, content, and cultural zeitgeist as its greatest strength and most singular feature. In his enthusiastic review for The New York Times, Clive Barnes hailed the musical as a theatrical achievement due to the creative innovation represented by its form and the candor with which it presented its content: "The show is the first Broadway musical in some time to have the authentic voice of today rather than the day before yesterday." ${ }^{, 79}$ Leo Mishkin of The New York Morning Telegraph expressed the same sentiment somewhat more succinctly: "[Hair $]$ is the musical theatre of $1968 .{ }^{, 80}$ Time attributed the musical's daring to its dramaturgical focus on the youth culture and described its features in counterculture terms: "The religion that Hair preaches, and often screeches, is flower power, pot, and protest. Its music is pop rock, and its dialogue is mostly graffiti. ${ }^{181}$ Few critics aside from Barnes and Mishkin mentioned the musical's political commentary or anti-draft stance; consequently, discussions of Hair's correlation to the current zeitgeist were generally confined to the musical's use of nudity, strong language, and rock music. While most critics sought to warn would-be viewers of Hair's potentially offensive material, John J. O'Connor of The Wall Street Journal foretold the musical's significance and urged his readers to attend the production because of its ability to shock, stating, "No matter the reaction to the content, though, I suspect the form will be important to the history of the

\footnotetext{
${ }^{79}$ Clive Barnes, "Hair-It's Fresh and Frank," New York Times, April 30, 1968, in New York Critics' Theatre Reviews. Vol. 29, ed. Joan Marlow and Betty Blake (New York: Critics' Theatre Reviews Inc., 1968), 289.

${ }^{80}$ Leo Mishkin, "Hair Explodes on Broadway," review of Hair by James Rado, Gerome Ragni, and Galt MacDermot, directed by Tom O'Horgan. Biltmore Theatre, New York, New York Morning Telegraph, May 1, 1968.

81 "Hair," review of Hair by James Rado, Gerome Ragni, and Galt MacDermot, directed by Tom O’Horgan. Biltmore Theatre, New York, Time, May 10, 1968.
} 
American musical." ${ }^{\prime 82}$ The critic went on to liken Hair to earlier landmark musicals such as Pal Joey, Oklahoma!, and West Side Story.

Following its April 26 opening, the first Broadway production of Hair ran for four years at the Biltmore theatre, playing a total of 1,750 performances. Although the musical received only two Tony Award nominations in 1969 and failed to win a single prize, its popularity with audiences and its overall commercial success more than made up for its lack of critical accolades. Attempting to capitalize on the exuberant response that Hair received from New York audiences, Michael Butler scattered the production across the United States, installing fourteen open-run companies in such cities as Los Angeles, San Francisco, Chicago, Boston, Seattle, Phoenix, St. Paul, Miami, Detroit, and Honolulu that ran concurrently with the Broadway production. Hair historian Barbara Lee Horn claims that the total grosses from these companies exceeded eighty million dollars. ${ }^{83}$ Butler and producing partner Bertrand Castelli would go on to mount over twenty international productions of Hair in cities such as London, Munich, Copenhagen, Stockholm, Paris, Sydney, Tokyo, Toronto, Belgrade, Tel Aviv, Mexico City, Helsinki, Buenos Aires, Madrid, Lisbon, and Amsterdam. Notable members of these domestic and foreign tribes included Diane Keaton, Melba Moore, Ben Vereen, Keith Carradine, Michael Lee (Meat Loaf) Aday, Ted Neely, Jennifer Warnes, Tom Smothers, Joe Mantenga, Tim Curry, and Donna Summer.

In addition to ticket sales and box office grosses, the overwhelming popularity of Hair was illustrated by the success of its original Broadway cast recording. The album

\footnotetext{
${ }^{82}$ John J. O'Connor, "The Theatre," Wall Street Journal, May 1, 1968, in New York Critics' Theatre Reviews. Vol. 29, ed. Joan Marlow and Betty Blake (New York: Critics' Theatre Reviews Inc., 1968), 289.

${ }^{83}$ Horn, xiv.
} 
earned Gold Record status from the Recording Industry Association of America and won the Grammy Award for Best Score of an Original Show Album in 1969. Two years later, the recording received Multi-Platinum status after having sold over three million copies. Additionally, the National Association of Recording Merchandisers named the album the best selling cast recording from 1969 to $1971 .^{84}$ In a 1970 interview with Billboard, Mike Stewart, then president of United Artists Music, charged that Hair represented "the most successful [musical theatre] score in history as well as the most performed score ever written for the Broadway stage." ${ }^{, 85}$ This claim, while possibly exaggerated, earns some credence from the fact that approximately 300 covers of MacDermot's songs for Hair were recorded by popular musical artists of the day during the musical's first two years on Broadway. The cadre of musicians to cut a tune from Hair included Nina Simone, The $5^{\text {th }}$ Dimension, Diana Ross and the Supremes, Engelbert Humperdinck, Anthony and the Imperials, Oliver, Andy Williams, The Cowsills, Shirley Bassey, Liza Minnelli, Sergio Mendes and the Brazil '66, Strawberry Alarm Clock, and Barbra Streisand. ${ }^{86}$

Hair's long run on Broadway, coupled with its substantial grosses and undeniable presence around the globe suggest that the musical was, in fact, something of a cultural phenomenon. The musical saturated the zeitgeist with its numerous productions and recordings, and its ubiquity arguably made the musical emblematic of the historical moment. As theatre historian Gerald Boardman has suggested, the piece was "far and

${ }^{84}$ Mike Gross, "Hair Sets the Style, and Broadway Now Accepts Pop Musicals as First Class Attractions," Billboard, November 6, 1971, 32.

${ }^{85}$ Quoted in Mike Gross, "Hair Is Doing Runaway Business as a Score and Play," Billboard, June 27, 1970, 1.

${ }^{86}$ Ibid. 
away the most important musical offering of the season, possibly of the era." ${ }^{\prime 87}$

Boardman's assessment has proved sound as the other musical offerings of the 19671968 Broadway season-George M!, Golden Rainbow, Darling of the Day, The Happy Time, The Education of $H^{*} Y^{*} M^{*} A^{*} N^{*} K^{*} A^{*} P^{*} L^{*} A^{*} N$, Leonard Sillman's New Faces of 1968, I'm Solomon, Here's Where I Belong, Henry, Sweet Henry, and How Now, Dow Jones - ran for one year or less and have enjoyed extremely limited (if not nonexistent) afterlives. ${ }^{88}$ Moreover, the only other musicals of the 1960 s to match Hair's commercial success and cultural visibility_Fiddler on the Roof(1964), Hello, Dolly! (1964), and Man of LaMancha (1965) — are generally considered to be the last great musicals of the Golden Age. Wollman credits Hair's acclaim and historical significance to its uniqueness and its dissimilarity from earlier Golden Age properties. ${ }^{89}$ In both form and content, Hair represented the dawning of a new age for the American musical on Broadway — an era in which librettists and composers would experiment with previously accepted conventions, dramatize unlikely subject matter, construct scores using popular musical idioms of the moment, and produce such works as Company (1970), Jesus Christ Superstar (1971), Pippin (1972), Godspell (1976), and Evita (1979)—musicals that, according to theatre

${ }^{87}$ Gerald Bordman, American Musical Theatre: A Chronicle (Oxford: Oxford University Press, 2010), 658.

${ }^{88}$ Though it received nominations for Tony Awards in 1969, Hair opened during the 1967-1968 Broadway season. According to Broadway legend, the Tony Nominating Committee (allegedly) moved the deadline for eligibility up three weeks in order to keep the controversial piece from participating in the 1968 Tony Awards. When the musical was still running on Broadway at the close of the 1968-1969 season, the committee had no choice but to allow Hair to be eligible for nominations.

${ }^{89}$ Wollman, 59. 
historian David A. Crespy, imported a spirit of experimentation from the downtown theatre scene to Broadway. ${ }^{90}$

In February of 1969, nine months into Hair's Broadway run, the musical's greatest champion, Clive Barnes, reviewed the production for The New York Times a second time and found the piece to be as fresh and as frank as it was at the time of his first viewing. The critic attributed Hair's legions of fans and remarkable grosses to the correlative relationship that the musical still enjoyed with the zeitgeist:

Its success stems from two things. First, its perfect reflection of a generation that seems in no mood to lower its voice - it knows what whispering can do to people. Second, the music by Galt MacDermot and the lyrics by Ragni and Rado. This is pop-pop, or commercial pop, with little aspirations to art - a clever and honest dilution of what is happening in pop music. Fundamentally, it is pure Broadwaybut Broadway 1969 rather than Broadway 1949. ${ }^{91}$

Barnes's evaluation suggested that the ongoing war, the discontent of the youth movement, and the pervasiveness of rock music sustained Hair, and that little had changed in the American culture to compromise its social relevance. However, when Barnes's New York Times colleague, Peter Schjeldahl, reviewed the musical for third time in September of 1970, the critic declared Hair obsolete. Schjeldahl claimed that the American cultural landscape had changed dramatically since the musical's premiere at the Public Theatre, particularly Nixon's following inauguration, and went on to suggest that hippie culture was currently in a state of decline. In his estimation, the growing discord between Hair and the current zeitgeist had stripped both the musical and its charms of their earlier veneer:

${ }^{90}$ David A. Crespy, Off-Off-Broadway Explosion: How Provocative Playwrights of the 1960s Ignited a New American Theatre (New York: Back Stage Books, 2003), 159.

${ }^{91}$ Clive Barnes, "Hair Holds Up Under Second Look," review of Hair by James Rado, Gerome Ragni, and Galt MacDermot, directed by Tom O'Horgan. Biltmore Theatre, New York, New York Times, February 5, 1969, 36. 
The three years of history that have changed me along with everyone else have also left a perceptible patina of age on Hair - a patina which no amount of newly minted anti-Nixon-and-Agnew jokes can dissipate—inspiring some glum thoughts ... it was America's first "relevant" musical. Unfortunately, relevance as a style is treacherous; it does not age gracefully, but rather passes from youth to senility without intermission. Watching the vividly real, passionate young folks of Hair today, one is repeatedly shocked by the rusty creak of allusions to Be-Ins, by the quaint ritual strewing of daises, by the sanguine vision of easy interracial harmony, and by innumerable other instant relics of an already doddering sensibility. ${ }^{92}$

Schjeldahl's evaluation demonstrates that the critic recognized Hair's time-bound qualities as early as 1970 and that the current zeitgeist had already begun to diverge from the milieu depicted in the musical. Furthermore, his allegation that the prevailing zeitgeist shifted so significantly over the relatively short span of three years suggests that American culture was evolving at a rapid pace, and that the cultural landscape at the time of Hair's first revival would in no way resemble the cultural landscape at the time of its creation.

\section{BROADWAY REVIVAL}

Hair returned to Broadway in October of 1977, a mere five years after the close of its first Broadway production. The catalyst for the revival was Michael Butler, who had abandoned his political aspirations and made a career of overseeing the musical's many companies across the United States and abroad from 1968 to 1972. Lorrie Davis contends that Butler viewed the musical as a holy scripture and his work as a spiritual calling, and speculates that the producer's choice to disseminate Hair around the world (as well as his

${ }^{92}$ Peter Schjeldahl, “Can Hair Be Taught To Hate?,” review of Hair by James Rado, Gerome Ragni, and Galt MacDermot, directed by Tom O’Horgan. Biltmore Theatre, New York, New York Times, September 27, 1970, 1. 
insistence on acting as each tribe's chief) gave the producer a sense of divine purpose. ${ }^{93}$ When Butler sat for his first formal interview following the revival's announcement, Nahma Sandrow of The New York Times asked the producer to explain his rationale for re-mounting Hair on Broadway so soon after the original production's close. Butler related that his motives were chiefly selfish and simply stated, "I wanted to see it again. ${ }^{, 94}$ In order to realize this desire, Butler reassembled the musical's original creative team, including director Tom O’Horgan. He then charged them with the task of recreating the original 1968 production for present day audiences as authentically as possible. This chosen method of revival allowed Butler to advertise the production as "historically accurate" and market the musical to two distinct audiences. New viewers who had not seen Hair during its initial Broadway run would now have the opportunity to experience the musical in its original form. Additionally, Hair enthusiasts could attempt to relive the Vietnam years again by encountering the musical again. ${ }^{95}$ Butler's rhetoric, however unwittingly, suggested that the musical and its era were now consigned to history. Consequently, the primary aim of the musical would be to replicate a past performance event rather than to reflect the current zeitgeist and present an immediate performance event.

While the revival's creative team were able to oblige Butler's desire for authenticity by recreating Hair's physical production, the bonds that once tied the musical to the present day could not be restored. The Vietnam War had ostensibly ended two years prior with the capture of Saigon. Moreover, the spirit of communitarianism that

${ }^{93}$ Davis, 40.

${ }^{94}$ Quoted in Nahma Sandrow, "What Will Hair Say to the 70s?" New York Times, October 2, 1977, D5.

${ }^{95}$ Paul Hosefros, “Recall When Hair Shocked Us?” New York Times, July 13, 1977, C16. 
guided the youth culture of the mid 1960s had given way to what journalist Tom Wolfe referred to as "The Me Decade." According to Wolfe, the 1970s American populace had turned away from the notion of serial mortality—living and working for the future benefit of the family, community, or nation - and instead focused their attention on personal improvement and introspection, which resulted in a widespread obsession with individualism and the self. ${ }^{96}$ Social critic and historian Christopher Lasch expanded on several of Wolfe's claims three years later in his assessment of American self-interest, The Culture of Narcissism: American Life in an Age of Diminishing Expectations, and cited a series of divisive national events occurring prior to or at the start of the 1970ssuch as the Vietnam War, the shootings at Kent State University, the Watergate scandal, and the impeachment of Richard Nixon—as the root causes of Americans' narcissistic tendencies. ${ }^{97}$ Lasch argued that the American public, in the wake of these events, abandoned the utilitarian rhetoric that had supported American discourse throughout the first half of the twentieth century. Having lost their faith in the government, their trust in institutions of authority and power, and their concern for the nation's continued wellbeing, the American people eschewed collective concerns and focused instead on their own self-preservation. While Wolfe and Lasch's conclusions were drawn almost entirely from their own observations and supported by largely anecdotal evidence, cultural historians such as Edward D. Berkowitz frequently cite their respective publications as foundational texts for the era as they represent similar (but also separate)

${ }^{96}$ Tom Wolfe, "The Me Decade and the Third Great Awakening," New York Magazine August 23, 1976, 26-40.

${ }^{97}$ Christopher Lasch, The Culture of Narcissism: American Life in an Age of Diminishing Expectation (New York: W.W. Norton, 1979), 34-33. 
assessments of American behavior in the mid-1970s written by public intellectuals monitoring the extant culture. ${ }^{98}$

Furthermore, historian Peter N. Carroll contends that the Vietnam War had begun to fade from American public discourse by the late 1970s. In an attempt to forget the atrocities of the previous decade and the decisive loss that the United States' participation in the Vietnam conflict represented, the American people declined to discuss the subject of war openly. Consequently, Vietnam remained relatively unacknowledged in the popular culture outside a smattering of published memoirs including Michael Herr's Dispatches (1977) and Phillip Caputo's A Rumor of War (1977) and feature films such as Michael Cimino's The Deer Hunter (1978) and Francis Ford Coppola's Apocalypse Now (1979). ${ }^{99}$ In 1978, the Reverend Theodore Hesburgh, President of the University of Notre Dame, theorized that the cause of this distinct and wholesale reticence in the 1970 s could be attributed to the fact that the Vietnam War permeated all aspects of American life in the 1960s:

The American people tend to put unpleasant and unsuccessful events far behind them as quickly as possible. While the decade was in progress, one heard or spoke of the war many times a day every day. It was an omnipresent incubus. Now one rarely speaks about the war or hears about it unless something unusual happens, like, another presidential pardon or a commission to search for those still 'Missing in Action.' 100

Moreover, Carroll argues that the 1970s youth culture differed from that of the previous decade, as its members were decidedly more apolitical, markedly more anti-social, and

\footnotetext{
${ }^{98}$ Edward D. Berkowitz, Something Happened: A Political and Cultural Overview of the Seventies (New York: Columbia University Press, 2006), 158.

${ }^{99}$ Peter N. Carroll, It Seemed Like Nothing Happened: The Tragedy and Promise of America in the 1970s (New York: Holt, Rinehart and Winston, 1982), 314.

${ }^{100}$ Reverend Theodore Hesburgh, Forward to Chance and Circumstance: the Draft, the War, and the Vietnam Generation by Lawrence M. Baskir and William A. Strauss (New York: Alfred A. Knopf, 1978), xi.
} 
noticeably more susceptible to the charms of the social mainstream than their 1960s counterparts. ${ }^{101}$ The reformist ambitions, communitarian spirit, and separatist ethic that characterized the youth of the Vietnam era did not necessarily survive the dawning of the Me Decade. Thus, Hair's return to Broadway seemed to harken to a bygone era as the musical's ethos contrasted, if not completely contradicted, the current cultural zeitgeist

Recognizing that the American cultural landscape had changed dramatically over the previous five years, Rado and Ragni elected to revise their original libretto to Hair in an effort to help the musical cohere to the current era. The musical's central premise and the structure of its narrative remained unchanged. The new libretto retained the musical's original wartime setting, cast of characters, and depiction of the hippie movement; however, the authors traded several of the book's now dated period allusions for references to cultural figures who present day audience members would more readily recognize. Among these revisions were mentions of singer Anita Bryant, electronics retailer Crazy Eddie, current first daughter Amy Carter, current Ugandan President Idi Amin, and Unification Church founder Reverend Sun Myuyng Moon. A passing reference to transsexual tennis star Renée Richards was relatively topical, as she had been denied entry to the U.S. Open in 1976. Even more current was a mention of Jedi Master Obi Wan Kenobi, a character from George Lucas's Star Wars which opened to critical and commercial acclaim five month before the start of Hair's return engagement. The amended libretto also included allusions to such recent events as the San Clemente Fire of 1976, the New York City Blackout of 1977, and the currently running Broadway revival of The King and I starring Yul Brynner. In addition to textual references to these

${ }^{101}$ Carroll, 264-266. 
events, the tribe carried new signs that read: "Only You Can Prevent Wildfires," "Con Ed Goofed," and "See Yul Brynner in Hair.,"102

While Rado and Ragni updated a fair number of Hair's cultural references, several of the original libretto's allusions endured as the public figures or events mentioned were still relevant and/or familiar to the American public. For example, the tribe continued to cite Doris Day, Annette Funicello, Wonder Woman, and Buckwheat as their hair idols. Having left her film career in favor of work in television, Day continued to act on her self-titled program, The Doris Day Show, (1968-1973), and periodically appeared as herself on variety programs such as The Carol Burnett Show throughout the rest of the decade. Funicello also remained in the public consciousness during the 1970s by guest starring on programs such as Love, American Style, Fantasy Island, and The Love Boat. Wonder Woman earned new cultural visibility with the 1975 premiere of ABC Television's Wonder Woman series starring Lynda Carter, and Buckwheat continued to live in the popular culture as The Little Rascals short films aired on syndicated television throughout the 1970s. While the original libretto's references to these cultural figures remained, Hair's authors replaced mentions of Veronica Lake and Little Orphan Annie with new allusions to Farrah Fawcett and Andrea McArdle respectively. ${ }^{103}$ Having risen to fame in 1976 with the premiere of ABC's police drama Charlie's Angels, Fawcett gained further notoriety, much like Lake, for her distinctive and identifiable hairstyle. The naming of McArdle proved to be not only a reference to the current popular culture, but also the current Broadway season as the young actress made her Broadway debut in Charles Strouse and Martin Charnin's new musical Annie,

\footnotetext{
${ }^{102}$ Horn, 111.

${ }^{103}$ Ibid.
} 
based on the "Little Orphan Annie" comic strip, at the Alvin Theatre four months earlier. With the introduction of allusions to the current zeitgeist and the retention of references to the musical's original milieu, Hair began to reference two eras simultaneously. The musical was no longer an incontrovertible artifact of the Vietnam years; it appeared to straddle two different eras.

Further contributing to this divided nature was the fact that Rado and Ragni composed new dialogue for Hair that allowed members of the tribe to address social issues of the present day. For example, Sheila, the tribe's political activist, explicated some of the chief concerns of second wave feminism including reproductive rights and workplace inequality. ${ }^{104}$ Another such addendum came in the form of a new monologue delivered by Berger. In the original libretto, Berger impersonated a middle-aged society woman and performed a somewhat mocking diatribe meant to reflect the older generation's response to 1960s drug culture:

BERGER: I was having luncheon with Mary Pickford the other day. And I was saying, not Mary, she's much too liberal minded-I was saying, Mary, they should take all these dope addicts and put them in one big heap, and pour gasoline over them. Jail is just wasting space and it is good people like us dear that have to suffer. The problem in the slums is the same as the problem in Beverly Hills-it's a moral one. Thank you for listening. ${ }^{105}$

By aligning herself with silent film star Mary Pickford, Berger's fictitious society woman represented an American culture long since passed and the monologue served as yet another reminder of the ever-increasing generation gap between the American youth culture and their elders. Rado and Ragni's revised monologue for the 1977 revival performed a similar function as the original in that it gestured to a fissure between the

\footnotetext{
${ }^{104}$ Ibid.

105 Ragni and Rado, 43.
} 
generations; however, it utilized a different social issue to illustrate the divide. Where the authors referenced the counterculture's use of illegal drugs in the original libretto, they now made mention of the burgeoning gay rights movement:

BERGER: I was having luncheon the other day with Anita Bryant ... God love her ... she's on God's side ... well, anyway, we were having luncheon at the Orange Grove at that chic café The Sunshine Tree and as we were sucking on our oranges, I was saying, Anita darling, the trouble with all these Gay people, these homosexual men and women, is that you can't always tell who is one. Now for example, Anita, take my son. He walks like a faggot and he talks like a faggot, he swishes like a faggot and he dishes like a faggot, and he dresses like a faggot and says 's' like a faggot, but he's not a faggot, he's a man. It's a problem of morale. Or is it morals? Whatever it is it's the same problem in Beverley Hills, Hollywood, San Francisco, Miami, Detroit, Boston, London, Moscow, Peking, and even Gay Paree. They live together in fag apartments, wear fag clothing bought in fag department stores, go to fag bars and fag movies, read fag magazines, they have fag dogs, usually poodles, and when they die they're buried in fag cemeteries and go to fag heaven. Ha, ha, ha! (One of the guys goes screaming offstage.) Who's that? Oh, just some screaming faggot! Well, thank you for listening. ${ }^{106}$

This revision to Hair's text not only presented a pointed critique of Anita Bryant's "Save Our Children" Campaign, but also introduced an acknowledgement of the gay community that did not exist in the previous Broadway production despite the fact that queer sexualities were present in the original libretto. Several members of the tribe espoused a belief in free love and admitted to having sexual relations with each other in a variety of gendered pairings. Moreover, the character of Woof confessed an attraction to Mick Jagger and was often coded as gay in performance throughout the musical's first run on Broadway ${ }^{107}$ Despite the musical's depiction of queer sexualities, none of Hair's

${ }^{106}$ Gerome Ragni and James Rado, Libretto to Hair: The American Tribal Love-Rock Musical, October 1977, Tom O'Horgan Collection, Box 6, Howard Gotlieb Archival Research Center at Boston University, np.

${ }^{107}$ Johnson, 68. 
principal characters openly identified as gay, lesbian, or even bisexual. While the musical's original libretto presented queer sexualities, any discussion of queerness was decidedly apolitical and inconsequential to Hair's central narrative. Berger's revised monologue was then significant as it represented a contribution to the current cultural dialogues on the state of gay rights in the United States. Additionally, Rado and Ragni incorporated recent events into their updated book as Bryant's campaign began in 1977 and led to the revocation of anti-discrimination ordnances in Dade County, Florida in June.

While Rado and Ragni made a concerted effort to update Hair for 1977 audiences, the musical could not be uprooted from its original era entirely as the revival still depicted the hippie culture of the 1960s and the youth movement's response to the Vietnam War. Moreover, the threat of a draft summons continued to motivate character behavior. These aspects of the musical's dramaturgy seemed to anchor Hair to its original era. Thus, Rado and Ragni's revisionist techniques split Hair and brought a tribe of hippies into a world in which hippies no longer represented the American youth culture. In an attempt to rationalize this discord, the musical's authors changed Hair's original description of setting. The revival's Playbill listed the musical's historical setting as "1960s" writ large and also contained the following justification: "It is the nature of Hair, born in the 60 s to live in the present, and, in its free form, to make reference to today." 108 Without a specific milieu to ground its narrative, Hair now appeared to vacillate between cultural moments, rendering the musical and its revival temporally adrift and historically incoherent.

${ }^{108}$ Playbill for Hair, Biltmore Theatre, New York City, September 1977. 
With the exception of the amendments made to its libretto Hair remained virtually unchanged for its 1977 revival as its design team worked to replicate their contributions to the original production. O'Horgan also aimed to reproduce his original staging per Butler's request. Consequently, the director resurrected stage pictures and bits of physical comedy that had developed organically in rehearsal nine years earlier using the original production's prompt script. In an interview with William Harris of The SoHo Weekly News, O'Horgan defended this approach to revival, claiming that he wanted to re-visit his original process in order to gain a deeper understanding of how Hair was created: "My reason for doing it again is to find out what we were thinking at the time ... it's a kind of evolution with all the revivals. Maybe we can revive ourselves." ${ }^{109}$ Expressing similar thoughts to Marilyn Stasio of Cue Magazine, the director stated, "If you make a movie or a tape of something, it's done. It exists. You can put it in and can play it back to remind yourself, anytime you feel like it. But to relive a show, you have to go back in time and examine every moment, every choice." ${ }^{\prime 10}$ O'Horgan's justifications relied on somewhat faulty rhetoric as his directing of Hair in 1968 involved the creating and molding of a musical alongside its authors, shepherding it into existence. His expanding of Hair's book by adding new material from rehearsals arguably made the director a contributor to, and perhaps even the architect of, the musical's ever evolving libretto. Furthermore, the fluid nature of Hair's book caused the musical to resist fixedness, making the work a continuously open text. Butler's directive to reproduce Hair's original production stood counter to O'Horgan's organic and collaborative process as it forced the director to intentionally restore staging rather than to create it throughout the course of a rehearsal 23.

${ }^{109}$ Quoted in William Harris, “Hair Transplant," SoHo Weekly News, September 8, 1977, ${ }^{110}$ Quoted in Marilyn Stasio, "The Roots of Hair," Cue, October 1-14, 1977, 11. 
process. Furthermore, reproducing Hair as a museum piece presumably required the director to work from a more stable edition of the musical's libretto. Hair's text, however, had always been somewhat erratic and unpredictable due to the circumstances of its creation. Improvisation was still a feature of the revival, but in a much more intentional and prepared manner. Recreating Hair's original staging arguably reified that staging and hardened what once was amorphous, giving the musical a more fixed narrative. Furthermore, the conscious attempt to create a single, stable, and definitive libretto arguably transformed the musical into a closed text-a work that remains relatively constant in performance.

Stabilizing Hair's libretto in this way presumably limited the creative contributions made by the revival's cast. According to Lorrie Davis, the tribe of actors assembled for the 1977 staging represented the most significant deviation from the musical's original production. ${ }^{111}$ Where Hair originally served as a performance vehicle for members of the counterculture, the dissolution of the hippie movement prohibited O'Horgan from selecting performers in the same manner that he had nine years earlier. Moreover, the paltry two-month rehearsal process that Butler provided all but required O'Horgan to hire musical theatre professionals who could both learn and metabolize Hair's book, music, and staging quickly. ${ }^{112}$ As these actors did not necessarily share the musical's stated values, the synchronicity that Hair once shared with its cast presumably dissipated. Butler's brief rehearsal process also seemed to forestall the creation of a community among Hair's new tribe. With the exception of three actors who left the company early, the original Broadway cast of Hair had rehearsed and performed with

\footnotetext{
${ }^{111}$ Horn, 112. members.

${ }^{112}$ See Appendix D for a complete list of the revival's cast and production team
} 
each other for well over one year prior to the production's opening. Having first come together for the musical's workshop period at the Public Theatre in the fall of 1967, the original tribe could convincingly portray inter-personal and collective concerns as they had cultivated a shared history. The majority of the revival's cast, however, came to the production with no prior ties to the musical or each other. Only three ensemble members—Eva Charney, Linda Myers, and Alaina Reed—had performed in regional productions of Hair prior to the revival. In a 2004 interview with Jonathan Johnson, Butler himself conceded that the revival's cast did not unify as a result of the accelerated rehearsal period: "The tribe was totally professional and they had no real love for the piece. They weren't really anchored to it. Tom was directing it, but we didn't have that time of being together. You really need that time." ${ }^{\prime 13}$ The company's lack of camaraderie and personal investment in the material presumably negated the authenticity that Butler desired despite the creative team's best attempts to recreate Hair's original production.

The first Broadway revival of Hair played 79 previews and ran for 43 performances at the Biltmore Theatre before closing on October 5, 1977, two months after its opening. The production received eight categorical pans from the major New York theatre critics, with headlines such as "Bald" and "Defoliated" demonstrating their collective antipathy. While none of the reviewers acknowledged Rado and Ragni's textual revisions, nearly all of them questioned the musical's cultural relevance in the wake of the Vietnam War. Douglas Watt of The Daily News argued that the five years separating Hair's original production from its revival changed the American zeitgeist so significantly that the musical now appeared almost antiquated:

${ }^{113}$ Quoted in Johnson, 177. 
For Hair, like long, undisciplined hair for hair's sake, has gone out of style. It and the 60s seem, at least at the moment, as dated as Irene and the First World War. The terms 'be-in' and 'psychedelic' and others employed in Hair conjure up a far distant patina which the 'flower children' who throng the Biltmore stage sound like and appear to be garish echoes of the Dead End kids. ${ }^{114}$

Richard Eder of The New York Times and Jack Kroll of Newsweek further challenged the need for a Hair revival so soon after the original production's close. Eder's review, prefaced by the headline "Revived Hair Shows Its Grey," addressed what the critic observed as a precarious relationship that the musical seemed to enjoy with the current historical moment. Eder aptly summarized the critical consensus when it declared the musical, "too far gone to be timely; too recently gone to be history or even nostalgia." 115 Kroll echoed this appraisal, stating "A lot has happened in the decade since Hair first blew in our eyes, and the Revelation According to St. Hippie is both too close chronologically and too distant emotionally to work now." ${ }^{116}$ Most critics addressed the outdated nature of Hair's content, pointing to the end of the Vietnam War and the now moribund hippie movement as support for their claims of obsolescence. Eder and John Beaufort of The Christian Science Monitor, however, also attended to the musical's form and argued that its novelty had faded. Beaufort alleged that previously shocking aspects of Hair's dramaturgy had "degenerated into banalities, as unattractive as ever."117

${ }^{114}$ Douglas Watt, "Those Were the Days," Daily News, October 6, 1977 in New York Critics' Theatre Reviews. Vol. 38, ed. Joan Marlow and Betty Blake (New York: Critics' Theatre Reviews Inc., 1977), 184.

${ }^{115}$ Richard Eder, "Revived Hair Shows Its Gray," New York Times, October 6, 1977, in New York Critics' Theatre Reviews. Vol. 38, ed. Joan Marlow and Betty Blake (New York: Critics' Theatre Reviews Inc., 1977), 183.

116 Jack Kroll, "Defoliated" New York Times, October 6, 1977, in New York Critics' Theatre Reviews. Vol. 38, ed. Joan Marlow and Betty Blake (New York: Critics' Theatre Reviews Inc., 1977), 185.

${ }^{117}$ John Beaufort, "Reviving Hair Is Notion Whose Time Has Gone," Christian Science Monitor, October 12, 1977, in New York Critics' Theatre Reviews. Vol. 38, ed. Joan Marlow and Betty Blake (New York: Critics’ Theatre Reviews Inc., 1977), 185. 
Similarly, Eder chided the tribe's use of improvisation and their deliberate breaking of the fourth wall, professing that the musical's moments of "planned spontaneity" were no longer startling or efficacious. ${ }^{118}$

The cultural viability of Hair in the present day was also of concern to Howard Kissel of Women's Wear Daily, who insisted that Hair had become a period piece even before the end of its first Broadway run. Consequently, he dismissed the production with little justification. T.E. Kalem of Time Magazine, however, offered a slightly more nuanced assessment of why the musical's dramaturgy might have appeared timeworn in revival: "The show's major bolstering prop was always offstage—-the Vietnam War-and its only emotional cohesion was the passions that the war aroused. Those passions are spent, the war has ended, and even more pertinently, it was lost. That is a psychic national wound from which the U.S. certainly has not recovered and which most Americans are extremely reluctant to probe." ${ }^{\prime 19}$ The revival's short run lends some credence to Kalem's claims, as do the unenthusiastic reviews that Milos Foreman's 1979 film adaptation of Hair received. Per Kalem's rhetoric, future revivals of the musical would not only require a cultural moment more comparable to that which occasioned Hair, but would also benefit from an offstage social cause analogous to the Vietnam War that would make the passions and protest of Hair's tribe more relevant to the theatergoing public.

The significant role that Hair played in O'Horgan's directing career cannot be overestimated. The original 1968 production, which was his Broadway debut, represented

${ }^{118}$ Eder, 183.

119 T.E. Kalem, "Defoliated," Time, October 17, 1977, in New York Critics' Theatre Reviews. Vol. 38, ed. Joan Marlow and Betty Blake (New York: Critics' Theatre Reviews Inc., 1977), 185. 
the director's most notable commercial and critical success. His next two projects, Julian Barry's Lenny and Andrew Lloyd Weber's Jesus Christ Superstar premiered on Broadway in 1971 and ran at the same time as Hair. Both productions received generally positive reviews and ran for well over a year. Despite this streak of good luck, evidence suggests that support for O'Horgan's directorial work on Broadway peaked in 1971. The director's subsequent projects - an off-Broadway production of Sgt. Pepper's Lonely Hearts Club Band on the Road (1974) and Broadway productions of Helen Miller and Eve Mirriam's Inner City (1971), Gerome Ragni and Galt MacDermot's Dude (1972), Dennis Reardon's The Leaf People (1975), and Oliver Hailey's I Won't Dance (1981)— were notable failures with most productions running less than one month. O'Horgan followed his 1977 staging of Hair with a minimalist, concert revival of Jesus Christ Superstar. The production closed after six weeks and represented only the second time that the director helmed a revival on Broadway. A 1984 production of Rudolf Friml's The Three Musketeers, which received a total of nine performances, brought this total to three and represented the director's final Broadway outing. Though O'Horgan enjoyed a long career in theatre, opera, and film, his directorial work did not receive many critical accolades beyond Drama Desk Awards for Lenny and off-Broadway productions of Paul Foster's Tom Paine (1968) and Rochelle Owens's Futz! (1969). In a 2009 tribute to the director, Michael Feingold, theatre critic for The Village Voice, suggested that O'Horgan's approach to directing, influenced by his training at La MaMa and his years spent working in avant-garde theatres, was relatively anathema to commercial theatre, particularly the Broadway marketplace, in the years that followed his production of Jesus 
Christ Superstar - a claim that is perhaps supported by the failure of Hair's first Broadway revival. ${ }^{120}$

\section{BROADWAY REVIVAL}

Despite two attempts to revive Hair in 2001, the musical did not make a second return to Broadway until 2009. This new production arrived on the Great White Way after two off-Broadway engagements produced by the Public Theatre, the first of which was a three-night concert event in September of 2007 celebrating the theatre's fortieth anniversary. Hair was the first theatrical work that Joseph Papp produced at the Public's Lafayette Street complex, and current Artistic Director Oskar Eustis believed that a restaging of the musical would perfectly commemorate the theatre's milestone. The concert, held at the Public's Delacorte Theatre in Central Park, sold out each of its performances, which then prompted Eustis to feature the musical as part of the New York Shakespeare Festival's 2008 summer season. A three-month run at the Delacorte and an overwhelmingly positive reception from audiences and critics led Eustis to transfer Hair to Broadway in a revival that opened on March 31, 2009. To helm all three iterations of Hair, Eustis tapped director Diane Paulus. Paulus began her directing career developing avant-garde productions that blended contemporary music and classical drama with her New York troupe, Project 400 Theatre Group, and would go on to stage operas for the Chicago Opera Theatre. Having earned a reputation for devising performances that synthesized experimental and mainstream theatre aesthetics, the director seemed a natural choice to oversee Hair's revival. ${ }^{121}$

${ }^{120}$ Michael Feingold, “Tom O’Horgan: 1924-2009,” Village Voice, January 21, 2009, 40.

${ }^{121}$ Arnold Aronson, American Avant-Garde Theatre (New York: Routlege, 2000), 207. 
Eustis and Paulus's process of resurrecting Hair occurred in tandem with the conclusion of George W. Bush's second term as president, and the prevailing social milieu appeared to provide the musical with a more hospitable environment than it had in 1977, assumedly because American culture seemed to exhibit symptoms of distress analogous to those it presented in the 1960s. Following the 2001 attack on New York City's World Trade Center, the United States entered the longest period of military conflict since the Vietnam War. War with Afghanistan gave way to war with Iraq, and by September of 2007, the United States had been embroiled in a two-front conflict for four years. While the threat of a government-sponsored draft was virtually non-existent, both campaigns received sharp criticism from the political left, including the Democratic Congress and the youth culture. Moreover, Bush's prolonging and broadening of the conflicts aroused significant animus for both the president and his cabinet. ${ }^{122}$ The financial crisis of 2007, triggered by the collapse of the housing market and resulting in a national recession, presumably exacerbated cultural anxiety further as several large financial institutions stood on the brink of collapse. The installation of the Economic Stabilization Act one year later, which attempted to save the U.S. financial system through a series of government bailouts, polarized Americans on either side of the political spectrum and arguably led to the formation and mobilization of both the conservative Tea Party movement in 2009 and the anti-consumerist Occupy Wall Street movement in 2011. As the national debt escalated and unemployment rates doubled

${ }^{122}$ William Bennett, A Century Turns: New Hopes, New Fears (Nashville: Thomas Nelson, 2009), 252. 
between 2007 and 2009, housing prices and stock values steadily declined, leading economists to identify the cultural moment as "The Second Great Depression.", Hair's second production at the Delacorte also ran amidst the last months of the 2008 presidential election, a tumultuous campaign that featured the first AfricanAmerican presidential nominee and the second female candidate for vice-president. Inciting cultural dialogues on race and gender, the election also seemed to catalyze and escalate national debates on a variety of social issues including immigration, reproductive rights, and gay marriage. These disputes, combined with opposing views on the Gulf Wars and the recession, served to divide the country along party lines - a breach epitomized by the marked differences between the two major party candidates. The Republican nominee, Arizona Senator John McCain, was a fiscal conservative and ardent supporter of President Bush's war efforts who abandoned his moderate stance on social issues in order to appeal to his party's more orthodox conservative base. McCain's campaign attempted to highlight his military experience and his twenty-five years of political service while at the same time downplaying his age. At 72, McCain was the second oldest presidential nominee in American history and the mainstream media frequently voiced concerns about the state of his health. Where the Republicans selected a political elder to represent their party-one who promised to maintain the status quothe Democrats chose a significantly younger nominee who couched his campaign in change. Barack Obama, a first-term senator from Illinois, opposed the Gulf wars and advocated for their moratorium, as well as the reformation of the healthcare system, increased energy independence, and gay rights. Twenty-five years McCain's junior,

${ }^{123}$ J. Bradford DeLong, "The Second Great Depression: Why the Economic Crisis is Worse Than You Think," Foreign Affairs 92.4 (2013): 159. 
Obama actively targeted the youth vote by recounting his adolescence, utilizing a variety of social media platforms, and framing his potential presidency with promises of hope and progress - themes which famously manifested in a series of posters designed by street artist Shepard Fairey that utilized vaguely psychedelic aesthetics and were modeled on Alberto Korda's famed 1960 image of Che Guevera. ${ }^{124}$ However inadvertently, the presidential election suggested that the American cultural divide was both ideological and (in part) generational, much as it had been during the Vietnam years. Although the specific circumstances contributing to the current zeitgeist's turbulence certainly differed from those that polarized the country forty years earlier, the kind of political and cultural tumult that occasioned and sustained Hair's first production was once again commonplace at the time of its second revival. The timing of the musical's return thus proved remarkably opportune, particularly as Barack Obama, the country's "hope and change" candidate, assumed the presidency three months before Paulus's production opened at the Al Hirschfeld Theatre.

In preparation for Hair's second Broadway bow, Paulus collaborated with Rado to revise the musical's libretto once again. Multiple versions of Hair existed by 2009 as Ragni (who died of an undisclosed cancer in 1991) and Rado continued to modify Hair's book following the 1977 revival. Thus, Paulus began her work by reviewing what she described as "the folios of Hair." ${ }^{125}$ She then attempted to clarify the musical's narrative for present day audiences by excising thirty-nine of the original libretto's fifty-nine period references. The twenty cultural allusions that remained referenced the major

${ }^{124}$ Bennett, 258-270.

${ }^{125}$ American Theatre Wing, "Downstage Center: Diane Paulus," Podcast, American Theatre Wing Website, mP3 file, September 8, 2008, http://americantheatrewing.org/downstagecenter/detail/diane paulus (accessed March 22, 2014). 
political figures of the 1960s (Lyndon B. Johnson, Richard Nixon, and Hubert Humphrey), entertainers of the era who continued to live in the public consciousness (Mick Jagger, James Brown, and Aretha Franklin), or constituted lyrics to songs such as "Manchester, England," "Ain't Got No," and "Hair." Paulus and Rado also updated one moribund reference that in all certainty would have read as alien to present day spectators. In the original Broadway production of Hair, a tribe member impersonated Aretha Franklin during Claude's nightmare and performed several stanzas of "Indian Love Call," an aria from Rudolf Friml's 1924 operetta, Rose Marie, in the "Queen of Soul's" signature style. "Indian Love Call," popularized by Jeanette McDonald and Nelson Eddy in 1936, was later recorded by jazz singer Gloria Lynn in 1964, but had otherwise disappeared from the popular culture by the turn of the twenty-first century. Consequently, Paulus and Rado amended this moment to have the tribe's Aretha sing strains of the more widely recognized "Respect," a number one single for Franklin in 1967. The removal and updating of potentially unfamiliar signifiers of the $1960 \mathrm{~s}$ presumably slackened the strong bonds that anchored Hair to its original era and allowed spectators of all ages and all levels of cultural literacy to engage with the musical's book.

Interestingly, rather than updating the musical's temporal setting, Paulus insisted on situating Hair's action one year earlier, in 1967. Viewing the year as a prelapsarian moment in the Vietnam era's historical narrative, the director wanted her revival to illustrate the hopeful idealism that spawned the hippie movement, spurred the Summer of Love, and predated the calamitous events of 1968, and was perhaps even more aligned with America's current year of "hope and change." ${ }^{126}$ In order to clarify the musical's

${ }^{126}$ Eric Grode, Hair: The Story of the Show That Defined a Generation (Philadelphia: Running Press Book Publishers, 2010), 141-142. 
milieu, Paulus and Rado expanded Hair's exposition and restored dialogue from the libretto used in the 1967 Public Theatre production of Hair, directed by Gerald Freedman. One such reinstatement involved Sheila describing her participation in the 1967 march on the Pentagon, claiming that she and her compatriots (which would have included Allen Ginsburg, Jerry Rubin, Todd Gitlin, Abbie Hoffman, and other members of the SDS) attempted to levitate the building through meditation and chanting. ${ }^{127}$ Paulus and Rado also recovered a scene featuring Claude's mother and father, who were portrayed by two tribe members in Freedman's production (as opposed to the six actors employed by O'Horgan) and made several appearances throughout the musical. One such cameo occurred during the "Hare Krishna" portion of the Be-In. As the hippies closed their eyes and chanted in unison, Claude's parents appeared and castigated the tribe for their lack of patriotism and willful ignorance of foreign relations:

MOM: We had another generation before you who went to war, went to college, worked for a salary - you're a disgrace to this country ...

DAD: Keep America strong. Make America stronger. May God bring our nation victory.

TRIBE: LOVE

LOVE

OMMMMMMMM

MOM: Oh, you're all so naïve. You don't know what's really going on - the truth about what's really happening in Red China.

TRIBE: LOVE

LOVE

OMMMMMMMM

${ }^{127}$ Gerome Ragni and James Rado, Libretto to Hair: The American Tribal Love-Rock Musical, July 31, 2008, Billy Rose Theatre Collection, New York Public Library for the Performing Arts, 53. 
DAD: We're fighting a war. Use atomic weapons and win it, for Crissake. Have faith in God and Nation and the Military-Industrial Complex . . . Your parents should care more about sex and stop worrying about drugs. Drugs are innocent compared to sex. It's time to deal with this sex mess.

TRIBE: LOVE

LOVE

OMMMMMMMM

MOM: You kids don't appreciate the maturity and wisdom that age brings.

DAD: My son doesn't like me. He doesn't like me. ${ }^{128}$

Resurrecting this dialogue assisted in further illustrating the generation gap of the 1960s by articulating Cold War anxieties over communism, the nuclear arms race, and the imminent sexual revolution. The hippies' collective meditation, occurring in tandem with the parents' tirade, further telegraphed the counterculture's rejection of the rhetoric and politics purported by their elders.

Paulus and Rado's final textual amendments aimed to establish the wartime zeitgeist further by providing present day spectators with additional historical context. The first addendum detailed the penalties for burning draft cards. All prior iterations of Hair's libretto contained a discussion of draft dodging or tampering with a draft summons; however, no one edition acknowledged the legal ramifications of such acts. Paulus and Rado's revised book included a counterargument to Dionne's suggestion that Claude and Berger destroy their draft card to avoid conscription: "Yeah? And go to prison? Five years hard labor." "129 Paulus also added a brief preface to "Colored Spade" in which Hud, the song's performer, attempted to justify the number's potentially polarizing

\footnotetext{
${ }^{128}$ Ibid., 43-44.

${ }^{129}$ Ibid., 28.
} 
lyrics. Presenting an extensive list of racial slurs used to describe the African-American community throughout history, the song as written utilized language that has been all but banished from the collective American parlance:

I'M A COLORED SPADE, A NIGRA, A BLACK NIGGER

A JUNGLE BUNNY JIGABOO, COON, PICKANINNY MAU-MAU

UNCLE TOM, AUNT JEMIMA, LITTLE BLACK SAMBO

COTTON PICKIN' SWAMP GUINEA, JUNK MAN, SHOE SHINE BOY

ELEVATOR OPERATER, TABLE CLEANER AT HORN AND HARDART

FLAT-NOSED TAP DANCER, RESIDENT OF HARLEM

AND PRESIDENT OF THE UNITED STATES OF LOVE. ${ }^{130}$

While the lyrics "Colored Spade" are foregrounded in the language of oppression, Hud's presentation of the song is consistent with the black power movement of the 1960s and its attempt to reclaim such slights. ${ }^{131}$ Even so, Paulus believed that an explanation of the song's lyrics would prevent the offense or alienation of audience members; consequently, Hud framed his song as a history of the black experience in American culture: "My name is Hud Johnson, but some people have called me and my beautiful black brothers and sisters many other things. Step to the back of the bus with me!" 132 In a manner akin to Paulus and Rado's other textual alterations, this revision to Hair's libretto arguably allowed spectators unfamiliar with the black power movement to understand the dramaturgical function of the song.

Paulus's design team, which included scenic designer Scott Pask and costume designer Michael McDonald, faced the challenge of re-imagining Hair's physical production in a manner that would support Paulus's vision, but also honor the original Broadway production and its horde of devotees. As Pask stated, "We were up against

\footnotetext{
${ }^{130}$ Ibid., 9.

${ }^{131}$ Farber, 204.

${ }^{132}$ Ragni and Rado (2008), 9.
} 
nostalgia . . . we wanted to be reverential yet open it up to a modern audience." ${ }^{, 133}$ Paulus and Pask retained the original production's physical setting and placed Hair's action in a deserted theatre space; however, Pask did not expose the bowels of the Hirschfeld in the same way that Wagner did with the Biltmore in 1968 and 1977. Instead, the designer constructed a façade of the theatre's back wall. A brightly colored mural featuring a sunset, night sky with stars, crystalline water, and a lush, verdant landscape adorned the façade, illustrating the hippie movement's interest in nature as well as their buoyant optimism. Pask covered the raked stage in Persian and Navajo carpets that spilled over the stage's apron, thus masking the traditional barrier between the actors and audience. In a nod to Robin Wagner's original design, Pask placed a hollowed truck at stage left for Hair's musicians. While the designer's scenery evoked the Vietnam era, it did so in a much less obvious manner than Wagner's design. Pask's environment contained no visible signifiers of the 1960s, and therefore, suggested the cultural moment without citing it directly.

McDonald looked to the Vietnam era's counterculture icons, particularly Donovan, Jimi Hendrix, and Janis Joplin, in devising the revival's costumes. The designer also conducted extensive visual research that included perusing magazines of the period and reviewing video footage of the 1967 Monterey Pop Festival, a three-day rock concert that anticipated the famed Woodstock Festival in $1969 .{ }^{134}$ Rather than attempt to fabricate 1960s fashions from scratch, McDonald collected several garments from thrift stores and vintage shops. The designer's personal costume archive, his mother's attic, and the Public Theatre's storerooms also provided authentic period

${ }^{133}$ Quoted in Ellen Lampert-Gréaux, “Tribal Revival,” Live Design, May 2009, 28.

134 Joe Dziemianowicz, "Fashion Flashback Now, Daily News, July 21, 2008, 21. 
attire. ${ }^{135}$ Comparing his costumes to the looks originally assembled by Nancy Potts, McDonald claims that his designs attempted to represent the hippie movement as it spread across the United States and across the globe:

In the original show, the clothes were very East Village-centric - mostly jeans and T-shirts. The thing that is different about my clothes is that I have tried to encapsulate a generation: the way people dressed in New York, Southern California, San Francisco, London. Mother Earth, Sgt. Pepper, Western wear, flowers, Victorian - all these vibes mushed together like a tribe. ${ }^{136}$

Despite the designer's dedication to authenticity and success in securing vintage garments for the revival, McDonald elected to purchase, dye, and distress new denim pants for the tribe as period trousers could not stand the wear and tear of the revival's athletic choreography.

With a handful of exceptions, the cast of Paulus's production was comprised of Broadway newcomers. ${ }^{137}$ The decision to hire novices over recognizable stars - as is often the custom with current-day revivals — was deliberate and borne out of concern for the musical's integrity. In an effort to serve Hair's themes of communitarianism, the director wanted actors who could come together as a cohesive ensemble and whose celebrity would not eclipse the musical itself: "I knew it had to feel authentic and you had to have people singing that material who were 'the tribe' . . it was cast very particularly."138 Thus, Paulus and Eustis engaged in an extensive casting process that included open calls for non-Equity actors. Twenty-three of the twenty-six actors hired for

${ }^{135}$ Lynn Yaeger, "Threads from the 60s," Village Voice, July 31, 2008, 10.

${ }^{136}$ Ibid.

${ }^{137}$ See Appendix E for a complete list of the revival's cast and production team members.

${ }^{138}$ Quoted in Jessica Lewis, "Diane Paulus Part II: Hair, The New Tribe, and the U.K." BroadwayWorld Online, February 9, 2010, accessed January 12, 2014, http://www.broadwayworld.com/article/BWW-Interviews-Diane-Paulus-Part-II-HAIR-The-NewTribe-and-The-UK-20100209\#. 
the musical's 2007 concert performances completed the 2008 run at the Delacorte Theatre and then accompanied the production when it transferred to Broadway in 2009. By the time that Hair premiered at the Hirschfeld Theatre, the revival's tribe had rehearsed and performed together for nineteen months, not unlike the tribe that opened the musical at the Biltmore Theatre forty-one years earlier.

Paulus honored O'Horgan's contributions to Hair's original performance text by encouraging her actors to break the fourth wall and engage with spectators.

Consequently, members of the tribe frequently left the stage and entered the house to sing, dance, and protest. The most notable instance of audience interaction occurred as Berger (portrayed by Will Swenson) introduced himself to the crowd immediately following "Aquarius." In a lightly improvised monologue, the leader of the tribe ambled through the house, panhandling and pontificating. He also mocked and flirted with patrons of all ages and genders. ${ }^{139}$ With one notable exception, every time members of the tribe entered the house, they did so with the express purpose of engaging with the audience. The final scene of the revival, however, represented an exception to this rule. Standing in a huddled mass in front of the Military Induction Center on Whitehall Street, the tribe sang the final chorus of "Let the Sunshine In" in hopes of stopping Claude (portrayed by Gavin Creel) from honoring his draft summons. Realizing that their efforts failed, Berger led his comrades off the stage, down the aisles, and out of the theatre, revealing Claude's lifeless body draped on top of an American flag. ${ }^{140}$ The solemnity of this final moment was soon broken as the tribe returned to the stage for curtain call and

\footnotetext{
${ }^{139}$ Ragni and Rado, 5.

140 Ragni and Rado (2008), 78.
} 
summoned the audience to join them onstage for a celebratory dance, just as they had in O'Horgan's production.

The 2009 revival of Hair ran for 519 performances at the Hirschfeld before closing on June 27,2010 . The production grossed $\$ 50,570,863$, recouping its initial $\$ 5.67$ million investment in four months. In addition to this financial success, the production earned critical accolades, winning the Drama Desk Award, the Outer Critics Circle Award, and the Tony Award for Outstanding Revival of a Musical in addition to earning a collective total of seventeen nominations in other categories. The major New York theatre critics seemed to greet Hair's Broadway return warmly, with twelve of fourteen reviewers praising Paulus's revival. Nearly every critic acknowledged the musical's timebound nature and its potential for obsolescence in the twenty-first century, but later claimed that Hair read as surprisingly fresh in the current zeitgeist. As Jeremy Gerard of Bloomberg stated, "Hair, for all its references to hippies, Vietnam, free love, and the revolution, feels utterly of the moment in its exuberance, its power to involve, and, in Diane Paulus's entrancing production, to move us."141 Similarly, Newsday's Linda Winer noted, "[Hair] grows again into an important, lovable, achingly timely piece about the horrors and the marvels, the burdens and the wild fun of young social change. Despite all that is different since $1967 \ldots$ the show finds a modern pulse of fury and hope without betraying the specifics of a period piece about Vietnam and all flavors of liberation."142 Ben Brantley of The New York Times, David Rooney of Variety, and Elisabeth

${ }^{141}$ Jeremy Gerard, "Hippies of Hair Still Explode With Great Music," review of Hair, directed by Diane Paulus, Al Hirschfeld Theatre, New York, Bloomberg News, March 31, 2009, accessed July 2, 2012, http://www.bloomberg.com/apps/news?pid=newsarchive \&sid=a7UFUAfVyn28.

${ }^{142}$ Linda Winer, “A Joyous Broadway Hair Transplant," review of Hair, directed by Diane Paulus, Al Hirschfeld Theatre, New York, Newsday, April 1, 2009, B4. 
Vincentelli of The New York Post further alleged that the current cultural moment did not only suit Hair, but also seemed to support the musical's themes of social unrest as recent events had visibly unsettled the American status quo. Gesturing to the presidential election and the financial crisis, Rooney claimed, "Fears that the Vietnam-era show's message, which struck such a chord in the waning days of the Bush administration, would have less impact in the Obama age now seem unfounded. While it's unmistakably a period piece Hair plays almost like a direct response to the fallout from a culture of shortsighted greed." ${ }^{143}$ Brantley identified the musical's depiction of disaffected youth and the revival's direction as additional factors that contributed to Hair's newly restored cultural coherence:

That there's nothing of the museum —or, worse, of the vintage jukebox —about Ms. Paulus's production isn't because she's reinterpreted or reframed it ... [she's found] depth of character and feeling in what most people dismissed as dried corn. It's not so much what Ms. Paulus brings to Hair; it's what she brings out of it, vital elements that were always waiting to be rediscovered . . . the kids of Hair are cuddly, sweet, madcap, and ecstatic. They're also angry, hostile, confused, and scared as hell —and not just of the Vietnam War, which threatens to devour the male members of the tribe. They're frightened of how the future is going to change them and not knowing what comes next. ${ }^{144}$

Vincentelli echoed Brantley's assessment, claiming that the current recession made the moments in which the tribe "exultantly reject the rat race" the most compelling. ${ }^{145}$ Furthermore, the critic ended her review stating, "Hair is a musical for the ages because it's a musical for the now." ${ }^{146}$ Vincentelli's claim seemed to suggest that Hair, while

${ }^{143}$ David Rooney, "Hair," review of Hair, directed by Diane Paulus, Al Hirschfeld Theatre, New York, Variety, April 1, 2009, 8.

${ }^{144}$ Ben Brantley, "A Frizzy, Fizzy Welcome to the Untamed 60s," review of Hair, directed by Diane Paulus, Al Hirschfeld Theatre, New York, New York Times, April 1, 2009, C1.

${ }^{145}$ Elisabeth Vincentelli, “An Amazing Hair Day," review of Hair, directed by Diane Paulus, Al Hirschfeld Theatre, New York, New York Post, April 1, 2009, 48. ${ }^{146}$ Ibid. 
anchored to its cultural moment, would find relevance in future eras so long as the dominant zeitgeist continues to complement it. As was the case with the 1977 revival, none of the 2009 production's critics acknowledged the revisions that Paulus and Rado made to Hair's libretto.

Despite receiving generally glowing remarks, the revival also earned a small number of criticisms that dealt chiefly in questions of novelty and authenticity. Joe Dziemianowicz of The Daily New enjoyed Paulus's production and recommended it to his readers, but acknowledged that the passage of time had stripped the musical of its ability to surprise audiences: "As an anti-establishment revue, [the musical] has been declawed by time and cultural tides-it's as edgy as Cats. But as a smile-inducing celebration of life and freedom, it's highly communicable." ${ }^{, 147}$ Like Dziemianowicz, Dan Kois of New York Magazine praised the revival but also avowed that the members of Hair's new tribe were not true disciples of the counterculture as their personal aesthetics belied the hippie ethos or represented highly stylized facsimiles. As the critic stated, "The hairless armpits and pecs; the gym-toned six-packs diving into low-rise jeans; the highly polished smiles; the high notes bursting with melisma: All are reminders that this time around, the hippies are being played by ambitious actors and singers, some of whom are wearing shining, gleaming, streaming, flaxen, waxen wigs. ${ }^{, 148}$ The revival's most vocal detractor, Hilton Als of The New Yorker, similarly addressed sartorial concerns, charging that Paulus's production and cast lacked the unkempt grit which characterized Hair's original production: "There is a curious lack of grunge onstage; although the majority of

147 Joe Dziemianowicz, "Hair Is Back: Hip, Hippie, Hooray!," review of Hair, directed by Diane Paulus, Al Hirschfeld Theatre, New York, Daily News, April 1, 2009, 32.

${ }^{148}$ Dan Kois and Scott Brown, "Sunshine Supermen," review of Hair, directed by Diane Paulus, Al Hirschfeld Theatre, New York, New York Magazine Online April 1, 2009, accessed April 24, 2012, http://nymag.com/arts/theater/reviews/55815/. 
the characters in Hair supposedly spend most of their time rolling around in a New York City park, they look as though dirty fingernails ick them out . . . filth [is] just one more thing for them to ignore as they set about assiduously loving one another."149 The critic would go on to denounce McDonald's costumes as clichéd and Gerard Kelly's wigs as “a hair fetishist's dream." ${ }^{150}$ However, Als directed his most exacting critique at Hair's libretto, which he accused of presenting hackneyed portraits of black characters, especially black men. The critic conceded that the musical and its book were products of a different era; however, he also argued that the irony and liberal self-consciousness with which the musical's white authorship drew their black characters was no longer defensible in the twenty-first century. Als took particular exception to the character of Hud and the song "Colored Spade," stating that "Hud is simply a construction, meant to validate the white hipness of the show ... the task of representing [race] falls on the overburdened black characters, who have to do almost everything here except tapdance." ${ }^{151}$ The critic's remarks suggest that even though Paulus and Rado revised Hair's libretto with the express purpose of preparing it for present day audiences, the book more than likely deserves further reconsideration as its presentation of African-American characters is no longer tenable in the current zeitgeist.

A remarkable aspect of Paulus's revival occurred offstage as members of the tribe rallied around a social cause and used Hair's ideals of peace, freedom, and happiness to perform advocacy, thereby bringing a political immediacy and authenticity to their production. The cause that they chose was marriage equality. Although not the same as the most urgent cause of Hair's libretto (that of anti-war protest), the subject of marriage

\footnotetext{
${ }^{149}$ Hinton Als, "Not So Free Love," The New Yorker, April 13, 2009, 82.

${ }^{150}$ Ibid.

${ }^{151}$ Ibid., 83.
} 
equality does correspond to the musical's celebration of free love and social justice, and is also an issue that was mobilizing the country's youth culture. On July 13, 2009, Eustis released a statement announcing that he and fellow producers intended to cancel the October 11 performance of Hair so that the musical's cast could travel to Washington D.C. to participate in the National Equality March—a political rally calling for equal protection under the law for all lesbian, gay, bisexual, and transgender Americans. The event would be the first organized march on Washington for LGBTQ rights since the Millennium March of 2000. While the choice to refund ticket sales for a Sunday matinee might have surprised members of the Broadway community, the reason for the cancellation surely did not. The cast of Hair had performed in public rallies protesting the Defense of Marriage Act across New York City since before the revival's official Broadway opening. Moreover, actor Gavin Creel had helped to found Broadway Impact, a grassroots organization dedicated to mobilizing the Broadway community in support of marriage equality, in late 2008 — during the early days of the production's rehearsal process. With Creel occupying leadership roles in both troupes, Hair's tribe and Broadway Impact began to collaborate on several projects. Prior to the National Equality March, the company of Hair participated in four of Broadway Impact's public protest events, including its May 2009 “Action Equals Equality” Rally held in Times Square where the tribe and a host of other Broadway actors performed for over five thousand attendees. According to Creel, his fellow tribe members' dedication to the cause of marriage equality and their desire to join forces with Broadway Impact was more than just good fortune - it was what made both the revival and the activist organization 
flourish: "Hair made Broadway Impact succeed, and in turn, Broadway Impact gave validity and power to Hair's message." 152

The partnership between Broadway Impact and Hair would continue throughout the course of the revival's initial Broadway run, its subsequent national tour, and its limited return engagement on Broadway during the summer of 2011. Broadway Impact would organize the effort to transport Hair's cast and crew to Washington D.C. for the 2009 Equality March. The cast of Hair would in turn host "Be-In" events in venues across New York City, and later in such cities as Los Angeles, Seattle, and Chicago, to benefit Broadway Impact. These mostly outdoor concerts were modeled after the "Be-In" that takes place at the end of Hair's first act; however, instead of urging attendees to burn their draft cards, tribe members would attempt to rally support for Broadway Impact's initiatives by singing songs from the musical and other anthems from the Vietnam era such as Bob Dylan's "Blowin' in the Wind" and The Beatles' "With a Little Help from my Friends." The two songs most routinely performed at Broadway Impact rallies were Hair's narrative bookends: "Aquarius" and "The Flesh Failures/Let The Sunshine In." Although Rado, Ragni, and MacDermot wrote these numbers in response to a different social concern, the revival's tribe was able to repurpose them for the cause of marriage equality as both songs reflected the tribe's idealism and vision for the future. "Aquarius" foretold the dawning of a new era while "Let the Sunshine In" was at once their song of mourning and a call to arms. Working in tandem, the songs projected an idealistic future and urged listeners to take action.

${ }^{152}$ Interview with Gavin Creel, Paul Creative Arts Center, University of New Hampshire, Durham, NH, February 7, 2012. 
By stepping off the musical stage and on to the political stage, this second revival of Hair became a vehicle for LGBTQ advocacy both in New York and across the country. The production continued to tour throughout 2011 and 2012 and continued to encourage civic engagement through its collaborations with Broadway Impact. Moreover, the activist work of Hair's actors yielded tangible results. On July 25, 2011, one day after gay marriage became legal in New York State, three queer couples from the Broadway community were married on the stage of the St. James Theatre after a matinee performance of Hair. In response to his production's continued work on marriage equality, Oskar Eustis has remarked, "Hair has never been just a show; its message of change and hope and inclusion is one we try to live and not just preach." 153

Like O'Horgan, Paulus made her Broadway directorial debut with Hair, with comparable success. Her treatment received praise from the major New York critics and earned the director Drama Desk, Outer Critics Circle, and Tony Award nominations. After helming Hair's national tour and West End production, Paulus brought two more musical revivals to Broadway: Porgy and Bess (2012) and Pippin (2013). Both productions originated at Harvard University's American Repertory Theatre (for which Paulus currently serves as Artistic Director), and like Hair, demonstrated an attempt to make the works intelligible and immediate for present day audiences. For Porgy and Bess, Paulus collaborated with Pulitzer Prize winning playwright Suzan Lori-Parks to revise DuBose Heyward's original libretto and earned her second Tony Award nomination. The director's acclaimed revival of Pippin honored Bob Fosse's original

${ }^{153}$ Quoted in Adam Hetrick, "Cast of Hair to Join Eustis, Jones, and Stone for Equality Rally in Central Park Aug. 28," Playbill Online, August 20, 2009, accessed April 24, 2012, http://www.playbill.com/news/article/132118-Cast-of-Hair-to-Join-Eustis-Jones-and-Stone-forEquality-Rally-in-Central-Park-Aug-28. 
production by utilizing his distinct choreography, but revitalized the musical's theme of self-discovery by placing its central action in the world of circus. Paulus's incorporation of acrobatics and tumbling, as well as her use of cross-gender casting, won the praise of critics and earned the director Drama Desk, Outer Critics Circle, and Tony Awards. In addition to these accolades, her productions of Porgy and Bess and Pippin won the 2012 and 2013 Tony Awards for Best Musical Revival. While the director continues to create theatrical work at the American Repertory Theatre and in regional opera, Paulus's recent career trajectory suggests that she is becoming one of the foremost revivalist directors on Broadway.

\section{CONCLUSION}

Hair's relationship to its original zeitgeist is indisputable. The aesthetics and ideologies of the Vietnam era pervade every aspect of the work and were reflected in the original production's libretto, score, staging, design, and casting. Profoundly time-bound, the musical presents a host of temporal challenges to the revivalist director. Of these challenges, one of the most decisive appears to be the fact that the musical's themes make its cultural relevance somewhat recurrent. As Hair's initial fame, profit, and ubiquity can be attributed to its mirroring of the turbulence and uncertainty of the Vietnam era, it is reasonable to surmise that national conflict makes the musical more resonant and compelling. Vincentelli's claim that Hair will continue to find favor with audiences during periods of unrest is astute, and this investigation suggests that recognizing and taking advantage of those historical correspondences is a crucial factor in successful revivals of time-bound works. 
O'Horgan's revival, which opened a mere five years following the close of Hair's original Broadway production, represents a case of temporal incongruence. In 1977, Hair was a work indelibly associated with the recent past—a past that the American populace wanted to forget. The tribe's antipathy for the government, resistance to the war effort, fear of the draft, and zeal for a more egalitarian, peace and love-filled future fueled the musical at the time of its premiere. By contrast, the disillusionment, cynicism, and selfinterest of the late 1970s (emerging in the wake of the Vietnam conflict and the Watergate scandal) seemed to contradict Hair's ethos and inherent optimism, and presumably contributed to the failure of its first revival. The American cultural landscape shifted so significantly in the five years between the original production's close and the revival's opening that, as the production's reviews suggest, the tribe's protests may have appeared quaint, if not redundant to Me Decade audiences. Moreover, the period separating these productions was remarkably brief. Neither the war nor the musical had dissipated from the collective cultural consciousness yet and critics repeatedly charged that the revival's timing (combined with the creative team's attempted resurrection of the original production) stripped Hair of the novelty it presented at the time of its Broadway premiere.

Conversely, critics found Hair remarkably relevant in 2009, despite the passage of forty years. While the concurrent Gulf Wars of the early 2000s did not permeate every aspect of American culture in the same manner that the war in Vietnam did, the cultural unrest of the moment (brought upon by the financial crisis and the polarizing effects of the presidential election) seemed analogous to that of the 1960s. Furthermore, the forty years separating Paulus's revival from the war and the original production presumably 
allowed viewers who lived through the Vietnam era to look upon the musical with fresh eyes. The memory of the war and the musical's first Broadway bow, which were quite strong at the time of its first revival, presumably lessened by the time that Paulus's production reached Broadway if for no other reason than the fact that four decades of potential audiences had not lived through the era.

In addition to a hospitable zeitgeist, Hair's relevance appears to depend upon its cultural intelligibility. Rado and Ragni chose to revise and update some of Hair's more passé allusions to 1960s culture in 1977 in order to make Hair more comprehensible to Me Decade viewers; however, in providing more timely cultural referents, the authors displaced the musical from its stated temporal setting and arguably compromised its intelligibility. Despite its foregrounding in the passions and politics of the Vietnam years, the first revival of Hair somewhat clumsily represented two eras simultaneously. Paulus's decision to decrease, rather than update, Hair's cultural signifiers and provide historical context in the form of exposition is perhaps a more efficacious method of preparing the libretto for present day audiences. As time continues to pass and the temporal distance between the Vietnam War and the present grows, the collective memory of the era will invariably wane. Consequently, Hair will only continue to represent a past, historical era. The addition of more contextual exposition could help to orient spectators to the cultural and political climate that the musical depicts, as could dramaturgical notes or a lobby display.

Paulus's revival also demonstrates that Hair not only benefits from a compatible zeitgeist, but more specifically from a clear correlation between the musical and the present day youth culture. In a 1970 article for Life Magazine, Tom Prideaux predicted, 
"Hair won't really work unless it really expresses the people who are doing it." ${ }^{154}$ The anxiety and passion aroused by adolescence drives Hair's action and gives the tribe a reason to sing, play, and protest. Paulus's revival arrived on Broadway at a time when a high percentage of American youth were politically mobilized over matters of social justice and out of concern for the future. The director's decision to backdate the musical one year arguably helped to align the Hair with a corresponding optimism and desire for "hope and change" among the current America's youth culture. Furthermore, her cast's advocacy for marriage equality helped the musical become an instrument for social change. Moreover, Hair's Broadway return coincided with a rash of musicals featuring disillusioned adolescents and generational conflict, including Duncan Sheik's Spring Awakening (2006), Twyla Tharp and Bob Dylan's The Times They Are A-Changing (2006), Stew's Passing Strange (2008), and Tom Kitt and Brian Yorkey's Next to Normal (2009). This notable interest in youth narratives presumably prepared a welcoming environment for Hair on Broadway in 2009.

Paulus's production appeared to benefit from a suitable social milieu and the fact that the musical had not appeared on Broadway in over thirty years. The three other musicals revived for the 2008-2009 season—Pal Joey, Guys and Dolls, and West Side Story — were all returning to Broadway for a fourth time. In addition to being produced in a rather inhospitable cultural climate, the 1977 production opened during a Broadway season that seemed to favor plays over musicals. A total of thirty-four plays opened on Broadway during the 1977-1978 season with revivals of highly canonized works such as Eugene O'Neill's A Touch of the Poet, George Bernard Shaw's Saint Joan, Molière's Tartuffe, Anton Chekhov's The Cherry Orchard, and Oscar Wilde's The Importance of 154 Tom Prideaux, “That Play Is Sprouting Everywhere,” Life, April 17, 1970, 83. 
Being Earnest finding favor with audiences. By comparison, only fourteen musicals played Broadway that year, and none of the seasons other revival's-Jesus Christ Superstar, Man of La Mancha, and Hello, Dolly! - performed particularly well at the box office.

The revivals of Hair mounted by O'Horgan and Paulus demonstrate multiple approaches to resurrecting the musical. The 1977 revival, while a critical and commercial failure, is perhaps the most informative as it helps to illuminate the degree to which Hair is time-bound. While producer Michael Butler ordered an authentic replica of Hair's original production, Rado and Ragni's revisions to the musical's libretto repudiated any claims of authenticity, as did the fact that the open and improvisational nature of O'Horgan's original staging resisted reproduction. Consequently, the revival did not fully reflect the original production in any manner other than its design. Rado and Ragni's updating of Hair's many cultural references illustrated an attempt to preserve the musical's timeliness and to force congruence between the work and the current zeitgeist. These textual revisions, however, caused the musical to reference two different eras simultaneously, thereby disturbing Hair's original temporal setting and rendering the work historically incoherent. Conversely, the intentional preservation of Hair's form undermined the authors' attempts to modernize the musical. Despite alterations to its libretto, the work retained strong aesthetic, thematic, and ideological ties to its original era that were further reified by the creative team's attempted duplication of the original production. These contradictory methods of revival presumably called attention to the fact that the Vietnam era had passed. Rado and Ragni's revisions to Hair's text, while largely superficial, represented the only instances of temporal modification and their 
updated period signifiers were meager compared to the production's signs of 1960s culture. The fact that no other attempts were made to make Hair align with the prevailing zeitgeist suggests that the musical naturally resists updating and cannot be wholly removed from its era. Its dramaturgical reliance on 1960s culture (particularly the war in Vietnam, the anti-draft movement, the generation gap, and the hippie ethos) keeps the musical's content, themes, and ideologies firmly tied to its moment in time. A study in contradictions, O'Horgan's production represented two contrasting strategies for revival, both of which were thwarted by the musical's time-boundedness. The revival also suggests that O'Horgan's directorial talents might have been tied to the creative context of the 1960s. Hair's marked success in 1968 and failure in 1977, combined with the director's successive flops following Jesus Christ Superstar, suggest that O'Horgan came to Broadway at a time that welcomed his particular brand of experimentation-a window of opportunity that was perhaps closing by 1977.

By comparison, Paulus's strategies for revival seemed to acknowledge the musical's substantial ties to its original zeitgeist. Recognizing the essential role that cultural intelligibility would play in the revival's reception, the director aimed to alter Hair's libretto in a manner that would orient her audiences to the Vietnam era. Her textual additions further highlighted the musical's generational conflict, recognized the prevailing social movements of the era, and clarified the causes of draft anxiety, thus providing audiences with historical context to inform their viewing of events long past. Furthermore, Paulus's encouragement of improvisation and direct engagement with the audience honored Hair's roots in experimental theatre. Restoring these aspects of Hair's original dramaturgy also helped to elucidate the nature of the musical's time- 
boundedness. A product of the 1960s downtown avant-garde performance movement, the original production of Hair was wild, untamed, dynamic, and unpredictable. To some extent, any attempt to revive the musical will undoubtedly petrify what made the musical unique among the Broadway fare of the day. The degree of freedom that Hair's original cast enjoyed in performance stands counter to the standards of professionalism associated with a commercial run on Broadway today. Consequently, Hair is also formally timebound. Paulus's production could only offer audiences an approximation of the rebellion and whimsy that characterized Hair in 1968. Even so, the revival's many awards, in addition to its critical and commercial success, suggest that Paulus's chosen strategies for re-staging Hair were effective. The director's continued success in re-staging classic musicals indicates that helming revivals is a specific directorial specialization that she has cultivated.

Hair's profoundly time-bound nature indicates that additional approaches to reviving the musical will need to be developed as the work continues on in the afterlife. The musical's period vernacular, aesthetics, themes, and ideologies will surely read as foreign to future audiences. Even so, the passage of time does seem to benefit the musical. Furthermore, Hair's time-bound nature is not necessarily a hindrance. As the memory of the Vietnam War and the tumult of the 1960s continue to fade from the collective cultural memory, Hair has become a valuable cultural artifact that reflects (with some creative liberty) what was happening in American culture during one of the most divisive periods of the twentieth-century. Therefore, devising more strategies for making the musical coherent and compelling in later years is imperative. 


\title{
CHAPTER THREE
}

\section{EVERYTHING'S DIFFERENT, NOTHING'S CHANGED: COMPANY}

\author{
EVERYTHING'S DIFFERENT, \\ NOTHING'S CHANGED, \\ ONLY MAYBE SLIGHTLY \\ REARRANGED ${ }^{155}$
}

\section{ORIGINAL 1970 BROADWAY PRODUCTION}

After Hair, the next watershed event that critics and scholars generally cite in the American musical's maturation and development is the original Broadway production of George Furth and Stephen Sondheim's Company. Directed by Harold Prince and choreographed by Michael Bennett, the musical opened at the Alvin Theatre on April 26, 1970, and garnered significant attention for its fragmented libretto, sophisticated themes, inchoate characters, and decidedly unsentimental depiction of marriage - features that represented a marked divergence from the Golden Age model. Hair exhibited several of these same traits as well when it premiered on Broadway just two years earlier; however, Company, while similar in form, represented a different mark of achievement. Penned by Broadway outsiders, Hair was a product of downtown experimentation and its eventual transfer to Broadway was something of a happy accident. Conversely, Company was fashioned by members of the Broadway establishment whose work openly defied the generally accepted maxims of musical making. Its historical significance then derives not merely from the fact that the musical broke with Golden Age tradition, but rather the 36.

${ }^{155}$ George Furth, Company: A Musical Comedy (New York: Random House, 1970), 35- 
manner in which the break occurred. A collection of loosely connected scenes and songs set against the backdrop of Manhattan's Upper East Side circa 1970, Company centered upon a thirty-five year old bachelor named Robert and chronicled his interactions with five well-to-do married couples—his "good and crazy friends"-and three paramours. Furth's book eschewed a linear plot and fully developed characters in favor of a more fractured narrative and fourteen broadly drawn character sketches. The musical's otherwise unrelated episodes were bound together by the notion of marriage with each couple representing a different view of or approach to the institution. Most scenes involved Robert visiting a particular pair of spouses and bearing witness to the various bargains, compromises, or personal sacrifices that they had made in the name of married life. During these stopovers, the couples questioned Robert's bachelorhood or entreated him to find a woman with whom he could enjoy a serious and sustained relationship. The character, however, remained single for the duration of the musical. He also did little as the play's protagonist to propel Company's action forward. Rather than taking an active role in his own life, Robert instead functioned as a passive and bemused observerquietly watching as his friends negotiated the tribulations of wedlock. His detached demeanor and continued resistance to partnership seemed to suggest that the character was either content in his solitude or incapable of forging meaningful bonds with anyone from outside his immediate circle. Several critics derided the character as being a cipher; however, it was through Robert that Company became more than an assessment of modern marriage. The musical also contemplated the related themes of commitment, connection and urban isolation—as described by Sondheim, "the increasing difficulty of making one-to-one relationships in an increasingly dehumanized society."

\footnotetext{
${ }^{156}$ Quoted in Craig Zadan, Sondheim and Co. (New York: Macmillan Publishing Co.,
} 
Contributing to the musical's lack of plot and character development was the fact that Company's fragmented libretto was also circular in shape. As critic Martin Gottfried contends, "The show is like a large, revolving sculpture with the character's life looked at from every angle: one complete rotation, that is the show's plot." ${ }^{\prime 157}$ This metaphor is particularly apt as Robert did not follow a linear path toward understanding partnership, but rather observed it from multiple perspectives. In watching his friends manage their own relationships, he circled and sidestepped the subject of marriage without confronting it directly. As Joanne Gordon, author of Art Isn't Easy: The Achievement of Stephen Sondheim, notes, "We are presented with fragments of Robert's life ... unlike the traditional hero, Robert does not journey forward. The audience can perceive the cumulative effect of his experiences, but never has the sense of inevitable progression and growth that would suggest the gradual enlightenment hero." ${ }^{158}$ Company also demonstrated a circular structure in that it ended in the same place it began: Robert's apartment on the eve of his thirty-fifth birthday where the five couples gathered together to throw their favorite bachelor a surprise party. Appearing four times over the course of the musical, the party scene functioned as a leitmotif that both organized the musical's plot and, as Gordon notes, dramatized "the protagonist's need to grow up." ${ }^{159}$ Harold Prince professes that he, Furth, and Sondheim conceived of the birthday gatherings as plot devices that would imbue Company with a "Pinteresque" quality as they presented four possible variations on a single occasion. By design each gathering was markedly different in tone: "the first was giddy, somewhat hysterical; the second, an abbreviated

Inc., 1974), 131.

${ }^{157}$ Martin Gottfried, Sondheim (New York: H.N. Abrams, 1993), 78.

${ }^{158}$ Joanne Gordon, Art Isn't Easy: The Achievement of Stephen Sondheim (Carbondale, IL: Southern Illinois University Press, 1990), 42.

${ }^{159}$ Ibid., 41. 
version of the first; the third, hostile and staccato; and the final one at the end of the show, warm, loving, and mature. ${ }^{\prime 160}$ Opening and closing each act, Robert's four birthday parties (always his thirty-fifth) effectively functioned as narrative bookends. Both the protagonist and the ensemble began and ended the musical in the same location under the same set of circumstances.

Company also challenged Golden Age convention in the varied and remarkable ways that it utilized music. Rather than emerging as an extension of the plot, Sondheim's songs frequently stopped the play's action in order to mark a transition, comment on unfolding events, or highlight Robert's seeming ambivalence towards marriage. Numbers such as "You Could Drive a Person Crazy" and "The Little Things You Do Together" interrupted scenes and allowed characters from outside the given moment to offer an almost Brechtian critique of Robert's behavior or married life writ large. Other tunes such as "Sorry-Grateful," "Side by Side by Side," and "Barcelona" functioned as scenes unto themselves. Company's songs, meliorated from its already episodic plot, would then provide the piece with a structure that helped to distinguish it from traditional Golden Age fare. Rather than recalling the more integrated musicals of prior decades, Sondheim and Furth's project resembled a modern musical revue — an evening of varied entertainments organized around complex questions and cultural anxieties.

In many regards, Company represented the apotheosis of what critic Martin Gottfried would later term the concept musical: "a show whose music, lyrics, dance, stage movement, and dialogue are woven through each other in the creation of a tapestry-

${ }^{160}$ Quoted in Carol Ilson, Harold Prince: A Director's Journey (New York: Hal Leonard Corporation, 2000), 165. 
like theme (rather than in support of a plot). ${ }^{\prime 161}$ While Hair and other earlier musicals such as Lady in the Dark (1941), Allegro (1947), Love Life (1948), Cabaret (1966), and Zorba (1968) had employed comparable methods of construction and were similarly focused on ideas rather than a linear plot, John Bush Jones contends that Company was one of the first musicals to receive Gottfried's designation. ${ }^{162}$ In his estimation, Sondheim and Furth's project helped give rise to the concept musical as a new and discrete category of the American musical, and in doing so, became "the archetypal exemplar of the genre. ${ }^{" 163}$ His claim is further supported by the rash of episodic and concept-driven musicals that appeared on Broadway following Company's premiere, including, but not limited to Follies (1971), Pippin (1972), Grease (1972), Chicago (1975), A Chorus Line (1975), Godspell (1976), Pacific Overtures (1976), Working (1978), Cats (1981), Nine (1982), Baby (1983), Quilters (1984), Grand Hotel (1989), and Assassins (1990). Consequently, Company's historical and artistic import arguably derives from the musical's formal innovation and its influence on the future of the form. In helping to inspire new methods of musical making, Sondheim, Furth, and Prince helped to inaugurate a new era of American musical theatre, and the 1970 opening of Company,

${ }^{161}$ Martin Gottfried, "Flipping Over Follies," review of Follies by James Goldman and Stephen Sondheim, directed by Harold Prince. Winter Garden Theatre, New York, New York Times, April 25, 1971.

${ }^{162}$ While Jones acknowledges the concept musical as a widely recognized sub-genre of the American musical, he takes issue with the term concept musical-particularly as it is used in reference to such works as Hair, Company, and A Chorus Line. By his charge, Gottfried's term is too broad to be of use as presumably every play or musical is founded upon some sort of theatrical concept. Jones prefers to identify these works and others like them as fragmented musicals - works whose episodic narratives contrasted with the more conventionally plotted pieces of the Golden Age. In his estimation, the term offers a more accurate of description of how and why these musicals are stylistically and structurally unique.

${ }^{163}$ John Bush Jones, Our Musicals, Ourselves: A Social History of the American Musical Theatre (Hanover, MA: Brandeis University Press, 2003), 275. 
timely in its novelty, confirmed that the American musical's much fabled Golden Age had indeed ended.

While the uniqueness of Company's formal qualities certainly contributed to its historical significance, the musical's defiance of Golden Age precepts also extended to the manner in which it treated the subjects of love, monogamy, and marriage. In Words and Music, his 1972 analysis of the American musical libretto, the eminent musical conductor and theorist Lehman Engel identified romantic love as one of the six primary needs of a Golden Age musical, claiming that the lyrical nature of the form required love as a modus operandi: "It should be clear that—-to date—no musical without principal romantic involvement has worked. Romance is the fuel that ignited the music and lyrics." ${ }^{164}$ Supporting Engle's allegation was the fact that countless Golden Age properties were in fact underpinned by romantic love, and generally featured a heterosexual couple that met, resisted each other, fell in love, pulled apart, and then reunited by the musical's end — often in a grand finale that depicted or suggested marriage. ${ }^{165}$ Consequently, love served as a dramaturgical device during the Golden Age that drove plot, created dramatic tension, and perhaps most importantly, gave characters a reason to sing. Thirty-seven years later, Raymond Knapp maintained Engel's stance on love's centrality in The American Musical and the Performance of Personal Identity:

The American Musical has been most consistently successful when its stories and themes resolve through the formation of conventional romantic relationships ...

${ }^{164}$ Lehman Engel, Words With Music: Creating the Broadway Musical Libretto, Updated and Revised by Howard Kissel (New York: Applause Cinema and Theatre Books, 2006), 113.

${ }^{165}$ A sampling of Golden Age musicals whose dramaturgy reflected this narrative structure (or a comparable structure) includes, but is in no way limited to Rodgers and Hammerstein's Oklahoma! (1943), South Pacific (1949), and The Sound of Music (1959), Irving Berlin's Annie Get Your Gun (1946), Cole Porter's Kiss Me Kate (1949), Frank Loesser's Guys and Dolls (1950), Richard Adler and Jerry Ross's The Pajama Game (1954), and Jerry Herman's Hello, Dolly! (1964). 
the dramatic crux will lie not in the larger trajectory (which is probably given) but in the ways in which the [romantic] relationships between and among the principals are delineated in musical and dramatic terms. ${ }^{166}$

The Golden Age musical's privileging of love and marriage presumably derived from Cold War era anxieties and its imperatives for a happy home and a loving nuclear family, which according to Stephanie Coontz were seen as a defense against the ever imminent threat of communism. ${ }^{167}$ Stacy Wolf contends that these metanarratives not only rigidly defined the era's gender roles, but also pervaded musicals of the Golden Age, and thereby reified heterosexual love and union as the Golden Age musical's modus operandi. ${ }^{168}$ Company, by comparison, did not culminate in a romantic union. While many musicals of the period, including Hair and A Chorus Line, generally eschewed romantic narratives, Company was unique in that it was foregrounded in questions of love and marriage, but featured a central character that remained uncoupled for the musical's duration. The musical's protagonist was a confirmed bachelor who dated multiple women simultaneously, engaged in casual sex, and actively avoided commitment and monogamy. While perplexing to several of his married friends, Robert's playboy behavior reflected the rhetoric of the growing sexual revolution. Beginning in the early 1960s, the sexual revolution initiated a slow uprooting of America's more puritanical attitudes towards adult relationships that reached an apex by the early 1970s. According to David Allyn, the advent of the combined oral contraceptive pill in 1960 helped to free acts of copulation from the threat of unwanted pregnancy, and in doing so, opened the

${ }^{166}$ Raymond Knapp, The American Musical and the Performance of Personal Identity (Princeton, NJ: Princeton University Press, 2006), 264.

${ }^{167}$ Stephanie Coontz, The Way We Never Were: American Families and the Nostalgia Trap (New York: Basic Books, 1992), 33.

${ }^{168}$ Stacy Wolf, Changed for Good: A Feminist History of the Broadway Musical (New York: Oxford University Press, 2011), 31-32. 
door to the possibility of sex outside of marriage. ${ }^{169}$ The years that followed demonstrated a collective softening in society's more abstemious attitudes towards sex, making it markedly more visible in film and print media, and an increasingly more casual topic of conversation. The years prior to Company's Broadway premiere witnessed the publication of Helen Gurley Brown's Sex and the Single Girl (1962), the United States premiere of Swedish director Vilgot Sjöman's controversial film I Am Curious (Yellow) (1967), and the American launch of Penthouse Magazine (1969). During Company's final year on Broadway, Alex Comfort would publish The Joy of Sex (1972). Two years later, the United States Supreme Court would legalize abortion with their ruling for the historic case, Roe v. Wade. The period saw a rise in documented cases of pre-marital sex, casual sex, group sex, "free love," and homosexual experimentation. ${ }^{170}$ The liberation of sex also helped to change the face of modern marriage. No longer was the institution a rigid and reticent model dedicated solely to the creation and rearing of children. Nena and George O'Neill's 1972 best-selling publication Open Marriage proposed a new paradigm for lawful partnerships that permitted extramarital sexual relations. In addition to open marriage, the era also gave rise to such phenomena as group marriage, swinging, and wife swapping. In light of such practices, the definition of marriage necessarily began to broaden. The art of the time began to chronicle this shift and began to reflect a variety of different approaches to the institution. Plays such as Edward Albee's Who's Afraid of Virginia Woolf? (1962), Arthur Miller's After the Fall (1964), and Harold Pinter's The Homecoming (1965) depicted turbulent or unromantic marriages built upon pretense or artifice. Films like Paul Mazursky's Bob \& Carol \& Ted \& Alice (1969) offered a

${ }^{169}$ David Allyn, Make Love Not War - The Sexual Revolution: An Unfettered History (Boston: Little, Brown and Company, 2000), 33.

${ }^{170}$ Ibid., 83-85. 
somewhat more whimsical, but nevertheless sexually progressive, depiction of open partnership. According to Coontz, this shift in societal mores also helped give rise to singles culture and began to push the average age for marriage closer to thirty. ${ }^{171}$ In the 1950s, men and women who had elected not to marry in their early twenties were frequently deemed as aberrant, ill, or wanton. By the 1970s, singles like Robert were often viewed as progressive and untrammeled. ${ }^{172}$ Nevertheless, musicals of the Golden Age had yet to advocate, even tacitly, unmarried life. As committed partnership was almost always a protagonist's unwitting endgame, Company's depiction of bachelorhood, like the sexual revolution itself, represented a clear break from Cold War rhetoric.

Despite the historical significance of the musical's original production, Company has had a rather contested afterlife. After its close in 1972, the piece would not appear on a Broadway stage for another twenty-three years. Furthermore, notable off-Broadway productions at the Equity Theatre Library (1978), Playwright's Horizons (1980), and the York Theatre Company (1987) received tepid reviews and markedly brief runs. In accounting for these disappointments and the musical's two-decade absence from Broadway, several critics and scholars have charged that the passage of time has rendered Company's content and themes obsolete. In his 1995 article, "Company - 25 Years Later," John Olson suggested that the work's original 1970s setting was at once a unique dramaturgical feature and a cause for contestations:

Company is one of the few Broadway musicals of the past thirty years to reflect the environment and lives of its original audiences. Like some other shows of its time ... it presents stories about 'present-day' New Yorkers. And while it is revived more frequently than these contemporaries [in regional and amateur theatres], its original 1970 setting is considered to be problematic and a barrier to

\footnotetext{
${ }^{171}$ Coontz, 197.

${ }^{172}$ Ibid., 186
} 
successful revival. If not for the reputation of its composer-lyricist Stephen Sondheim and the importance of the piece to his canon, perhaps Company would have been similarly forgotten. ${ }^{173}$

Comparing Company to other musicals set within their given zeitgeist such as How Now Dow Jones (1967), Promises, Promises (1968), and Seesaw (1973)—musicals that had yet to receive a Broadway revival as of 1995-Olson implied that Company's depiction of life in 1970s New York would forestall the musical from enjoying an auspicious afterlife. He also inferred that the musical's temporal specificity inadvertently anchored Company's text — its libretto, score, and themes — to its era. Musical theatre historian Thomas S. Hischak echoed this sentiment a bit more didactically seven years later in Boy Loses Girl, his 2002 study of Broadway librettists. As he alleged, "Today, Company is difficult to produce. It is so set in the 1970 s mentality that it cannot be satisfactorily updated or revised. Furth was so concerned with writing a contemporary comedy that many of the script's ideas were out of date a few years later ... Company may be the greatest of unrevivable Broadway musicals." ${ }^{174}$ The historian would go on to describe Sondheim's score as well as the musical's discussion of marriage and overall worldview as outmoded. ${ }^{175}$ Through his rather pejorative stance, Hischak refuted theatre critic Foster Hirsch's claim that Company "goes hardly deeper into its milieu than a Neil Simon gagfest" and suggested that Company is not merely dated, but rather unequivocally timebound, and therefore, un-producible. ${ }^{176}$

${ }^{173}$ John Olson, “Company - 25 Years Later," Stephen Sondheim: A Casebook, ed. Joanne Gordon (New York: Garland Publishing Inc., 1997), 47.

${ }^{174}$ Hischak, 169.

175 Ibid.

${ }^{176}$ Foster Hirsch, Harold Prince and the American Musical, Expanded Edition (New York: Applause Theatre and Cinema Books, 2005), 89. 
Though their claims of obsolescence were relatively resolute, Olson and Hischak offered little in terms of support for their dismissal of Company. Neither critic presented evidence for how the musical was a product of its zeitgeist, identified what aspects of its dramaturgy kept the work mired with the milieu of the 1970s, or addressed how audiences received the musical at the time of its original production or in later decades. Therefore, an assessment of the musical's durability would benefit from a more thorough investigation of its libretto, score, and original production. Further challenging the critics' charges of unrevivability is the fact that Company has received two Broadway revivals. The first of these productions was directed by Scott Ellis and produced by the Roundabout Theatre Company in 1995. John Doyle helmed a second production for Broadway in 2006. With varying degrees of success, these directors mounted Company for contemporary audiences. Evaluating the efficacy of their respective approaches to revival might illuminate the merits (or demerits) of Olson and Hischak's claims.

The allegation that Company is unsuitable for revival also rests upon an assumption that the musical's original 1970 setting is an immutable feature of the workone that anchors it to its era and prevents it from resonating with audiences in later eras. Both the Playbill for the original Broadway production and the first edition of the published libretto described Company's setting as "New York City, NOW," which would situate the play's action within the years of its original run: 1970 to 1972 . Outside of this directive, however, the original libretto only inferred the 1970s as the musical's temporal setting. Furth's book did not contain any direct references to the current year or cultural climate. Unlike Hair, which depicted members of a specific social movement during a specific time of cultural unrest, Company's plot did not unfold against the backdrop of a 
significant event in American history. The musical's characters did not discuss current events such as the Vietnam War, domestic or global politics, the current popular culture, recent history, or any subject endemic to the Nixon era at length. Furthermore, the majority of Robert's compatriots did not relate their ages, occupations, memories of childhood, or any personal information that would help to situate them within a singular moment in time. Because the libretto to Company did not trade in these time-related specifics, one can infer that the musical's temporal setting (or even time itself) had little bearing on the musical's plot, making the work dramaturgically different from Hair. Where the current year almost functioned as a character in Hair, Sondheim and Furth attached comparatively little importance to the current year in Company.

While Company's implied temporal setting is a relatively minor feature of its libretto, Furth's book was not completely devoid of period signification. On occasion, characters mentioned public figures that audiences of the time might have recognized, referred to current tastes and trends, and utilized colloquialisms endemic to the era. Company's use of cultural allusion, however, was meager compared to that of Hair. In total, Furth's libretto contained only ten overt period references. Three of these references pointed specifically to public figures. In the musical's second episode, Sarah—wife of Harry - told Robert of the various types of food she desires but is not permitted to eat due to her strict self-imposed diet. In describing her longing for cake, Sarah proclaimed Sara Lee as "the most phenomenal woman since Mary Baker Eddy." "177 Later in the second act, when Robert accompanied socialite Joanne and her husband Larry to an unnamed New York nightclub, Robert and Joanne sit and have a conversation about her two previous marriages while watching Larry dance with various club patrons. Joanne, embarrassed by

\footnotetext{
${ }^{177}$ Furth, 25.
} 
her current spouse's dance floor antics, described Larry as “jerking and sashaying all over the place like Ann Miller." ${ }^{, 178}$ When Larry returned to Robert and Joanne's table, his wife entreated him to take off his red shoes—an allusion that could refer to the 1845 Hans Christian Andersen dance fable, The Red Shoes, but more likely points to the popular 1948 Michael Powell and Emeric Pressburger film of the same name. ${ }^{179}$ Prior to the scene's close, when Larry left to pay the bar bill, Joanne suggested that she and Robert have an affair and warned the nervous bachelor not to evade her proposition with what she cited as his "folksy Harold Teen" shtick. ${ }^{180}$ Mary Baker Eddy, Ann Miller, and Harold Teen—while certainly notable historical figures—were not necessarily emblems of American culture at the time of Company's premiere. Eddy, the founder of Christian Science theology, had died sixty years prior. Ann Miller danced in regional theatre productions for much of the 1960s and 1970s, but had not appeared in a major motion picture since 1954. Moreover, the popular Harold Teen comic strip ended its twenty-four year run in 1943. Rather than signaling the early 1970 s, these figures gestured to the years that preceded Company's creation. One could argue that invoking their names helped to indicate the musical's temporal setting by suggesting the ages of Furth's characters. Robert's married friends, who are purported to be older than the thirty-five year old bachelor, might have come of age in the 1940s — decades in which Eddy, Miller, and Teen were more visible within the popular culture. However, because Furth's three allusions do not cite the 1970s directly, they functioned more as cultural anachronisms than historical touchstones.

\footnotetext{
${ }^{178}$ Ibid., 105.

${ }^{179}$ Ibid.

${ }^{180}$ Ibid., 110.
} 
The libretto's remaining period references could be considered equally anachronistic when read in the current day. Like the allusions noted above, they recalled the past, but did not necessarily point to one specific historical moment. Joanne drank vodka stingers, took Librium, and smoked cigarettes inside the nightclub - an act that the New York State legislature would eventually ban in $2003 .{ }^{181}$ Robert referred to April as a stewardess rather than a flight attendant. ${ }^{182}$ He later likened the pulse of New York City to a busy signal. Sarah teased Robert for gathering trivia "like some old quiz kid"presumably a reference to the radio and television game show Quiz Kids that aired on NBC for much of the 1940s and 1950s. ${ }^{183}$ Harry chided Sarah for subscribing to over forty magazines - a habit that could read as passé in 2014 given the steady decline of the publishing industry. ${ }^{184}$ In almost every case, these references were brief, sporadic, and made in passing. The one exception to this rule, however, occurred in the musical's fourth scene when spouses Jenny and David smoked marijuana with Robert in their home after their children had gone to bed. While the conversation between the married couple and the bachelor focused on Robert's checkered dating history, the episode itself was foregrounded in their shared consumption of the aforementioned drug — an act which Jenny eventually described as "trying to keep up with the kids." "185 Olson contends that this scene situates Company squarely within the Vietnam era as recreational drugs were more abundant and attitudes toward drug use were more lax than they would eventually become in the 1980s and 1990s. As a sign of the hippie movement, marijuana's marked presence within the scene combined with Jenny's suggestion that pot smoking is the
${ }^{181}$ Ibid., 105, 108.
182 Ibid., 45.
${ }^{183}$ Ibid., 21.
${ }^{184}$ Ibid., 26.
${ }^{185}$ Ibid., 50. 
province of the young could support Olson's claim. However, in light of marijuana's recent legalization in Washington and Colorado, the strength of the drug's associations with the 1960s and 1970s could potentially lessen over time, thereby extricating the scene from the era in question.

By comparison, Sondheim's lyrics for Company's fifteen songs contained fewer period references than the musical's book; however, the composer did employ five allusions that were arguably more evocative of the musical's historical moment than any of the cultural references found in Furth's dialogue. In the song "Another Hundred People," Marta made reference to her answering service. ${ }^{186}$ The telephone answering service, a staple of urban life in the 1960s and 1970s, would become somewhat less ubiquitous with the popularization of personal answering machines in the 1990s. During "You Could Drive a Person Crazy," Robert's three girlfriends lamented his inability to commit and claimed that they could understand his behavior if a relationship was "not a person's bag." ${ }^{87}$ Similarly, in “The Ladies Who Lunch," Joanne's second act indictment of urban society women, she referred to pseudo-intellectuals as "a gas." ${ }^{" 188}$ According to The New Partridge Dictionary of Slang and Unconventional English, both turns of phrase entered the American vernacular in the late 1960s. ${ }^{189}$ Joanne then alleged that the aforementioned women take class in optical art and went on to describe urban housewives as "clutching a copy of Life, just to keep in touch."190 Jon Borgzinner of Time Magazine first coined the term "Op Art" in 1964, and according to John Lancaster, the

${ }^{186}$ Ibid., 56.

${ }^{187}$ Ibid., 46.

${ }^{188}$ Ibid., 106.

${ }^{189}$ Tom Dalzell and Terry Victor, eds., The New Partridge Dictionary of Slang and Unconventional English, Vol. 1 (New York: Routledge, 2006), 71, 841.

${ }^{190}$ Furth, 106. 
ensuing movement of art that utilized tessellations in order to create optical illusions enjoyed four years of continued popularity in the United States. ${ }^{191}$ The venerable Life Magazine, first launched in 1936, gained notoriety for documenting American culture for nearly four decades and remained in circulation as a weekly publication until 1972. It returned to newsstands as a monthly magazine in 1978 before becoming an intermittent newspaper supplement in 2000 and then a website under the auspices of Time Magazine in 2009. It is more than plausible that "girls who play wife," and even Joanne herself, would have regularly perused the magazine in the early 1970 s in order to keep abreast of current events. It is less likely that any of these women would read Life for the purpose of keeping in touch much after 2000.

In total, Company's original libretto and lyrics offered fifteen scattered references to American life and culture. Because these references invoked nearly three decades of cultural history - from the early 1940 s to the late 1960 s — they served to suggest the musical's temporal setting albeit indirectly. Unlike Hair, which confirmed and reinforced its social milieu with four mentions of the current year as well as forty-five allusions to current events and hippie life, Company's text inferred its setting through decidedly broader gestures. By sporadically referencing the past, both recent and distant, Furth and Sondheim projected the early 1970 s as the musical's temporal setting without overdetermining it. Consequently, the musical's temporal setting functions more as a suggestive backdrop than it does as an indelible landscape that determines character behavior or situates the musical within a particular moment in time. Earlier drafts of the musical, however, featured moments of stronger temporal determination. In Finishing the Hat, his first of two published collections of lyrics, Sondheim reveals that earlier drafts of

${ }^{191}$ John Lancaster, Introducing Op Art (London: BT Batsford Limited, 1973), 30. 
"The Little Things You Do Together," penned before Company's out of town premiere in Boston, referenced the then current zeitgeist more directly than the final libretto would. His original quatrain for the song read:

IT'S NOT THE PROFOUND, PHILOSOPHIC DISCUSSIONS THAT GET YOU THROUGH DESPERATE NIGHTS. IT'S NOT TALK OF GOD, AND THE MOON, AND THE RUSSIANS, IT'S WHO GETS TO TURN OUT THE LIGHTS. ${ }^{192}$

Sung by Joanne and the married couples during the musical's second scene, "The Little Things You Do Together" offered extensive lists of behaviors, routines, and best practices for helping to cultivate and preserve what they term "perfect [married] relationships. ${ }^{, 193}$ Citing deliberation about the Cold War as a feature of married life would have strengthened Company's relationship to its zeitgeist by bringing the extant political climate to bear on the musical's discussion of wedlock. It would have also been the only moment in the musical in which American affairs of state were at all mentioned. Conversations about the Soviet Union, particularly its rivalry with the United States in space exploration, were au courant for much of the 1960s after the Soviet Union became the first country to land a spacecraft on the surface of the moon successfully in 1959. Ten years later, NASA's famed Apollo 11 Mission became the first manned spaceflight to the moon, reigniting discussion of space travel ten months before Company's Broadway opening. Keeping the quatrain would have presumably strengthened the musical's relationship to the extant zeitgeist; however, because the composer revised the lyric prior

192 Stephen Sondheim, Finishing the Hat: Collected Lyrics (1954-1981) with Attendant Comments, Principles, Heresies, Grudges, Whines, and Anecdotes (New York: Alfred A. Knopf), 174.

${ }^{193}$ Furth, 29. 
to the musical's opening, Company's text maintained a relatively thin relationship with its era.

Hischak's observation that the score to Company is foregrounded in musical idioms of its era is not entirely without merit as several of Sondheim's songs drew from popular genres of the late 1960s, including calypso ("The Little Things You Do Together"), bossa nova (“The Ladies Who Lunch"), and urban folk (“Another Hundred People"). However, his implication that Sondheim's music mires the work within its era is perhaps a bit hyperbolic as a handful of numbers also recalled musical styles from earlier historical periods. "You Could Drive a Person Crazy," sung by April, Kathy, and Marta, was a parody of an Andrews Sisters Routine from the 1940s. "Side by Side by Side," the second act opener in which Robert and his friends mawkishly express their mutual affection," was a light foxtrot—a musical and social dance form which first emerged circa 1914. The subsequent "What Would We Do Without You?" was a military quick march akin to the American marches of the $18^{\text {th }}$ century. Choreographer Michael Bennett staged both of these numbers as a combined vaudeville act with the married couples brandishing canes and tipping straw skimmer hats. Additionally, musicologist Steve Swayne contends that the first act's "Have I Got a Girl for You" begins as a 1960s jazz waltz, but demonstrates evidence of more antiquated composition techniques when it fluidly transitions into the ballad, "Someone is Waiting." As he notes in How Sondheim Found His Sound, the sequence begins with a driving and percussive waltz beat as the husbands of the ensemble attempt to arouse Robert's interest in various single women they know. The number then transforms into a more buoyant comic waltz-endemic to the $1930 \mathrm{~s}$ - as the men begin to mock the bachelor for his consideration of relinquishing 
his single life. Finally, the comic waltz metamorphoses into a valse lente-a slow waltz form popular in the 1890s — when Robert begins to envision his ideal woman as a composite of the ensemble's wives. ${ }^{194}$ Because it utilizes a variety of musical idioms from a variety of time periods, Sondheim's score, a tuneful collage of musical anachronisms, might be better classified as pastiche rather than an unqualified homage to its era.

While the score to Company is not beholden to a single musical style, musicologists such as Stephen Banfield and Raymond Knapp contend that several of the musical's songs demonstrate evidence of rock influence. Both scholars credit Jonathan Tunick, arranger of Company's original orchestrations, with imbuing Sondheim's otherwise stylistically disparate melodies with this contemporary sensibility. Tunick's twenty-four-part orchestra included an electric piano, electric organ, and two guitarists playing the acoustic, electric, and bass guitar. Additionally, the number of woodwind and brass instruments utilized more than doubled the number of stringed instruments-a notable change from earlier years in which Broadway orchestras featured comparatively larger string sections. By balancing the instrumentation in this manner and employing several electric piano and guitar figurations, Tunick created moments of what Raymond Knapp refers to as "symphonic rock." 195 In The American Musical and the Performance of Personal Identity, the author analyzes Company's score and suggests that Tunick's original orchestrations evoked the tenor and pulse of rock music, but also remained somewhat conventional when compared to more overt rock scores of musicals like Hair

${ }^{194}$ Steve Swayne, How Sondheim Found His Sound (Ann Arbor, MI: University of Michigan Press, 2007), 65.

${ }^{195}$ Knapp, 295. 
by "mostly avoiding the obvious rock gesture of the backbeat." ${ }^{196}$ Of Company's fifteen songs, two in particular exhibited these qualities of symphonic rock. The first was "Company," which served as the musical's opening number as well as its recurrent musical theme. A dizzy and tuneful succession of endearments—-"Bobby Baby, Bobby Bubi, Robert Darling"- this frequent refrain was sung, or perhaps more accurately chanted in rhythm, by the five couples at various moments throughout the musical. Both maudlin and insistent, the sequence was at once a love letter to the bachelor and a demand for his attention. Underscoring the ensemble as they catalogued Robert's many nicknames was a steady, but driving two-note vamp played by a distorted electric guitar and meant to evoke the sound of a busy signal. ${ }^{197}$ Sondheim and Tunick introduced this motif with nearly twenty-five measures in the first moments of the musical's opening number and returned to it five more times before the final curtain. Much like the birthday scenes, each reprise worked to establish a specific mood. The first was bright and buoyant. The penultimate was fast and forceful. The last was ecstatic. While each reprise was fundamentally different in tone, the instrumentation of its accompaniment never changed. Consequently, the distinct sound of a distorted electric guitar-which can also be heard in phrases of "The Little Things You Do Together" and "Another Hundred People"-was an almost ubiquitous feature of Company's original score. Along with its notable guitar figurations, the title number also contained such contemporary rock signifiers as electric organ fills during the song's choruses and vigorous use of percussion at the number's close. Together these sounds suggested — in addition to the

${ }^{196}$ Ibid.

${ }^{197}$ Stephen Banfield, Sondheim's Broadway Musicals (Ann Arbor, MI: University of Michigan Press, 1993), 149. 
aforementioned busy signal—car horns, construction, and the frenetic hustle and bustle of urban life.

The second song to rely on symphonic rock sounds, "Tick-Tock," came from the musical's second act and underscored Robert's sexual encounter with flight attendant April. An entirely instrumental piece, the number performed two significant narrative functions. First, it served as musical accompaniment for Robert and April's respective inner monologues - which were presented to the audience as recordings throughout the tryst. Second, the song formed the musical foundations for a dance solo performed by Robert's former flame, Kathy. Her routine, choreographed by Bennett, explicated the tryst visually through erotically charged movement and was composed of two sequences, titled "Having Sex" and "Making Love." 198 The first half of the combination, meant to evoke the carnal pleasure of sexual relations, was comprised of sudden and fervid thrusts, lunges, and bourrées. Dressed only in a silk slip, Kathy began the combination by pantomiming foreplay—caressing and clinching an unseen partner. These small, tantalizing gestures gradually increased in both size and intensity and she began to frug, jerk, and chassé across the stage with wild abandon. The start of the second movement marked a stylistic shift in the number's music as "Making Love" aimed to suggest a more intimate and tender exchange between April and Robert; consequently, Kathy's choreography became increasingly lyrical, employing gestures and steps that were more fluid and controlled than those used in "Having Sex." Bennett conceived "Tick-Tock" as a vehicle to feature the virtuosic talents of Kathy's portrayer, Donna McKechnie- the only trained dancer among Company's cast. The sequence, however, stood apart from the rest of Company's numbers as the only moment told exclusively through dance.

\section{${ }^{198}$ Furth, 94.}


Additionally, Bennett's staging for "Tick-Tock" differed from the rest of Company's choreography as it combined popular social dance idioms of the period with more formal modern dance and ballet techniques.

Much like the musical's opening number, the score for "Tick-Tock" relied heavily on the orchestra's percussion, brass, electric piano, and electric guitar. It also featured the sounds of four female pit singers referred to as the Vocal Minority. The quartet's primary purpose throughout the musical was to provide vocal reinforcement for such songs as "Company" and "What Would We Do Without You?" and "Someone is Waiting." During "Tick-Tock," however, the voices helped to musicalize the nature of Robert and April's liaison. Intoning on open vowels, the Vocal Minority suggested the pair's pleasure and eventual climax through pitch, rhythm, and shifting dynamics. The use of background vocalists, while relatively common in the popular music of the late $1960 \mathrm{~s}-$ particularly in the work of composers such as Burt Bacharach, Herb Alpert, and Sergio Mendes - was a relative anomaly on Broadway until the 1968 premiere of Bacharach's musical collaboration with Hal David and Neil Simon, Promises, Promises. Bacharach's score, comprised of several of the songwriter's studio hits, identified its pit singers as "orchestra voices" to suggest that the vocalists contributed to musical's accompaniment as equally as the orchestra's other instruments. Sondheim's Vocal Minority would continue this trend, as would later musicals such as The Wiz and A Chorus Line. While "Tick-Tock" was orchestrated by Tunick and contained strains of Sondheim's "Poor Baby" and "Someone Is Waiting," the song itself was the work of composer David Shire and the only piece in Company's score not composed by Sondheim-a fact that accounts for why it sounded stylistically different from most songs in the musical. Sondheim's 
compositions suggest several time periods. However, Shire's “Tick-Tock," more than most songs in Company's catalogue, was evocative of its era.

Where Company's libretto, music, and lyrics only seemed to suggest the early 1970s as the musical's temporal setting, the mise-en-scène of its original production arguably depicted the era more directly. Scenic designer Boris Aronson created an abstract, multi-leveled steel structure that utilized ladders, staircases, and two working elevators. Accented with chrome and Plexiglas, the Tony Award winning constructivist set resembled a contemporary urban high-rise and was composed of multiple cubic spaces that served as "apartments" for each of the musical's married couples. Justifying his aesthetic and choice of materials, the designer stated, "Married life in New York city isn't rocking the afternoon away on a front porch in Maine. In New York, people sit stacked on top of each other in transparent cages. We live in a Plexiglas world now."199 In order to further establish the musical's location and mood, over six hundred photographs of current day New York City were projected onto the upstage cyclorama. Aronson intentionally avoided traditional signifiers of New York City such as recognizable skyscrapers or the neon lights of Times Square so as to forestall any suggestions of urban life as a romantic or exciting metropolis. Rather, the New York that he sought to evoke in the spacious Alvin Theatre was cold, impersonal, and imposing. Aronson drew inspiration for his design from the Theatre Reference Reading Room at the New York Public Library for the Performing Arts, which had opened at Lincoln Center in November of 1965. A relatively sterile space enclosed by walls of glass, the room was in Aronson's view, analogous to urban domiciles: “Apartments are like hospitals, antiseptic

${ }^{199}$ Quoted in Frank Rich and Lisa Aronson, The Theatre of Boris Aronson (New York: Alfred A. Knopf, 1987), 220. 
environments without privacy. ${ }^{, 200}$ By modeling his unit set on this room, the designer not only represented modern Manhattan architecture, but also helped to explicate Company's secondary theme of urban isolation visually. Aronson's scenic design for Company received significant praise from the New York critics for creating an atmosphere that was, in Gottfried's words, "sleek, cold, and bitter ... that make the place look like the technological age in which [the musical] exists. ${ }^{201}$ Collaborating with costumer D. D. Ryan on Company's scenic décor, Aronson dressed the stage with predominantly plastic furniture - the inspiration for which came from the latest issues of Vogue Italia. Ryan also provided the patterned fabrics used for furniture upholstery—several of which were later incorporated into her costume design. ${ }^{202} \mathrm{~A}$ fashion editor for Harper's Bazaar and later assistant to fashion designer Roy Halston Frowick, Ryan dressed the musical's cast in high end, up-to-the-minute fashions. The women of the ensemble wore brightly colored mini-dresses, tunics, peasant blouses, patterned jumpsuits, and hostess pajamas. Company's men sported long side burns and wore narrow collared shirts, ascots, singlebreasted sport coats, and bell-bottom trousers in plaids or stripes. Because of the presumed affluence of Company's married couples, most characters' costumes replicated the on trend fashions found in magazines such as Vogue, Elle, GQ, and Ryan's own Harper's Bazaar.

In addition to potent visual markers offered by the production's designers, Company's ongoing debate on the merits of marriage versus single life might have helped to mark the musical's moment in time. Many of Company's characters regarded the fact

${ }^{200}$ Quoted in Ibid., 228.

${ }^{201}$ Martin Gottfried, “The Theatre: Company," Women's Wear Daily, April 27, 1970, in New York Critics' Theatre Reviews. Vol. 31, ed. Joan Marlow and Betty Blake (New York:

Critics' Theatre Reviews Inc., 1970), 261.

${ }^{202}$ Rich and Aronson, 229-230. 
that Robert was not partnered as cause for concern. With the possible exception of twicedivorced Joanne, Robert's compatriots painted him as an aberration for not having married and expressed an unceasing desire — the wives especially— to see him settled and committed to one woman. The couples presumably married during the $1950 \mathrm{~s}$, a decade in which the average age for men and women at the time of marriage rapidly decreased to the early twenties or sooner. ${ }^{203}$ While the onset of the sexual revolution and its reconsideration of marital mores would help to raise this statistic — the average age of men at first marriage leapt to twenty-five by the early 1970s — it stands to reason that couples who wed during the postwar era would look upon the bachelor's single status with suspicion and believe that his inability to sustain a relationship with a female partner signaled a larger problem. This perhaps accounts for why several critics and scholars have perceived Robert as a closeted gay man. Martin Gottfried was one of the first critics to voice this interpretation in his assessment of the protagonist and his first portrayer, television and film star Dean Jones. Gottfried charged that the character's aversion to married life coupled with the actor's cool performance persona caused Robert to appear conspicuously chaste - a characteristic that coded him (albeit through conflation) as gay: "He can seem sexless and must watch it or the show's theme (and honesty) will be confused by homosexuality. ${ }^{, 204}$ Clive Barnes did not attempt to scrutinize Robert's sexual orientation himself; however, he did acknowledge that audience members might have questions of their own: "In case you had any doubts about his sexual inclinations-

${ }^{203}$ David Farber, The Age of Great Dreams: America in the 1960s (New York: Hill and Wang, 1994), 11.

${ }^{204}$ Gottfried, 261. 
and I am not sure that I did - he has three girls on the side."205 While Gottfried and Barnes were the only critics of Company's original production who thought to draw meaning from Robert's sexual ambivalence in their reviews, they weren't the only audience members to find queer subtext in the musical's book. Novelist and screenwriter William Goldman, an avowed fan of Company in 1970, took umbrage with what he saw as the musical's author's unwillingness to confirm Robert's sexuality: "I remember seeing Company five times and loved it, and I had a huge fucking problem, which is that the main character is gay, but they don't talk about it." ${ }^{206}$ Despite Sondheim and Furth's repeated claims that Robert is not homosexual, but merely heterosexual and emotionally adrift, arguments for how Robert is tacitly coded as gay have proliferated from reviewers of later revivals and scholars such as John M. Clum, D.A. Miller, and Bruce Kirle. ${ }^{207}$ Kirle alleges that the libretto to Company leaves the question of Robert's sexual proclivities open to interpretation and that later revivals must answer the question in performance since the original production did not. ${ }^{208}$ The Stonewall Riots, a series of violent demonstrations in New York's City's Greenwich Village that triggered the gay liberation movement of the 1970s, occurred only one year prior to Company's opening. Several historians, including Dudley Clendinen and Adam Nagourney, credit the riots with making the queer community visible to American society. Gay liberation groups

${ }^{205}$ Clive Barnes, “Company Offers Guide to New York's Marital Jungle,” The New York Times, April 27, 1970, in New York Critics' Theatre Reviews. Vol. 31, ed. Joan Marlow and Betty Blake (New York: Critics' Theatre Reviews Inc., 1970), 261.

${ }^{206}$ Quoted in Meryl Secrest, Stephen Sondheim: A Life (New York: Alfred A. Knopf, 1998), 371.

${ }^{207}$ See John Clum, Something for the Boys: Musical Theatre and Gay Culture (New York: St. Martin's Press, 1999) and D.A. Miller Place for Us: Essay on the Broadway Musical (Cambridge, MA: Harvard University Press, 1998).

${ }^{208}$ Bruce Kirle, Unfinished Show Business: Broadway Musicals as Works-in-Process (Carbondale, IL: Southern Illinois University Press, 2005), 183. 
urged closeted men and women not only to disclose, but also to publicly declare their sexual orientation. Additionally, gay figures began to appear in public life and popular entertainment. ${ }^{209}$ The commercial success of Mart Crowley's 1968 play The Boys in the Band also presumably helped to increase queer visibility in the world of New York Theatre. Later years would provide even more vehicles for presenting gay identities to the American public, including the made-for-television movie That Certain Summer (1972), Broadway musicals such as Applause (1970) and Seesaw (1973), and television series such as Hot l Baltimore (1975) and Soap (1977). Even as the queer community's discernibility grew over the course of Company's Broadway run, Furth's original libretto offered no evidence or forthright indication (other than his conspicuously single status) that Robert might be gay. Thus, assumptions about his sexual proclivities were purely speculative and presumably derived from the character's enigmatic nature, the length of his bachelorhood, his resistance to commitment, and the growing gay liberation movement's suggestion that life outside of the closet was possible.

Rather than directly address the question of Robert's sexual identity, the original production of Company instead lifted the veneer of 1950s idealism and depicted the challenges that accompanied partnership. Sarah and Harry vented their respective frustrations through bouts of bickering and wrestling matches. Susan and Peter opted for consensual divorce - a relatively novel phenomenon outside of cases involving abandonment or adultery_-but also elected to continue living and parenting together. Jenny and David sought to recapture the pleasures of their youth through recreational drug use. The marriages that were depicted were at once happy, loving, and quietly

${ }^{209}$ Dudley Clendinen and Adam Nagourney, Out for Good: The Struggle to Build a Gay Rights Movement in America (New York: Touchstone, 1999), 12. 
conflicted. When Robert asks Harry if he ever has regrets over marrying Sarah, Harry spoke for the entire ensemble with the following sung response:

YOU'RE ALWAYS SORRY, YOU'RE ALWAYS GRATEFUL, YOU'RE ALWAYS WONDERINGING WHAT MIGHT HAVE BEEN. ${ }^{210}$

The paradox of which Harry spoke signaled a recognition that the more traditional and idealized notions of marriage from past decades (and the societal expectations that they reified) were no longer (and perhaps never were) tenable. Even so, none of the couples admitted to considering life apart from their spouse, even cohabitating divorcees Peter and Susan. Though divorce rates gradually rose throughout 1960s and 1970s, historian Kristin Celello contends that the choice to remain in dysfunctional or marginally happy partnerships was still something of a cultural imperative. In Making Marriage Work: A History of Marriage and Divorce in the Twentieth Century United States, Celello contends that single culture, however en vogue, did not supplant married life. Rather, married couples often rejected Cold War imperatives and re-defined the terms of their union utilizing the rhetoric of compromise and the language of work: "[Marriage's] very flexibility, paired with a dearth of practical alternatives, had ensured its place as common marital wisdom." ${ }^{211}$ If Robert's single status and resistance to marriage were commensurate with the prevailing cultural discourse at the time of Company's, then so was the couples' commitment to partnership. In electing to remain with their respective spouses, Robert's good and crazy friends arguably challenged the Cold War metanarrative of happy and fulfilling marriage.

${ }^{210}$ Furth, 35 .

${ }^{211}$ Kristin Celello, Making Marriage Work: A History of Marriage and Divorce in the Twentieth Century United States (Chapel Hill, NC: University of North Carolina Press, 2009), 106. 
Opening night critics divided over the merits of Company; consequently, the musical received five positive notices, two mixed reviews, and three pans. Reviewers unanimously praised Prince's direction, Bennett's choreography, Aaronson's scenic design, and the musical's talented ensemble cast. Sondheim's score received particularly enthusiastic remarks - a first for his work as both a lyricist and composer. The musical's formal qualities and overall temperament, however, aroused dissension. Clive Barnes of The New York Times was among the musical's more notable and vocal detractors. The critic chided Company's episodic narrative and its overall dissimilarity from Golden Age works, charging that the resemblance of the respective vignettes combined with the libretto's marked lack of character development made Robert's circular journey seem monotonous. ${ }^{212}$ Conversely, Martin Gottfried of Women's Wear Daily heralded the musical's creative singularity as an accomplishment and identified Company's alleged hereticism as not only timely, but also its greatest feature. Comparing the piece to past masterworks such as West Side Story and Fiddler on the Roof, Gottfried stated:

Company is quite simply in a league by itself . . It isn't a story musical but an alternative to the 'book show,' which any sophisticated (and there aren't many) musical theatre person knows is silly, passé and doomed ... it is an ensemble or chamber musical with words and music and musical movement and dance that flow, organically from the same source. ${ }^{213}$

The critic would later suggest that the musical's greatest feat was its successful synthesis of dramaturgical experimentation (derived from the current downtown theatre scene) and Broadway tradition. $^{214}$

${ }^{212}$ Clive Barnes, “Company Offers a Guide to New York’s Marital Jungle,” New York Times, April 27, 1970, in New York Critics' Theatre Reviews. Vol. 31, ed. Joan Marlow and Betty Blake (New York: Critics' Theatre Reviews Inc., 1970), 262.

${ }^{213}$ Gottfried, 261.

${ }^{214}$ Ibid. 
Gottfried also cheered the musical's overall tenor, describing the piece as "unsentimental and sometimes unemotional" and crediting these qualities to its sophistication (as compared to Golden Age works) and its "frightening" candor concerning the complexities of married life. ${ }^{215}$ Walter Kerr maintained a similar view and also saw the musical as a timely innovation; however, his review for The New York Times employed somewhat stronger language: "The mood is misanthropic, the view from the peephole is jaundiced, the attitude middle-aged mean. That, of course, is a highly original stance for a Broadway musical to be taking, and the fact of the matter is that just about everything else in Company is equally original and uncompromising. ${ }^{, 216}$ Without providing much in the way of explanation, Kerr attributed the musical's tone to the mood of the prevailing zeitgeist; consequently, his praise of Company derived from its critique of present day mores. As he stated, "It gets right down to brass knuckles without a moment's hesitation, staring contemporary society straight in the eye before spitting in it. ${ }^{\text {217 }}$ Barnes also recognized Company's contemporaneity, but found it less compelling than Gottfried or Kerr. In his view, the musical's dramatis personae resembled present day Manhattanites too well, and cited their mostly upper-middle-class married problems as maudlin and grating: "In the first place these people are just the kind of people you expend hours each day trying to escape from ... Go to a cocktail party before the show and when you get to the theatre you can have masochistic fun in meeting all the lovely, beautiful people you had spent the previous two hours avoiding. ${ }^{, 218}$ Despite these

${ }^{215}$ Ibid.

${ }^{216}$ Walter Kerr, "Company: Original and Uncompromising," New York Times, May 3, 1970, in New York Critics' Theatre Reviews. Vol. 31, ed. Joan Marlow and Betty Blake (New York: Critics' Theatre Reviews Inc., 1970), 263.

${ }^{217}$ Ibid.

${ }^{218}$ Barnes, 262. 
allegations, the critic tacitly acknowledged congruence between the world of the play and the current social milieu.

Beyond these assessments of the musical's tone and structure, only one of the ten critics to review Company remarked its ties to the present culture directly. In his appraisal of the musical's score, Douglas Watt of The Daily News noted, “Though Sondheim obviously has been listening to the sounds of today, he wisely favors his own which apply perfectly to the 30 ish crowd on stage." 219 The dearth of commentary related to time suggests that critics of the period did not view the musical as overtly connected to the present. Where reviewers of Hair catalogued the various ways in which the musical aligned with its zeitgeist, Company's critics seemed to subtly suggest that the work's artistic novelty made it a musical for the present cultural moment.

Company ran on Broadway for 705 performances and recouped all of its initial financial investment. In addition to Dean Jones, the ensemble featured the indomitable Elaine Stritch as alcoholic socialite Joanne, Broadway regulars such as Barbara Barrie (Sarah), Charles Braswell (Larry), Beth Howland (Amy), and Donna McKechnie (Kathy), and several talented newcomers including Susan Browning (April), Charles Kimbrough (Harry), Pamela Meyers (Marta), and Teri Ralston (Jenny). Larry Kert, West Side Story's original Tony, replaced Jones two weeks into the run and stayed with the production until it closed on January $1,1972 .{ }^{220}$ By the end of the 1970-1971 Broadway season, the musical earned a New York Drama Critics Circle Award, five Drama Desk Awards, and seven Tony Awards of a record fourteen nominations, including the award

${ }^{219}$ Douglas Watt, “Company Has Brilliant Fun with Couples in Manhattan,” Daily News April 27, 1970, in New York Critics' Theatre Reviews. Vol. 31, ed. Joan Marlow and Betty Blake (New York: Critics' Theatre Reviews Inc., 1970), 260. members.

${ }^{220}$ See Appendix F for a complete list of the production's cast and production team 
for Best Musical and individual honors for Sondheim, Furth, Prince, and scenic designer Boris Aronson. The musical's cast recording also won Sondheim his first of eight Grammy Awards for Best Musical Theatre Album. Eleven months into the Broadway run, a national tour of Company launched at the Ahmanson Theatre in Los Angeles with George Chakiris in the role of Robert. Elaine Stritch left the Broadway production to tour as Joanne. Several of her original cast mates, including Howland, McKechnie, and Meyers joined the road production for the first months of its year long, eighty-six city journey. Seventeen days after the Broadway production shuttered, a third production of Company opened at Her Majesty's Theatre in London where the musical played a brief, but critically lauded 344 performances. Kert, Stritch, and a handful of other members of the Broadway Company traveled across the Atlantic to reprise their roles. While the West End production closed at a loss, the show earned, according to Craig Zadan, "the best reviews any musical received in British theatre history." ${ }^{221}$ By the time that the West End production ended its run on November 4, 1972, Company was both a proven creative success and landmark achievement in musical theatre history. Lehman Engel confirmed the work's import in Words with Music, dedicating a significant portion of the book's final chapter to an analysis of Company. The conductor repeatedly referred to the musical as "significant" and in the final moments of his chapter declared it "the best new show since West Side Story and Fiddler on the Roof, and let us be eternally grateful for that and especially for Stephen Sondheim and Harold Prince, who produced and directed it.",222 Engle, the leading authority on musical theatre for much of the 1970s, gave Company a

${ }^{221}$ Zadan, 147.
${ }^{222}$ Engel, 425. 
place of distinction within the American musical repertoire. Later musical theatre historians would follow suit and also cite the work as significant.

\section{BROADWAY REVIVAL}

Despite its accolades and status as a landmark work, Company did not receive its first Broadway revival until twenty-five years after the close of its original production. When the musical returned to Broadway in 1995, cultural attitudes toward marriage had changed significantly since its 1970 premiere. Between 1960 and 1980, the American divorce rate more than doubled with the institution and spread of no-fault divorce laws. ${ }^{223}$ Consequently, the concept of divorce began to lose its social stigma and entered the cultural vernacular, particularly through popular entertainment. Norman Lear's hit situation comedy One Day at a Time premiered in 1975 and depicted life after divorce as generally fruitful and fulfilling for nine seasons. Films such as Kramer v. Kramer (1979), The Four Seasons (1981), The War of the Roses (1989), When Will I Be Loved? (1990), and Husbands and Wives (1992) proliferated and projected the dissolution of marriage as both a heartbreaking trial and a source of comedy. By 1995, American culture had acclimated to divorce narratives and recognized that marriage was no longer a cultural imperative, but rather a matter of personal choice. Coontz affirms that Americans began to exercise more discretion in when they married and that the percentage of singles in their late twenties increased from one in ten circa 1960 to roughly forty percent by 1998 . Moreover, the number of couples cohabitating outside of marriage increased sevenfold

${ }^{223}$ W. Bradford Wilcox, “The Evolution of Divorce,” National Affairs, Vol. 1 (2009): 81. 
between 1970 and $1990 .{ }^{224}$ Reflecting on this shift in cultural mores, Coontz noted that the years following the sexual revolution "displaced [marriage] from its pivotal position in personal and social life." ${ }^{225}$ Thus, the prevailing zeitgeist at the time of Company's first Broadway return was one in which the cultural imperatives over marriage had diminished. Where Robert's avoidance of marriage perplexed his married friends in 1970 and marked him as wayward, the social milieu at the time of Company's first revival seemed to suggest that it was they who were errant.

Produced by the Roundabout Theatre Company, the 1995 Broadway revival of Company was directed by Scott Ellis and choreographed by Rob Marshall. William Ivey Long and Tony Walton designed the revival's costumes and scenery respectively. The production opened at the Criterion Center Stage Right Theatre on October 5, 1995 after forty-three previews and featured actor Boyd Gaines as Robert. Gaines, fresh from his Tony Award winning performance in Ellis's 1994 revival of Bock and Harnick's She Loves Me, battled viral laryngitis throughout the production's short run and missed several performances. Standby James Clow portrayed Robert in Gaines's absence. Ellis cast Deborah Monk, a 1993 Tony winner for Lanford Wilson's Redwood Curtain, in the role of Joanne. The production also featured performances from the accomplished Kate Burton (Sarah) as well as several up-and-coming Broadway actors including Danny Burstein (Paul), Veanne Cox (Amy), Charlotte d'Amboise (Kathy), and Jane Krakowski (April). ${ }^{226}$ Ellis's directorial approach to Company involved conceiving the musical's episodes as a series of flashbacks in the protagonist's mind. Prior to joining his friends

${ }^{224}$ Stephanie Coontz, Marriage, A History: From Obedience to Intimacy or How Love Conquered Marriage (New York: Viking, 2005), 264.

${ }^{225}$ Ibid., 280. members.

${ }^{226}$ See Appendix G for a complete list of the production's cast and production team 
for his annual "surprise" birthday party, Robert stood outside his uptown apartment and reminisced about times spent with the married couples. As the director explained:

The play takes place in the split second before he walks into this birthday partyat least that's how I'm perceiving it—and, at that moment, Bobby is asking himself, 'Am I going to go in and celebrate my birthday with my friends, or am I not going to walk in and realize that I can't be dependent on them anymore, that I've got to be by myself to be able to commit to somebody?' At that moment he has that flash, and snapshots of his life with these friends pass before him. ${ }^{227}$

Unlike Harold Prince, who accepted the musical's fragmented form as an exercise in Pinteresque dramaturgy, Ellis attempted to apply a narrative logic to Company in order to rationalize its anecdotal structure. Ellis also set Company's action in a temporally indistinct era. Where the Playbill to Company's original production identified both its geographic and temporal setting, the revival's Playbill listed only the musical's locale and gave no indication of when Company's action would occur. Ellis's choice to forgo historical specificity was, by his admission, an attempt to remove the musical from the landscape of the Nixon era and make the musical appear timeless: "I don't put a date on it. There are hints of the 70s. There are hints of today. It can be anytime. It's not about the 70s. You're dealing with a man who's not able to commit and that certainly is very viable today . . our goal has been to focus on the story, not the time. ${ }^{, 228}$ Viewing Robert's emotional conflict as perennial, Ellis aimed to extricate Company from the 1970s by removing any instances of overt temporal designation. The director's chosen method for accomplishing this goal, however, appeared to belie his own rhetoric as Ellis and his creative team interwove visual and aural signifiers of both the current era and the 1970s throughout the revival — a choice which caused the musical to reference two eras

${ }^{227}$ Quoted in Harry Haun, “Company Man,” Playbill 95.9 (1995): 47.

${ }^{228}$ Quoted in Paul Wontorek, "Scott Ellis Directs Company," Theatre Week 9.8 (1995): 9. 
simultaneously. Ellis justified his vision by claiming that any attempt to set the musical in the 1990s would only serve to date the piece again in later years. ${ }^{229}$ Therefore, his method of removing Company from its original era would require that the musical exist somewhere between the past and the present.

Both Furth and Sondheim collaborated with Ellis on the Roundabout revival, making slight amendments to the libretto and lyrics that served the director's temporal conceit by introducing aspects of the current social milieu to the musical's text. With only a handful of exceptions, the original book remained largely intact. Furth's modifications were relatively minor, cosmetic in nature, and had no significant bearing on the musical's plot; however, they did help to reflect the changes in beliefs and values that occurred since Company's inaugural production. For example, Robert more readily referred to his paramours as "women" than "girls." This slight shift in designation evinced the changes in the collective discourse on gender that occurred in the United States as a result of the second and third waves of feminism. However, two of Furth's revisions, presumably made to accommodate Ellis's casting choices, were more notable. For the revival, Furth aged the bachelor three years, thus making Robert's thirty-eighth birthday the musical's stated occasion. While Furth might have added years to the bachelor's life in an effort to bring the character's age closer to that of his portrayer (Boyd Gaines was forty-two at the time of the production), his choice arguably helped to make Robert's single status appear more conspicuous to a present day audiences, thereby justifying the concern of his married friends. Furth's second revision addressed the subject of race and highlighted Robert's obliviousness to matters of racial diversity. In

\footnotetext{
${ }^{229}$ Olson, 57.
} 
Company's original libretto, the bohemian Marta goaded Robert for his lack of first-hand experience with diverse populations:

MARTA: How many Puerto Ricans do you know?

ROBERT: I'm not sure.

MARTA: How many blacks?

ROBERT: Well, very few, actually. I seem to meet people only like myself. ${ }^{230}$

Marta would go on to explain that she identified with the city's various minority groups and made a point to build relationships with persons of diverse ethnic and racial backgrounds. The casting of the original production confirmed Robert's response to Marta's question as all of his friends and female consorts (including Marta) were played by white actors. According to Sondheim, Furth imagined Marta as "a feisty, outspoken, quintessentially New York Jewish girl” whose earthy downtown persona would stand counter to his Upper East Side cohort. ${ }^{231}$ The libretto, however, rewrote the part to fit the talents of Marta's first portrayer, Pamela Meyers, who Sondheim described as "blond, Midwestern, looked like a 4-H poster girl and was about as Jewish as the squeaky-clean MGM ingénue June Allyson, whom she distantly resembled. ${ }^{232}$ Costume helped to distinguish Marta as a free spirit, and therefore dissimilar from Company's other Manhattanites. However, as portrayed by Meyers, the character assumedly enjoyed white privilege, and her claim of identifying with minority groups might have appeared disingenuous to the musical's first audiences. For the Roundabout revival, Ellis cast black actor LaChanze in the role of Marta, a choice that added racial diversity to the production's otherwise white ensemble and also further established Marta as an outsider. As Marta never made reference to her own racial heritage in Company's original libretto,

\footnotetext{
${ }^{230}$ Ibid., 60.

${ }^{231}$ Sondheim, 180.

${ }^{232}$ Ibid.
} 
Ellis's casting did not contradict Furth's text. While Marta's original dialogue remained unchanged, Furth altered a single line in Robert and Marta's exchange so that the bachelor might acknowledge his bohemian paramour's racial identity:

MARTA: How many Puerto Ricans do you know?

ROBERT: I'm not sure.

MARTA: How many blacks?

ROBERT: Aside from you? None. ${ }^{233}$

This slight revision to the text represented the only instance in which characters discussed and acknowledged race. However minor, Furth's textual amendment (combined with Ellis's casting) represented a notable divergence from Company's original production as it established that Robert could indeed have a relationship with someone from outside his circle of white friends. It also helped to lift what director Sam Mendes has called "the white middle-class chic New York curse, which is the thing that above all dates Company the most." ${ }^{234}$ Robert's enjoying a sexual relationship with a black woman might have raised audience eyebrows in 1970, a mere three years after the U.S. Supreme Court declared anti-miscegenation laws unconstitutional in their landmark ruling for Loving $v$. Virginia. However, as Ellis hoped to introduce present day values into the musical, the presence of an interracial relationship was relatively unremarkable in his production.

Even though Furth's textual revisions represented an attempt to insert present day signifiers into Company's text, nearly all of the original libretto's more explicit period references remained in the script used for the Roundabout revival. The only overt cultural allusion that Furth altered was Sarah's mention of Mary Baker Eddy. Sarah now

${ }^{233}$ Company: A Musical Comedy, by George Furth and Stephen Sondheim, directed by Scott Ellis, Roundabout Theatre Company, New York, November 29, 1995, VHS, Theatre on Film and Tape Archive at the New York Public Library for the Performing Arts.

${ }^{234}$ Quoted in Matt Wolf, Sam Mendes at the Donmar: Stepping into Freedom (New York: Limelight Editions, 2003), 28-29. 
proclaimed pastry manufacturer Sara Lee as "the most phenomenal woman since Eleanor Roosevelt." ${ }^{325}$ This substitution allowed Furth to retain the essence of his original joke, but also to utilize a figure more recognizable to modern audiences. Conversely, the original libretto's period references were more dated in 1995 than they had been in 1970 and their presence within the musical's text kept Company connected (at least in part) to the past.

Sondheim's contributions to the Roundabout's production were considerably less than Furth's as the composer made only one significant revision to his lyrics for the revival — a substitution that represented both noteworthy change and an exercise in political correctness. Sondheim's original lyrics for "You Could Drive a Person Crazy" presented a list of situations or scenarios in which Robert's girlfriends could excuse a man's inability to commit to them. The original quatrain read:

\section{COULD UNDERSTAND A PERSON, IF IT'S NOT A PERSON'S BAG I COULD UNDERSTAND A PERSON, IF A PERSON WAS A FAG ${ }^{236}$}

Defending his initial lyric, Sondheim explains that he never viewed his word choice as potentially objectionable: "In 1970, the word 'fag' was only faintly demeaning, perfectly appropriate for the girls' annoyance without being offensive to the audience. [In 1995,] it sounded not only offensive, but old-fashioned, so I changed it."237 The composer's revised lyric, which now appears in all published and licensed versions of Company's libretto, read as follows:

${ }^{235}$ Company: A Musical Comedy, by George Furth and Stephen Sondheim, directed by Scott Ellis, Roundabout Theatre Company, New York, November 29, 1995, VHS, Theatre on Film and Tape Archive at the New York Public Library for the Performing Arts.

${ }^{236}$ Furth, 46.

${ }^{237}$ Sondheim, 177. 
I COULD UNDERSTAND A PERSON,

IF HE SAID TO GO AWAY

I COULD UNDERSTAND A PERSON

IF HE HAPPENED TO BE GAY ${ }^{238}$

In removing "fag," a pejorative in present parlance, Sondheim helped to bring his musical into the post-Stonewall era. While the gay liberation and gay rights movements made strides throughout the 1970s and 1980s, the collective discourse on homosexuality was still relatively tenuous at the time of the revival due to the AIDS epidemic and the lobbying efforts of Conservative Christian organizations such as The Christian Coalition and Focus on the Family to oppose gay rights issues. Thus, Kathy, April, and Marta's change of word choice reflected a more careful and considerate parlance.

While Company's book and lyrics remained relatively unchanged for Ellis's production, the musical's score received a notable makeover. In order to accommodate the Roundabout's budget and space constraints, original orchestrator Jonathan Tunick reduced the musical's instrumentation from twenty-four pieces to nine, removing much of the doubling originally used in the brass and string sections. Synthesizers replaced the missing instruments, effectively digitizing Sondheim's songs and causing them to sound strikingly modern. Tunick also eliminated the quartet of female pit singers, and in doing so, excised one of the most prominent musical signifiers of the late 1960 s present in the original score. "Tick-Tock," the song that had featured the Vocal Minority most prominently in 1970, became a purely instrumental number. Tunick re-orchestrated "Tick-Tock," using synthesizers to stand in for the missing pit singers. His efforts, however, created something of a musical anachronism - a song written in an expressly 1960s idiom, but performed with present day digital instrumentation.

\footnotetext{
${ }^{238}$ Ibid.
} 
Anachronism also characterized the revival's physical production, which appeared to be a conscious collection of visual signifiers that recalled the early 1970s and the 1990s simultaneously. William Ivey Long's costume designs mirrored fashion trends of the late 1960s. April wore a periwinkle air hostess uniform, an image made complete by a pillbox hat. Free-spirited Marta sported gold go-go boots and hot pants. Amy and Jenny's dresses cast baby-doll and shirtwaist silhouettes respectively—patterns that emerged in the late 1950s and gained popularity throughout the 1960s. The rest of the ensemble wore more contemporary garments with period accessories or accents. With the exceptions of Joanne and Larry (who were dressed for cocktail hour), several of Robert's friends sported the casual, comfortable, slightly oversized looks that typified the Clinton era. In 1970, Company's married set were chic and stylish uptowners. In 1995, many of them appeared to have walked off the set of Seinfeld or Mad About You.

Long's costumes, a visual pastiche in bright jewel tones - emerald, amethyst, ruby, and sapphire - provided contrast for Tony Walton's stark and relatively monochromatic scenic design. A student of Boris Aronson, Walton devised three Art Deco inspired, cantilevered platforms that supported the production's ambiguity by recalling several eras at once. The unit featured black-mirrored glass and four winding staircases with aluminum handrails. A large clock face with Roman numerals hung above the playing space to suggest what the designer felt to be "the pressure of time on Robert's decisions." 239 This same image appeared on the stage's faux marble floor and provided the ensemble with points of reference for arranging the production's few pieces of furniture. Budget and space limitations prohibited Walton from designing scenery for Company that would compare to Aronson's in terms of scale. Where the original designer

${ }^{239}$ Robert Sandla, “Designer Sketchbook: Company,” TCI 30.1 (1996): 62. 
used size and chiefly perpendicular lines to evoke the feeling of a towering urban jungle, Walton employed perspective to suggest a more disorienting environment. His platform unit was intentionally asymmetrical and suggested a surreal turn by featuring lines that were slanted, twisted, or gibbous in nature. Walton's aesthetic then supported Ellis's concept of Company's action as an extended daydream as did the cityscape projected on the theatre's cyclorama. An assortment of skyscrapers in silhouette with yellow lights against a midnight blue sky, the backdrop depicted a glittering "city playground after dark. ${ }^{240}$ At various moments, the romantic New York skyline transformed into letters spelling out Robert's various nicknames—Bobby Baby, Bobby Bubi, Robert Darling, and so on.

Nearly every reviewer of Ellis's revival heralded the Broadway return of Sondheim's score and applauded the efforts of the production's talented cast; however, only three of thirteen critics gave the production a relatively favorable notice. Eight reviewers chided Ellis's direction with many citing his treatment of time as the production's chief failing. The choice to abjure a specific temporal setting in favor of overlapping decades confused Brad Leithauser of Time, who pointedly asked, "Is [Robert] living in the 70s or the 90s? The production uneasily straddles the two eras."241 Vincent Canby of The New York Times expressed a similar view and described the production as having "a split personality that only the incandescent Sondheim score renders irrelevant." ${ }^{242}$ Ken Mandelbaum, writing for Theatre Week, remarked that the revival's evocation of multiple time periods created a cognitive dissonance that setting

\footnotetext{
${ }^{240}$ Ibid.

${ }^{241}$ Leithauser, 446.

${ }^{242}$ Canby, 452.
} 
the musical in its original milieu would have solved. ${ }^{243}$ For other critics, the choice to gesture to 1970 at all eclipsed any visual references to the present moment. Variety's Jeremy Gerard viewed the musical as a period piece and believed that Long's costumes and Ellis's direction worked in concert to create an affectionate, albeit forced caricature of the $1970 \mathrm{~s} .{ }^{244}$ Similarly, the images summoned by the revival's mise-en-scène caused Linda Winer of Newsday to believe that Company's action still took place in $1970 .{ }^{245}$ By and large, reviewers of the Roundabout revival did not see Ellis's production as presenting a timeless musical. With only minimal changes to Company's libretto and a physical production composed chiefly of anachronisms, many critics dismissed the production as dated or disorienting.

In addition to assessing the execution of Ellis's directorial approach, several critics compared the revival to Company's original Broadway production, commenting on the novelty and creative achievement that the musical represented in 1970 and alluding to the important and allegedly peerless contributions of Prince, Aronson, and Bennett before mentioning the revival. Barnes labeled Tony Walton's set as "a poor substitute for Aronson's fascinating homage to the American elevator. ${ }^{246}$ Michael Feingold of The Village Voice similarly fixed on the revival's scenery, stating, "Where Boris Aronson's complex metal structure made terrifying objective correlative for the

${ }^{243}$ Ken Mandelbaum, "Company," review of Company by George Furth and Stephen Sondheim, directed by Scott Ellis. Roundabout Theatre Company, New York, Theatre Week, October 23, 1995.

${ }^{244}$ Jeremy Gerard, “Company," Variety October 9, 1995 in New York Critics' Theatre Reviews. Vol. 55, ed. Joan Marlow and Betty Blake (New York: Critics' Theatre Reviews Inc., 1995), 444.

${ }^{245}$ Linda Winer, “Company," Newsday October 6, 1995 in New York Critics' Theatre Reviews. Vol. 55, ed. Joan Marlow and Betty Blake (New York: Critics' Theatre Reviews Inc., 1995), 450.

${ }^{246}$ Barnes, 447. 
original, here we get only a bland space to echo Ellis's blandly competent staging." 247

Rob Marshall's dance routines received marked criticism for utilizing much of the same choreographic vocabulary employed by Bennett twenty-five years prior. Bennett famously designed dance steps for the largely non-dancing cast and staged numbers utilizing simple, but rhythmic movements that frequently called for the ensemble to vigorously beckon or reach for Robert. While critics praised Bennett's efforts in 1970, Marshall's work was mostly maligned. Barnes claimed that Marshall's choreography contained "undigested borrowings from Bennett" and appeared "second rate" by comparison. ${ }^{248}$ Winer and Gerard, along with John Simon of New York Magazine and Donald Lyons of The Wall Street Journal, joined Barnes in castigating the choreographer's steps as pale in comparison to those created by Bennett. The nature of these criticisms, combined with the fact that half of the major New York critics contrasted Ellis's revival with Prince's original, suggests that the memory of Company's first Broadway production was strong and remained in the minds of critics as they received the revival.

A handful of critics also looked to the past in assessing the musical's cultural relevance and alleged that the piece failed to correlate with the values of the current zeitgeist. Canby charged that Company's relatively misanthropic depiction of marriage and urban isolation, while novel twenty-five years earlier, was no longer startling and inadvertently rooted the musical to its original zeitgeist: "Though the new production pretends to be timeless, the talk of relationships and commitment forever anchors the

${ }^{247}$ Michael Feingold, "Musical Chores," The Village Voice 17 October, 1995 in New York Critics' Theatre Reviews. Vol. 55, ed. Joan Marlow and Betty Blake (New York: Critics' Theatre Reviews Inc., 1995), 447.

${ }^{248}$ Barnes, 447. 
show in the 1970s, when sending up such jargon seemed a wittier endeavor than it does in the 1990s." ${ }^{249}$ Leithauser also found the musical less compelling in revival and alleged that Robert's playboy behavior read as [patronizing] in the present day:

[Company] was celebrated for its punch. Here was an innovative, hard-hitting musical that trafficked in booze and pot, bile and cynicism, promiscuity and adultery. Yet these are the aspects of Company that seem most dated a quartercentury later ... Robert's dissatisfied juggling of the women he dates looks a little smug and patronizing. Evidently he doesn't realize he's suffering from Peter Pan syndrome - and a dozen other pop-psychological maladies illuminated on post70s talk shows.

Mark Steyn of The New Criterion believed that Ellis intended to depict the present day with his revival and claimed that the musical would require even more updating in order for Company to reflect the diversity of prevailing American attitudes towards marriage: "But Scott Ellis's revival tries to be timeless and, in so doing, exposes the dishonesty of the piece ... a similar group in the Manhattan of 1995 would include some marrieds, some divorcees, some significant others, probably a token gay couple—but none of them would feel obliged to be married or feel the need to hustle Bobby into it."250

The Roundabout Theatre Company's revival of Company closed on December 3, 1995, after a total of sixty performances. The production earned a Tony Award nomination for Best Revival of a Musical, as did Veanne Cox for her critically lauded performance as Amy. However, at the end of the 1995-1996 Broadway season, the revival failed to win a single award. Critically and commercially, the production was eclipsed by the season's other revivals, all of which were arguably less time-bound and featured a celebrated star turn: Christopher Renshaw's The King and I starring Donna

\footnotetext{
${ }^{249}$ Canby, 451-452.

${ }^{250}$ Mark Steyn, “Company \& Company,” New Criterion 14.3 (1995): 44.
} 
Murphy and Lou Diamond Phillips, Jerry Zak's A Funny Thing Happened on the Way to the Forum starring Nathan Lane, and Carol Channing's fourth Broadway appearance in Hello, Dolly! The season also featured Julie Andrews's long-awaited Broadway return in Victor/Victoria and the premiere of two relatively groundbreaking musicals that were much lauded for reflecting the current zeitgeist: Reg E. Gaines's Bring in 'da Noise, Bring in 'da Funk and Jonathan Larson's Rent. Compared to the season's other musical offerings, Company was somewhat out of place as it was neither a Golden Age musical nor a musical of the moment.

Following his 1995 revival of Company, Scott Ellis continued his relationship with the Roundabout Theatre Company as a Resident Director, helming productions of $A$ Thousand Clowns (1996) and 1776 (1997) before becoming its Associate Artistic Director in 1998. As restaging established works is tantamount to the company's mission, a significant number of Ellis's subsequent directing projects have been revivals, including The Rainmaker (1999), The Man Who Had All the Luck (2002), The Boys from Syracuse (2002), Twelve Angry Men (2004), Harvey (2012), and The Mystery of Edwin Drood (2012). His extensive career in the theatre has also included the development and direction of original musicals, such as Steel Pier (1997), The Adventures of Tom Sawyer (2001), The Look of Love (2003), and Curtains (2007), as well as new plays, including The Little Dog Laughed (2006). His collective directorial efforts have earned him six Drama Desk nominations, five Outer Critics Circle nominations, and six Tony Award nominations. Of these seventeen nods, the director won two Drama Desk Awards in 1991 for off-Broadway productions of A Little Night Music and The World Goes 'Round. He also earned an Outer Critics Circle Award for his widely praised direction of the 
Roundabout's 1993 production of She Loves Me. The director followed this accolade with his 1995 revival of Company. Ellis's previous directing credits, however, consisted almost entirely of revues, traditional well-made plays, and musicals with linear structures. Company, by comparison, represented his most conceptual project to date. While the critics' antipathy for the revival suggests Company was not the director's strongest production, his long and respected career in musical revivals indicates that he is not without talent.

\section{BROADWAY REVIVAL}

In 2007, nine months after the opening of Company's second Broadway revival, the Associated Press reported that the American divorce rate had fallen to its lowest level since 1970 and attributed the statistic to recent studies that revealed an overall decline in marriages and an increase in couple cohabitation outside of marriage. ${ }^{251}$ While the results of these studies suggested that social imperatives for marriage continued to weaken throughout the 1990s and early 2000s, a series of cultural debates over the definition and supposed sanctity of marriage were being waged as the United States entered the twentyfirst century. The popularization and proliferation of the Internet led to the creation of numerous dating websites. Additionally, a rash of reality television programs depicting courtship and possible marriage bombarded the airwaves in the early 2000s including, but not limited to Who Wants to Marry a Multi-Millionaire? (2000), The Bachelor (2002), The Bachelorette (2003), Joe Millionaire (2003), and Average Joe (2004). Conservative critics would deride these programs, but their overwhelming popularity and high ratings

${ }^{251}$ Associated Press, "U.S. Divorce Rate Falls to Lowest Level Since 1970," NBC News Online, May 10, 2007, accessed May 29, 2014, http://www.nbcnews.com/id/18600304/ns/ us_news-life/t/us- divorce-rate-falls-lowest-level/\#.U4ZAxK1dXoQ 
kept many of them viable for multiple seasons. Both of these trends represented a commercialization of coupledom that quietly implied that the previous method of finding a partner through happenstance was no longer viable. It also suggested that single life was more common than married life. Furthermore, the Massachusetts Supreme Judicial Court's ruling to permit same-sex marriages in 2004 sparked a culture war between gay rights activists and conservative opponents such as the National Organization for Marriage. While the next two U.S. states to legalize same-sex marriage would not do so for another four years, arguments over the changing face of American marriage and family ensued - arguments that were somewhat analogous to those over the broadening of marriage norms during the sexual revolution.

Company returned to Broadway in a production helmed by Scottish director John Doyle. Doyle's revival, a transfer from the Cincinnati Playhouse in the Park, opened at the Ethel Barrymore Theatre on October 30, 2006, and featured scenery by David Gallo and costumes by Ann Hould-Ward. The production's cast featured Tony nominees Raúl Esparza and Barbara Walsh in the roles of Robert and Joanne as well as twelve actormusicians who doubled as the production's orchestra. ${ }^{252}$ With the exception of Robert, each member of the ensemble contributed to the musical's accompaniment by playing multiple instruments on stage. Doyle's actor-musician concept was an approach that he introduced to Broadway audiences the previous season in his critically lauded revival of Sweeney Todd and developed over time in Great Britain during his tenures as Artistic Director of the Everyman Theatre in Liverpool and Associate Director of the Watermill Theatre in Newbury. According to Doyle, the initial inspiration to have actors accompany members.

${ }^{252}$ See Appendix H for a complete list of the production's cast and production team 
themselves was borne out of pragmatic need rather than a decided artistic agenda. When the director elected to stage Leonard Bernstein's Candide at the Everyman Theatre in 1992 and found that he was unable to pay the actors and instrumentalists needed for the operetta, he hired eight musicians to serve in both capacities. For the duration of the production, the ensemble of actors (with instruments in tow) sat at music stands across the upstage area and crossed downstage (sans instruments) to take part in their characters' book scenes. Doyle cultivated and refined this technique over the next fifteen years with productions of Carmen, Cabaret, Into the Woods, Fiddler on the Roof, and Sweeney Todd and worked to integrate both actor and instrument into the world of his chosen musical. As a result, characters carrying their instruments on stage became an accepted convention of his productions, and playing one's instrument a mode of character communication tantamount to singing. The director has charged that his actor-musician approach to directing aims to extend an audience's disbelief by presenting a version of reality that is highly theatrical: "[My technique] asks the audience to take a journey that goes beyond their preconception of what real life is. I suppose you could say that it takes you to ... an abstraction of reality. That's what I'm interested in more than anything ... what it does to the relationship between the actor and the audience. ${ }^{, 253} \mathrm{He}$ has also claimed that inherently non-realistic musicals, as well as works in which song serves as characters' primary mode of expression, supported his approach best. ${ }^{254}$ Company's episodic structure, combined with its varied uses of music and its surrealistic leanings made the musical well-suited for Doyle's distinctive brand of theatre making.

${ }^{253}$ John Doyle, "John Doyle," interview by Howard Sherman and John von Soosten, Podcast Downstage Center, XM Satellite Radio and the American Theatre Wing, New York: November 24, 2006.

${ }^{254}$ Ibid. 
Doyle's actor-musician concept endowed Company with a potent new allegory for marriage and served to further highlight Robert's outsider status. The bachelor, in characteristic fashion, quietly observed as his friends created music together throughout the evening. As Ben Brantley of The New York Times noted in his review of the production, "Bobby's failure to pick up an instrument and join the band becomes a natural-born metaphor for his refusal to engage with others ... as the other cast members [play] their instruments, it is clear they possess talents for connecting that Bobby lacks, fears and longs for. ${ }^{, 255}$ Furthermore, the ensemble and their instruments remained on stage - visible to the audience - throughout the production. Cast members would occasionally step out of the actor-orchestra to take part in a scene; however, the visual image of a collective musical ensemble loomed large over the production. For the majority of the production, Robert stood in one place while the ensemble sang to him or marched around him. Robert made two attempts to join the instrument-wielding ensemble, the first of which occurred during the last moments of the second act opener, “Side by Side by Side.” Sondheim's number originally included breaks for four call-andresponse tap dance routines. Designated married couples performed the first three routines with one spouse starting and the other spouse finishing the eight-count step. Robert initiated the fourth and final routine, and although he executed his tap sequence perfectly, no one responded. Both Prince and Ellis's production featured this bit of staging. For his revival, Doyle translated the mode of expression used in this moment from dance into music. Rather than calling and responding to each other though tap, three

${ }^{255}$ Ben Brantley, “A Revival Whose Surface of Tundra Conceals a Volcano," review of Company by George Furth and Stephen Sondheim, directed by John Doyle. Ethel Barrymore Theatre, New York, New York Times, November 30, 2006. 
couples stepped forward, and each spouse performed a four-count solo that demonstrated the virtuosity of their musicianship. Robert, assigned to the fourth break as before, stepped forward and blasted an indistinct note on a small kazoo — an instrument that requires virtually no training or technique. As in the productions that preceded it, Robert's call received no response and his effort to join the orchestra was marked as unsuccessful. The bachelor attempted to join the ensemble a second time during the musical's penultimate scene. Upon hearing the final reprise of the recurring "Bobby Baby" motif, Robert sat down at a grand piano, and with great tentativeness, accompanied himself in the final number, "Being Alive." The piano line created by orchestrator Mary-Mitchell Campbell began very simply and required Robert to play only sustained chords. As Robert's resolve grew, however, the piano accompaniment slowly increased in both speed and difficulty, aurally demonstrating a paradigm shift within the character. Robert's hidden fear of isolation and his newfound desire for partnership suddenly manifest in not only his ability to join the orchestra, but also in his ability to play a musical instrument with great skill. Through his actor-musician approach, Doyle supplied Company with a new metaphor for interpersonal relationships and explicated it in both visual and aural terms. Robert's struggle to connect or commit to another person was reflected in his struggle to make music.

Doyle's revival utilized a moderately revised libretto that Furth developed in collaboration with British director Sam Mendes for a production of Company at London's Donmar Warehouse in 1996. For this new libretto, Furth changed Robert's age back to thirty-five and removed all of the musical's overt period references save for mentions of Eleanor Roosevelt, Ann Miller, and The Red Shoes. The period references found in 
Sondheim's lyrics, however, remained untouched. Furth also truncated the first party scene and inserted a prologue in which various friends and lovers left messages on Robert's answering machine. This dramaturgical device helped to provide exposition and clarified the nature of Robert's relationships with those individuals who left messages. Olson suggests that it also re-conceptualized the musical's opening number as a series of one-sided messages that justified the couples' incessant clamoring for the bachelor's attention. ${ }^{256}$

Furth's other notable revision arguably helped to develop Robert's character and quell previous speculation about the bachelor's sexual orientation. The librettist restored a conversation between Robert and the newly divorced Peter that had been cut from the original libretto during the first production's Boston tryout. When Robert suggested that both he and his friend were too "square" for younger companions, Peter asked Robert if he ever had a sexual encounter with another man:

PETER: Robert, did you ever have a homosexual experience?

ROBERT: I beg your pardon?

PETER: I don't mean as a kid. I mean, since you've been adult. Have you ever?

ROBERT: Well, yes, actually, yes, I have.

PETER: You're not gay, are you?

ROBERT: No, no. Are you?

PETER: No, no, for crissake. But I've done it more than once though.

ROBERT: Is that a fact?

PETER: Oh, I think sometimes you meet somebody and you just love the crap out of them. Y'know?

ROBERT: Oh, absolutely, I'm sure that's true.

PETER: And sometimes you just want to manifest that love, that's all.

ROBERT: Yes, I understand. Absolutely.

PETER: Oh, I'm convinced that two men really would, if it wasn't for society and all the conventions and all that crap, just go off and ball and be better off for it, closer, deeper, don't you think?

${ }^{256}$ Olson, 54. 
ROBERT: Well, I-I don't know.

PETER: I mean like us, for example. Do you think that you and I could ever have anything like that?

ROBERT (Looks at him for a long and uncomfortable moment. Then a big smile): Oh, I get it. You're putting me on. Man, you really had me going there, you son of a gun. ${ }^{257}$

This new exchange represented a substantial change from previous stagings of Company in that it introduced queer sexuality to the musical's narrative-something that existed as speculative subtext in Prince and Ellis's productions. The thirty-six years between Company's original production and Doyle's revival witnessed several Broadway musicals that featured gay characters such as La Cage aux Folles (1984), Falsettos (1992), Kiss of the Spiderwoman (1993), Rent (1996), Avenue $Q$ (2003), The Boy from Oz (2003), and Taboo (2004). Moreover, the years between Ellis and Doyle's revivals saw marked increase in gay visibility across popular entertainments, particularly in television shows. The protagonist of Ellen DeGeneres's self-titled ABC sitcom came out as a lesbian in 1997 soon after DeGeneres herself publicly declared her own sexual identity. Programs featuring gay characters in leading roles such as Will and Grace (1998), Queer as Folk (2000), Six Feet Under (2001), and The L Word (2004) soon followed, as did feature films such as In and Out (1997), The Object of My Affection (1998), Boys Don't Cry (1999), Capote (2005), and Brokeback Mountain (2005). Despite Robert's admission of having shared a sexual experience with another man, Robert did not come out as gay, and Sondheim vehemently maintains that the character is heterosexual. Even so, by 2006 social attitudes toward sexual orientation and identity had shifted just enough for Robert to mention his queer past and for Peter to suggest his queer future.

${ }^{257}$ Furth, Company (1996), 102. 
Sondheim's score remained unchanged for the revival, with one notable exception. Doyle cut "Tick-Tock" from the musical's second act, thereby removing Company's most prominent vestige of the 1960s. Doyle's actor-musician concept also necessarily altered Company's orchestrations. To service Doyle's staging needs, MaryMitchell Campbell reduced the score's instrumentation to a grand piano along with select brass, strings, and winds. In total, the ensemble of thirteen played thirty-two instruments, none of which produced electric or digital sounds. ${ }^{258}$ As Rick Pender suggested, these new orchestrations "washed away most of the late-60s pop tonalities" of the musical's score and transformed Company into an evening of instrumental chamber music. ${ }^{259}$ Additionally, the ensemble played instruments that matched the personality or temperament of their characters. The effervescent Sarah played a lilting flute and piccolo. Frenetic and emotionally overwrought Amy blared her frustrations on the French horn and trumpet. Disinterested Joanne sporadically contributed to the ensemble, but only played instruments that required a modicum of exertion of effort. On occasion, she coolly tapped a triangle, a glockenspiel, and a vodka glass. While Doyle and Campbell selected instruments based on the needs of Company's score first, they also gave strong consideration to what instrument given characters might use to express themselves and also - in the case of the married couples — how they might a create a musical language for those instruments. ${ }^{260}$ Consequently, several couples played the same instrument or complementary instruments. Peter and Susan played the piano both separately and

${ }^{258}$ See Appendix H for a complete list of the instruments played by each actor.

${ }^{259}$ Rick Pender, "Thoughts Shared, Souls Bared: Company Returns to Broadway via John Doyle and 14 Actor-Musicians," The Sondheim Review 13.3 (2007): 8.

${ }^{260}$ Doyle interview. 
together. Amy and Paul shared the score's brass lines. David's cello along with Jenny's violin and double bass made up the orchestra's string section.

Whereas Doyle's actor-musician vision for Company simplified the musical's sound, his physical production likewise embraced simplicity. Scenic designer David Gallo set Company's action in a sleek Upper East Side loft whose only furnishings consisted of a single cast-iron Corinthian column surrounded by a steam radiator, three Plexiglas cubes, a Steinway grand piano, a rolling bar cart, and a vase of calla lilies. The apartment itself featured a floor made of blonde wood, a single brick wall painted black, and forty-nine identical lighting fixtures hung across the ceiling — an arrangement meant to recall the lobby of New York City's Whitney Museum. ${ }^{261}$ Contrary to prior designs created by Aronson and Walton, Gallo's scenery for Company did not include any semblance of a skyline or images meant to depict New York City writ large. Moreover, the designer made no attempt to suggest any of the physical settings prescribed by Furth's libretto visually. Every scene, regardless of its intended location, played out in Robert's apartment. Rather than traveling to Central Park, a nightclub, or the homes of his married friends as he had in previous productions, Robert remained at home while various characters intruded upon his living space. Situating the musical's episodes in the bachelor's home helped to support the director's vision of the other characters as "the demons in Bobby's head, the pictures on his walls ... the people who he needs to get away from if he's ever going to grow. ${ }^{262}$ Like Gallo, costume designer Ann Hould-Ward embraced a minimalist aesthetic. Utilizing an almost entirely black palate, Hould-Ward dressed the ensemble in designer apparel that reflected modern sensibilities, but did not

${ }^{261}$ Christa Skiles, "In Comes Company," Prologue: Celebrating Sondheim, Pre-Show Publication of Cincinnati Playhouse in the Park, (Cincinnati: March 2006), 5.

${ }^{262}$ Doyle interview. 
necessarily quote current trends. The classic cut and silhouette of the clothes - chosen from such fashion houses as Armani, Dolce and Gabbana, Hugo Boss, and Diane von Furstenburg - established Company's cast of characters as chic New York sophisticates. $^{263}$ The simplicity of Gallo’s scenery combined with the stylish uniformity of Hould-Ward's costumes kept the musical from citing its original era or any era in particular.

John Doyle's revival of Company received eight positive notices, four that were mixed, and only three categorical pans. Several reviewers cheered Doyle's use of actormusicians claiming that the approach helped to revitalize the musical. Variety's David Rooney described the director's concept as "illuminating" and claimed that the production prompted him to reconsider what he thought he knew about Company's characters, songs, and score. ${ }^{264}$ Likewise, Linda Winer of Newsday remarked that Doyle's production forced her to view the musical (a piece with which she was very familiar) through new eyes. As she enthused, "Somehow [Doyle] has made more than a few scenes seem so fresh, even daring, that we had to check the script to make sure we'd heard most of them before. ${ }^{, 265}$ Critics also alleged that the director's concept helped to loosen Company's bonds to its original zeitgeist. As Michael Sommers of The StarLedger noted, "Company looks and sounds like a contemporary show, rather than a

${ }^{263}$ Skiles, 5 .

${ }^{264}$ David Rooney, "Company," review of Company by George Furth and Stephen Sondheim, directed by John Doyle. Ethel Barrymore Theatre, New York, Variety, December 4, 2006.

${ }^{265}$ Linda Winer, "Bobby and Company Were Never So Together," review of Company by George Furth and Stephen Sondheim, directed by John Doyle. Ethel Barrymore Theatre, New York, Newsday, November 30, 2006. 
period piece ... the effect is one of deeper humanity than before. ${ }^{266}$ Rooney saw the revival's action as unfolding in "a ghostly chamber of the mind," and like Sommers, believed that the revival helped to align Company with the current moment: "Doyle's elegantly spare production is set in no specific time. Via certain lyrics and such period staples as a pot-smoking scene, it remains rooted in the 1970s, but bristles with anxieties that feel entirely contemporary. ${ }^{267}$ John Lahr of The New Yorker praised the production's nominal period signification, suggesting that the approach minimized the musical's setting and placed a greater emphasis on Sondheim's score. ${ }^{268}$ Counter to Ellis's revival, only one critic of fifteen made a direct comparison between Doyle's production of Company and Prince's original.

John Doyle's revival of Company closed on July 1, 2007 after 246 performances. Despite this relatively modest run, the production was critically decorated, winning the Drama Desk Award, the Drama League Award, the Outer Critics Circle Award, and the 2007 Tony Award for Best Revival of a Musical. For his portrayal of Robert, Esparza took home the Drama Desk Award and Outer Critics Circle Award for Best Actor in a Musical. He and Doyle also received Tony Award nominations. In a surprising reversal, Thomas S. Hischak contradicted his earlier claim concerning the musical's revivability and declared Doyle's production of Company a success. In an article written for PBS, the critic claimed that Doyle solved the problem of the musical's time-boundedness by

${ }^{266}$ Michael Somers, "Company," review of Company by George Furth and Stephen Sondheim, directed by John Doyle. Ethel Barrymore Theatre, New York, The Star-Ledger, November 30, 2006.

${ }^{267}$ Rooney.

${ }^{268}$ John Lahr, "Sour Ball: The Acid Thoughts of Stephen Sondheim and David Hare," review of Company by George Furth and Stephen Sondheim, directed by John Doyle. Ethel Barrymore Theatre, New York, The New Yorker, December 11, 2006. 
removing time from the production: "In the true concept musical, time is a convention that can be disposed of. The details of an era disappear and only the ideas remain."269 In the years following his Broadway revival of Company, John Doyle has continued to mount notable revivals of American musicals for theatres across the United States and throughout England. Moreover, he has cultivated a reputation for creative and innovative staging. The director continued to hone his actor-musician technique with a West End revival of Mack and Mable in 2006 and two productions of Merrily We Roll Along, one produced by the Watermill Theatre in 2008 and another staged by the Cincinnati Playhouse in the Park in 2012. The director's other recent credits include the Road Show at the Public Theatre (2008), Oklahoma! at the Chichester Festival Theatre (2009), Kiss Me Kate at the Stratford Festival (2010), Passion at New York's Classic Stage Company (2013), and The Color Purple at London's Menier Chocolate Factory (2013). Doyle received the Drama Desk, Outer Critics Circle, and Tony Award for Best Direction of a Musical in 2005 for his Broadway revival of Sweeney Todd, as well as nominations for all three awards in 2006 for Company. The nature and trajectory of his career suggests that Doyle, like Diane Paulus, is one of the foremost revivalist directors working in the musical theatre today.

\section{CONCLUSION}

While Company shares observable ties to its moment in time, the musical appears to be less dramaturgically determined by its original temporal setting than other timebound works. George Furth's libretto and Stephen Sondheim's lyrics contain

${ }^{269}$ Thomas S. Hischak, "Company and the Concept Musical," Great Performances, http://www. pbs.org/wnet/ gperf/shows/company/essay1.html (accessed November 11, 2009). 
substantially fewer cultural allusions and instances of period parlance than Hair.

Sondheim's score, which periodically referenced the popular musical idioms of the time, is largely a pastiche that employed a variety of styles from a variety of eras. Company made no mention of current events or foreign affairs, and despite the fact that the musical ran on Broadway during the final years of the Vietnam War, the musical did not engage with the prevailing political landscape. Consequently, Company provides little dramaturgical evidence of its temporal setting. The original production's creative team helped to confirm the musical's milieu as 1970 by incorporating the current trends in architecture and fashion into their designs; however, these period signifiers were largely ornamental and had little to no bearing on the musical's narrative.

Because Company's overt ties to its past are somewhat intermittent, it might appear that the musical's time-boundedness is largely superficial. However, Company's most significant connection to its zeitgeist was its depiction of evolving beliefs, assumptions, and values with respect to sex and marriage. The growing sexual revolution displaced the primacy of marriage in American culture and actively challenged Cold War metanarratives regarding matrimony and family. Moreover, the expanding definition of marriage presented new alternatives to partnership. Company arguably chronicled this ideological shift as it occurred. The musical's implicit critique of wedlock, combined with its decidedly unromantic portrait of married life suggests that Company's timebound nature does not derive from obvious signifiers, but rather the attitudes and behavior demonstrated by the musical's characters. The anxieties that Robert's married friends express over his single status and their respective confessions regarding the tenuous nature of their own partnerships are reflective of the musical's moment in time. 
Therefore, as Company's most substantial ties to its zeitgeist relate to values, customs, and ideologies, the musical's time-boundedness is somewhat elusive.

However inadvertently, Ellis and Doyle's respective approaches to reviving Company altered perceptions of the musical's temporal setting. Ellis's efforts to make the musical appear timeless resulted in a production that seemed to suggest two historical periods simultaneously. A mildly updated libretto and the introduction of aural and visual signifiers from the present culture did not remove the musical from its original moment in time, but rather forged new bonds between the musical and its revival context, therein making Company appear doubly time-bound. The critics' repeated claims of temporal confusion indicate that Ellis's attempts to manufacture timelessness were not particularly successful. Furthermore, their frequent allusions to Harold Prince, Boris Aronson, and Michael Bennett suggests that the memory of Company's original Broadway production was still strong, even after a twenty-five year absence from Broadway, and that Ellis and his creative team had not yet done enough to divorce their production from the original. Even so, the director's stated rationale seemed to recognize Company's propensity for time-boundedness and his chosen strategies for revival, while confusing to critics, represented an attempt to extricate the musical from its moment in time.

By contrast, Doyle's later revival of Company seemed to accomplish what Ellis's production could not. The director's actor-musician concept necessarily abstracted the musical's action, and consequently, removed most indications of time and place from the production - particularly the period signifiers present in Sondheim's score. Minimizing Company's temporal setting in this manner helped to confirm its relative inconsequence to the musical's dramaturgy. As a result, Doyle's production appeared to exist outside of 
time. With little signification to anchor it to a particular era, the musical's new temporal setting was once again imprecise. However, the critics' generally favorable reviews indicate that Doyle's brand of temporal ambiguity was not an impediment to reception. Doyle's revival then appeared more timeless than Ellis's in that temporality did not feature as prominently. Where Ellis's approach to revival only seemed to raise questions of time, Doyle's concept forestalled them. By decreasing impressions of realism, with actors playing musical instruments on stage, the director minimized a time-binding factor. Sondheim himself suggests that abstracting time is a sound strategy for staging Company. In a 2002 interview with Frank Rich, the composer seemed to anticipate Doyle's method of revival while castigating Ellis's concept: "People who try to update Company make a mistake, I think. It should either be performed as a 70s piece or with no date, but not with an attempt to make it 90 s or contemporary."270

Doyle's chosen approach to revival also seemed to represent a formal innovation that helped to rejuvenate Company by giving it a contemporary relevance. The musical's episodic structure and misanthropic tone, while uncommon and unsettling to theatregoers in 1970, were no longer unique by 2006. Doyle's production then represented a fresh approach to reviving Company. The director's actor-musicians provided a new and highly theatrical means for presenting the musical's content, which remained, with very few exceptions, largely unchanged. Consequently, Doyle seemed to restore the formal singularity that Company enjoyed thirty-six years earlier. The revival's reviewers barely mentioned Prince's production and focused instead on remarking the artistry of Doyle's new staging.

${ }^{270}$ Frank Rich, "Side by Side by Side," The American Theatre Reader: Essays and Conversations from American Theatre Magazine (New York: Theatre Communications Group, 2009), 493. 
Doyle's actor-musician technique also facilitated what may be the most significant accomplishment of his revival, in its revelation of Company's themes and inherent ideologies. The director's concept constructed a potent metaphor for marriage that helped to explicate the tension between Robert and his married friends visually. The bachelor's inability to sustain a partnership was represented by his removal from the actor-musician ensemble. Marked as a non-musical interloper, Robert watched his compatriots make music from a removed distance in the same manner that he watched them navigate married life. The married couples' concern over Robert's bachelorhood and their desire to seem him settled down registered as an eagerness for him to join the orchestra. Doyle's metaphor arguably lessened the thematic and ideological ties that Company shares with its original zeitgeist and helped to illuminate the somewhat more universal message that undergirds the musical.

Beyond its discussion of marriage, Company addresses the challenges associated with sustaining meaningful interpersonal relationships. This struggle is relatively perennial, keeping the musical from becoming exceedingly time-bound. While attitudes towards marriage and partnership have evolved since the musical's original production, the need for authentic connection to other beings has not. In the case of Company's two revivals, everything was different, but nothing had changed. The divorce rate and the social imperatives for marriage in 1995 and 2006 contrasted greatly to those from 1970, and while critics of both productions noted the potentially dated attitudes toward marriage, most noted that Robert's struggle remained relevant. As the difficulty of forging meaningful relationships only seems to grow with time, it is possible that Company will find continued relevance in the afterlife. Rapid changes in technology, the 
advent and proliferation of social media platforms, and the preponderance of dating websites and online social communities suggest that new challenges confront human beings in search of interpersonal relationships and that they are going to great lengths to meet them. It stands to reason then that Robert's journey will continue to compel audiences for years to come, providing directors continue to experiment with innovative ways of re-imagining that journey for future audiences. 


\title{
CHAPTER FOUR
}

\section{LOVE'S WHAT WE'LL REMEMBER: $A$ CHORUS LINE}

\author{
GONE \\ LOVE IS NEVER GONE \\ AS WE TRAVEL ON \\ LOVE'S WHAT WE'LL REMEMBER ${ }^{271}$
}

\section{BROADWAY PRODUCTION}

When the original 1975 Broadway production of A Chorus Line closed on April 28, 1990, after a record setting 6,137 performances at the Shubert Theatre, the musical was arguably the most successful piece of theatre-musical or otherwise - ever presented on the Great White Way. Playing to over 6.5 million theatregoers over the course of fifteen years, the production grossed over 150 million dollars and held the mantle of longest running musical in Broadway theatre history from 1983 to 1997 . The musical was also an unqualified critical success, receiving unanimous praise from the major New York critics when it premiered Off-Broadway at Joseph Papp's Public Theatre in April of 1975, three months prior to the start of its Broadway engagement. The musical's many artistic accolades included six Drama Desk Awards, a New York Drama Critics Award, an Outer Critics Circle Award, nine Tony Awards (including the award for Best Musical), and the 1976 Pulitzer Prize for Drama. Following its Broadway opening, $A$ Chorus Line toured North America for more than six years and spawned twenty-three international companies throughout Western Europe and in such countries as Australia, Japan, Argentina, Brazil, Singapore, Puerto Rico, New Zealand, and South Africa. The

${ }^{271}$ James Kirkwood and Nicholas Dante, A Chorus Line: The Book of the Musical (New York: Applause Books, 1995), 138. 
grosses from these productions would bring the musical's total earnings to over 280 million dollars. ${ }^{272}$ While later musicals such as Cats (1982), Les Misérables (1987), The Phantom of the Opera (1988), and The Lion King (1997) would eventually eclipse $A$ Chorus Line's many records, the musical ended its Broadway run in 1990 as an American cultural phenomenon, an international sensation, and a landmark achievement within American musical theatre history.

Conceived, directed, and choreographed by the inimitable Michael Bennett, $A$ Chorus Line told the tale of seventeen Broadway gypsies - dancers who earn their living performing in the ensemble — as they auditioned for a new, unnamed musical at an unspecified Broadway theatre. The setting was a final callback circa 1975, during which a director/choreographer known only as Zach sought to hire four men and four women for his dancing corps. After testing the dancers' talent and training through rigorous jazz and ballet combinations, Zach (portrayed by Robert LuPone) positioned the gypsies on a white line across the stage and asked each of them to step forward and introduce themselves. The director's interest in their personal lives then prompted him to inquire about their childhood, their adolescence, and the challenges that they now faced as adults working in the entertainment profession. The exchanges that followed—Zach's probing questions from the back of the house and the dancers' subsequent responses - constituted the majority of the musical's content.

Like Hair and Company before it, $A$ Chorus Line defied Golden Age convention in that it featured a relatively fragmented storyline. Rather than charting the linear journey of a single protagonist, the musical presented a vast array of characters all in

${ }^{272}$ Gary Stevens and Alan George, The Longest Line - Broadway's Most Singular Sensation: A Chorus Line (New York: Applause Books, 1995), 236. 
pursuit of the same goal: to win a place in Zach's ensemble. To this end, the gypsies worked to satiate the director's curiosity about their lives by answering his questions and presenting personal narratives of varying lengths. Mike Costa recounted his experience of observing and eventually joining his sister's dance class at the age of four. Sheila Bryant, Bebe Benzenheimer, and Maggie Winslow told of how training in ballet helped them to escape the unhappiness of their respective childhood homes. Diana Morales described how her dreams of becoming a serious actor were continuously challenged by a draconian instructor at New York City's High School for the Performing Arts. Valerie Clark revealed how altering her appearance vis-à-vis cosmetic surgery revitalized her lackluster dance career. During the musical's longest monologue, Paul San Marco disclosed the sexual abuse he endured as a child, his process of coming to terms with his homosexuality, and his parents' discovery of his secret life as a female impersonator. $A$ Chorus Line's libretto, a collection of these anecdotes and several other reminiscences, was then more collage than it was causal. In his analysis of the musical's structure, musicologist Joseph P. Swain describes the work and its audition premise as a frame story, a form that "emphasizes the low-level events, that is, the individual stories, at the expense of overall plot. The frame story sacrifices high-level tension and resolution, and puts in its place a series of small dramas, little waves of tension and resolution."273 Within the frame of the audition narrative, each confession represented a discrete episode. Furthermore, A Chorus Line's action unfolded in real time- - two hours sans intermission — and alternated between the world of Zach's callback and a surreal dreamscape where the dancers performed their respective memories, anxieties, and

${ }^{273}$ Joseph P. Swain, The Broadway Musical: A Critical and Musical Survey (New York: Oxford University Press, 1990), 311. 
private thoughts for the musical's audience. When the harsh white of the theatre's work lights dimmed and gave way to softer lavender hues, various members of the ensemble shared their inner monologues. This frequent interchange between reality and the dancers' minds further subdivided A Chorus Line 's plot into a series of distinct interludes.

Approximately three months prior to the end of A Chorus Line's run on Broadway, Lloyd Rose of Connoisseur Magazine suggested that the musical's remarkable success could be attributed in part to how well it reflected the cultural undercurrent of its historical moment. By his charge, the musical's central dramaturgical conceit of staged testimonials aligned with the dominant beliefs and reigning values that quietly guided American life in the mid-1970s:

If ever there was a show for the 'Me Decade,' A Chorus Line is it. For fifteen years, it has been packing in audiences and submitting them to confession after confession, as the dancers take their turns in the spotlight and reveal how much they suffer. Playwrights have always satirized the egotism, pettiness, self-pity, and self-importance of show people. A Chorus Line's stroke of dread genius was to take it all seriously. ${ }^{274}$

Rose's suggestion that A Chorus Line dramatized the Me Decade ethos — a claim that would be echoed by later musical theatre historians such as John Bush Jones, Stacy Wolf, and Gerald Mast — was then particularly astute, as the egoism described by Tom Wolfe and Christopher Lasch fueled the musical. Throughout A Chorus Line, characters stepped forward and offered their respective autobiographies to Zach. While these anecdotes occasionally took the form of spoken monologues, the dancers more frequently presented them in such songs as "I Can Do That," "At the Ballet," "Sing," "Nothing," "Dance: Ten; Looks: Three," and "The Music and the Mirror." These numbers afforded the characters

${ }^{274}$ Lloyd Rose, “Connoisseur’s World,” Connoisseur Magazine, February 1990, 30. 
that performed them the opportunity to distinguish themselves, however, temporarily, from the other dancers standing on Zach's line. As Wolf suggests, these numbers also reified and extended one of the musical theatre's primary conventions of articulating a protagonist's point of view and desires in musical terms through an "I Am/I Want" song. ${ }^{275}$ Where most Golden Age musicals traditionally featured a single "I Am/I Want" song early in their first act, the score to A Chorus Line featured seven such songs, making the work's individualistic bent both dramaturgical and musical.

A Chorus Line's fictional audition further represented a Me-Generation fantasy in that most of the stories the characters told were based upon the lives of the musical's original cast members. Compiled by Bennett and later adapted by book writers James Kirkwood and Nicholas Dante, as well as lyricist Edward Kleban, these discrete narratives were first shared during a much mythologized late-night gathering of two dozen professional dancers, assembled by Broadway gypsies Tony Stevens and Michon Peacock, on January 26, 1974. Bennett attended the meeting at Manhattan's Nickolaus Exercise Center and asked those present-many of them his friends and colleagues - - to speak to him about their lives as dancers. Much like Zach, Bennett asked those gathered a series of questions about their personal histories and then documented their responses using a reel-to-reel tape recorder. These interviews became the raw material for $A$ Chorus Line's final libretto, which would be developed and refined over six months of workshops at the Public Theatre. ${ }^{276}$ The authenticity of the dancers' highly personal histories combined with their eventual public presentation, following the 1970s trend of

${ }^{275}$ Stacy Wolf, Changed for Good: A Feminist History of the Broadway Musical (New York: Oxford University Press, 2011), 119.

${ }^{276}$ Robert Viagas, Baayork Lee, and Thommie Walsh, On the Line: The Creation of A Chorus Line (New York: William Morrow and Company, Inc., 1990): 24-38. 
encounter groups, reflected the decade's imperative to "let it all hang out." As historian David Frum suggests, “the public display of one's suffering, one's wrongs, one's pitiableness, one's misfortunes, which would have seemed shameful, ignoble, even disgusting before World War II, became in the 1970s the distinctive American national style."277 If confession was the vogue of the era, then A Chorus Line's libretto proved remarkably on trend. Over time, the persistent recounting of personal narratives transformed Zach's audition into something of a group therapy session, and the director's almost maniacal interrogation of the dancers prompted them to reveal-reluctantly at first - the painful, awkward, embarrassing, and devastating moments of their personal histories. Goaded by the director's questions, the gypsies took turns baring their souls to him in hopes that their candor might earn his favor. While A Chorus Line's central conceit was emblematic of mid-1970s values, its fifteen years on Broadway suggests that the musical remained suited to the zeitgeist even as the Me Decade gave way to the 1980s. Consistent ticket sales throughout the 1970s and 1980s indicate that audiences continued to find the musical pertinent as the years passed. Thus, the musical demonstrated a certain durability that preserved the dancers' stories for the duration of its Broadway run and suggested that $A$ Chorus Line might withstand the passage of time.

The durability of A Chorus Line's mythos would be tested when the musical returned to Broadway thirty-one years after its initial opening. In January of 2005, John Breglio, Michael Bennett's former lawyer and the executor of his estate, announced his plans to produce a revival of $A$ Chorus Line that would be-by design — a near replica of the original production. Several theatre journalists responded to Breglio's news with

${ }^{277}$ David Frum, How We Got Here: The 70s - The Decade that Brought You Modern Life - For Better or Worse (New York: Basic Books, 2000), 99. 
skepticism and questioned whether the most successful musical of the 1970s would attract a new generation of theatregoers. As Dennis Harvey of Variety queried, "Can a verbatim revival [of $A$ Chorus Line] conjure enough 'event' status to re-conquer Broadway?"278 The New York Post's notoriously caustic theatre columnist, Michael Riedel, posed similar questions concerning what the producer's chosen approach to revival would beget: "Will it be a fresh, lively re-creation of a classic or a lovingly restored, but lifeless museum piece?" ${ }^{279}$ The commentator also identified himself as one of many journalists who doubted the timeliness and relevance of $A$ Chorus Line's testimonials sixteen years after the close of its original Broadway production and thirtyone years after its premiere. As he suggested, "The issue about how much $A$ Chorus Line has dated is also being debated in theatre circles. Monologues about masturbation, homosexuality and breast implants—raw stuff for Broadway in 1975—seem pretty tame today." ${ }^{280}$ Mervyn Rothstein voiced a similar concern in the pages of Playbill, and in doing so, tacitly cited the musical as rigidly time-bound: "Is A Chorus Line merely history? It's so very much a musical of the 1970s, and the 1970s was long ago. Will it hold up in the world of 2006?"281 The questions posed by Riedel and Rothstein suggest that both writers recognized a disparity between the zeitgeist that occasioned A Chorus Line and the current cultural moment. Moreover, they projected the possibility of discord between the musical and audiences even before the revival opened.

${ }^{278}$ Dennis Harvey, "A Chorus Line," review of A Chorus Line by James Kirkwood, Nicholas Dante, Marvin Hamlisch, and Ed Kleban, directed by Bob Avian. Curran Theatre, San Francisco, Variety, August 4, 2006.

${ }^{279}$ Michael Riedel, “A Classic's on the Line,” The New York Post, September 1, 2006 : 40.

${ }^{280}$ Ibid.

${ }^{281}$ Mervyn Rothstein, “Back On the Line,” Playbill 25.1 (2006): 10. 
Much like Hair and Company, A Chorus Line's time-boundedness arguably derives from the fact that the musical's temporal setting and the historical moment in which it was created were one and the same — making the work a somewhat fictionalized portrait of its present culture. For the first five years of its Broadway run, the Playbill for A Chorus Line listed the musical's setting as an audition with the following dictum: "Time: Now. Place: Here." ${ }^{282}$ This billing not only confirmed the musical's action as an immediate real time event, but also suggested that $A$ Chorus Line's historical backdrop was relatively fluid and would remain in alignment with the current year as time passed. The chronological congruence between Zach's audition and the world outside of the Shubert Theatre would come to an end, however, when the production's official description of setting changed to "The Time: 1975. The Place: A Broadway Theatre" in the early months of $19800^{283}$ This new description of setting signaled that the musical's original milieu and the extant zeitgeist had begun to separate. It also arguably marked $A$ Chorus Line as a period piece for the remainder of its Broadway engagement. Until its close in 1990, the musical would be, by its own admission, a historical and cultural artifact from the middle years of the 1970s.

The specificity of $A$ Chorus Line's historical setting would be further reified in 1986 when Tams-Witmark Music Library released the musical's script for amateur productions, and again in 1995 when Applause Books published a trade edition of the same libretto. Representing the musical's definitive text, the book to $A$ Chorus Line also cited the musical's action as occurring in 1975, thus stating that all future productions of the musical should take place in that year. The libretto did not, however, feature any

${ }^{282}$ Ken Mandelbaum, A Chorus Line and the Musicals of Michael Bennett (New York: St. Martin's Press, 1989), 310.

${ }^{283}$ Ibid. 
direct reference to 1975 outside of its description of setting. Neither Zach nor the assembled dancers spoke of current events, political affairs, or any of the social movements at work in American life during the mid-1970s. Allusions to the current popular culture were also relatively scant. Even so, the libretto to A Chorus Line established its present in a manner akin to that of Company-by repeatedly gesturing to the dancers' pasts. The first and perhaps most explicit set of references to earlier times occurred early in the musical's action, immediately following Zach's first round of eliminations. With the remaining dancers arranged in a line across the stage, the director instructed them to step forward, one at time, and state both their stage name and given name. He also asked them to relate where and when they were born. While several of the gypsies, such as Sheila and Judy Turner, used this opportunity to individuate themselves from their gathered peers, the subsequent introductions were more or less variations on a shared template:

SHEILA (Stepping forward): I'm Sheila Bryant. Really Sara Rosemary Bryant, which I really hate. I was born August 8, 1946 in Colorado Springs, Colorado. And I'm going to be thirty real soon. And I'm real glad. (Backs into line) ${ }^{284}$

JUDY (Coming forward): My name is Judy Turner. My real name is Lana Turner. (Laughing at her own joke) No, no, no, no, no-it's always been Judy Turner. Born July 21, 1947. (She starts backing up; RICHIE starts out, she stops him and goes on) Oh, I was born in El Paso . . El Paso, Texas. (Backs into line) ${ }^{285}$

The vast majority of the dancers related their complete birthdate, including the year, as well as their current age. As the dancers were born between 1944 and 1955, the early years of the Post-World War II Baby Boom, their ages ranged from thirty-two to twenty. The repetition of ages and birthdates, along with a bit of mental arithmetic, worked to

\footnotetext{
${ }^{284}$ Kirkwood and Dante, 25.

${ }^{285}$ Ibid., 27.
} 
establish 1975 as the musical's setting prior to the start of Zach's inquisition. Further supporting this temporal setting was the rash of references to American life during the 1950s and 1960s that followed once the dancers began to share their stories. Including Judy's aforementioned reference to Hollywood screen siren Lana Turner, the libretto to $A$ Chorus Line contained a total of twenty-eight period references, twenty-one of which gestured to the years of the dancers' childhood and adolescence. The majority of these allusions referred to the various entertainers and cultural icons that somehow influenced their formative years and appeared in either in the dancer's monologues or in Kleban's lyrics for the musical's four-part song montage, "Hello Twelve, Hello Thirteen, Hello Love." In mentioning their celebrity crushes and professional idols, the gypsies confirmed their status as baby boomers and further corroborated the musical's moment in time. Bebe sang of her teenage lust for stage actor and recording artist Robert Goulet, film star Steve McQueen, and ballet dancer Rudolf Nureyev. ${ }^{286}$ The short but exuberant Connie Wong described her childhood dream of growing up to become a prima ballerina and modeling her career on that of Maria Tallchief. ${ }^{287}$ Similarly, the vocally challenged Kristine Urich explained that her desire to pursue a life in the entertainment industry stemmed from watching The Ed Sullivan Show and her longing to sing like Doris Day. When she discovered that she was incapable of matching or maintaining pitch, the young Kristine began her dance training and transferred her admiration to dancer Ann Miller. ${ }^{288}$ Bobby Mills shared his aspirations of becoming a matinee idol akin to Troy Donahue and George Hamilton. ${ }^{289}$ Valerie, generally referred to as Val, likened her own story of
${ }^{286}$ Ibid., 62, 70, 78.
${ }^{287}$ Ibid., 63.
${ }^{288}$ Ibid., 50-51.
${ }^{289}$ Ibid., 70, 123. 
leaving her family home and boarding a Trailways bus for New York City at age eighteen to June Allyson's portrayal of runaway heiress Ellie Andrews in the 1956 Columbia Pictures film, You Can't Run Away from It—a musical adaptation of Frank Capra's 1934 Academy Award winning It Happened One Night. Paul told Zach of his adoration for dancer Cyd Charisse, his time spent as a female impersonator at New York's Jewel Box Revue, and his uncanny resemblance to Chinese American actress Anna May Wong when performing in drag. ${ }^{290}$

In addition to these mentions of public figures, the dancers also referenced other signs of the post-war American culture that characterized their youth. Sheila wistfully recalled her first viewing of Michael Powell and Emeric Pressburger's 1948 film, The Red Shoes. Bobby lamented his parents' lack of sophistication and their choice to cover their patio with astroturf, which received its first patent in 1965. A melodramatic Judy shared her attempt to commit suicide by standing in front of a moving streetcar after learning that she had missed an opportunity to audition for The Ted Mack Amateur Hour, a televised talent competition that ran on various networks from 1948 to $1970 .{ }^{291}$ Mark Anthony, the youngest member of the group, confessed to locking himself in his parent's bathroom and clandestinely reading Grace Metalious's 1956 novel Peyton Place. ${ }^{292}$ Bronx native Al DeLuca remembered his parents' frequent trips to the Roseland Ballroom and recalled the image of his mother returning home "with her shoes in her hand. ${ }^{, 293}$ Roseland, a Manhattan nightclub that first opened in 1922, became a center for Latin dances such as the cha-cha and mambo, as well as marathon dance competitions in

\footnotetext{
${ }^{290}$ Ibid., 86, 99, 103.

${ }^{291}$ Ibid., 73.

${ }^{292}$ Ibid., 70.

${ }^{293}$ Ibid., 72.
} 
the years following World War II. ${ }^{294}$ Openly gay Gregory Gardner divulged his early love of fashion and his predilection for a pair of pants made of powder blue and pink gabardine. ${ }^{295}$ According to fashion historians Amy T. Peterson and Ann T. Kellogg, design houses of the 1950s and 1960s regularly used patterned or brightly colored gabardine in the creation of ready-to-wear garments, particularly men's suits and trousers. ${ }^{296}$ While the majority of the narratives featured in A Chorus Line were highly personal and idiosyncratic to the experience of specific dancers, many of the musical's stories referenced a shared social history and employed a common cultural vernacular that both its characters and its initial audiences (or anyone who lived through the years preceding the baby boom) would have understood.

The seven remaining cultural references in A Chorus Line's libretto also helped to establish the musical's temporal setting by remarking the current historical moment. For example, Judy professed her dream of becoming a Broadway star and attaining the same level of recognition and success as Gwen Verdon. ${ }^{297}$ When A Chorus Line opened at the Shubert Theatre in July of 1975, Verdon - a winner of four Tony Awards for her roles in Can-Can (1953), Damn Yankees (1955), New Girl in Town (1957), and Redhead (1959) — was then performing in her eleventh and final Broadway production two blocks away at the $46^{\text {th }}$ Street Theatre. For her portrayal of Jazz Age murderess Roxie Hart in John Kander and Fred Ebb's musical vaudeville Chicago, the fifty-year old Verdon received generally positive notices from the major New York critics as well as her sixth

${ }^{294}$ Cary D. Wintz and Paul Finkelman, eds., The Encyclopedia of the Harlem Renaissance, Volume 2: K-Y (New York: Routledge, 2004), 1072.

${ }^{295}$ Kirkwood and Dante, 76.

${ }^{296}$ Amy T. Peterson and Ann T. Kellogg eds., The Greenwood Encyclopedia of Clothing Through American History: 1900 to the Present (Westport, CT: Greenwood Press, 2008), 307.

${ }^{297}$ Ibid., Kirkwood and Dante, 132. 
Tony Award nomination in 1976. The dancing star and frequent muse of choreographer Bob Fosse would lose the award to another choreographer's muse: Donna McKechnie, who portrayed Cassie in A Chorus Line. Val affirmed that her ambitions of stardom did not lie in the theatre, but rather in film when she alleged that she would gladly give up the life of a Broadway gypsy for the chance to act in a major motion picture, stating "I don't care if I dance another step as long as I live. I'd be happy just going to Hollywood and replacing Jill St. John." ${ }^{298}$ Working steadily in film and television throughout the 1960s, Jill St. John received international attention as the seventh "Bond Girl" when she appeared opposite Sean Connery in the 1971 James Bond film, Diamonds Are Forever. While many of the entertainers mentioned in A Chorus Line's libretto were still alive and working at the time of the musical's premiere, the vast majority of them were presented as historical figures - representations of celebrity from earlier decades. Conversely, Verdon and St. John epitomized present day stardom, serving as models of success in the entertainment industry for the mid-1970s.

Beyond Judy and Val's mentioning of recognizable figures, Paul made a passing reference to Channel 47, a New York television station that produced Spanish-language programming for much of the 1970s and 1980s. ${ }^{299}$ Sheila carried prescription Darvon in her dance bag and admitted to taking the controversial painkiller recreationally. ${ }^{300}$ Diana's solo number, "Nothing," chronicled her experience as a student at New York City's High School for the Performing Arts (known locally as PA), an alternative public high school founded in 1947 that trained students in music, theatre, and dance. ${ }^{301}$ The
${ }^{298}$ Ibid.
${ }^{299}$ Ibid., 99.
${ }^{300}$ Ibid., 129.
${ }^{301}$ Ibid., 64. 
school, housed in a facility just north of Times Square, operated independently until 1984 when it merged with the city's school of Music and Art to form the Fiorello H. LaGuardia School of Music and Art and the Performing Arts at Lincoln Center. While Diana's time at PA occurred prior to A Chorus Line's audition scenario, the school's initial home on $44^{\text {th }}$ Street remained open for the first nine years of A Chorus Line's Broadway engagement. Furthermore, Alan Parker's 1980 film about the school, Fame, and the subsequent television series of the same name that aired from 1982 to 1987 , arguably kept Diana's song and her reference to the school timely until the musical's 1990 closing.

Whereas the majority of the narratives presented in A Chorus Line depicted events from the dancers' younger days, the story told by Cassie — a seasoned dancer and Zach's former lover-focused exclusively on her recent past. Having ended her relationship with the choreographer just as her star had begun to ascend, Cassie described the difficulty she now faced securing work as a performer after leaving Zach and relocating from New York to Los Angeles. Consequently, nearly all of Cassie's cultural allusions were more immediate than those offered by her colleagues. Among Cassie's sporadic jobs was that of a go-go dancing extra in a television movie-of-the-week. ${ }^{302}$ She also told Zach of her experience auditioning for commercials and related that she "almost got to squeeze a roll of toilet paper, but lost out in the finals. ${ }^{303}$ Go-go dancing, a French tradition of scantily clad female performers in dances such as the Twist, the Monkey, the Pony, or the Watusi in a cage or on top of the tables of a discotheque for male patrons, immigrated to the United States in the mid-1960s and remained popular through the early 1970s thanks to

\footnotetext{
${ }^{302}$ Ibid., 93.

${ }^{303}$ Ibid.
} 
its more sanitized presence on television variety shows such as Shindig (1964-1966), Hullabaloo (1965-1966), and Laugh-In (1968-1973). ${ }^{304}$ The American Broadcasting Company's (ABC) Movie-of-the-Week series, a weekly anthology of two-hour films created for television, aired from 1969 to 1976, and then on a more intermittent basis throughout the 1980s and 1990s. Moreover, Proctor \& Gamble's advertising campaign for Charmin toilet paper from 1964 to 1985 featured over five hundred television commercials depicting various consumers disregarding fictional grocer Mr. Whipple's

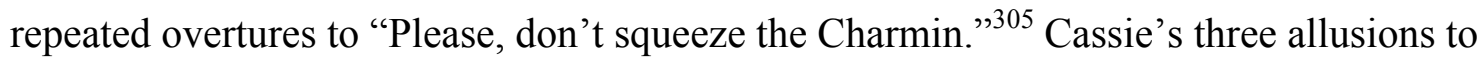
the current culture, along with the three others mentioned above, arguably served to remind 1970s audiences of the musical's present day setting. Scattered among several mentions of the 1950s and 1960s, they helped to further foreground 1975 as the year of Zach's callback. A Chorus Line then stands apart from Hair and Company in that its characters established the musical's temporal setting through references to the present and the past. Whereas the members of Hair's tribe generally discussed their extant zeitgeist, and Company's married set traded almost exclusively in references to the years preceding the musical's action, the gypsies of $A$ Chorus Line remarked both their current day and days past. Their chronological allusions further established the musical's temporal setting and served to bind its action to the mid 1970s.

A similar claim could be made concerning Marvin Hamlisch's musical score for $A$ Chorus Line. The musical's catalogue bore a slight resemblance to Sondheim's score for Company in that Hamlisch invoked a variety of musical styles ranging from the classical

\footnotetext{
${ }^{304}$ Claudia A. Mitchell and Jacqueline Reid-Walsh, Girl Culture: Studying Girl CultureA Reader's Guide (Westport, CT: Greenwood Publishing, 2008), 328-330.

${ }^{305}$ Davis Dyer, Dr. Frederick, Dalzell, and Rowena Olegario, Rising Tide: Lessons from 165 Years of Branding at Proctor \& Gamble (Boston: Harvard Business School Publishing, 2004), 129.
} 
to the contemporary. "At the Ballet," the song in which Sheila, Bebe, and Maggie recounted the beauty they observed at the ballet as children and the safety they eventually discovered in their own ballet training, employed both strands of bossa nova and classical waltz. Kristine's "Sing," a number in which the dancer and her husband Al DeLuca enumerated her shortcomings as a vocalist, was a patter song following in the tradition of patter found in nineteenth century comic operas, particularly in the works of W.S. Gilbert and Arthur Sullivan. The accompaniment for Val's "Dance: Ten; Looks: Three" resembled the underscoring of burlesque routines from the 1930s. As the dancer sashayed across the stage, displaying the "tits and ass" that she purchased in hopes of improving her chances for employment, the orchestra's trombones, low woodwinds, and percussion punctuated her choreographed presentation of self. During the third part of the Montage, Maggie sang a folk ballad entitled "Mother" that recalled the early days of the American folk music revival which began in the 1940s and reached its peak in the 1960s. A Chorus Line's final song, "One,” a lavish production number for Zach's unnamed musical in which the chosen members of the ensemble will extol the virtues of the unseen leading lady, followed a musical tradition that began on stage in the early 1920s with such musicals as Irene (1919), Sally (1920), and Sunny (1925), gained popularity in the films of Busby Berkeley during the 1930s, and would return to the stage during the Golden Age of Musical Theatre in such notable works as Jerry Herman's Hello, Dolly! (1964) and Mame (1966). Hamlisch claims that his choice to interweave a variety of musical genres throughout $A$ Chorus Line's score derived in part from the musical's dramaturgical focus on individual dancers' lives. According to the composer, his use of pastiche was intentional and allowed him to craft music that was idiosyncratic to specific 
characters: "We tried to make each song in a different style so that every person would be unique. And that offered me the possibility of mixing musical styles—rock, classical, folk, theater." ${ }^{306}$ Consequently, nearly all of $A$ Chorus Line's characters received their own musical theme in the form of solo numbers, individual musical passages throughout the Montage, or personalized underscoring that accompanied the presentation of specific monologues. By individuating the musical's characters through music as well as text, Hamlisch further suffused $A$ Chorus Line with Me Decade values. Vis-à-vis the composer's score, the gypsies presented their stories to Zach and further marked themselves as distinct personalities.

Despite Hamlisch's frequent use of musical styles from previous eras, a significant portion of the music for $A$ Chorus Line relied upon a strong backbeat and instrumentation associated with popular musical forms of the 1970s. The charts for five of the musical's fifteen songs- -I Hope I Get It," "At the Ballet," "Hello Twelve, Hello Thirteen, Hello Love," "Nothing," and "Gimme the Ball"—called for a rock tempo or what Hamlisch described as "Tempo di Funk."307 The composer's use of rock idioms was consistent with the growing preponderance of Broadway musicals in the early 1970s to feature a rock or rock-inspired score. Following the remarkable success of Hair, works such as Andrew Lloyd Webber's Jesus Christ Superstar (1971), Joseph M. Kookolis and Scott Fagan's Soon (1971), Peter Link's Earl of Ruston (1971), Galt MacDermot's Two Gentlemen of Verona (1971), Via Galactica (1972) and Dude (1972), Tom Martel's Hard Job Being God (1972), and Stephen Schwartz's Pippin (1972) brought various brands of

\footnotetext{
306 "Interview with Marvin Hamlisch," Souvenir Program for A Chorus Line, New York Shakespeare Festival, 1975, 2.

${ }^{307}$ Marvin Hamlisch and Edward Kleban, A Chorus Line: Vocal Score (New York: Edwin H. Morris \& Company, 1977), 18, 49, 74, 85, 112.
} 
rock music into Broadway theatres. Hamlisch's use of funk in A Chorus Line, which emphasized a rhythmic bass line and distorted electric guitar sounds, represented a slight departure from this trend and arguably reflected the growing popularity of funk music in the 1960s and 1970s thanks to such solo artists as James Brown and bands such as Charles Wright \& the Watts $103^{\text {rd }}$ Street Rhythm Band, Sly and the Family Stone, The Isley Brothers, and George Clinton's Parliament. Funk idioms appeared in the scores of other Broadway musicals prior to A Chorus Line's opening; however, those works-Ain't Supposed to Die a Natural Death (1971) and The Wiz (1975) chief among them-were both created and performed by companies of solely black artists. As Elizabeth Wollman notes, funk and its stylistic sibling, soul, were prevailing musical forms throughout the $1960 \mathrm{~s}$ and $70 \mathrm{~s}$, but associated almost exclusively with African-American culture. ${ }^{308}$ Hamlisch's use of both rock and funk in A Chorus Line was significant then as it not only reflected current trends in popular music, but also it employed them in a musical whose company members represented a variety of racial identities and ethnicities.

Further contributing to A Chorus Line's rock and funk sounds was the composition of its pit orchestra. The instrumentation, prepared by orchestrators Bill Byers, Hershy Kay, and Jonathan Tunick, called for seventeen musicians to play nearly thirty instruments and featured substantial brass and woodwind sections, but virtually no traditional stringed instruments. ${ }^{309}$ Aside from the double bass, banjo, and harp, which appeared only sporadically throughout the score, the orchestra's primary stringed

\footnotetext{
${ }^{308}$ Elizabeth Wollman, The Theatre Will Rock: A History of the Rock Musical, From Hair to Hedwig (Ann Arbor, MI: University of Michigan Press, 2006), 117.

${ }^{309}$ While Byers, Kay, and Tunick are traditionally credited as A Chorus Line's chief orchestrators, several sources on the creation and development of the musical claim that musicians Ralph Burns, Philip J. Lang, Harold Wheeler, and Larry Wilcox made significant, but often unacknowledged, contributions to the musical's orchestrations.
} 
instruments were an electric bass and electric guitar. The score to A Chorus Line frequently called for moments of distorted electric guitar and featured the effect prominently (approximately one-third of the song or more) in the charts to "I Hope I Get It," "Hello, Twelve, Hello Thirteen, Hello Love," "Gimme the Ball," and "The Music and the Mirror." 310 Additionally, "Gimme the Ball" featured a two-measure electric guitar and rhythm section solo referred to in the score as the "Shaft Effect," presumably referring to the 1971 blaxploitation film, Shaft, and its widely recognizable theme song written and performed by soul-funk artist Isaac Hayes. ${ }^{311 ~ " T h e ~ T h e m e ~ f r o m ~ S h a f t, " ~ w h i c h ~}$ spent sixty weeks on the Billboard charts in 1971 and 1972, opened with nearly three minutes of uninterrupted distorted electronic riffs that evoked a funk sensibility. In alluding to Hayes's work, Hamlisch and the musical's orchestrators further embedded present-day musical idioms into $A$ Chorus Line's score.

In addition to the previously cited guitar and bass, an electric organ, electric harpsichord, and a seventy-three key Fender Rhodes electric piano supplemented the orchestra's timely sound. The latter of these instruments played a significant role in the accompaniment to four of the musical's songs: "I Hope I Get It," "And," "At the Ballet," and "Hello Twelve, Hello Thirteen, Hello Love." The distinct digital tones of the Fender Rhodes piano provided the musical foundations for each of these songs, appearing in nearly half of each song's total measure count. First manufactured in the 1960s, the Fender Rhodes piano was a mainstay of major recording studios throughout the 1970s

${ }^{310}$ The portion of "I Hope I Get It" referred to as "The Jazz Combination" contained a total of 153 measures, 51 of which called for distorted electric guitar tabulations. "Gimme the Ball" and the small reprise of "Hello Twelve, Hello Thirteen, Hello Love" that preceded it contained 66 measures of electric guitar out of its total 141 measures. Additionally, of the 131 measures dedicated to Cassie's dance solo in "The Music and the Mirror" 43 contained electric guitar tabulations.

${ }^{311}$ Hamlisch, 125. 
before falling into relative obscurity in the late $1980 \mathrm{~s} .{ }^{312}$ Its presence within the pit orchestra for A Chorus Line, much like the funk-producing electric guitar, helped Hamlisch's score to reflect current musical trends in popular music.

While the libretto and score to A Chorus Line continuously established the musical's temporal setting through frequent textual and musical gestures to the mid1970s, Robin Wagner's scenic design offered, by contrast, no visual markers to indicate the musical's moment in time. Wagner, who adorned the stage of the Biltmore theatre with numerous signs of hippie culture seven years prior for the original Broadway production of Hair, provided a single white line that stretched across an otherwise bare stage and eight revolving periaktoi. The three surfaces of each periaktoid unit displayed a large mylar dance mirror, a brick wall, and a fraction of a "sunburst" pattern for the musical's finale constructed from strips of gold and copper mylar. Tharon Musser's lighting design, which required the use of Broadway's first computerized light board, projected colorful patterns modeled after the artwork of Piet Mondrian on to the stage, but also did not represent the given time period.

As the dancer's bodies, whether standing still or moving through space per Bennett's choreography, served as the production's only set dressing, it fell to costume designer Theoni V. Aldrege to foreground the current historical moment with her design for the characters' individual audition attire. Aldrege took her inspiration for A Chorus Line's costumes from the dancewear that the members of the original company sported during the musical's extensive workshop period at The Public Theatre. Armed with a Polaroid camera, the designer observed six months of rehearsals and photographed each

${ }^{312}$ Paul Trynka, ed., Rock Hardware: 40 Years of Rock Instrumentation (London: Balafon Books, 1996) 1958-1960. 
dancer in an attempt to gain insight into their respective personalities. Her designs, which changed several times during the musical's Off-Broadway engagement as well as its first years at the Shubert Theatre, reflected both the gypsies' individual styles and the current trends in dance garments. For example, several of the ensemble's men wore bellbottomed dance pants.

In addition to being the primary visual indicator of the musical's era, Aldrege's costumes helped to individuate and distinguish each dancer across the musical's Broadway run, its numerous domestic tours, and its international companies. While Aldrege did alter her designs slightly to accommodate new cast members during the musical's initial years on Broadway, certain costume pieces seemed to form an almost symbiotic relationship with their given characters over time, presumably allowing audience members to identify the characters regardless of the actor portraying the role. For fifteen years, $\mathrm{Al}$ always sported a sleeveless Kelly green t-shirt with a pink TKTS logo (a garment that celebrated the 1973 opening of the Theatre Development Fund's discounted ticket booth in Times Square); Sheila always appeared in a cream colored Danskin leotard with long sleeves, and Bobby always wore a red scarf around his neck. Cassie's costume — a red dance leotard with a matching knee-length half skirt—-became a signature of the character. According to Alyce Gilbert, the musical's Wardrobe Supervisor, every actor portraying Cassie on Broadway wore some variant of the original red costume per the instruction of Aldrege and Michael Bennett. ${ }^{313}$ Aldrege's costumes also became the primary identifying feature of each character in the early years of $A$ Chorus Line's marketing campaign. The musical's logo consisted of the original members of the production's primary cast standing in the same formation and order that

\footnotetext{
${ }^{313}$ Quoted in Stevens and George, 58.
} 
they occupied during Zach's interrogation. Because the faces of the individual dancers were obscured — as if to suggest that any actor could assume any of the musical's rolesthe characters' costumes and their placement within the line helped to distinguish each of the dancers as individuals.

Unlike Hair and Company, which achieved historical significance over time in spite of somewhat mixed reviews, A Chorus Line earned overwhelmingly consistent, positive notices from the major New York theatre critics. Each and every reviewer seemed to herald the musical as a creative triumph and showered the musical with superlatives. Douglas Watt of The Daily News described A Chorus Line as "a splendid achievement.”314 The Wall Street Journal's Edwin Wilson offered similar sentiments, calling the piece "the best integrated, the most original, and in some ways, the most exciting musical of the season." ${ }^{315}$ Martin Gottfried, writing for The New York Post, looked beyond the current year in his review and proclaimed the musical's historical import, declaring the work "a major event in the development of the American musical theatre. ${ }^{316}$ While several of the musical's champions offered sweeping remarks that attested to A Chorus Line's significance, John Simon presented a more thorough explanation of how the work represented a watershed event in the genealogy of the American musical. According to Simon, the musical's "ravaging frankness" imbued it with an authenticity previously unseen on the Broadway stage. As he stated, "A Chorus

314 Douglas Watt, “Tell Me, Little Gypsy,” Daily News, May 22, 1975 in New York Critics' Theatre Reviews. Vol. 36, ed. Joan Marlow and Betty Blake (New York: Critics' Theatre Reviews Inc., 1975), 238.

${ }^{315}$ Edwin Wilson, "Bring On the Dancing Girls," The Wall Street Journal, May 22, 1975 in New York Critics' Theatre Reviews. Vol. 36, ed. Joan Marlow and Betty Blake (New York: Critics' Theatre Reviews Inc., 1975), 241.

${ }^{316}$ Martin Gottfried, "Dance, He Said, and They Did," New York Post, May 22, 1975 in New York Critics' Theatre Reviews. Vol. 36, ed. Joan Marlow and Betty Blake (New York: Critics' Theatre Reviews Inc., 1975), 239. 
Line is something new and historic in musical comedy, the first musical-vérité ... to be sure, the show is staged cinéma-vérité." ${ }^{.317}$ Alluding to the form of documentary filmmaking that attempts to capture unadulterated truth, Simon identified the musical's confession scenario as the source from which A Chorus Line's authenticity flowed and further explicated how the dancer's presentation of their private, psychological pain was, for him, so deeply compelling:

There they stand, these sixteen; one at a time they are made to step in front of the white line - which becomes a veritable character in the show-each in turn spilling out his or her guts. The director's voice from the outer darkness is ruthlessly inquiring, with the insistence of a tongue on a sore tooth, or fingernails on a scab. And the victims of this inquisition - sometimes tenderly, sometimes funnily, sometimes terrifyingly - lay themselves bare, in words, songs, and dance ... I doubt very much whether such questions get asked of persons applying for anything short of the CIA, but it is a pardonable device in view of how well it works and how effectively it is executed. ${ }^{318}$

In addition to Simon, five of $A$ Chorus Line's reviewers referred specifically to the libretto's reliance on personal narrative and the characters' tendency toward total and public candor as the musical's most remarkable features, the latter of which was still a relatively novel concept despite the ethos of the Me Decade. In his review for The New York Times, chief theatre critic Clive Barnes claimed, "What makes A Chorus Line so devastatingly effective is its honesty of subject matter ... it is a psychological striptease, and slowly the kids undress in a series of sad, if funny, vignettes ... yet somehow the hokum all works - because it is undisguised and unapologetic." ${ }^{319}$ Gottfried presented a similar assessment, suggesting that "the ticks and self defenses and practiced personality

${ }^{317}$ John Simon, On Theatre: Criticism, 1974-2003 (New York: Applause Theatre \& Cinema Books, 2005), 50.

${ }^{318}$ Ibid.

${ }^{319}$ Clive Barnes, “A Tremendous 'Chorus Line' Arrives,” New York Times, May 22, 1975, in New York Critics' Theatre Reviews. Vol. 36, ed. Joan Marlow and Betty Blake (New York: Critics' Theatre Reviews Inc., 1975), 238-239. 
routines of chorus people are laid out, sometimes painfully, sometimes comically, but always with truth, a quality with which this show overflows." ${ }^{320}$ Jack Kroll of Newsweek focused his review on what he described as "the gripping sincerity of the performers.",321 Time's T.E. Kalem, who at first described the dancers and their stories as "mawkish, banal, self-absorbed, and dream-bent as would be those of any of the playgoers," quickly absolved the narratives for their inherent honesty and the characters for their "terrifying vulnerability." ${ }^{, 22}$ In his estimation, Michael Bennett and his collaborators employed the setting of an audition and the symbol of a chorus line to construct a powerful metaphor for American life that demonstrated both the pervasiveness of the American success ethic and the rather inexplicable and capricious manner in which success is attained. ${ }^{323}$

A Chorus Line's uniformly positive reviews included significant praise for Michael Bennett's concept, choreography and direction, Ed Kleban's lyrics, James Kirkwood and Nicholas Dante's libretto, and the acting performances delivered by dancers Donna McKechnie (Cassie), Kelly Bishop (Sheila), Priscilla Lopez (Diana), and Sammy Williams (Paul). Moreover, nearly every critic acknowledged Robin Wagner, Tharon Musser, and Theoni Aldrege's contributions to the musical's physical production with approval. Only Marvin Hamlisch's score received lukewarm notices with four of nine critics charging that the ingenuity and guile of A Chorus Line's central premise was all but absent in what appeared to be rather conventional musical theatre songs. Gottfried

${ }^{320}$ Gottfried, 239.

${ }^{321}$ Jack Kroll, "The Kids on the Line," Newsweek, June 2, 1975, in New York Critics' Theatre Reviews. Vol. 36, ed. Joan Marlow and Betty Blake (New York: Critics' Theatre Reviews Inc., 1975), 242.

${ }^{322}$ T.E. Kalem, "Dance of Life," Time, June 2, 1975 in New York Critics' Theatre Reviews. Vol. 36, ed. Joan Marlow and Betty Blake (New York: Critics' Theatre Reviews Inc., 1975), 242.

${ }^{323}$ Ibid. 
further suggested that the musical's numbers were perhaps too rooted to the context of the libretto and the experience of their respective characters to ever find a life outside the confines of the musical. ${ }^{324}$ Aside from these quibbles with Hamlisch's music, however, $A$ Chorus Line received only praise from reviewers and the even tenor of its responses arguably distinguished the piece from all other original musicals that opened on Broadway during the 1975-1976 season: Chicago, The Robber Bridegroom, Treemonisha, Pacific Overtures, Rockabye Hamlet, Bubbling Brown Sugar, and 1600 Pennsylvania Avenue —-works that received decidedly mixed reviews or categorical pans from the major New York critics. By comparison, A Chorus Line was an unequivocal critical smash. Moreover, the uniformity of its reviews suggested that the secret of the musical's success was the unwavering honesty that poured forth from the dancers' confessions.

While $A$ Chorus Line's reviewers seemed to extol (perhaps unwittingly) the features of the musical's dramaturgy that reflected the Me Decade zeitgeist, Kirle suggests that the musical won the favor of critics and audiences because it reconciled what he cites as two warring internal conflicts within the mid-1970s American populace: the need to assert one's individuality and the need to conform. The musical celebrated both the individual dancer and the dancing community. Furthermore, it placed fifteen singular personalities in competition for a place within an ensemble. Zach's audition required the gypsies, performers unaccustomed to the proverbial spotlight, to establish themselves as special or unique. Zach would reward those dancers who rose to the occasion and revealed the most about their lives with a place in the chorus, where the need for uniformity would once again strip them of the uniqueness. As Kirle states, "The

\footnotetext{
${ }^{324}$ Gottfried, 239.
} 
tension in A Chorus Line is between the autonomy of the individual and the need to be a team players, or to put it differently, between outsider and insider." ${ }^{325}$ In his estimation, an increasingly corporate culture and its call for conventionality had permeated the Me Decade ethos. Kirle later contends that $A$ Chorus Line advocates assimilation as much as it glorifies individualism and the musical's true conflict is not between the demanding director and the compliant dancers, but rather between the exceptional individual and collective mediocrity. While Kirle offers little by way of evidence for his cultural assessment, historians such as Andreas Killen and David Frum have offered similar claims about American life in the 1970s and further suggest that the same historical events that allegedly prompted the Me Decade simultaneously incited a backlash against individualism, resulting in a cultural imperative for group allegiance. Having separated themselves from the social institution in the wake of the Vietnam War and the Watergate Scandal, Americans longed for a simpler past characterized by community and shared values. As Killen argues in 1973 Nervous Breakdown: Watergate, Warhol, and the Birth of Post-Sixties America, feelings of nostalgia prompted the American public to search for group affiliation: "The Me Decade was also the Them-Decade.", ${ }^{326}$ Killen goes on to suggest that membership in civic organizations, religious organizations, and cults increased dramatically in the 1970s, as Americans sought to transform themselves or find their own individual identity in relation to a shared group identity.

While much of $A$ Chorus Line's dramaturgical conceit involved presenting singular identities and sharing highly personalized stories, the musical also demonstrated this cultural tension between the individual and the aggregate in a variety of ways. The

${ }^{325}$ Kirle, 151.

${ }^{326}$ Andreas Killen, 1973 Nervous Breakdown: Watergate, Warhol, and the Birth of PostSixties America (New York: Bloomsbury, 2006), 113. 
musical's characters told their own histories through monologues and solo numbers; at the same time, they also expressed shared thoughts and communal feelings in several of the musical's ensemble songs. Throughout "I Hope I Get It," the company vented their mutual anxiety over Zach's audition. In between the director's battery of dance assessments, the gypsies expressed their self-doubt, their urgent need for employment, and their fear of failure by chanting the same lyrics on the same pitch. Together they articulated the same fears, utilizing the same lyrics and the same vocal line:

GOD, I HOPE I GET IT.

I HOPE I GET IT. HOW MANY PEOPLE DOES HE NEED? $?^{327}$

GOD, I REALLY BLEW IT!

I REALLY BLEW IT. HOW COULD I DO A THING LIKE THAT? $?^{328}$

I REALLY NEED THIS JOB. PLEASE, GOD, I NEED THIS JOB. I’VE GOT TO GET THIS JOB. ${ }^{329}$

Singing these sentiments in unison arguably served to align all of the dancers in terms of their objective and their emotional state. Regardless of their individual histories, the composition and function of "I Hope I Get It" presented the gypsies as a relatively unified throng. A similar phenomenon occurred during the final moments of the musical's penultimate song, "What I Did for Love." Following the lead of soloist Diana Morales, the ensemble collectively acknowledged the temporality of a dancer's career and asserted that they would neither forget nor regret the sacrifices they made and hardships that they endured in order to make dancing their vocation. When the gypsies

\footnotetext{
${ }^{327}$ Kirkwood and Dante, 9.

${ }^{328}$ Ibid., 13.

${ }^{329}$ Ibid., 16.
} 
joined Diana for the song's final bridge and verse, they did so en masse and articulated the same sentiments together:

LOVE.

LOVE IS NEVER GONE.

AS WE TRAVEL ON,

LOVE'S WHAT WE'LL REMEMBER.

WE DID WHAT WE HAD TO DO.

WON'T FORGET, CAN'T REGRET, WHAT I DID FOR LOVE. ${ }^{330}$

Additionally, several portions of the Montage served to align and individuate the company almost simultaneously. Throughout the sequence, the ensemble sang of adolescence writ large together while individual characters interjected their own memories of puberty, peer relationships, sexual awakening, and resisting parental authority. Presenting their personal experiences in this manner not only allowed the dancers to further define themselves as individuals for Zach, but also prompted them, however inadvertently, to create a community founded on shared or common experience.

If Killen's suggestion that the 1970s American populace longed, somewhat paradoxically, for both collectivism and individualism is correct, then A Chorus Line's finale arguably depicted this cultural desire through song, dance, and an undeniable image of assimilation. For the ironically titled "One," the characters shed their personal dance attire—-the most potent visual signifier of their individuality—and donned matching gold tuxedos in order to present a production number from Zach's unnamed musical. Forming a unified corps and dancing in perfect unison, the individual members of the company were virtually indistinguishable. The song's irony then derived from its celebration of singularity. Extoling the virtues of the musical's unseen female star, "One"

\footnotetext{
${ }^{330}$ Ibid., 138-139.
} 
lauded one exceptional individual above all others — one out of many —at the same time that it obscured the individuality of the musical's central characters. The number also represented the apotheosis of Bennett's primary objective for A Chorus Line, which was to individuate Broadway dancers as people — with names, distinct personalities, and unique personal histories - before stripping them of their identity and sending them back to the chorus as hardworking unknowns:

You're going to get to know all these dancers as individuals and care about each one. Then, at the very end of the play ... they're going to blend. They're going to do everything you've ever seen anyone in a chorus line do. It's going to be the most horrifying moment you will ever experience in the theatre. I have a vision of them forming a VF and marching with frozen smiles, like in Metropolis. If I do this right, you will never see another chorus line in a theatre. Everybody will reevaluate what it is they're watching. ${ }^{331}$

Accordingly, the musical ended not with a traditional curtain call, but rather with the tuxedo-clad cast vigorously high-kicking to "One's" famed Broadway vamp as the lights dimmed. This final image suggested that the recompense for the dancers' hard work and frankness was anonymity rather than stardom. Instead of winning notoriety, the gypsies earned the chance to dance, albeit anonymously, for another day.

A Chorus Line's continuous negotiation of individual and collective identities is yet another feature of the musical's libretto that a handful of critics praised in their review of its original production. In describing the musical's structure, Simon charged that the book's collection of singular narratives eventually melded to form a mosaic of diverse voices representing the concerns of a single community: "This musical never lets us forget that it comes at us out of a collective consciousness, that it is a polyptych, that behind the fierce or frightened solos there is a choral hymn of aspiration, anxiety, and

${ }^{331}$ Quoted in Ken Mandelbaum, A Chorus Line and the Musicals of Michael Bennett (New York: St. Martin's Press, 1989), 170-171. 
hope." ${ }^{332}$ Simon would go on to suggest that the polyphonic nature of the libretto is what kept the musical from becoming overly sentimental, and that $A$ Chorus Line's whole was greater and more compelling than the sum of its distinct parts. Kroll also located the musical's efficacy in both its individuation and assimilation of a body politic. As he stated in his review for Newsweek, "These mini-psychodramas interlock until the chorus line becomes a community at once special and ordinary, a family linked by blood, sweat, laughter, and tears. ${ }^{333}$ Four months after the publication of his initial review, Kroll penned a feature article on the meteoric success of A Chorus Line for Newsweek, and in doing so, attempted to locate the source of the musical's widespread popularity. After interviewing the musical's production team and cast, as well as members of its audience, Kroll suggested that part of the musical's appeal lay in its depiction and valorization of the everyperson — a facsimile of a distinct persona with whom any audience member could identify. He would go on to cite the musical's finale as the second secret of the musical's success, offering a description of its final moments that mirrored Bennett's stated intentions for the musical:

It's a thrilling finish, but the thrill is laced with a kind of horror. All the sweat and desperation have exploded into this apotheosis of anonymity, in which the dancers' skills and personalities are welded into a banal kicking machine whose very mindless precision sends thrills down the most sophisticated of spines. ${ }^{334}$

Simon and Kroll's respective assessments of $A$ Chorus Line suggest that it was not only the musical's presentation of individual lives, but also the celebration of a community that won the favor of critics and audiences and helped the musical align with the Me Decade zeitgeist. While none of the musical's reviewers spoke of the current cultural

\footnotetext{
${ }^{332}$ Simon, 50.

${ }^{333}$ Kroll, 242.

${ }^{334}$ Jack Kroll, “Broadway’s New Kick,” Newsweek, December 1, 1975, 66.
} 
climate in their reviews or made overt cases for the musical's compatibility with the present day, their overwhelming support of the musical suggests that the accord between A Chorus Line and its zeitgeist was implicit. Furthermore, the remarkable run of $A$ Chorus Line's initial Broadway production further indicates that the musical and its collection of personal narratives retained their relevance well beyond the Me Decade. For fifteen years, A Chorus Line's depiction of the unique individual and the faceless aggregate presumably stimulated the collective imagination of theatre audiences both on Broadway and across the United States.

\section{BROADWAY REVIVAL}

A Chorus Line's confessional premise and presentation of real time events, which critics cheered as uniquely compelling in 1975 , was arguably a more common feature (if not altogether a fixture) of American life when the musical returned to Broadway in 2006. The sixteen years that separated the musical's original production and first revival witnessed the popularization of daytime talk shows such as Donahue (1970-1996), The Sally Jessy Raphael Show (1983-2002), The Oprah Winfrey Show (1986-2011) and Geraldo (1987-1998) throughout the 1970s and 1980s. A television program in which guests willingly divulged their personal histories or hitherto untold secrets for public consumption, the genre was nearly ubiquitous throughout the 1990s as other highly rated tabloid talk programs such as The Jenny Jones Show (1991-2003), The Jerry Springer Show (1991-present), Maury (1991-present), and Ricki Lake (1993-2004) filled the syndicated daytime television landscape. Reality television programs also won the enthusiastic favor of viewing audiences in the 1990s when MTV's The Real World 
(1992-present) and Road Rules (1995-2007) attempted to introduce the tenets of cinéma vérité to television and claimed to present the real life events of manufactured and makeshift communities authentically. Later reality competitions such as Survivor (2000present), Big Brother (2000-present), and The Amazing Race (2001-present) also borrowed from this premise and placed contestants in an adversarial conflict that would recall A Chorus Line's plot—a collection of relative strangers openly compete for a given prize. Furthermore, the emergence of televised talent competitions such as Star Search (1983-1995), American Idol (2002-present), and So You Think You Can Dance (2005present)—programs that borrowed from A Chorus Line's dramaturgical conceit—worked to redefine the audition process and its system of rewards by promising that anyone, regardless of training and experience, can achieve show business fame. The attention that these entertainments placed on the uniqueness of the everyday individual suggests that the Me Decade ethos continued to resonate with the American populace across three decades. Moreover, one might conclude that the widespread proliferation of these entertainments following the close of $A$ Chorus Line's original Broadway production would prepare audiences for and attract them to a revival of the landmark musical. With a new generation of theatregoers habituated to reality narratives, the musical's revival would presumably not require any revisionist techniques.

John Breglio's decision to present $A$ Chorus Line in its original form was foregrounded in a desire not only to preserve the work of Michael Bennett (who died from AIDS-related lymphoma in 1987), but also to expose audiences-both new and old - to the piece in its definitive form. As he alleged, the revival would offer viewers 
"the standard and quality that you saw in the [first] Broadway production.",335 This rhetoric aligned with Bennett's management of A Chorus Line in the late 1970s and early 1980s as new companies were formed and traveled across the globe. According to Bob Avian, Bennett's longtime assistant and collaborator on A Chorus Line's choreography, each subsequent production of the musical was prepared as a replica of the director's original, and with few exceptions, utilized the same scenery, costumes, lights, orchestrations, choreography, and blocking employed by the Broadway production. ${ }^{336}$ Additionally, Bennett frequently required new company members to model their acting performances on the performances given by the musical's original cast. Kerry Casserly, who joined the cast of the Broadway production several years into A Chorus Line's original run in the role of Kristine, reports that Bennett charged the production's dance captains and stage management with preserving the musical—its choreography and performances_-as new actors entered the company: "They taught us every finger movement, hand gesture - exactly what to do." 337 Janet Wong, the third actress to take on the role of Connie Wong on Broadway recalls that she learned of Bennett's re-staging process when an original cast member approached her and said, "Welcome to the factory," suggesting that the production had become something of a self-replicating machine. ${ }^{338}$ Casserly and Wong's testimonials gesture to an impulse to preserve $A$ Chorus Line as it first appeared on Broadway in 1975 for the duration of its run at the

\footnotetext{
${ }^{335}$ Quoted in Susan Kittenplan, “High Kicks,” Vanity Fair no. 553 (September 2006): 204.

${ }^{336}$ Bob Avian, “An Interview with John Beglio, Bob Avian, Baayork Lee,” Every Little Step: The Journey of A Chorus Line, DVD, Directed by James D. Stern and Adam Del Deo, New York: Sony Pictures Classics, 2009.

${ }_{337}^{337}$ Quoted in Stevens and George, 10.

${ }^{338}$ Ibid., 22.
} 
Shubert Theatre as well as its pilgrimage around the United States and beyond-an impulse that would guide the planning and production of the musical's revival.

In order to reproduce Michael Bennett's vision for $A$ Chorus Line as faithfully as possible, Breglio assembled much of the original Broadway production's creative team for the revival: Hamlisch, Wagner, and Aldrege. Avian agreed to direct the production. Baayork Lee, who originated the role of Connie Wong on Broadway and served as the musical's first dance captain, restaged Bennett and Avian's original dance routines. Lee oversaw most of A Chorus Line's international companies during the 1980s and acted as Bennett's proxy before and after his death. In explaining Bennett's rationale and defending Breglio's choice to remount the musical's inaugural production, Lee states, "Michael Bennett wanted an audience anywhere to experience what was seen in New York. So the [physical] elements remain the same. We haven't changed the show. We want you to see it as it was. ${ }^{״ 339}$ Between 1977 and the revival's opening, Lee staged over thirty-five productions of $A$ Chorus Line using Bennett's template. As authentic reproduction has not only been the historical precedent for the musical, but also the modus operandi for many of its original artists and stakeholders, it stands to reason that Bennett and his creative team always considered the musical to be a closed text-an authoritative work for which there is (assumedly) only one interpretation and one accepted method of staging. This view is supported by the fact that reviving the original production —or at least the memory of the original production — was the only course of action considered for the artists in 2006. When Susan Kittenplan of Vanity Fair asked Breglio if he or director Avian planned on updating the musical in any significant way,

${ }^{339}$ Quoted in Chin Hui Wen, "Baayork Lee for A Chorus Line," I-S Online, May 3, 2012, http://is.asia-city.com/events/article/interview-baayork-lee-chorus-line (accessed February 7, 2013). 
the producer responded by claiming, "No one wants a deconstructed Chorus Line."340 Avian addressed the same question, stating, "What would they have us do, put the dancers in a circle? I did the original. I cannot be asked to update myself. That's for some other director. ${ }^{, 341}$

Despite Avian's insistence on resurrecting Bennett's original production and his apparent refusal to amend $A$ Chorus Line in any way, Bennett himself did experiment with updating the musical during its original run, establishing a precedent for updating the work so that it would align with later eras. At the same time that he established 1975 as the unequivocal setting of the Broadway production, Bennett allowed the Bus and Truck Company of A Chorus Line to use the current moment as the musical's temporal setting - a decision that placed the musical's action squarely within the early 1980s. While several production elements, such as Wagner's scenery and Musser's lighting design, remained untouched by Bennett's decision, Aldrege necessarily adapted her costume designs to reflect current trends in dance apparel. The men of the company no longer wore bell-bottomed pants; moreover, several original costumes that had been constructed with cotton, wool, or Danskin fabrics were replaced with new garments made of milliskin spandex. ${ }^{342}$

Additionally, several of the period references in Kleban's lyrics and Kirkwood and Dante's libretto were revised in order to accommodate the temporal change. The years of the characters' birthdates were adjusted by a decade in order to ensure that their dancers' respective ages remained consistent with the stated ages of the original libretto.

${ }^{340}$ Kittenplan, 204.

${ }^{341}$ Quoted in Rohan Preston, "On Stage: Peripatetic, Poetic, and Chic," The Star Tribune, June 13, 2009: 16.

${ }^{342}$ Mandelbaum, 310. 
Allusions to celebrities and public figures also changed in accordance to the new, present day setting. For example, Judy Turner, who originally claimed that her given name was Lana Turner, now jokingly alleged that her name was Tina Turner. She later cited Ann Reinking as her dancing idol rather than Gwen Verdon as she had in the original libretto. Val's mention of June Allyson's performance in You Can't Run Away From It was revised and now referenced Sandy Duncan's portrayal of Sandy Stockton in the 1971 CBS sitcom The Sandy Duncan Show. Furthermore, Bebe's self-avowed adolescent crush on Steve McQueen shifted to Roger Moore. ${ }^{343}$ These slight revisions to A Chorus Line's libretto and lyrics were presumably made to help the musical cohere to its new temporal setting and to provide present day audiences with more current and recognizable cultural references. Tina Turner was arguably one of the most successful female recording artists when critically acclaimed album Private Dancer was released by Capitol Records in 1984. Ann Reinking, a protégé of choreographer Bob Fosse, won notoriety in the 1970s for originating dancing roles in Broadway musicals such as Over Here! (1974), Goodtime Charley (1975), and Dancin' (1978), as well as replacing both Donna McKechnie in $A$ Chorus Line and Gwen Verdon in Chicago in 1976 and 1977 respectively. Her appearances in later films such as Fosse's All That Jazz (1979) and John Huston's Annie (1982) seemingly established her as a dancing star of the 1980s. Although CBS canceled Sandy Duncan's self-titled sitcom after two seasons, Duncan remained in the public eye throughout the 1970s and 80s by appearing in television miniseries such as Roots (1977) and by starring in the first Broadway revival of Mark Charlap and Jule Styne's musical adaptation of Peter Pan from 1979 to 1981. Finally, British actor Roger Moore famously portrayed the title role in the popular James Bond film series from 1973 to 1985.

${ }^{343}$ Stevens and George, 20. 
The touring production's use of an updated temporal setting and libretto lasted for slightly over one year before the company received word from Bennett to restore the original 1975 book, lyrics, and costumes. ${ }^{344}$ According to Avian, the rationale for this reversion was that Bennett himself felt $A$ Chorus Line to be too much a product of the 1970s: "It started to become dishonest . . . we had to stay true to the morality of 1975 and the perspective of the year." 345 Therefore, despite a clear precedent for revising A Chorus Line's text, particularly for the purpose of updating its era, Avian maintained that his revival of the musical would retain its original setting and would continue to reflect American culture and values of the mid 1970s. ${ }^{346}$

With the discourse of authentic resurrection guiding the production, the revival's creative team oversaw the restoration of their respective contributions to A Chorus Line. Though authenticity was Breglio's stated goal, some minor alterations were made to the musical's look and sound to accommodate advancements in theatrical technology. Wagner and Aldrege attended to the musical's physical production-recreating the revolving periaktoi and rehearsal garments that they provided thirty-one years prior. Modeled after his initial design, Wagner's scenery now pivoted thanks to computerized scenic automation, and his "sunburst" effect for the musical's finale was achieved with fiber-optic lighting rather than strips of mylar. Aldrege's period costumes appeared identical to those that she created for the original production but were constructed with new stretch fabrics for a slimmer and more flattering silhouette. Lighting designer Natasha Katz adapted Tharon Musser's Mondrian-inspired light plot for present-day

${ }^{344}$ Mandelbaum, 310.

${ }^{345}$ Quoted in Gordon Cox, “Can 'Chorus' Still Line Up Auds?," Variety, July 17, 2006, 45. ${ }^{346}$ Ibid. 
instruments but dutifully retained the spirit of Musser's original design. ${ }^{347}$ Hamlisch, in collaboration with orchestrator Jonathan Tunick (the last living member of $A$ Chorus Line's orchestration cohort), modified the musical's original instrumentation slightly by replacing the orchestra's harp and electric guitar with digital synthesizers. Tunick also introduced entirely new instruments to the orchestral score by adding a third synthesizer to create multiple string effects. The orchestrator claimed that he always believed the musical's original underscoring sounded too brash due to the pit orchestra's disproportionately large brass section and notable lack of string instruments. Likening his methods for re-orchestrating $A$ Chorus Line to the task of restoring an old car, Tunick described his work as "replacing the worn out and dirty parts" and further suggested that his contributions to the revival would be largely imperceptible: "It was all under the hood. You don't see it. You just know that the car drives better. ${ }^{348}$ While these new orchestrations would not necessarily erase the innate 1970s sensibility of Hamlisch's score, they would perhaps dilute some of the more pervasive aural signifiers of the era that were embedded within it—particularly the sound of the distorted electric guitar.

Kirkwood and Dante's libretto to $A$ Chorus Line remained largely intact for the revival. The book's twenty-seven period references remained and helped to project the revival's setting as the mid 1970s by gesturing to preceding decades; however, director Avian excised all other mentions of time from the libretto, most notably the dancers' birthdates. The repetition of birth years — seventeen in total—had helped to confirm the original production's temporal setting thirty-one years earlier, but now Avian believed 26.

${ }^{347}$ Ellen Lampert-Gréaux, “The Ultimate Line Dance,” Live Design, December 2006, 25 -

${ }^{348}$ Masterworks Broadway, “A Chorus Line - Jonathan Tunick," Podcast, Masterworks Broadway Website, mP3 file, October 10, 2006, http://www.masterworksbroadway.com/podcast/series/a-chorus-line (accessed April 24, 2013). 
that the citing of dates would confuse or distract present day audiences. ${ }^{349}$ Consequently, the dancers cited only their current ages as they introduced themselves to Zach. Despite a surfeit of visual, aural, and textual signifiers that suggested the musical's moment in time, the revival's only direct reference to a year appeared in the production's Playbill.

The only additional change to the musical's libretto took the form of a minor, and almost imperceptible addition to the end of Gregory Gardner's speech in the fourth part of the Montage. In the original libretto, the dancer told Zach of sexual awakening and recounted the events that led to his coming out as a gay man. Now secure in his sexual identity, Greg would go on to disclose that his coming out was followed by a period of depression: "It was the first time that I realized I was homosexual. And I got so depressed because I thought being gay meant being a bum all the rest of my life. ${ }^{350}$ For the revival, the production team altered this line slightly to read, "And I got so depressed because I thought being gay meant being an outcast all the rest of my life, a bum.. ${ }^{351}$ While this alteration to the text was slight, it arguably changed, or perhaps clarified, Greg's perception of what life would be like for a self-identified gay man in the years of his adolescence: the late 1950s and1960s. Without context of qualification, the word "bum" could potentially read as a pejorative to present day viewers, suggesting someone who was a derelict, delinquent, or even a vagrant. Moreover, these rather abrogating connotations could cause audiences to view the character of Greg as self-loathing or shamefaced. The years separating A Chorus Line's original production and first revival witnessed a remarkable upsurge in gay visibility throughout all aspects of American

${ }^{349}$ Interview with Bob Avian, Elaine Paige on Sunday, BBC Radio, February 17, 2013.

${ }^{350}$ Kirkwood and Dante, 76.

${ }^{351}$ James Kirkwood and Nicholas Dante, Libretto to A Chorus Line, April 4, 2007, Billy Rose Theatre Collection, New York Public Library for the Performing Arts, 38. 
culture with numerous public figures - from entertainers and athletes to politicians and business leaders - coming out of the closet and exposing their sexual identities to the American populace, as well as the onset of the AIDS epidemic in the early 1980s, the formation and public advocacy work of such groups as the Gay Men's Health Crisis (GMHC), the AIDS Coalition to Unleash Power (ACT UP), Queer Nation, and the Lesbian Avengers in the late 1980s and early 1990s, a marked increase in openly gay characters featured in television programs and feature films throughout the 1990s, the U.S. Supreme Court's repealing of sodomy laws in 2003, and the 2004 legalization of same-sex marriage in Massachusetts. In 2006, queer identities were arguably a fact of American culture, a decided change from the general consensus of the 1970s when a significant portion of the American population regarded gays and lesbians as members of a categorically deviant subculture. Cultural Historian Edward D. Berkowitz reports that the predominant position of the medical community during the 1970s was that gay men and lesbians suffered from psychiatric illness; furthermore, a 1974 Harris Poll revealed that $65 \%$ of American citizens believed the queer community to be potentially harmful to society. ${ }^{352}$ Berkowitz further claims that while the gay liberation movement's efforts to secure civil rights for the queer community throughout the 1970s necessarily increased gay visibility throughout all areas of American public life, living openly as a gay man or lesbian became a mark of identificatory difference not unlike racial, ethnic, or religious identity. ${ }^{353}$ Thus, Greg's use of the word "outcast" in A Chorus Line's revised libretto helped to clarify cultural attitudes toward homosexuality in earlier decades by connoting social displacement and not his own feelings of aberrancy. By virtue of this small

${ }^{352}$ Edward D. Berkowitz, Something Happened: A Political and Cultural Overview of the Seventies (New York: Columbia University Press, 2006), 151-152.

${ }^{353}$ Ibid., 153. 
addition to the libretto, Greg remained a character who appeared to be untroubled by his sexual identity.

While changes to A Chorus Line's physical production, music, and text were relatively minor, Avian did deviate from the original production's template in his casting of African-American dancer Deidre Goodwin as Sheila—a character originated by and based upon the life of Tony Award winner Kelly Bishop. In an age of color-blind casting, the director's choice to cast a black actor in a historically white role might appear somewhat unremarkable. As Angela C. Pao notes in No Safe Spaces: Re-casting Race, Ethnicity, and Nationality in American Theatre, the origins of non-traditional and colorblind casting as an intentional artistic practice in the United States can be traced to the 1950s and 1960s with Joseph Papp and Zelda Fichandler's direction of productions for the New York Shakespeare Festival and the Arena Stage in Washington D.C. respectively, as well as performances staged by the Los Angeles Inner City Cultural Center. Moreover, the advocacy work of the Non-Traditional Casting Project, led by Harry Newman and Clinton Turner Davis, actively promoted equity in casting for actors of color, women, and the disabled from its formation in 1986 into the 1990 s. ${ }^{354}$ Colorblind casting on Broadway, particularly in musical revivals, became increasingly common in the 1990s and 2000s with productions such as Nicholas Hytner's Carousel (1994), Jeff Calhoun's Grease (1994), Des McAnuff's How to Succeed in Business Without Really Trying (1995), Walter Bobbie's Chicago (1996), and Susan Stroman's The Music Man (2000) featuring actors of color in key roles hitherto portrayed by white actors on Broadway. Even so, Avian's casting choice proved significant as Goodwin was

${ }^{354}$ Angela C. Pao, No Safe Spaces: Re-casting Race, Ethnicity, and Nationality in American Theatre (Ann Arbor: University of Michigan Press, 2010), 3-4. 
the first black actor ever to portray the character on Broadway. Moreover, it opened the musical's assumedly closed text to new readings and interpretations. The libretto to $A$ Chorus Line specifies the race and ethnicity of four characters: Connie, Richie, Diana, and Paul. Connie Wong, born and raised in the Lower East Side of Manhattan's Chinatown district, is of unspecified Asian descent. Diana Morales and Paul San Marco (given name Ephrain Ramirez) both identify themselves as Puerto Rican, and Richie Walters is, according to the musical's book, A Chorus Line's sole black character. Like Sheila, these roles were modeled on the dancers who attended and shared their testimonies at the Nickolaus Exercise Center tape sessions. Librettists Kirkwood and Dante based the characters of Connie and Diana on the lives and experiences of Baayork Lee and Priscilla Lopez, the actors who would go on to originate the roles. Similarly, Dante used his own story of growing up gay in Spanish Harlem, as well as his secret life as a drag artist in creating a backstory for Paul—a role for which the character's portrayer, Sammy Williams, won the 1976 Tony Award for Best Featured Performance by an Actor in a Musical. Dancer Ron Dennis inherited the role of Richie and the song "Gimme the Ball" when his friend Candy Brown left the production during its workshop period at the Public Theatre. Kirkwood and Dante changed the gender of Brown's character when Dennis joined the project, but not the character's racial identity. Throughout the musical's Off-Broadway development, Brown and Dennis were the only black dancers in the musical's company; consequently, Richie became the only black character to stand on Zach's line. Although numerous actors would portray Connie, Diana, Paul, and Richie over the course of A Chorus Line's fifteen years on Broadway, 
the characters' stated ethnicities and racial identities always stayed true to that of the dancer who inspired the part.

The libretto used for Avian's 2006 revival of A Chorus Line retained all of the original book's references to the aforementioned characters' racial and ethnic backgrounds - a fact that suggests that racial and ethnic identity are immutable features of these roles. The question of whether racial and ethnic specificity also applies to the musical's remaining fifteen characters, however, was raised by Avian's casting of Deidre Goodwin. Neither Sheila nor the other dancers on Zach's shortlist ever make mention of their race, presumably because the dancers who inspired the roles were white, and because whiteness, as numerous critical race scholars have suggested, regularly goes unremarked. ${ }^{355}$ Reifying these characters' whiteness is the fact that white actors traditionally portrayed the roles on Broadway, on tour, and around the world throughout A Chorus Line's initial run. Because Sheila never references her own racial background, Avian's choice to cast Goodwin in the role did not necessarily contradict the musical's text. Specifying Sheila's heretofore unmentioned racial identity, however, arguably altered the musical's subtext in a variety of subtle, yet significant ways. For example, Richie initially introduced himself to Zach by saying, "My name is Richie Walters. I was born on a full moon in Herculaneum, Missouri. And I'm black"-presumably to acknowledge that he was the only black dancer to have been kept for the director's callback. ${ }^{356}$ His self-identifying gesture is at once a joke-Richie's blackness is strikingly evident when compared to the predominantly white bodies that flank him — and a comment on the state of racial diversity on Broadway during the mid 1970s. According to

${ }^{355}$ See, for example, Mike Hill, After Whiteness: Unmaking an American Majority (New York: New York University Press, 2004), 3.

${ }^{356}$ Kirkwood and Dante, 27. 
Dennis the number of black dancers who worked on Broadway frequently enough to declare themselves gypsies at the time of A Chorus Line's opening was quite small, and while the musical's libretto never addresses the homogeneity of its ensemble in earnest, the disproportionate ratio of white dancers to dancers of color was representative of the era. ${ }^{357}$ During A Chorus Line's workshop process, the dancer often described his role as "a lone island of black in a sea of white faces" and referred to the musical itself as $A$ Group of White Dancers. ${ }^{358}$ By adding a second dancer of color to the cast of his $A$ Chorus Line revival, Avian introduced more racial diversity to the musical's company, but also arguably displaced Richie as the musical's lone black dancer, and therefore changed the meaning of his first lines to Zach. In the revival, Richie's motives for stating his racial identity appeared to be less about individuating himself from the rest of the assembled dancers and more about stating the obvious. This slight alteration to the libretto arguably undermined the rather pointed statement about racial diversity within the Broadway community that the character made with his introduction. Richie's choice to assert his racial identity, thereby highlighting the lack of racial diversity among Zach's assembled dancers could be read as a critique of both the director and Broadway casting practices writ large. The presence of a second black dancer on Zach's line meant that Richie no longer represented the African-American community alone. Moreover, the weight or significance that his introduction previously held presumably diminished, devolving from an incisive commentary to an awkward bit of comedy.

The casting of Goodwin also amended A Chorus Line's subtext as the character of Sheila was created for and tailored to her original portrayer, Kelly Bishop, and the story

\footnotetext{
${ }^{357}$ Viagas, 111.

${ }^{358}$ Ibid., 157.
} 
that Sheila shares about her childhood was based upon Bishop's own early life. Both Sheila and Bishop were born in the middle years of the 1940s and came of age in the 1950s during a period of legalized racial segregation. Presumably, Bishop's experience of childhood and adolescence, as well as her opportunities in the world of dance, would have been different as a young white dancer from those of an aspiring dancer of color. Sheila's story, told vis-à-vis a monologue and the first verse of "At the Ballet," focuses primarily on her parents' unhappy marriage, her dream of becoming a ballet dancer, and how ballet class functioned as an escape from the tumult of life at home. Shelia never once mentions experiencing the discrimination, prejudice, or oppression that a black dancer of the period would have surely encountered prior to the Civil Rights Act of 1964. Additionally, Sheila attributes her desire to pursue dance to the fact that her mother was a successful ballerina prior to marrying Sheila's father. While Brenda Dixon Gottschild contends that the years between World War I and World War II saw an increase in dance schools in urban black communities, the fact that the first all-black ballet companies in the United States, such as the First Negro Classic Ballet (founded in 1947), New York Negro Ballet (founded in 1954), and the Dance Theatre of Harlem (founded in 1969), were not established until after Sheila's birth suggests that her mother's opportunities for professionalization would have been limited if she were black as well. ${ }^{359}$ Furthermore, Sally Banes contends that black dancers had limited access to white ballet companies during the 1930s and 40s as much of the white ballet establishment believed that black dancers had "the wrong bodies" for ballet. ${ }^{360}$ If Sheila were indeed an African-American

${ }^{359}$ Brenda Dixon Gottschild, Joan Myers and the Audacious Hope of the Black Ballerina: A Biohistory of American Performance (New York: Palgrave MacMillan, 2012), 6.

${ }^{360}$ Sally Banes, Writing Dancing in the Age of Postmodernism (Hanover, NH: University Press of New England, 1994), 69. 
character, then her claim that her mother enjoyed a successful ballet career is not entirely outside the realm of possibility; however, the historical narrative suggests that it is less plausible than if Sheila were a white character with a white mother. In addition to not remarking her own racial identity, Sheila never mentions her parents' race. The dancer never addresses the subject of race in any way, leaving one to assume that her race was not as central to her identity as it was to Connie, Diana, Paul, and Richie. These characters openly remarked their racial identities, and the presence of a racialized character that did not mention race or racism arguably skewed the musical's discussion of race. Avian's color-blind casting did not necessarily repudiate any aspect of Sheila's character as dictated by A Chorus Line's libretto; however, it stands to reason that it did tacitly alter Sheila's backstory and biography — changing the way in which the character experienced the world as a child. It also presumably challenged, or perhaps even contradicted, the extant historical narrative of race in the United States, particularly with regard to classical dance.

Avian's casting of Goodwin was also somewhat conspicuous as it was his only instance of overt color-blind casting for his revival. Aside from Sheila, the director selected white dancers to play the remaining twelve historically white roles. This choice not only mirrored the casting of the original production, but also arguably reified said characters as white and in doing so, reified the original production as the revival's template. Avian's casting is also remarkable in that it was the first overt instance of colorblind casting in A Chorus Line's history on Broadway. During the musical's fifteen-year run, all of A Chorus Line's characters save two were cast according to the ethnicity or 
racial identity of the dancers who inspired and/or first played the characters. ${ }^{361}$ On occasion, white dancers performed the roles of Diana and Paul, including Paul's original portrayer, Sammy Williams. While the ethnicities of the actors portraying these roles did not always correlate to that of Diana and Paul, the characters' stated ethnicities never changed during the course of the musical's run. Diana and Paul always identified themselves as Puerto Rican regardless of whether the actors bringing the characters to life on stage were Latinos or not. The original libretto arguably allowed for this casting as both Paul and Diana suggested that their ethnicities were not necessarily detectable. Paul alleged to have traded his Puerto Rican surname for a name of Italian origin when he entered the entertainment industry in part because he did not appear Puerto Rican. ${ }^{362}$ Conversely, Diana related that she did not change her family name when she began her dancing career because she "figured ethnic was in." ${ }^{, 363}$ Her admission suggested that she, like Paul, considered, if only momentarily, concealing her ethnic identity by selecting a different professional name. Paul and Diana's admissions of ethnic ambiguity would allow Avian to cast Jason Tam and Natalie Cortez, dancers of Hawaiian and French/Argentinian heritage, as Paul and Diana without overtly contradicting the musical's text. However, as the musical's libretto makes no such mention of Sheila's racial identity, the character appeared as white throughout $A$ Chorus Line's initial run on Broadway. Goodwin's black body stood in sharp contrast to Bishop's and every other dancer who portrayed Sheila in productions of the musical directed by Michael Bennett. In representing a derivation from Bennett's original template for $A$ Chorus Line, the

${ }^{361}$ This approach to casting applied to all of A Chorus Line's various national tours, bus and truck companies, and international companies as well.

${ }^{362}$ Kirkwood and Dante, 98.

${ }^{363}$ Ibid., 28. 
casting of Goodwin contradicted Breglio and Avian's repeated claims that their revival would be an authentic replica of the original production. However, adding another dancer of color to A Chorus Line's dramatis personae not only introduced more racial diversity to the musical's predominantly white company, it also subtly moved the musical forward in time. Furthermore, it demonstrated that the musical might not be a patently closed text.

Beyond the director's treatment of race, Avian's casting of the revival also differed from the original production in that a significant portion of his company were not necessarily veterans of the Broadway stage. For the original production, Bennett cast several of his close friends and colleagues - dancers with whom he had previously worked as a choreographer or had performed alongside in various Broadway musicals or on television variety programs such as Hullabaloo and The Milliken Breakfast Show. The vast majority of these dancers identified as Broadway gypsies and had built and sustained careers by performing in the chorus of Broadway musicals throughout the 1960s and 1970s. Consequently, a significant portion of $A$ Chorus Line's principal cast had procured several Broadway credits prior to the musical's opening. Together, the sixteen dancers who played principal roles in the production had appeared in a total of sixty-five Broadway productions. Baayork Lee (Connie) held the distinction of having performed in the most Broadway musicals with a total of ten credits to her name. Kay Cole (Maggie), Priscilla Lopez (Diana), and Don Percassi (Al) had each appeared in the companies of six Broadway musicals. Michael Stewart (Greg) and Pamela Blair (Val) held five Broadway credits, as did Donna McKechnie who was arguably the most recognizable member of $A$ Chorus Line's cast, having won critical acclaim for her featured dance performances in Promises, Promises (1968), Company (1970), and the first Broadway revival of On the 
Town (1971). With the exception of Ron Kuhlman (Don) and Nancy Lane (Bebe), who made their respective Broadway debuts in A Chorus Line, and Cameron Mason (Mark) who had only appeared in one Broadway musical to date, the other thirteen members of the musical's principal cast were seasoned dancers whose careers had been forged on the Broadway stage, particularly in musicals choreographed by Michael Bennett: A Joyful Noise (1966), Henry, Sweet Henry (1967), Promises, Promises (1968), Coco (1969), Follies (1971), and Seesaw (1973). ${ }^{364}$

While a significant number of Bennett's chosen dancers for $A$ Chorus Line represented a cadre of Broadway warhorses, Avian's revival company contained a high number of Broadway neophytes. The director and his casting team, a cohort comprised of Breglio, Lee, and casting director Jay Binder, auditioned approximately 1,700 dancers from across the United States for over ten months, the process of which was chronicled by filmmakers James D. Stern and Adam Del Deo for their 2008 documentary entitled Every Little Step. ${ }^{365}$ Avian's final cast contained three Broadway veterans: Charlotte D'Amboise, Michael Berresse, and Deidre Goodwin. D'Amboise inherited the role of Cassie, and much like Donna McKechnie before her, had earned some fame in musical theatre circles prior to $A$ Chorus Line for her dancing roles in the original Broadway productions Jerome Robbins' Broadway (1989) and Contact (2000), as well as revivals of Damn Yankees (1994), Company (1995), and Chicago (1996). Having appeared in nine Broadway musicals, D'Amboise was the most accomplished member of the revival cast. Berresse (Zach) and Goodwin (Sheila) also boasted substantial resumes with eight and seven Broadway credits to their name respectively. These statistics, however, stood in

${ }^{364}$ See Appendix I for a complete list of the original production's cast and production team members.

${ }^{365}$ Kittenplan, 204. 
sharp contrast to the comparatively small number of Broadway credits that the majority of Avian's company claimed. While nearly every member of the production's principal cast had worked extensively in regional theatres or performed in the ensembles of several national tours, a significant percentage of the group was comprised of dancers with little to no Broadway experience. Five of the dancers cast in principal roles-Ken Alan (Bobby), James T. Lane (Richie), Heather Parcells, (Judy), Paul McGill (Mark), and Jason Tam (Paul) — had only appeared in a single Broadway production prior to the revival's opening. An additional five dancers—Natalie Cortez (Diana), Mara Davi (Maggie), Jessica Lee Goldyn (Val), Alisan Porter (Bebe), and Chryssie Whitehead (Kristine) — made their Broadway debuts in the production. ${ }^{366}$ Thus, dancers whose careers did not necessarily align with the ethos of the Broadway gypsy portrayed ten of the musical's sixteen principal roles.

The majority of Bennett's original cast members had struggled to break out of the Broadway chorus for years and articulated their frustrations with Broadway casting practices, as well as their anxieties over future job security during the Nickolaus Exercise Center tape sessions. Librettists Kirkwood and Dante then folded these frustrations and anxieties into the musical's book, the majority of which appeared in what Bennett termed the "Alternatives Scene," a dialogue between the assembled gypsies about the temporality of a dancer's career. Following Paul's exacerbation of an old knee injury that sent him to the hospital and eliminated him from the casting competition, Zach asked the dancers to consider what they would do if they were no longer able to pursue a career in dance. Their responses, which culminated in the song "What I Did for Love," addressed

${ }^{366}$ See Appendix J for a complete list of the revival production's cast and production team members. 
the subject of dancing writ large; however, several characters - Diana in particularspoke to how dancing on the Broadway stage and being a Broadway gypsy constituted their identities:

DIANA: Look, I sit around get depressed and worry about all these things, too. But I meet somebody and they say to me: "Wow, you dance on Broadway! How fabulous! You got somewhere. You're something." And Christ, I get this feeling - (Music under) — inside because I used to stand outside of that stage door and watch all these girls come out of there, with their eyelashes and their make-up and I'd think: "God, I'll never be that old. I'll never be that old. I'll never be old enough to come out of that stage door." But deep down inside I knew I would and, goddam it, I've come this far and I'm not giving up now. ${ }^{367}$

Because membership within the Broadway community was a defining characteristic of $A$ Chorus Line's dramatis personae and original cast members, it is somewhat curious and even conspicuous that a significant portion of Avian's ensemble had yet to perform in more than a single Broadway production when the 2006 production opened. The revival company's collective Broadway credits totaled forty-nine; however, this statistic includes twenty-four productions provided by the substantially more seasoned Goodwin, Berresse, and D'Amboise. Excluding the contributions made by their extensive resumes, the total number of Broadway credits for the remaining thirteen company members was twentyfour - nearly half of the total productions boasted by the musical's original cast. The alignment between character and actor — a fictional Broadway gypsy portrayed by an actual Broadway gypsy—was a unique dramaturgical feature of $A$ Chorus Line in 1975 that arguably contributed to the air of truthfulness and authenticity that so many critics of the original production cheered. With a significant percentage of the revival's cast being new to Broadway, it's possible that authenticity did not necessarily translate as fully as it

${ }^{367}$ Kirkwood and Dante, 135. 
might have had Avian cast true gypsies. Instead, the musical became something of a vehicle for Broadway newcomers.

While A Chorus Line was the darling of the New York Theatre critics in 1975, the 2006 revival met with marked dissension. Out of fifteen reviews, the production received six positive notices, five that were mixed, and four categorical pans. Those critics who lauded the revival tended to err on the side of hyperbole and focused their remarks on the musical's historical import, the achievement of Michael Bennett's staging, the thrill of reencountering his choreography, and the rare pleasure of witnessing an iconic musical in its original form. Only two of these reviewers, however, spoke to how the musical's story and themes resonated with the current cultural climate. Joe Dziemianowicz of The Daily News described A Chorus Line's central metaphor of life as an audition as "durable and universal" and claimed the dancers' personal confessions, though no longer novel or outrageous, were still compelling. ${ }^{368}$ Similarly, Bloomberg's John Simon continued to praise the musical as he had in 1975, describing it as "utterly fresh" and declaring it a higher-caliber of musical than most of Broadway's recent hits. ${ }^{369}$ Despite their clear admiration of the revival and their repeated claims of the musical's social relevance, neither critic explained precisely how they saw A Chorus Line as aligning with the present zeitgeist. The nine reviewers who offered more lukewarm assessments, however, dealt in questions of time almost exclusively. Describing the revival as meticulous, tired, servile, bloodless, recycled, and quaint, these reviewers argued that time had begun to

${ }^{368}$ Joe Dziemaianowicz, "Chorus of Approval," review of A Chorus Line by James Kirkwood, Nicholas Dante, Marvin Hamlisch, and Ed Kleban, directed by Bob Avian. Gerald Schoenfeld Theatre, New York, Daily News, October 6, 2006, 59.

${ }^{369}$ John Simon, "Chorus Line Still Fresh in First Broadway Revival," review of A Chorus Line, directed by Bob Avian, New York, Bloomberg News Online, October 6, 2006, accessed March 3, 2013, http://www.bloomberg.com/apps/news?pid=newsarchive\&sid=aHUUhxigv2PA. 
strip the musical of its novelty and that Breglio, Avian, and Lee's choice to present $A$ Chorus Line as a museum piece only served to exacerbate the problem. Ben Brantley of The New York Times, Clive Barnes of The New York Post, Jeremy McCarter of New York Magazine, David Rooney of Variety, and Linda Winer of Newsday all alleged that by duplicating the original production, the revival's creative team forestalled the excitement of discovery for anyone who had seen A Chorus Line during its initial Broadway run or its years of touring. Barnes characterized the revival as a "facsimile" and suggested that Avian and his team had "done a pious job of all but embalming Bennett's creation." He then advised that anyone who had witnessed the original production need not rush to attend a performance revival lest they want to mar their memories of the musical. ${ }^{370}$ The subject of memory seemed to foreground Brantley's review as the critic continuously compared his experience of the new production with reminiscences of his viewing Bennett's original as a college student: "The introductory rush of timelessness congeals into a time warp. Watching the show, directed by Bob Avian, is like drinking from a pitcher of draft beer. You never repeat the tang or sting of that first swig." ${ }^{371}$ McCarter presented a slightly less favorable assessment, claiming that the musical showed signs of dilapidation. As he stated, "This is a musical that looks its age. Some of the stories are a trifle musty, and the sound - from the horn fanfare that evokes cop shows in which everyone has facial hair to the drum breaks that are pure Action News-reeks of

${ }^{370}$ Clive Barnes, "Embalming Fluidity," review of A Chorus Line by James Kirkwood, Nicholas Dante, Marvin Hamlisch, and Ed Kleban, directed by Bob Avian. Gerald Schoenfeld Theatre, New York, New York Post, October 6, 2006, 41.

${ }^{371}$ Ben Brantley, "From the Top: Five, Six, Seven, Eight!" review of A Chorus Line by James Kirkwood, Nicholas Dante, Marvin Hamlisch, and Ed Kleban, directed by Bob Avian. Gerald Schoenfeld Theatre, New York, New York Times, October 6, 2006, sec. E, p.1. 
polyester." ${ }^{372}$ Winer followed suit by describing the production as a "tracing-paper revival" and deriding Avian's direction: "the treatment of every step-kick as holy scripture brings the faint whiff of mothballs to memory lane." ${ }^{, 373}$ Rooney also found fault with Avian's method of revival, suggesting that authentic reproduction prevented the production's actors from locating the honesty for which the musical was originally revered: "Fitting into the established contours of existing performances rarely generates the same sparks as creating them from scratch. The actors on stage feel like topnotch replacements rather than originators. It's the sense of duplication—albeit masterfully executed — that keeps the revival from soaring., ${ }^{374}$

Michael Feingold of The Village Voice, Elysa Gardner of USA Today, Howard Shapiro of the Philadelphia Inquirer, and Peter Marks of The Washington Post joined with the aforementioned critics to suggest that the sense of urgency and desperation that fueled A Chorus Line's original production was all but missing from the revival. As Brantley stated, "In providing us with an archivally and anatomically correct reproduction of a landmark show, its creators neglected to restore its central nervous system, and most important, its throbbing heart. ${ }^{, 375}$ Marks echoed this sentiment by claiming, "But in the slavish determination to bottle the Chorus Line essence, the odor grows stale ... the desperate sense of needing this audition to succeed—of "God, I Hope

372 Jeremy McCarter, "Broadway Melody of 1975," review of A Chorus Line by James Kirkwood, Nicholas Dante, Marvin Hamlisch, and Ed Kleban, directed by Bob Avian. Gerald Schoenfeld Theatre, New York, New York, October 6, 2006.

${ }^{373}$ Linda Winer, "Chorus Still Kicking, but Not Quite So High," review of A Chorus Line by James Kirkwood, Nicholas Dante, Marvin Hamlisch, and Ed Kleban, directed by Bob Avian. Gerald Schoenfeld Theatre, New York, Newsday, October 6, 2006, sec. B p.7.

${ }^{374}$ David Rooney, "A Chorus Line," review of A Chorus Line by James Kirkwood, Nicholas Dante, Marvin Hamlisch, and Ed Kleban, directed by Bob Avian. Gerald Schoenfeld Theatre, New York, Variety, October 6, 2006, 2.

${ }^{375}$ Brantley. 
I Get It"- just hasn't translated. ${ }^{, 376}$ McCarter, Gardner, and Shapiro also remarked that $A$ Chorus Line's ability to stir audiences derived from the characters' candid and public confessions - a conceit that aligned with Me Decade values, but was still relatively uncommon at the time of the musical's premiere. All three reviewers found the musical's premise to be less groundbreaking in an era of reality television and YouTube stardom. As Gardner stated, "Of all the dated aspects of A Chorus Line ... the most glaring might be the notion that someone trying to gain recognition in show business would be reluctant to share the details of his or her personal life in public." ${ }^{377}$ Shapiro gestured to a bevy of current reality television program that utilized A Chorus Line's premise, citing them as descendants of an entertainment lineage that originated with the musical:

It was a singular sensation when it opened on Broadway thirty-one years ago, but it's not singular anymore ... [the musical] returns to an America that bursts with the show's legacy: a slew of elimination grabbers on TV. Which survivor will get the boot? Who will be America's newest idol? Or top runway body? Who lacks the stuff of an apprentice? And who - please, we demand it - who is The Biggest Loser? ${ }^{378}$

The reviewer would go on to praise the dancing ability of the revival's cast and the charm of their performances, but also continued to temper his accolades with meditations on how the passage of time not only affected his reception of the musical, but also

${ }^{376}$ Peter Marks, "Dulling a Singular Sensation: Revived A Chorus Line Duplicates the Original, But Not Its Kick," review of A Chorus Line by James Kirkwood, Nicholas Dante, Marvin Hamlisch, and Ed Kleban, directed by Bob Avian. Gerald Schoenfeld Theatre, New York, Washington Post, October 9, 2006, sec. C p. 2.

${ }^{377}$ Elysa Gardner, "A Line of Talent Lifts 'Chorus'; Broadway Musical Revival is a Little Out-Of-Date, But Not out of Charm," review of A Chorus Line by James Kirkwood, Nicholas Dante, Marvin Hamlisch, and Ed Kleban, directed by Bob Avian. Gerald Schoenfeld Theatre, New York, USA Today, October, 9, 2006, sec. D p. 2.

${ }^{378}$ Howard Shapiro, "Thirty-One Years Later, A Chorus Line is Sensational Again in Its Broadway Revival, Even With a Still-Unsettling Sense of Voyeurism," review of A Chorus Line by James Kirkwood, Nicholas Dante, Marvin Hamlisch, and Ed Kleban, directed by Bob Avian. Gerald Schoenfeld Theatre, New York, Philadelphia Inquirer, October 8, 2006, sec. H p. 1. 
unwittingly rendered the musical and its milieu relatively obsolete: "When you look at the premise of $A$ Chorus Line ... and you and the world are thirty years older than when you first visited the show, the wrinkles of experience influence your gaze ... it now registers as somewhat quaint. ${ }^{, 379}$ Citing the recovery of New York City’s Times Square area in the late 1990s as an exemplar of how time inadvertently disturbed his enjoyment of the musical, Shapiro reminded his readers that the manner in which A Chorus Line's characters described not only the location, but also Broadway economics would invariably differ from how they were perceived in the present. Paul's story of being molested in one of Times Square's adult movie theatres and the dancers' frequent lamenting over what they perceived to be the death of Broadway would surely stand counter to what was now a tourist destination for families and a thriving entertainment industry filled with bankable stars from film and television. ${ }^{380}$

The 2006 revival of $A$ Chorus Line ran for just under two years at the Gerald Schoenfeld Theatre and grossing a total of $\$ 54,540,021$. The production recouped its initial $\$ 8,000,000$ in financial investment in its first nineteen weeks on Broadway. It also outran and outsold all of the other musical revivals of the 2006-2007 Broadway season: John Doyle's Company, Lonny Price's 110 in the Shade, Gary Griffin's The Apple Tree, and John Caird and Trevor Nunn's Les Misérables. The production was in no way a commercial failure; however, the production did fail to approximate the financial success of A Chorus Line's original production. Moreover, at the close of the 2006-2007 award season, the revival earned only two Tony Award nominations (Best Featured Actress for

${ }^{379}$ Ibid. 
Charlotte D'Amboise and Best Revival of a Musical) and failed to win a single prize. The production closed on August 17, 2008, after 759 performances.

While it would be foolhardy for anyone to expect a revival of $A$ Chorus Line to duplicate the many achievements of its original production, Avian and Breglio repeatedly claimed that the musical would resonate with current day audiences as much as it had thirty-one years prior. "The relevance is going to be exactly the same," Avian assured Vanity Fair's Susan Kittenplan prior to the revival's opening. ${ }^{381}$ Recalling the American zeitgeist at the time of $A$ Chorus Line's 1975 premiere, he would later charge that the timing of his revival was not only opportune, but also that the current zeitgeist was analogous to American culture in the mid-1970s:

When we opened the show in in 1975, we were losing the war in Vietnam, we were about to abandon Saigon, we had just gotten over Nixon's retirement, resigning rather, and the country's dissatisfaction with the government in general. And then you saw these kids up on the stage speaking the truth and speaking from their hearts and it was a breath of fresh air. So where are we today? We're in a war in Iraq that is futile. And we're very disillusioned with the government and all we see is a congress that seems to be lying to us ... and here again, we're watching the kids again up on the stage telling their truths with their sweet souls. ${ }^{382}$

The parallel that Avian drew between the American political climates in 1975 and 2006 is reasonably astute; however, his suggestion that $A$ Chorus Line would win the favor of current day audiences because the assembled dancers reveal their innermost secrets to Zach and speak the truth does not account for one of the musical's central dramaturgical precepts. The libretto to $A$ Chorus Line asks an audience to suspend their disbelief and

${ }^{381}$ Kittenplan, 204.

${ }^{382}$ Masterworks Broadway, “A Chorus Line - Bob Avian,” Podcast, Masterworks Broadway Website, mP3 file, October 10, 2006, http://www.masterworksbroadway.com/podcast/series/a-chorus-line (accessed April 24, 2013). 
assume that Zach's dancers present themselves and their backstories truthfully. We are never given any reason not to trust their testimonials; however, any of the characters could have very well fabricated their anecdotes in order to impress the director and better their chances of being cast. In an era of "reality" television, when producers and directors are known to manufacture events and participant stars often present a modified version of themselves to the viewing public, it is reasonable to believe that theatregoers attending Avian's revival would receive the dancers' statements of supposed truth with a certain amount of skepticism. Furthermore, the director's conviction that the musical would retain its relevance seems to disregard the time-bound aspects of $A$ Chorus Line's libretto and original production. The specificity of the musical's temporal setting, combined with the time-specific content of the dancers' stories, the post-Vietnam cultural attitudes and anxieties embedded within them, the libretto's twenty-eight period references, and the score's repeated use of 1970s musical idioms could have kept audience members without a highly developed historical or cultural vernacular from fully engaging with the musical in 2006. The musical's original libretto, physical production, and staging remained largely unchanged for the revival while cultural attitudes toward the musical's subject matter (homosexuality, masturbation, cosmetic surgery) invariably shifted, and period references faded from the collective consciousness.

Audience viewing habits on Broadway had certainly changed as well. The thirtyone years that separated the original production of $A$ Chorus Line from its first revival saw the rise and popularization of megamusicals, properties from Great Britain such as Les Misérables (1987), The Phantom of the Opera (1988), and Miss Saigon (1989) that traded in scale, spectacle, sweeping scores, and epic stories. The relative simplicity of $A$ 
Chorus Line's narrative and physical production stood in stark contrast to this new trend. Into this new Broadway landscape also came a rash of musicals adapted from widely recognizable and pre-existing materials such as feature films and popular songwriters' catalogues. Movicals such as Sunset Boulevard (1994), Beauty and The Beast (1994), The Lion King (1997), The Producers (2001), and Hairspray (2002), as well as jukebox musicals such as Mama Mia! (2001), Movin' Out (2002), Jersey Boys (2005), and Rock of Ages (2006), proliferated across Broadway throughout the late 1990s and early 2000s before becoming distinct (and relatively ubiquitous) sub-genres of the American musical. Avian's revival of $A$ Chorus Line returned to a Broadway that appeared to be alive and thriving, which also stood counter to the Broadway landscape of the musical's original production. Musical theatre historian Gerald Bordman describes the years immediately preceding A Chorus Line's premiere as "barren" and contends that the disreputable state of New York City's Theatre District combined with the remarkably low output of new musicals and small number of hits had severely crippled the Broadway theatre industry. ${ }^{383}$ Thus, A Chorus Line's meteoric success was truly singular in 1975 and allowed the musical to bolster the Broadway economy. In 2006, the musical returned to a Broadway already awash in long-running hit musicals.

A Chorus Line also returned to a Broadway overrun with musicals, especially revivals, that featured a recognizable performer in a starring role: film and television actors, recording artists, professional athletes, reality television stars, and other celebrities from across American popular culture. In particular, revivals of Grease (1994), How to Succeed in Business Without Really Trying (1995), Chicago (1996), and Cabaret (1998) relied heavily on the casting of celebrities in order to prolong their respective runs.

\footnotetext{
${ }^{383}$ Bordman, 737.
} 
Again, A Chorus Line stood counter to current Broadway trends in that it did not lend itself to this approach to casting. Throughout its original run on Broadway, the musical never functioned as a star vehicle. Bennett's desire to showcase a wide array of Broadway dancers kept the piece ensemble-driven. While the libretto featured characters such as Sheila, Diana, Val, and Paul more prominently than others (because of their lengthy monologues or solo numbers), each of the assembled dancers was given the same opportunity to present themselves to Zach and the audience, which suggests that no one character was more important than other.

The only character who might have represented an exception to this rule was Cassie. Cassie's romantic past with Zach separated her from the rest of the dancers, as did her virtuosic talents and her featured dance solo, "The Music and the Mirror." During Cassie's conversation with Zach, the first of only two exchanges with the director not witnessed by the entire company, Zach repeatedly told Cassie that her superior dancing skills made her "too good for the chorus," and therefore separated her from the assembled dancers. ${ }^{384}$ Later in the musical, the unresolved nature of Zach and Cassie's relationship manifested in a heated argument between the pair as the rest of the dancers dutifully rehearsed "One," a quarrel that seemed to centralize Cassie's importance to A Chorus Line's overall narrative. Further evincing the importance of the role was the fact that her portrayer, Donna McKechnie, was arguably the most accomplished member of the musical's inaugural company. McKechnie's turn as Cassie was greeted with a bevy of Awards, including the 1976 Tony Award for Best Actress in a Musical, as well as effusive praise from the New York theatre critics. However, McKechnie's many accolades and Cassie's apparent import to the musical's plot does not gainsay the fact

\footnotetext{
${ }^{384}$ Kirkwood and Dante, 92.
} 
that the original production of $A$ Chorus Line never claimed to feature a single, incontrovertible star. Like the rest of the musical's characters, Cassie actively participated in only a portion of the overall plot, remaining relatively silent until the start of her private dialogue with Zach. Hers was only one of the diverse narratives shared by the relatively large cast of characters in a musical that always remained an ensemble piece.

The prominence of star casting at the time of $A$ Chorus Line's revival coupled with the fact that the production's ticket sales began to lag eighteen months after its opening is perhaps what prompted Breglio to replace Broadway veteran Michael Berresse with former Saved By the Bell actor Mario Lopez in the role of Zach—a choice which arguably gave the musical its first star. The casting of Lopez as A Chorus Line's enigmatic director was rather conspicuous for several reasons. First, Lopez was not a member of the Broadway community and held no professional theatre credits prior to his turn in the musical. The actor had cultivated the bulk of his fame through television appearances, most notably by hosting reality programs. Lopez's presence within the production thus introduced a Hollywood personality into a musical expressly about the New York theatre scene and the lives of Broadway gypsies. Second, Lopez had no formal dance training to speak of when he accepted the role of Zach outside of his ten-week appearance on the third season of ABC's popular dance competition, Dancing With the Stars. Ending the season as the program's first runner-up, Lopez demonstrated an aptitude for dance and an ability to learn steps quickly. However, unlike any of the actors to previously portray Zach on Broadway, Lopez was not a trained dancer. 
The casting of Lopez, a Broadway outsider who was a celebrity in his own right and claimed very little dance experience, was then somewhat anathema to the musical's history and overall dramaturgy, as were the changes that Avian made to A Chorus Line's blocking and choreography in order to showcase the production's new star. Zach, who previously spent the majority of the musical sitting in the back of the house and speaking to the dancers with the aid of a microphone, now occasionally walked to the front of the house and stepped on to the stage. Not only did this alteration to the musical's staging place Zach in closer proximity to the dancers, making him appear less enigmatic and less intimidating, but it also placed the character in full view of the audience. Furthermore, two of the moments in which Zach now appeared on stage changed the subtext of $A$ Chorus Line's original libretto. During Cassie's dance solo in "The Music and the Mirror," Zach left his post at the back of the theatre and walked toward his former paramour, where he climbed the steps to the stage and watched her dance from the edge of the apron. Hitherto, Cassie always believed herself to be dancing on stage alone. Zach's presence on the stage during the song, even while standing still and watching quietly, pulled focus away from Cassie by asking the audience to divide their focus between the dancer and the director. What had previously been a featured moment for Cassie and an opportunity to express herself as a solo artist was now an experience that she shared with Zach. A similar claim of intrusion could be made regarding Paul's monologue, which Zach now also received from the stage. In previous productions, Paul delivered his story while standing on stage alone and speaking into the darkened house. Zach then made his first appearance on stage since the musical's opening combinations to comfort Paul when the young dancer unexpectedly broke into tears, an act that 
demonstrated the director's capacity for kindness and empathy, but not until the dancer lost his composure. Placing Zach onstage during Paul's heart-wrenching monologue also forced the character to share the scene and arguably served to humanize the director earlier than in the original production. Finally, Avian altered Bennett's staging for the musical's finale by placing Zach at the center of several dance formations, a position previously held by Paul. ${ }^{385}$ Situating Lopez at the center of these formations placed him in full view of the audience — the rest of the company danced behind him — and served to confirm his status as the revival's supposed star. These alterations to Bennett's original staging, occasioned by the casting of Lopez, represent yet another instance in which Avian and Breglio, however inadvertently, amended and subsequently opened Bennett's supposedly closed text. Rather than asking Lopez to follow Bennett's original template, the revival's director adapted the musical in order to make the headlining actor's presence more visible.

These alterations to Bennett's staging combined with the choice to cast Lopez as Zach (and not another character) also suggest that Avian and Breglio sought to separate the television star from the rest of the musical's company. Of the nineteen characters that comprise A Chorus Line's dramatis personae, Zach is perhaps the most integral to the musical's overall dramaturgy, and along with Cassie, is arguably A Chorus Line's only other leading role. He is a constant presence throughout the musical despite the fact that he is rarely seen and reveals almost no meaningful information about himself. Even so, he drives the musical's action and sits at a removed distance from the auditioners. These

${ }^{385}$ Matthew Murray, "A Chorus Line," review of A Chorus Line by James Kirkwood, Nicholas Dante, Marvin Hamlisch, and Ed Kleban, directed by Bob Avian. Gerald Schoenfeld Theatre, New York, Talkin' Broadway Reviews, June 29, 2008, http://www.talkinbroadway.com/world/ChorusLine2008.html (accessed February 23, 2013). 
qualities endow the character with a certain eminence that could make it suitable for celebrity casting. Giving the role to Lopez, however, changed the character and musical's text, much in the same way that the casting of Goodwin changed the character of Sheila. All of the extant published histories of A Chorus Line allege that the character of Zach was modeled on Michael Bennett, who was of a rather diminutive stature, slim build, and Italian and Jewish heritage. Like Sheila, Zach never specified his ethnic or racial identity; however, only white actors portrayed the role in the musical's Broadway and touring companies. Additionally, the actors cast in the role tended to resemble Bennett in physical appearance. The casting of Lopez ended this tradition as the actor was tall, muscular, and of Mexican descent. As a result of this casting, Zach joined the musical's growing cohort of racial and ethnic minorities, and the total number of dancers of color to appear in A Chorus Line increased from four in 1975 to six in 2006. As was the case with Goodwin, the casting of Lopez did not contradict the musical's libretto explicitly, but it did alter Bennett's performance text—-the same performance text the Avian and Breglio claimed to preserve. Zach, the musical's unquestioned authority figure whose interrogation of the dancers suggested an awareness of his own power and privilege, became a character whose presence on stage connoted the metanarrative of American progress. Zach was now a Broadway choreographer of color, which was still something of a rarity in the 1970s. A handful of African-American choreographers, including Louis Johnson, Donald McKayle, and George Faison, staged dances for the Broadway productions prior to the opening of $A$ Chorus Line; however, the majority of these musicals — most notably Purlie (1970), Raisin (1974), and The Wiz (1975)—were written by black authors for primarily black casts. Moreover, none of these choreographers 
served as the musical's director. While the number of African-American chorographers working on Broadway in the early 1970s was quite small, choreographers of Hispanic or Latin heritage were virtually nonexistent. The book to A Chorus Line established Zach as a distinguished choreographer with an extensive resume, who like Bennett, parlayed his accomplishments in this initial role into an equally auspicious career directing Broadway musicals. With Lopez inhabiting the role, Zach represented not only a choreographer of color, but also a preeminent member of the Broadway establishment who attained a remarkable degree of success and stature (presumably throughout the civil rights struggles of the 1960s) in spite of his ethnic identity. In this way, Avian and Breglio's casting not only altered the musical's subtext, but also the extant historical narrative of race and ethnicity on Broadway.

Prior to the 2006 revival of $A$ Chorus Line, Avian enjoyed a long and fruitful career in the American musical theatre, beginning as a dancer in the first Broadway revival of West Side Story (1960) and the original Broadway production of Funny Girl (1964). His association with Bennett, which originated in the ensemble of West Side Story, eventually turned into a creative collaboration, with Avian serving as Associate Choreographer for five of Bennett's musicals: Promises, Promises (1968), Coco (1969), Company (1970), Follies (1971), and Seesaw (1973). After co-choreographing A Chorus Line with Bennett and winning the 1976 Tony Award for Outstanding Choreography, Avian would go on to co-choreograph Bennett's most notable flop, Ballroom (1978), and co-produce his final production, Dreamgirls (1981). He would continue to work independently following Bennett's death, providing the musical staging and choreography for Broadway productions of Miss Saigon (1994) and Sunset Boulevard 
(1994), for which he earned Tony Award nominations, as well as London productions of Follies (1987), Martin Guerre (1996), and The Witches of Eastwick (2000). His revival of A Chorus Line, however, represented the only time in which Avian worked on Broadway as a director. Aside from serving as Bennett's Assistant Director for Neil Simon's comedy, God's Favorite (1974), Avian's theatrical resume boasts no directing experience outside of subsequent productions of $A$ Chorus Line. Nominal directing credits combined with a long career in dance perhaps help to explain Avian's chosen strategies for reviving A Chorus Line, particularly as preserving and transferring a choreographer's creative product, reverently and precisely, is customary in the field of dance.

\section{CONCLUSION}

Avian's 2006 revival of $A$ Chorus Line attempted to replicate an inaugural production authentically, representing yet another distinct approach to reviving a timebound musical. However, Avian's revival did not necessarily represent a completely faithful recreation of Michael Bennett's landmark 1975 production. Despite the fact that Avian and his production team made a concerted effort to stage the piece according to Bennett's original template, minor alterations to the musical's libretto and score, combined with Avian's choice to deviate from Bennett's original casting procedures by hiring Broadway newcomers and employing color-blind casting methods revised and opened A Chorus Line's text - a text that (with very few exceptions) had remained closed for thirty-one years. The repeated resurrection of Bennett's production (vis-à-vis national tours and regional stagings) prior to the 2006 Broadway revival arguably reified his template as not only a closed text, but also as a definitive urtext. Consequently, any 
amendments to the original production's blueprint in revival would belie the creative team's repeated claims of authenticity. Avian may have restored Bennett's choreography and staging, but his amendments to the musical's text kept the revival from representing an exact facsimile of the original production. As the desire to preserve A Chorus Line's 1975 production derived from Bennett, Avian's chosen method of revival might have begun as an attempt to confirm Bennett's production as the only legitimate model for the musical. In the end, however, Avian's minor deviations demonstrated that Bennett's model was not a monolith and that A Chorus Line's text was not categorically closed. Furthermore, the director's slight departure from Bennett's template could be seen as lessening some of the musical's ties to its original era. The removal of the dancers' birthdates expunged all citations of time from the libretto. Additionally, Avian's use of color-blind casting introduced more racial and ethnic diversity to the musical's historically white cast - a feature that surely dated the piece to some extent. While the director's choices may have deviated from Bennett's original casting procedures, they were consistent with current casting practices on Broadway and reflected the distinct range of racial and ethnic identities present within the Broadway community.

The slight loosening of $A$ Chorus Line's temporal bonds was continually challenged, however, by Avian and Breglio's imperatives for authenticity. The retention of the original libretto's twenty-eight period references combined with an unaltered score kept the work textually and musically tied to the 1970s. Furthermore, charging the surviving members of the musical's first creative team to slavishly replicate the original production's staging and mise-en-scène restored not only Bennett's vision, but also the formal ties that the musical originally shared with its era. Despite his attempts to 
minimize the presence of time textually, Avian's revival displayed its moment in time through a glut of aural and visual signifiers.

Despite a somewhat disappointing critical and peer response, Avian's revival of $A$ Chorus Line represented a clear commercial success. The production received a respectable run and recouped its initial financial investments in a relatively short span of time, thereby suggesting that the musical was not wholly obsolete. The favor that the revival found with audiences could be attributed to a variety of factors. A Chorus Line was arguably the most recognizable property revived for the 2006-2007 Broadway season. Moreover, the season's musical offerings included several critical successes, such as Scott Frankel and Michael Korie's Grey Gardens, but few unqualified commercial hits outside of Duncan Sheik's Spring Awakening, Nell Benjamin and Lauren O'Keefe's Legally Blonde, and Disney's Mary Poppins. The relative absence of profitable musicals presumably provided fertile ground for $A$ Chorus Line, a renowned and proven Broadway smash. Avian and Breglio's repeated promises of authentic recreation also provided audiences with an extremely rare opportunity: to view a classic American musical in its original form. Avian's stated method of revival appealed to nostalgia and presumably attracted both aficionados of the musical who wanted to observe the musical again and younger musical theatre enthusiasts who had yet to encounter the musical vis-à-vis Bennett's template. By way of authentic reproduction, Avian and Breglio vowed to transport both parties back in time thirty-one years so that they might observe the definitive production of $A$ Chorus Line. None of the season's other musical revivals offered audiences a similar experience. Furthermore, no revival in recent memory had utilized this approach so expressly. Avian and Breglio then provided theatregoers with a 
relatively unique happening. While $A$ Chorus Line itself was no longer of the moment, the event that the revival represented was certainly novel.

The production's markedly mixed reviews, however, and its Tony snubs, challenge the merits of Avian's approach to revival. The production's dearth of critical approval seemed to derive from its perceived lack of creative singularity, especially as the season's reviewers continuously cheered John Doyle and Lonny Price for their comparatively more innovative approaches to staging Company and 110 in the Shade. The mild tenor of the revival's reviews indicates that the critics found Avian's approach uninspired and something of an impediment that kept $A$ Chorus Line from adapting to a new zeitgeist. Moreover, as the critics' chief complaints centered on questions of datedness, the skepticism that initially surrounded the revival, particularly concerning $A$ Chorus Line's timeliness and cultural relevance, might have been well deserved. The musical's confessional premise, so fresh in 1975 and so emblematic of Me Decade values, was relatively commonplace to a viewing public habituated to consuming personal narratives. Moreover, these newer narratives dealt primarily in the search for fame or the creation of a star, and consequently, were incompatible with A Chorus Line's central narrative about dancers who do not struggle for notoriety, but rather the anonymity of the chorus. While Avian and the revival's marketing team frequently likened the musical to such talent competitions as American Idol and So You Think You Can Dance, their comparison is ultimately inaccurate. ${ }^{386}$ In order to resemble these programs, $A$ Chorus Line would have required a new libretto and a new concept in which Zach auditioned fifteen dancers for the starring role in his unnamed musical. Reviews of the season's other revivals indicate that the current crop of critics placed a high premium ${ }^{386}$ Cox, 45. 
on artistic innovation and revisionist approaches, rather than fidelity to the original. Had Breglio and Avian thoroughly revised A Chorus Line's book or re-conceptualized Zach's audition scenario, it is possible that reviewers might have been more receptive to the revival. However, doing so would disprove any claims that the musical is a patently closed text, and furthermore, would displace Bennett as A Chorus Line's chief creative force. Viewing himself as the musical's architect, Bennett himself played a significant role in ensuring that the musical always remained true to his form. Therefore, revising or re-conceptualizing A Chorus Line would necessarily diminish his authorial role.

Despite the misgivings expressed by the revival's critics, A Chorus Line is not so profoundly time-bound that it cannot find relevance with present day audiences. The musical's greatest asset, and arguably the cause of its lengthy first run, was the fact that it presented several archetypal characters and traded in an everyman myth. Audiences could presumably identify with one or more of the dancers' stories, as many of the experiences they related were exceedingly familiar. As Stacy Wolf notes, "the characters suffered the same rites of passage . . . the everyday traumas of finding themselves, yet each character experiences something unique, whether it's a crush on a movie star, walking in on parents having sex, or the childhood desire to grow up and become a kindergarten teacher., ${ }^{\text {, } 87}$ While the stories that the dancers shared did establish them as individuals, the range of common experiences that they articulated served to align them not only with each other, but also with audiences. Additionally, in depicting an audition, A Chorus Line presented a relatively recognizable scenario that could easily serve as an allegory for competitionfor being "on the line" — in a variety of fields. While only one of the critics to review Avian's revival remarked the continued relevance of this metaphor, the various themes ${ }^{387}$ Wolf, 123. 
that spring from it—hard work, tenacity, resilience, and love for one's labor-are relatively eternal.

Even so, the time-bound qualities of $A$ Chorus Line are considerable and present several challenges to directors of future revivals. Replicating Bennett's original production represented an illuminating project, but the choice to favor reverence over innovation arguably re-confirmed the musical as both a museum piece and a cultural artifact. While this approach to revival might work well with Golden Age properties or musicals that have a more yielding relationship with time, it only served to strengthen several of the roots that $A$ Chorus Line shared with its original era. Uprooting the musical from the Me Decade will more than likely require making substantial revisions to its libretto, score, and lyrics, as well as ultimately disassociating the work from Bennett's original production. Preserving the musical as it appeared in 1975 will undoubtedly keep the work rooted to its era and perpetuate the myth that the musical is a closed text. Without more substantial revision than Avian offered, it will be Bennett's version of $A$ Chorus Line that we invariably remember. 


\section{CHAPTER FIVE}

\section{CONCLUSION}

As all musicals are social documents, reflecting the beliefs, assumptions, values, and anxieties of the era in which they were first created, all musicals are to some extent bound to their given moment in time. Regardless of their designated setting, historical import, cultural significance, or continued popularity across decades, all works contain textual, aesthetic, formal, and thematic ties to their original zeitgeist. The strength of these ties determines the extent to which the musical is time-bound. A musical's propensity for time-boundedness is perhaps never more evident than when it is revived years after its original production. When the era that occasioned the piece has passed and the attitudes that it first espoused have changed, a musical that was once fresh and timely can appear quaint, absurd, impolitic, or even myopic to a contemporary audience. Moreover, if the forms of song and dance first employed by that musical are outmoded, and not altered or updated in some way, then the work may read aesthetically as well as socially obsolete. Those works that feature fainter ties to their moment in time tend to be revived more frequently. As they are somewhat less moored to the past, they appear to travel across time rather effortlessly, and consequently, require less authorial or directorial modification in revival. However, musicals that feature more substantial ties to their original era may not traverse time as readily. Despite Thomas S. Hischak's claims these musicals are unrevivable, several time-bound works have been remounted on Broadway to varying degrees of success. ${ }^{388}$

388 Thomas S. Hischak, Boy Loses Girl: Broadway's Librettists (Lanham, MD: Scarecrow Press, 2002), 169. 
This project challenges Hischak's contention that any theatrical work displaying strong ties to its past is unequivocally dated, and therefore unrevivable, and supports Bruce Kirle's belief that all musicals are works-in-process that can and should be revived so long as they are refitted to the era in which they are being produced and made intelligible for present day audiences. ${ }^{389}$ This project has revealed a number of strategies by which production teams have approached the task of "refitting," with varying degrees of success. The purpose of this study was to investigate the various methods and strategies that directors and their creative teams have employed in reviving time-bound musicals on Broadway. The three musicals selected as representative case studies are works that bear strong ties to the era in which they were written and first produced. Despite their canonization and their import to musical theatre history, they are also works that have elicited claims of datedness and unrevivability from critics such as Hischak. In order to understand the challenges that revivalist directors have faced in staging these musicals better, I first determined the nature and degree of each work's timeboundedness through close readings of their respective libretti, lyrics, scores, and original Broadway productions. In addition to noting the instances of period signifiers in each of these texts, I also analyzed the musicals with respect to their original zeitgeists in order to determine how the works' themes or inherent ideologies reflected the dominant beliefs, assumptions, and values of their eras. After assessing the various ways that the musicals classify as time-bound, I examined their Broadway revivals to establish how directors and creative teams addressed each given work's ties its original era. Assessing the efficacy of their efforts required that I analyze the musicals with respect to their revival

${ }^{389}$ Bruce Kirle, Unfinished Show Business: Broadway Musicals as Works-in-Process (Carbondale, IL: Southern Illinois University Press, 2005), 14. 
contexts in an effort to discover how the works might have resonated with critics and audiences in their new cultural moments. In addition to addressing questions of timeboundedness, this study sought to illuminate methods that theatre artists have used to negotiate time-boundedness and to what effect.

The three musicals surveyed in this study demonstrate varying degrees of timeboundedness. The number and potency of each musical's period signifiers differ, which further suggests that time-boundedness is a variable quality that exists on a continuum. Despite such variation, the musicals display similar ties to their respective eras. The first, and perhaps most obvious, demonstration of time-boundedness relates to a musical's content. A work's composite text, comprised of a libretto, lyrics, and score, may contain notable period signifiers. With respect to libretto and lyrics, these signifiers can take the form of cultural allusions and period slang. The musical idioms and instrumentation prescribed in the work's score can also evince a musical's moment in time. In addition to the period notation found in its text, a musical's time-bound nature may derive from its subject matter. If the work depicts current events or is dramaturgically dependent upon its zeitgeist (to the degree that the cultural climate determines character behavior), then its content is considerably more time-bound.

A second manifestation of time-boundedness occurs with regard to a musical's formal, or structural, qualities. All three of the musicals selected for this study emerged from approximately the same moment in musical theatre history and similarly repudiated the Golden Age model of an integrated musical with a linear structure in favor of a concept-driven work with a decidedly more episodic plot. The musicals' comparable dramatic structure was indicative of the Post-Golden Age era and served to fix them to 
the late 1960s and early 1970s. Furthermore, the creative teams that oversaw the musicals' original productions utilized the aesthetics of the era to a considerable degree. By way of their scenery, costumes, and choreography, the theatre artists who brought these works to life strengthened the musicals' formal ties to their era by displaying current tastes and trends in fields such as architecture, fashion, and dance.

A somewhat more elusive form of time-boundedness occurs when a musical's themes and inherent ideologies seem to emerge from the work's original zeitgeist. Less overt than textual or formal ties to the past, these bonds can take the form of metanarratives, rhetoric, attitudes, and character behavior. The three musicals included in this study feature strong thematic ties to their respective zeitgeists. Hair's discussion of war and reflection of the hippie ethos situated the musical's action in the Vietnam era. Company's critique of marriage and consideration of contemporary urban relationships were consistent with the beliefs supporting the sexual revolution that had traveled rapidly from the youth subculture into a somewhat related upper middle-class manifestation. $A$ Chorus Line's presentation of personal narratives and its dramaturgical objective of individuating members of Broadway's dancing corps evinced the prevailing values of the Me Decade.

The nature of these various period signifiers suggest that there are at least four forms of time-boundedness. The first two classifications are more observable and relate to a musical's content and form. The third and fourth categories are slightly more implicit and pertain to a musical's overriding themes and the beliefs that it espouses. Hair, Company, and A Chorus Line demonstrate different degrees of each type of timeboundedness; consequently, each musical poses a different array of challenges to the 
revivalist director. Of the three musicals addressed in this study, Hair appears to be the most securely time-bound. The musical's libretto and lyrics feature fifty-nine instances of period reference and vernacular. These signifiers combined with its unassailable rock score, reflection of hippie culture, and critique of war anchor Hair to the Vietnam era. Moreover, the original production's unstable performance text, frequent reliance on improvisation, and use of period design aesthetics emerged from New York City's burgeoning experimental theatre scene. Hair's status as a watershed event in musical theatre history and a rather omnipresent cultural phenomenon throughout the late 1960s derived in part from the musical's forthright reflection of the era and endowed the work with a certain cultural import; however, because of the musical's time-bound nature, questions of obsolescence threaten to compromise its afterlife. The task of reviving Hair represents a considerable challenge as the volume and strength of its temporal ties are substantial. The historical specificity of the Vietnam War and the hippie movement surely prohibits directors from changing the work's temporal setting without making substantial revisions to its libretto and score. Furthermore, the musical's themes of war, disillusionment, generational conflict, and national tumult are more compelling when they are reflected by the current zeitgeist. With its text, aesthetics, form, and themes firmly grounded in 1960s culture, Hair demonstrates all four forms of time-boundedness to a considerable degree. Consequently, the work is perhaps one of the best exemplars of a profoundly time-bound musical.

Company, by comparison, appears to be relatively less time-bound. Where the cultural unrest of 1968 penetrated nearly every aspect of Hair's dramaturgy, Company, which premiered on Broadway just two years later, did not directly engage or even 
acknowledge the socio-political climate. George Furth's libretto and Stephen Sondheim's lyrics contained only fifteen overt cultural allusions and instances of period parlance. Sondheim's score, which periodically referenced the popular musical idioms of the time, was largely a pastiche that employed a variety of styles from a variety of eras.

Furthermore, the musical's themes of marriage and isolation, as well as its implicit moral regarding an individual's need to cultivate authentic human relationships, are always relevant. Despite its less appreciable relationship with time, Company has elicited claims of datedness that are comparable to that of Hair. These allegations presumably derive from the fact that Company addressed attitudes, beliefs, and behaviors regarding marriage, partnership, and sex endemic to the sexual revolution that were relatively disquieting at the time of its premiere. As perspectives on these issues have evolved over time, Company's ability to shock audiences has apparently diminished. Furthermore, as cultural imperatives for wedlock have lessened over time and the national rates for marriages and divorces exist in a constant state of flux, Company's continued cultural relevance and prospects in the afterlife are relatively tenuous. Company is then somewhat elusively time-bound as its ties to the past are more ideological and pertain to the attitudes and behaviors exhibited by the musical's characters.

A Chorus Line's time-boundedness derives in part from its presumed status as a closed text. Reverence for Michael Bennett's original production and the imperative to re-stage the musical according to the director's template reified A Chorus Line's temporal setting. It also preserved most of the musical's textual and aesthetic ties to its original zeitgeist, which included twenty-eight cultural allusions in its libretto, as well as rock and funk idioms scattered throughout its score. The Me Decade's influence on A Chorus 
Line's dramaturgy is also prominent. At the time of its premiere, critics and audiences found the characters' frank confessions and the candid disclosure of their private pain both shocking and compelling. The musical's themes, however, appear to share a somewhat more enduring relationship with time. As in Company, many of the thematic subjects addressed in A Chorus Line are born of, but not necessarily constrained by, time. The musical's implicit everyman narrative and life-as-an-audition metaphor have universal appeal. With its form, content, and ideology tied to its era, the musical's themes presumably kept the work viable for the duration of its fifteen-year run on Broadway.

The revivals surveyed in this study reveal a range of practices and procedures for re-staging time-bound musicals. In most instances, a director's chosen strategies addressed the ways in which the musical's temporal setting manifests through its content and/or form. While their methods may have altered audience perceptions of the musical's temporal setting, none of the directors intentionally transposed their temporal setting forward in an effort to situate its action in a later era. Consequently, this conclusion will not address the processes of converting a time-bound musical to a distinct, albeit different, moment in time. Instead it will assess how these directors addressed questions of time-boundedness while maintaining or mitigating their given musical's temporal setting.

Tom O'Horgan's revival of Hair in 1977 and Bob Avian's revival of A Chorus Line in 2006 demonstrate concerted attempts to restage an original production authentically. In theory, this approach would conserve a musical's temporal setting and preserve all of its ties to the zeitgeist from which it first emerged. It would also mark the work as an unequivocal period piece. The rhetoric of authenticity that supports this 
approach also presumes the work being revived is a closed text. Rather than opening the musical to new possibilities in performance, authentic reproduction reaffirms the assumption that the musical's original production is definitive and implacable. In the case of both revivals, producers sought to capitalize on the myth of Hair and A Chorus Line's original productions and promised theatregoers a faithful and carefully crafted replica-a pledge that clearly appealed to nostalgia and cultural memory.

Despite these assurances, both revivals failed to demonstrate total fidelity to their original productions. Gerome Ragni and James Rado's revisions to Hair's libretto altered the musical's original text. Moreover, their insertion of more timely cultural allusions threatened to displace Hair's Vietnam era setting. Avian's deviation from Michael Bennett's template for A Chorus Line did not necessarily amend the musical's content or overall dramaturgy; however, it did belie claims of authenticity and arguably modified its subtext. The director's use of color-blind casting not only changed the racial and ethnic identities of two characters, but also implicitly amended their respective backstories. Avian's choice also represented a significance divergence from the casting procedures used throughout the original production's fifteen-year run on Broadway. Both revivals then demonstrate that authenticity is often elusive (if not altogether illusory) and therefore difficult to manufacture, as any variance will necessarily negate it.

Hair and A Chorus Line's validity proves somewhat tenuous, however, as aspects of their original productions resist replication. Both musicals featured a notable affinity between its characters and the performers who portrayed them. In the case of Hair, several members of the acting ensemble were or later became members of the hippie movement. The musical then provided these actors with an opportunity to portray slightly 
fictional versions of themselves and to perform their politics on stage. The allegiance between actor and role was even more pronounced in the original production of $A$ Chorus Line as several members of the cast provided librettists James Kirkwood and Nicholas Dante with the personal narratives that would eventually comprise the musical's book. The characters featured in A Chorus Line, while ultimately fictional, were based upon and tailored to the talents of particular dancers. Furthermore, the stories that the dancers shared were rooted in authentic experience. Faithful reproduction, as a strategy for revival, can preserve most of a musical's ties to its past. However, the revivals of Hair and $A$ Chorus Line suggest that capacity for reproduction is not absolute.

The revivals' differing commercial success and critical response also reveal that authentic reproduction does not necessarily result in favorable outcomes. O'Horgan's revival opened only five years after the original Broadway production of Hair closed. The production's uniformly negative reviews and brief run suggest that the memory of its first run — presumably reified by fourteen concurrent national productions — was still fresh in the minds of theatregoers. Conversely, A Chorus Line's revival proved popular with audiences. Despite mixed critical notices, the production ran on Broadway for almost two years and generated over fifty-four million dollars in ticket sales. This success, combined with the fact that $A$ Chorus Line's revival opened sixteen years after the original production's close, suggests that authentic reproduction, as a method of revival, might benefit from a longer interval between an original production and its revival. With the memory of its original production dampened, a replica revival offers theatregoers a rare opportunity to travel back in time and witness a musical in its initial form. It also marks the musical as a period piece, a designation that critics often use as a 
pejorative. Even so, replication provides a sound strategy for staging time-bound works. This method, however, does not necessarily mitigate a work's inherent ties to the past as much as it accepts them. Reproduction seems to require that theatre artists and audiences acknowledge, and perhaps even forgive, a musical's time-bound nature. While this approach to revival might not represent the most creative of solutions, it does offer one approach to addressing the problem of time-boundedness.

To varying degrees, all of the revivals addressed in this study present the revision of content as a second strategy for attending to a musical's time-bound nature. In cases of content-related time-boundedness, the musicals may read as unintelligible to present day viewers who do not possess the cultural literacy required to understand the meaning or significance of its period signifiers. Other audience members might recognize markers of the past, but only as a distant memory. Time-bound content then threatens to dampen a musical's cultural coherence and perceptions of its universality. As these revivals demonstrate, revising a musical's libretto, lyrics, and score appears to thwart incoherence. The productions staged by Diane Paulus and John Doyle seem to have employed the most textual revision. Both directors, in collaboration with their musicals' librettists, reduced the cultural references and period vernacular found in the musicals' respective libretti and lyrics, thereby loosening the works' ties to their original eras. They also restored material that had been cut from earlier drafts of the libretti in an effort to clarify action and character behavior. Paulus's contributions to Hair took the form of contextual information that familiarized or reminded viewers of the events, laws, and attitudes that dominated American life during the Vietnam era. Presumably, this action strengthened the musical's ties to its temporal setting; however, as the purpose of this 
information was to orient viewers to the cultural landscape, it also arguably increased Hair's cultural coherence. For his revival of Company, Doyle's recovery of an exchange regarding sexuality helped to resolve questions about Robert's orientation that had long haunted the musical. Opening the musical to queer possibility arguably diminished some of the musical's ties to its original zeitgeist as it demonstrated that queerness could exist in a Broadway musical in 2006, particularly with regard to its leading man, in way that it could not in 1970.

The revivals of Company staged by Doyle and Scott Ellis demonstrate further evidence of revision, particularly with regard to the musical's score. Sondheim's original score relied heavily on pit singers and electronic instruments (piano, organ, guitar, and bass) that suited the composer's period use of current musical idioms. Jonathan Tunick's reduction of Company's orchestra and his introduction of synthesizers, digitized and arguably modernized the music in Ellis's revival. Doyle's use of actor-musicians also necessitated a re-orchestration of Company's score. His chosen instrumentation removed any electronic sounds from the work's accompaniment and dampened the score's more overt moments of symphonic rock.

Of the revivals surveyed in this study, Ellis and Doyle's respective productions of Company also demonstrate the greatest degree of formal revision. O'Horgan and Avian's commitment to authentic production preserved the formal qualities of their musicals' original production. Moreover, as Paulus's revival of Hair relied heavily upon the aesthetics of the Vietnam era, her revisions to the musical pertained only to its text. Ellis and Doyle, however, employed distinct metaphors that informed the mise-en-scène of their productions and (to varying degrees) distanced their revivals from Harold Prince's 
original production. Ellis perceived Company's action as occurring in Robert's imagination and sought to create a milieu that appeared timeless. In collaboration with his creative team, however, the director devised a landscape that appeared to denote two decades simultaneously: the 1970s and the 1990s. While displaying the aesthetics of both eras confused critics and arguably rooted the musical to a second moment in time, Ellis's conceit, however ineffective, represented an attempt to mitigate Company's ties to its era through formal revision. Doyle's revival seemed to accomplish Ellis's goal to greater effect. The director's mise-en-scène contained comparatively little period signification. The dearth of temporal markers suggested a landscape removed from time. Furthermore, his use of actor-musicians illuminated a striking production metaphor that visually explicated Company's central conflict. The production's generally positive reviews suggest that critics found Doyle's efforts more effective than those employed by Ellis. Critical response notwithstanding, Doyle's revival represented an even greater departure from Company's original production. Demonstrating evidence of creativity and formal innovation, the production is perhaps the most artistically singular of all the given case studies, making Doyle the most revisionist of the directors.

The strategies for revival employed by the directors in this study represent a range of practices that appeared to be guided by either reverence for an original production or the desire to radically revise its form. These contrasting artistic agendas recall the initial designations given to the American Theatre Wing's award for revivals. In its first two years of existence, the award's name (Most Innovative Production of a Revival) suggested that the organization privileged originality and encouraged directors to reimagine plays and musicals for new audiences. The subsequent designation (Best 
Reproduction of a Play or Musical) implied that the organization now favored fidelity and evaluated revivals on their degree of likeness to an original production. The category's current title (Best Revival of a Musical) no longer denotes evaluative criteria; however, the major New York theatre critics appear to prefer artistry and revision. Of the revivals addressed in this study, Diane Paulus's Hair and John Doyle's Company demonstrated the most innovation in revision and received the most favorable reviews. Conversely, the two revivals that displayed the most fidelity to their original production-O'Horgan's Hair and Avian's A Chorus Line - received collective pans and decidedly mixed notices respectively. Lukewarm reviews notwithstanding, Avian's revival was a success with audiences. The production ran longer and earned more money than revivals staged by Paulus or Doyle.

In addition to demonstrating a variety of approaches to staging time-bound musicals, this study's revivals also reveal a variety of factors that can contribute to the success of a time-bound work in the afterlife. Congruence between the revival's zeitgeist and the musical's themes and/or ideologies appears to be one of the most decisive causes. A time-bound work's thematic and ideological ties to an era are the only temporal bonds that cannot be revised without also substantially revising its content. Therefore, these bonds appear less conspicuous and less dated when they mirror or resonate with the reigning beliefs, assumptions, and values of the revival context. Paulus's revival of Hair clearly benefitted from such accord, particularly as critics and peers found the musical itself compelling even after a thirty-two year absence from Broadway. The widespread social and political unrest that characterized the cultural landscape at the time of the revival provided fertile soil for the musical's discussion of war and its hippie ethos to 
take root. Similarly, the cultural landscape at the time of O'Horgan's revival—a time of comparative peace (or inertia) and marked individualism—-failed to support the musical's themes and ideologies as critics continuously attested. Reviewers made similar charges of discord in their assessment of Avian's revival of A Chorus Line. Alleging that attitudes towards show business success had changed since the musical's original production, critics implied that the incongruence between the musical's metanarratives and the current zeitgeist eroded what once made the musical uniquely compelling. The revival's clear commercial success, however, suggests that critics and audiences may have held differing views.

The length of time that separates an original production from a new staging also appears to be a mitigating factor in a revival's success. Of the five productions surveyed, the revivals that fared best opened thirty years or more after the original production's opening. This extended interval assumedly distances audiences and/or critics from the musical's original era and helps to minimize the memory of its inaugural production, thereby allowing spectators to view the work through relatively fresh eyes. Hair's two Broadway revivals seem to illustrate this phenomenon. O’Horgan's revival, produced only five years after the original production's close, failed to draw audiences or win critical or peer approval, presumably because the memory of the Vietnam War and the musical's first staging was too strong. Conversely, Paulus's revival opened on Broadway almost thirty-seven years after Hair's original run ended. The temporal distance between the musical's first staging and her revival consigned Hair and the Vietnam War to relatively distant history and marked the musical as a period piece. Similarly, John Doyle's production of Company enjoyed thirty-four years of distance from the close of 
Harold Prince's original staging. A significant temporal interval combined with Doyle's revisionist treatment of Company's central concept seemed to distance the musical from its moment in time and exorcise the ghost of Prince's landmark production. By comparison, the critical response to Ellis's production of Company and Avian's production of A Chorus Line seems to indicate that not enough time had passed between the musicals' original productions and their first Broadway revivals. Frequent comparisons to the musicals' initial Broadway productions suggest that the memory of these stagings affected the critics' reception of the revivals.

In each of these case studies, the second Broadway revival of a time-bound work fared better than the first. With regard to critical accolades and the length of their run, Paulus and Doyle's revivals were markedly more successful than those helmed by O'Horgan and Ellis. The relative failure of O'Horgan and Ellis's productions seemed to derive in part from the directors' disregard for or mishandling of the musicals' timebound qualities. These first revivals are illuminating as they might have informed later directors of the challenges associated with staging the musicals. They might have also demonstrated what method and strategies to avoid. While this study does not necessarily provide enough evidence to suggest a trend, the case studies seem to indicate that future revivals might benefit from the mistakes of past revivals.

As musical revivals continue to permeate the Broadway season each year, the revival repertoire continues to expand. The 2012 and 2013 Broadway seasons each boasted five musical revivals. Of these ten musical works, seven had never received a Broadway revival prior to that season: Evita, Godspell, Annie, Cinderella, Jekyll and Hyde, Pippin, and The Mystery of Edwin Drood. The remaining three revived musicals 
included Follies, Jesus Christ Superstar, and Porgy and Bess. The first two musicals were receiving their second Broadway revivals. Porgy and Bess, arguably more of an American folk opera than a traditional book musical, received its seventh Broadway revival. The current Broadway season has only featured two musical revivals, a comparatively smaller number than previous seasons. In order to round out the American Theatre Wing's Best Musical Revival category, the organization classified this year's production of Hedwig and the Angry Inch and Violet as revivals due to their age and relatively long afterlives. However, neither musical has played Broadway prior to this year.

Despite boasting fewer revivals, the current Broadway season witnessed an unprecedented type of revival. The Roundabout Theatre Company produced an authentic reproduction of their critically acclaimed 1998 Broadway revival of Cabaret. Directed by Sam Mendes, the Roundabout's Cabaret came to Broadway by way of London's Donmar Warehouse and represented a radical departure from the original production directed by Harold Prince in 1966. According to Miranda Lundskaer-Nielsen, Mendes's environmental production was "more consistently seedy and sinister than Prince's, evoking a darker reading of [Cabaret's] underlying themes. ${ }^{3390}$ The formal departure represented by Mendes's first revival, coupled with the Roundabout's choice to restage the revival authentically further demonstrates that revivalist practice seems to exist on a continuum between innovation and fidelity to an original production.

The history of the American musical, as is currently recounted, has been a chiefly chronological narrative that charts the growth and development of the form throughout

${ }^{390}$ Miranda Lundskaer-Nielsen, Directors and the New Musical Drama: British and American Musical Theatre in the 1980s and 90s (New York: Palgrave MacMillan, 2008), 129. 
the nineteenth and twentieth centuries using representative "masterworks" to mark significant moments in the form's maturation. These masterworks are almost always discussed as original Broadway productions, thereby reifying the assumption that a musical's original Broadway production is the most significant and definitive iteration of that work, an assumption that this study, and the recent work of innovative, revivalist directors, brings into question. This privileging of original productions tends to neglect any significant discussion of a given musical's afterlife and overlooks the contributions made by those theatre artists who have worked almost exclusively in revivals. However, the preponderance of musical revivals on Broadway and around the world indicates their popularity, their vitality, and their overall significance. Consequently, the historical narrative will need to expand to include musicals' afterlives. This broadening will necessarily alter the manner in which given works are presented. Rather than addressing musicals as complete, contained, and defined by their original Broadway production, scholars and artists should perhaps adopt Kirle's model of works-in-process that have received multiple stagings and will continue to present multiple possibilities in production. As the revival appears to be the province of directors (as opposed to librettists and composers), these new productions will most likely come to be identified by their director-i.e. Diane Paulus's Hair and John Doyle's Company.

The expansion of the revival repertoire also suggests that previously unrevived musicals will eventually return to Broadway. Several of these works are sure to display high degrees of time-boundedness. The musicals addressed in this study represented time-bound works first written and produced between 1968 and 1975. A representative sampling of time-bound works that postdate this era and have yet to receive a Broadway 
revival include I Love My Wife (1977), Ballroom (1978), Woman of the Year (1981), Baby (1983), Chess (1988), Falsettos (1992), Rent (1995), The Full Monty (2000), and Avenue $Q$ (2003). Those works that do return to Broadway will present directors with an array of challenges comparable to those inherent within Hair, Company, and A Chorus Line. With luck, inspiration, and artistry they may succeed in turning the works away from their today and point them toward tomorrow and the afterlife-investing new life and energy into the American musical theatre.

Time-bound musicals serve as potent cultural artifacts that illuminate the nature of their given era. The practice of reviving these musicals not only allows us to analyze, dissect, question, and critique the beliefs, assumptions, and values reflected in the musical, but also to consider them in relation to our own era. Therefore, time-bound works are particularly valuable as their presentation naturally sparks our historical imagination. In order to exploit the value of these musicals' relationship to time, directors and producing organizations must continue to revive them. Moreover, scholars must continue to analyze the strategies that directors have used to stage them. It is my hope that this analysis may be of use to future theatre artists and that similar studies of musical theatre will be undertaken to continue the research and deepen our understanding of this practice. 


\section{APPENDIX A:}

\section{THE MOST FREQUENTLY REVIVED AMERICAN MUSICALS IN BROADWAY HISTORY ${ }^{391}$}

\begin{tabular}{|c|c|c|}
\hline Title/Year of Premiere & Number of Revivals & Years of Revivals \\
\hline Show Boat (1927) & 6 & 1932, 1946, 1948, 1954, 1983, 1994 \\
\hline Guys and Dolls (1950) & 5 & 1955, 1965, 1976, 1992, 2009 \\
\hline Peter Pan (1954) & 5 & 1979, 1990, 1991, 1998, 1999 \\
\hline Brigadoon (1947) & 4 & $1950,1957,1963,1980$ \\
\hline Carousel (1945) & 4 & $1949,1954,1957,1994$ \\
\hline $\begin{array}{c}\text { Fiddler on the Roof } \\
\text { (1964) }\end{array}$ & 4 & 1976, 1981, 1990, 2004 \\
\hline Gypsy (1959) & 4 & $1974,1989,2003,2008$ \\
\hline $\begin{array}{c}\text { Man of La Mancha } \\
\text { (1965) }\end{array}$ & 4 & $1972,1977,1992,2002$ \\
\hline Oklahoma! (1943) & 4 & 1951, 1953, 1979, 2002 \\
\hline Pal Joey (1940) & 4 & 1952, 1963, 1976, 2008 \\
\hline West Side Story (1957) & 4 & 1960, 1964, 1980, 2009 \\
\hline Cabaret (1966) & 3 & 1987, 1998, 2014 \\
\hline Camelot (1960) & 3 & 1980, 1981, 1993 \\
\hline Finian's Rainbow (1947) & 3 & $1955,1960,2009$ \\
\hline
\end{tabular}

${ }^{391}$ Statistics taken from The Internet Broadway Database (http://www.ibdb.com). The chart above does not include musical works that historians traditionally classify as operettas. Because of this, Porgy and Bess (1935), which has received seven Broadway productions, does not appear here as many scholars (including myself) contend that it is more correctly categorized as an American folk opera. Additionally, The Threepenny Opera (1933), which has been revived on Broadway five times and bears a closer resemblance to the American book musical, has not been included here as it written and first produced in Germany. Andrew Lloyd Webber's Jesus Christ Superstar (1971), which has received three Broadway revivals is also not listed here as it was written and first produced in the United Kingdom. 


\begin{tabular}{|c|c|c|}
\hline Floradora (1900) & 3 & $1902,1905,1920$ \\
\hline Hello, Dolly! (1964) & 3 & $1975,1978,1995$ \\
\hline $\begin{array}{c}\text { The King and I (1951) } \\
\begin{array}{c}\text { Little Johnny Jones } \\
(1904)\end{array}\end{array}$ & 3 & $1977,1985,1996$ \\
\hline $\begin{array}{c}\text { The Most Happy Fella } \\
(1956)\end{array}$ & 3 & $1905,1907,1982$ \\
\hline My Fair Lady (1956) & 3 & $1959,1979,1992$ \\
\hline
\end{tabular}




\section{APPENDIX B:}

THE LONGEST RUNNING MUSICAL REVIVALS IN BROADWAY HISTORY ${ }^{392}$

\begin{tabular}{|c|c|c|c|}
\hline Title/Year of Premiere & Year of Revival & Director & Performances \\
\hline Chicago (1975) & 1996 & Walter Bobbie & $7,269^{393}$ \\
\hline Oh! Calcutta! (1969) & 1976 & Jacques Levy & 5,959 \\
\hline Cabaret (1966) & 1998 & Sam Mendes & 2,377 \\
\hline $42^{\text {nd }}$ Street $(1980)$ & 2001 & Mark Bramble & 1,524 \\
\hline Grease (1972) & 1994 & Jeff Calhoun & 1,505 \\
\hline Guys and Dolls (1950) & 1992 & Jerry Zaks & 1,143 \\
\hline Annie Get Your Gun (1946) & 1999 & Graciela Daniele & 1,045 \\
\hline South Pacific (1955) & 2008 & Bartlett Sher & 996 \\
\hline Show Boat (1927) & 1994 & Harold Prince & 947 \\
\hline Kiss Me Kate (1948) & 1999 & Michael Blakemore & 881 \\
\hline No, No Nanette (1925) & 1971 & Bert Shevelove & 861 \\
\hline Anything Goes (1934) & 1987 & Jerry Zaks & 784 \\
\hline Fiddler on the Roof (1964) & 2004 & David Leveaux & 781 \\
\hline The King and I (1951) & 1996 & Christopher Renshaw & 780 \\
\hline A Chorus Line (1975) & 2006 & Bob Avian & 759 \\
\hline West Side Story (1957) & 2009 & Arthur Laurents & 748 \\
\hline Candide (1956) & 1974 & Harold Prince & 740 \\
\hline $\begin{array}{c}\text { A Funny Thing Happened } \\
\text { on the Way to the Forum } \\
\text { (1962) }\end{array}$ & 1996 & Jerry Zaks & 715 \\
\hline
\end{tabular}

392 Statistics taken from The Internet Broadway Database (http://www.ibdb.com).

${ }^{393}$ Statistic current as of May 18, 2014 


\begin{tabular}{|c|c|c|c|}
\hline The Music Man (1957) & 2000 & Susan Stroman & 699 \\
\hline The King and I (1951) & 1977 & Yuriko & 695 \\
\hline
\end{tabular}




\title{
APPENDIX C:
}

\section{PRODUCTION INFORMATION FOR HAIR ORIGINAL 1968 BROADWAY PRODUCTION}

\author{
Opened April 29, 1968 \\ Closed July 1, 1972 \\ 1,750 performances at the Biltmore Theatre \\ Produced by Michael Butler \\ Production Team \\ Directed by Tom O'Horgan \\ Musical Numbers Staged Julie Arenal \\ Scenic Design by Robin Wagner \\ Costume Design by Nancy Potts \\ Lighting Design by Jules Fisher \\ Musical Direction by Galt MacDermot
}

\section{$\underline{\text { Cast }}$}

Claude James Rado

Ron Ronald Dyson

Berger. Gerome Ragni

Woof. Steve Curry

Hud. .Lamont Washington

Sheila .Lynn Kellogg

Jeanie Sally Eaton

Dionne. Melba Moore

Crissy. Shelley Plimpton

Mother Sally Eaton, Jonathan Kramer, Paul Jabara

Father. Robert I. Rubinsky, Suzannah Norstrand, Lamont Washington

Principal. .Robert I. Rubinsky, Suzannah Norstrand, Lamont Washington Tourist Couple Jonathan Kramer, Robert I. Rubinsky 
Waitress. Diane Keaton

Young Recruit.. Jonathan Kramer

General Grant Paul Jabara

Abraham Lincoln Lorrie Davis

Sergeant Donnie Burks

Parents Diane Keaton, Robert I. Rubinsky

The Tribe

Donnie Burks, Lorrie Davis, Leata Galloway, Steve Gamet, Walter Harris, Diane Keaton, Hiram Keller, Marjorie LiPari, Emmaretta Marks, Natalie Mosco, Suzannah Norstrand, Robert I. Rubinsky 


\title{
APPENDIX D: \\ PRODUCTION INFORMATION FOR HAIR 1977 BROADWAY REVIVAL
}

\author{
Opened October 5, 1977 \\ Closed November 6, 1977 \\ 43 performances at the Biltmore Theatre \\ Produced by Michael Butler in association with K.H. Nezhad \\ Production Team \\ Directed by Tom O'Horgan \\ Musical Numbers Staged Julie Arenal \\ Scenic Design by Robin Wagner \\ Costumes by Nancy Potts \\ Lighting by Jules Fisher \\ Musical Direction by Denzil A. Miller, Jr.
}

\section{Cast}

Claude

Randall Easterbrook

Berger. Michael Hoit

Woof. Scott Thorton

Hud. Cleavant Derricks

Sheila Ellen Foley

Jeanie Iris Rosenkrantz

Dionne Alaina Reed

Crissy. Kristen Vigard

Shopping Cart Lady Michael Leslie

Mother Perry Arthur, Annie Golden, Louis Mattioli

Father Eva Charney, James Rich, Martha Wingate

Principal. Michael Leslie, Linda Myers, Carl Woerner

Tourist Couple Perry Arthur, Carl Woerner 
General Grant. ..Carl Woerner

Abraham Lincoln. Linda Myers Parents James Rich, Lori Wagner

The Tribe

Perry Arthur, Emily Bindiger, Paul Binotto, Eva Charney, Loretta Devine, Doug Katsaros, Michael Leslie, Louis Mattoli, Linda Myers, Raymond Patterson, James Rich, James Sbano, Debora Van Valkenburgh, Lori Wagner, Doug Wall, Martha Wingate, Carl Woerner, Charlaine Woodard 


\title{
APPENDIX E: \\ PRODUCTION INFORMATION FOR HAIR 2009 BROADWAY REVIVAL
}

\author{
Opened March 31, 2009 \\ Closed July June 27, 2010 \\ 519 performances at the Al Hirschfeld Theatre
}

\begin{abstract}
Produced by The Joseph Papp Public Theatre/New York Shakespeare Festival, Jeffrey Richards, Jerry Frankel, Gary Goddard Entertainment, Kathleen J. Johnson, Nederlander

Productions, Inc., Fran Kirmser Productions/Jed Bernstein, Marc Frankel, Broadway Across America, Barbara Manocherian/Wencarlar Productions, JK Productions/Terry Schnuck, Andy Sandberg, Jam Theatricals, The Weinstein Company/Norton Herrick and Jugamcyn Theaters
\end{abstract}

\author{
Production Team \\ Directed by Diane Paulus \\ Choreography by Karole Armitage \\ Scenic Design by Scott Pask \\ Costumes by Michael McDonald \\ Lighting by Kevin Adams \\ Musical Direction by Nadia Digiallonardo
}

\section{$\underline{\text { Cast }}$}

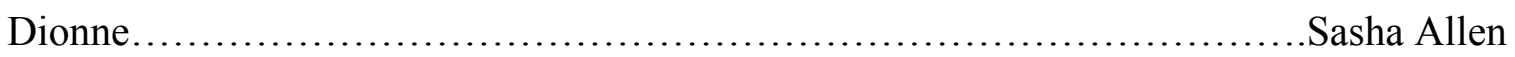

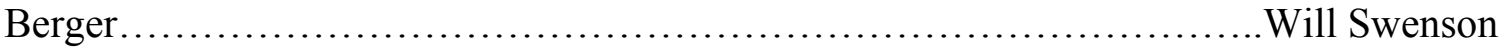

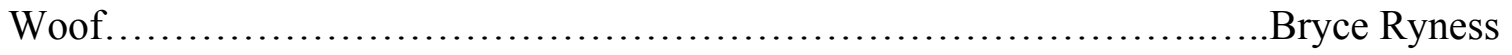

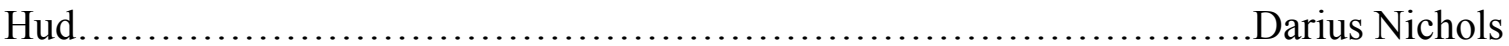

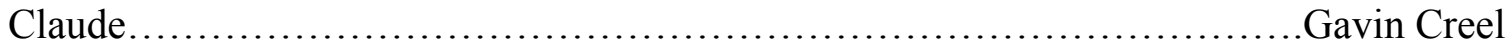

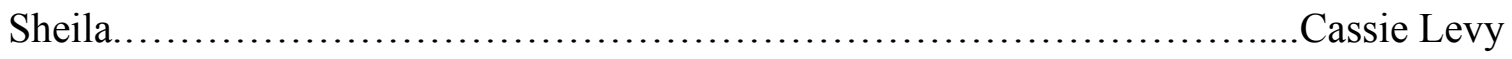

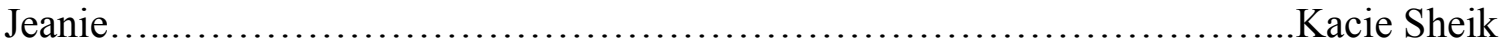

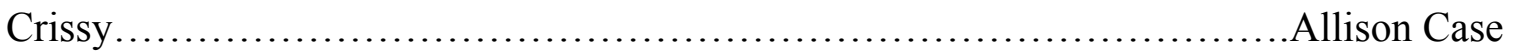

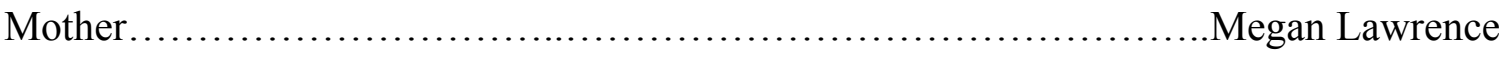


Dad Andrew Kober

Margaret Mead. Andrew Kober

Hubert.................................................... Theo Stockman

Abraham Lincoln. Saycon Sengbloh

Buddahdalirama. .Megan Lawrence

The Tribe

Ato Blankson-Wood, Steel Burkhardt, Jackie Burns, Lauren Elder, Allison Guinn, Anthony Hollock, Kaitlin Kiyan, Megan Lawrence, Nichole Lewis, John Moauro, Brandon Pearson, Megan Reinking, Paris Remillard, Saycon Sengbloh, Maya Sharpe, Theo Stockman, Tommar Wilson 


\title{
APPENDIX F:
}

\section{PRODUCTION INFORMATION FOR COMPANY ORIGINAL 1970 BROADWAY PRODUCTION}

\author{
Opened April 26, 1970 \\ Closed January 1, 1972 \\ 690 performances at the Alvin Theatre
}

Produced by Harold Prince in association with Ruth Mitchell

\author{
Production Team \\ Directed by Harold Prince \\ Musical Numbers Staged by Michael Bennett \\ Sets and Projections by Boris Aronson \\ Costume Design by D.D. Ryan \\ Lighting Design by Robert Ornbo \\ Musical Direction by Harold Hastings \\ Orchestrations by Jonathan Tunick
}

\section{$\underline{\text { Cast }}$}

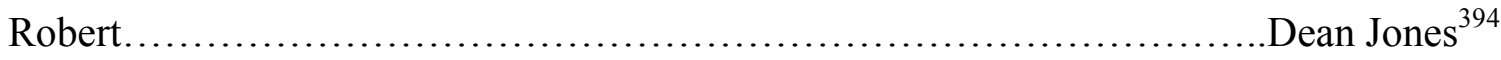

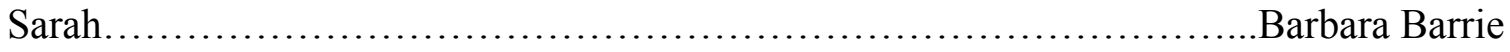

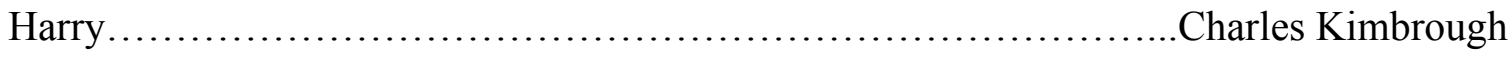

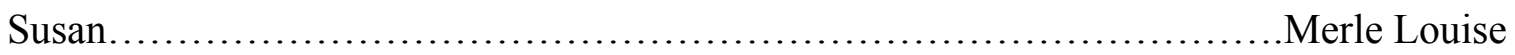

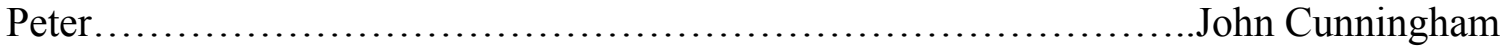

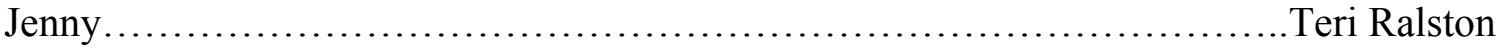

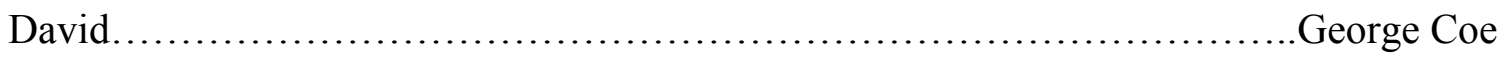

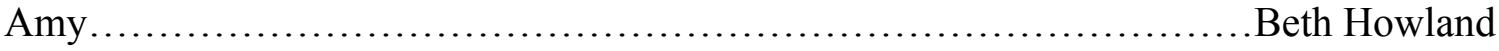

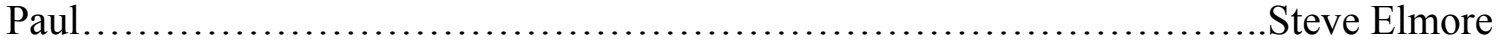

Joanne....................................................... Elaine Stritch

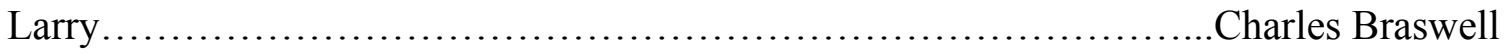

${ }^{394}$ Larry Kert replaced Dean Jones in the role of Robert on May 29, 1970. 


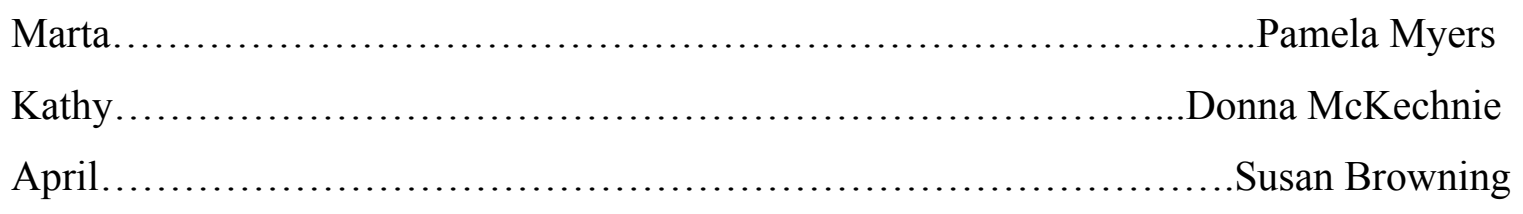

The Vocal Minority

Cathy Corkill, Carol Gelfand, Marilyn Saunders, Dona D. Vaughn 


\title{
APPENDIX G:
}

\section{PRODUCTION INFORMATION FOR COMPANY 1995 BROADWAY REVIVAL}

\author{
Opened October 5, 1995 \\ Closed December 3, 1995 \\ 60 performances at the Criterion Center Stage Right Theatre \\ Produced by The Roundabout Theatre Company
}

Production Team

Directed by Scott Ellis

Musical Staging by Rob Marshall

Scenic Design by Tony Walton

Costume Design by William Ivey Long

Lighting Design by Peter Kaczorowski

Musical Direction by David Loud

Orchestrations by Jonathan Tunick

$\underline{\text { Cast }}$

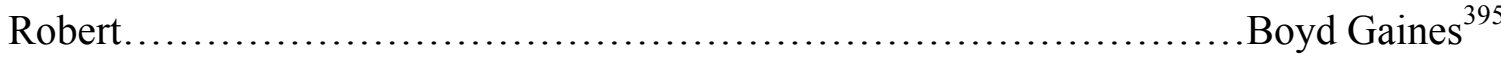

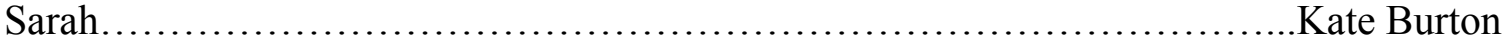

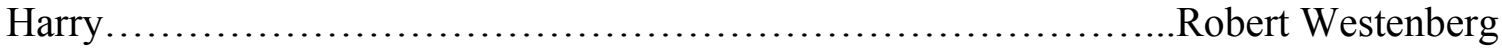

Susan ............................................................. Patricia Ben Peterson

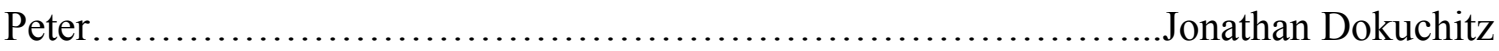

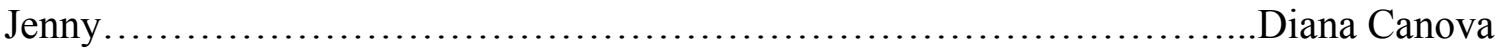

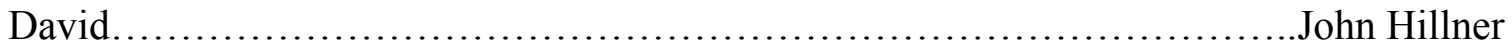

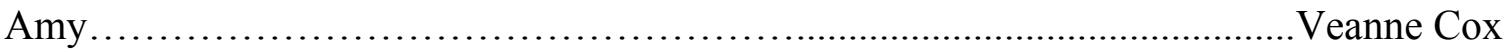

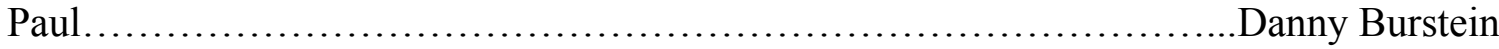

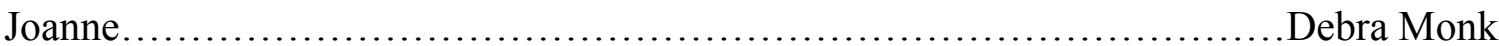

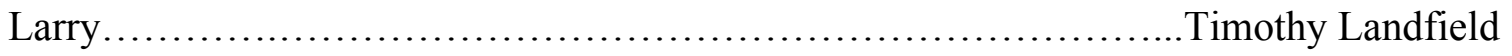

${ }^{395}$ Standby James Clow portrayed Robert at several performances. 


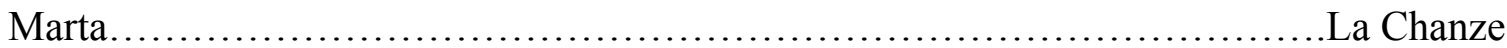

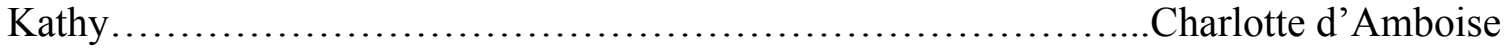

April.........................................................Jane Krakowski 


\title{
APPENDIX H:
}

\section{PRODUCTION INFORMATION FOR COMPANY 2006 BROADWAY REVIVAL}

\author{
Opened November 29, 2006 \\ Closed July 1, 2007 \\ 246 performances at the Ethel Barrymore Theatre \\ and Cincinnati Playhouse in the Park

\section{Production Team} \\ Directed and Choreographed by John Doyle \\ Orchestrations by Mary-Mitchell Campbell \\ Scenic Design by David Gallo \\ Costume Design by Ann Hould-Ward \\ Lighting Design by Thomas C. Hase \\ Sound Design by Andrew Keister
}

Produced by Marc Routh, Richard Frankel, Thomas Viertel, Steven Baruch, The Ambassador Theatre Group, Tulchin/Bartner Productions, Darren Bagert,

\section{Cast}

Robert (Piano).................................................... Eaúl Esparza

Sarah (Flute, Alto Saxophone, and Piccolo).... Kristin Huffman

Harry (Trumpet and Trombone) ... Keith Buterbaugh

Susan (Piano and Orchestra Bells). Amy Justman

Peter (Piano and Double Bass) Matt Castle

Jenny (Violin, Guitar, and Double Bass)

.Leenya Rideout

David (Cello, Alto Saxophone, and Tenor Saxophone). Fred Rose

Amy (French Horn, Trumpet, and Flute). Heather Laws

Paul (Trumpet and Drums) Robert Cunningham

Joanne (Orchestra Bells and Percussion). Barbara Walsh

Larry (Clarinet and Drums) Bruce Sabath 
Marta (Violin and Alto Saxophone).

Angel Desai

Kathy (Flute and Alto Saxophone).................................. Kelly Jeanne Grant

April (Oboe, Tuba, and Alto Saxophone)................................Elizabeth Stanley 


\title{
APPENDIX I:
}

\section{PRODUCTION INFORMATION FOR $A$ CHORUS LINE ORIGINAL 1975 BROADWAY PRODUCTION}

\author{
Opened July 25, 1975 \\ Closed April 28, 1990 \\ 6,137 performances at the Shubert Theatre \\ Produced by The New York Shakespeare Festival \\ Production Team \\ Conceived, Directed, and Choreographed by Michael Bennett \\ Co-Choreographed by Bob Avian \\ Scenic Design by Robin Wagner \\ Costume Design by Theoni V. Aldredge \\ Lighting Design by Tharon Musser \\ Musical Direction and Vocal Arrangements by Donald Pippin \\ Orchestrations by Bill Byers, Hershy Kay, and Jonathan Tunick
}

\section{Cast}

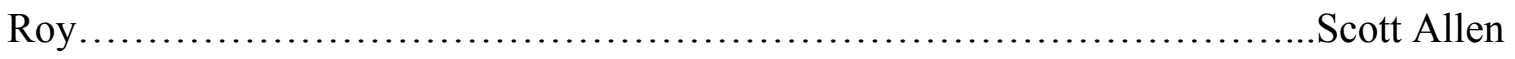

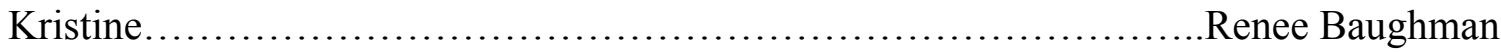

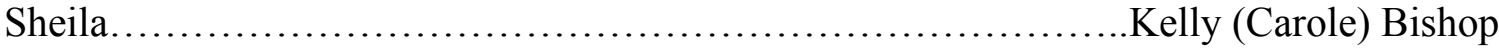

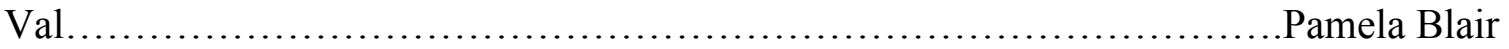

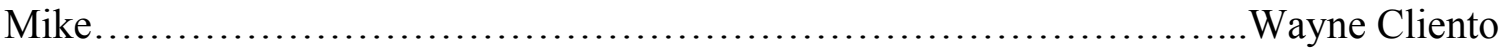

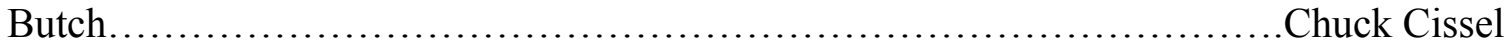

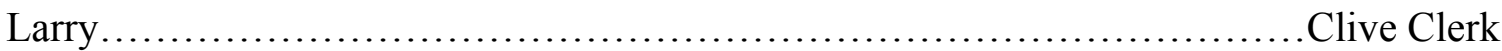

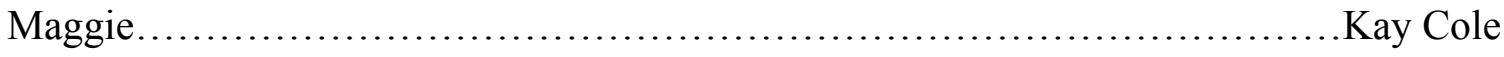

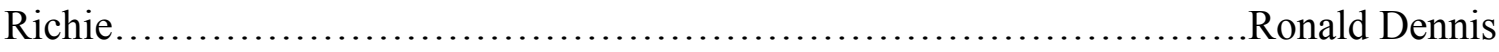

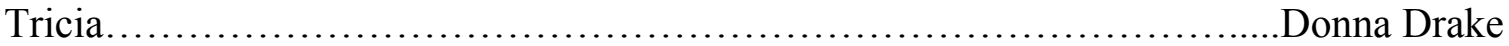

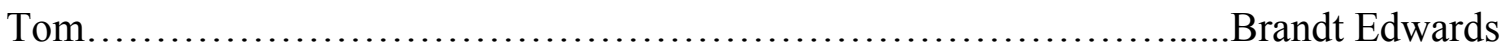

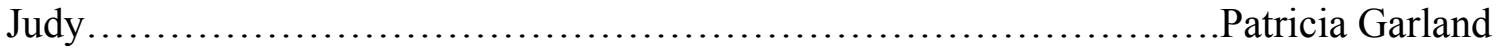

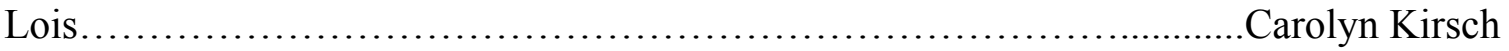




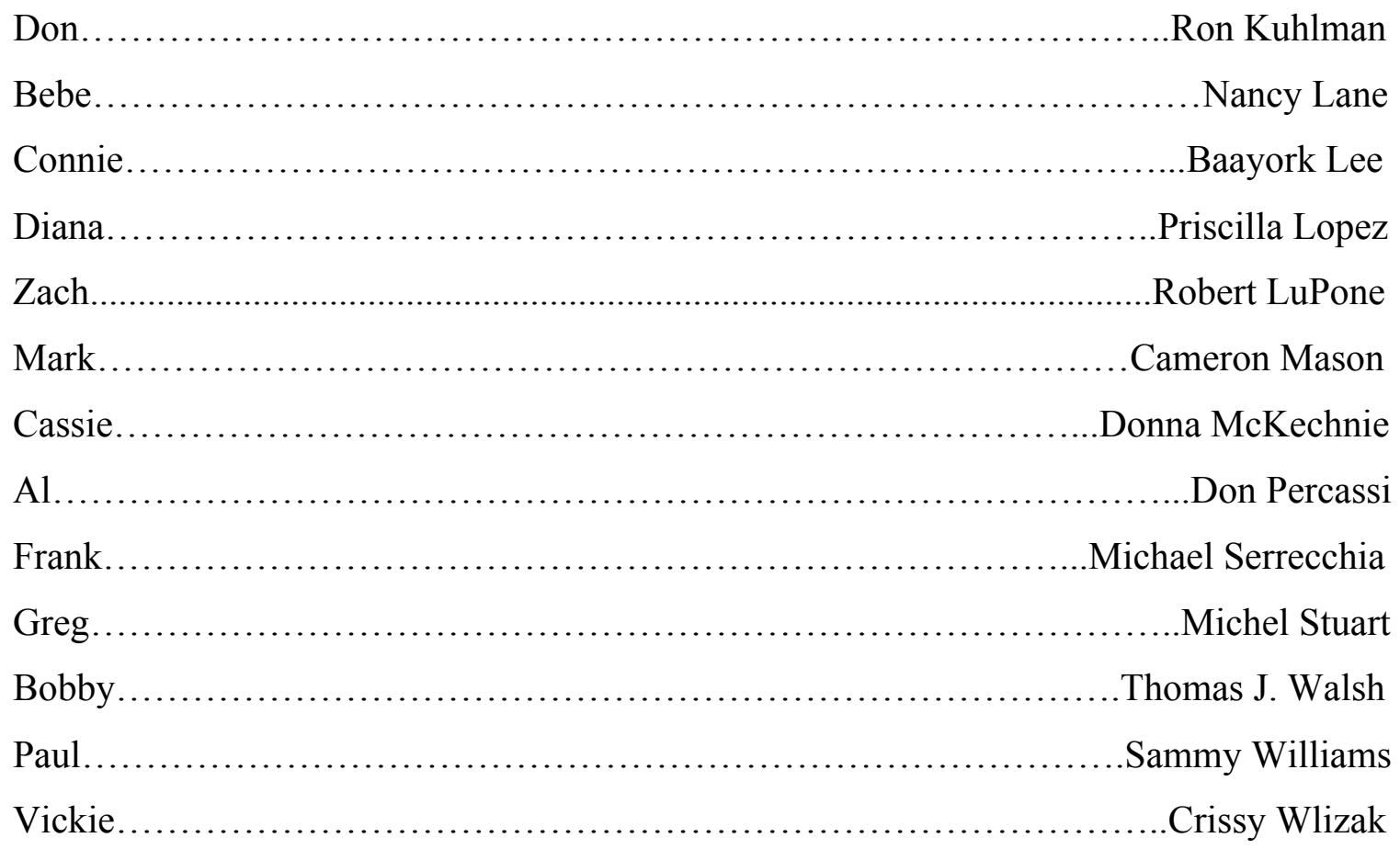




\title{
APPENDIX J:
}

\section{PRODUCTION INFORMATION FOR $A$ CHORUS LINE 2006 BROADWAY REVIVAL}

\author{
Opened October 5, 2006 \\ Closed August 17, 2008 \\ 759 performances at the Gerald Schoenfeld Theatre \\ Produced by Vienna Waits Productions \\ Production Team \\ Directed by Bob Avian \\ Choreography Re-Staged by Baayork Lee \\ Scenic Design by Robin Wagner \\ Costume Design by Theoni V. Aldredge \\ Lighting Design by Tharon Musser and Adapted by Natasha Katz \\ Musical Direction by Patrick Vaccariello \\ Orchestrations by Bill Byers, Hershy Kay, and Jonathan Tunick
}

\section{Cast}

Bobby. . . Ken Alan

Don Brad Anderson

Tricia Michelle Aravena

Roy David Baum

Zach. Michael Berresse

Tom Mike Cannon

Butch E. Clayton Cornelious

Diana Natalie Cortez

Cassie... Charlotte d'Amboise

Maggie Mara Davi

Val Jessica Lee Goldyn

Sheila Deidre Goodwin Larry. Tyler Hanes 
Lois Nadine Isenegger

Richie. James T. Lane

Vickie. Lorin Latarro

Mark Paul McGill

Judy Heather Parcells

Greg. ...Michael Paternostro

Bebe. Alisan Porter

Mike. Jeffrey Schecter

Connie Yuka Takara

Paul. Jason Tam

Frank Grant Turner

Kristine ..Chryssie Whitehead Al. Tony Yazbeck 


\section{BIBLIOGRAPHY}

Allyn, David. Make Love, Not War. The Sexual Revolution: An Unfettered History. Boston: Little Brown, 2000.

Als, Hinton. "Not So Free Love.” New Yorker, April 13, 2009.

American Theatre Wing. "Downstage Center: Diane Paulus." American Theatre Wing Website, mP3 file, http://americantheatrewing.org/downstagecenter/detail/ diane paulus (accessed March 22, 2014).

Aronson, Arnold American Avant-Garde Theatre. New York: Routlege, 2000.

Banes, Sally. Writing Dancing in the Age of Postmodernism. Hanover, NH: University Press of New England, 1994.

Banfield, Stephen. Sondheim's Broadway Musicals. Ann Arbor, MI: University of Michigan Press, 1993.

Barnes, Clive. "Company Offers Guide to New York's Marital Jungle.” The New York Times, April 27, 1970, in Marlow, Joan and Betty Blake ed., New York Critics' Theatre Reviews. Vol. 31. New York: Critics’ Theatre Reviews Inc., 1970.

---. "Embalming Fluidity." Review of A Chorus Line, directed by Bob Avian, New York. New York Post, October 6, 2006.

---. "Hair Holds Up Under Second Look.” Review of Hair, directed by Tom O'Horgan. New York. New York Times, February 5, 1969.

---. “Hair-It's Fresh and Frank." New York Times, April 30, 1968, in Marlow, Joan and Betty Blake ed. New York Critics' Theatre Reviews. Vol. 29. New York: Critics' Theatre Reviews Inc., 1968.

---. “A Tremendous 'Chorus Line' Arrives.” New York Times, May 22, 1975, in Marlow, Joan and Betty Blake ed., New York Critics' Theatre Reviews. Vol. 36. New York: Critics’ Theatre Reviews Inc., 1975.

BBC Radio. "Interview with Bob Avian." Elaine Paige on Sunday. BBC Radio Online, mP3 file, http://www.bbc.co.uk/programmes/p0157vf3 (accessed April 24, 2013).

Beaufort, John. "Reviving Hair Is Notion Whose Time Has Gone." Christian Science Monitor, October 12, 1977, in in Marlow, Joan and Betty Blake ed,, New York Critics' Theatre Reviews. Vol. 38. New York: Critics’ Theatre Reviews Inc., 1977. 
Bechtel, Roger. Past Performance: American Theatre and the Historical Imagination. Lewisburg, PA: Bucknell University Press, 2007.

Bennett, William. A Century Turns: New Hopes, New Fears. Nashville: Thomas Nelson, 2009.

Bordman, Gerald. American Musical Theatre: A Chronicle. Oxford: Oxford University Press, 2010.

Bennett, William. A Century Turns: New Hopes, New Fears. Nashville: Thomas Nelson, 2009.

Berkowitz, Edward D. Something Happened: A Political and Cultural Overview of the Seventies. New York: Columbia University Press, 2006.

Bechtel, Roger. Past Performance: American Theatre and the Historical Imagination. Lewisburg, PA: Bucknell University Press, 2007.

Brantley, Ben. "A Frizzy, Fizzy Welcome to the Untamed 60s." Review of Hair, directed by Diane Paulus, New York. New York Times, April 1, 2009.

---. "From the Top: Five, Six, Seven, Eight!" Review of A Chorus Line, directed by Bob Avian, New York. New York Times, October 6, 2006.

---. “A Revival Whose Surface of Tundra Conceals a Volcano." Review of Company, directed by John Doyle, New York. New York Times, November 30, 2006.

Carlson, Marvin. Theatre Semiotics: Signs of Life. Bloomington, IN: Indiana University Press, 1990.

Carroll, Peter N. It Seemed Like Nothing Happened. New York: Holt, Rinehart, and Winston, 1982. Reprint, New Brunswick, NJ: Rutgers University Press, 1990.

Celello, Kristin. Making Marriage Work: A History of Marriage and Divorce in the Twentieth Century United States. Chapel Hill, NC: University of North Carolina Press, 2009.

Chapman, John "Hair Is Itchy, Twitchy, and Dirty; The Company Dances With Zest" Daily News, April 30, 1968, in Marlow, Joan and Betty Blake ed. New York Critics' Theatre Reviews. Vol. 29. New York: Critics' Theatre Reviews Inc., 1968.

Clendinen, Dudley and Adam Nagourney. Out for Good: The Struggle to Build a Gay Rights Movement in America. New York: Touchstone, 1999.

Coontz, Stephanie. Marriage, A History: From Obedience to Intimacy or How Love Conquered Marriage. New York: Viking, 2005. 
---. The Way We Never Were: American Families and the Nostalgia Trap. New York: Basic Books, 1992.

Crespy, David A. Off-Off-Broadway Explosion: How Provocative Playwrights of the 1960s Ignited a New American Theatre. New York: Back Stage Books, 2003.

Dance, Stanley. "Galt MacDermot: Heir to Hair." Downbeat, November 9, 1972.

Davis, Lorrie. Letting down My Hair: Two Years with the Love Rock Tribe-From Dawning to Downing of Aquarius. New York: A. Fields Books, 1973.

Dalzell, Tom and Terry Victor, eds. The New Partridge Dictionary of Slang and Unconventional English. Vol. 1 New York: Routledge, 2006.

DeLong, J. Bradford. "The Second Great Depression: Why the Economic Crisis is Worse Than You Think." Foreign Affairs, July/August, 2013.

Dyer, Davis et al. Rising Tide: Lessons from 165 Years of Branding at Proctor \& Gamble. Boston: Harvard Business School Publishing, 2004.

Dziemaianowicz, Joe. "Chorus of Approval." Review of A Chorus Line, directed by Bob Avian, New York. Daily News, October 6, 2006.

---. "Hair Is Back: Hip, Hippie, Hooray!" Review of Hair, directed by Diane Paulus, New York. Daily News, April 1, 2009.

Eder, Richard. "Revived Hair Shows Its Gray." New York Times, October 6, 1977, in Marlow, Joan and Betty Blake ed,, New York Critics' Theatre Reviews. Vol. 38. New York: Critics' Theatre Reviews Inc., 1977.

Engel, Lehman. Words With Music: Creating the Broadway Musical Libretto. Rev. ed. New York: Applause Theatre and Cinema Books, 2006.

Farber, David. The Age of Great Dreams: America in the 1960s. New York: Hill and Wang, 1994.

Feingold, Michael. "Musical Chores," The Village Voice 17 October, 1995, in New York Critics' Theatre Reviews. Vol. 55, ed. Joan Marlow and Betty Blake (New York: Critics' Theatre Reviews Inc., 1995), 447.

Foley, Michael S. Confronting the War Machine: Draft Resistance During the Vietnam War. Chapel Hill, NC: University of North Carolina Press, 2003.

Frommer, Myrna Katz and Harvey Frommer. It Happened on Broadway: An Oral History of the Great White Way. New York: Harcourt Brace \& Company, 1998.

Frum, David. How We Got Here: The 70s - The Decade that Brought You Modern Life- 
For Better or Worse. New York: Basic Books, 2000.

Furth, George. Company: A Musical Comedy. New York: Random House, 1970.

---. Company: A Musical Comedy. New York: Theatre Communications Group, 1996.

Gardner, Elysa. "A Line of Talent Lifts 'Chorus'; Broadway Musical Revival is a Little Out-Of-Date, But Not out of Charm." Review of A Chorus Line, directed by Bob Avian, New York. USA Today, October, 9, 2006.

Gerard, Jeremy. "Company." Variety October 9, 1995, in Marlow, Joan and Betty Blake ed., New York Critics' Theatre Reviews. Vol. 55. New York: Critics' Theatre Reviews Inc., 1995.

---. "Hippies of Hair Still Explode With Great Music." Review of Hair, directed by Diane Paulus, New York. Bloomberg News Online, March 31, 2009, accessed July 2, 2012, http://www.bloomberg.com/apps/news?pid=newsarchive \&sid=a7UFUAfVyn28.

Gitlin, Todd. The Sixties: Years of Hope, Days of Rage. New York: Bantam Books, 1993.

Gordon, Joanne. Art Isn't Easy: The Achievement of Stephen Sondheim. Carbondale, IL: Southern Illinois University Press, 1990.

Gottfried, Martin. "Dance, He Said, and They Did," New York Post, May 22, 1975, in Marlow, Joan and Betty Blake ed., New York Critics' Theatre Reviews. Vol. 36. New York: Critics' Theatre Reviews Inc., 1975.

---. Sondheim. Rev. ed. New York: Abrams, 2000.

---. "The Theatre: Company." Women's Wear Daily, April 27, 1970, in Marlow, Joan and Betty Blake ed., New York Critics' Theatre Reviews. Vol. 31. New York: Critics’ Theatre Reviews Inc., 1970.

Gottschild, Brenda Dixon. Joan Myers and the Audacious Hope of the Black Ballerina: A Biohistory of American Performance. New York: Palgrave MacMillan, 2012.

Grode, Eric. Hair: The Story of the Show that Defined a Generation. Philadelphia: Running Press, 2010.

Gross, Mike. "Hair Is Doing Runaway Business as a Score and Play" Billboard, June 27, 1970.

---. "Hair Sets the Style, and Broadway Now Accepts Pop Musicals as First Class Attractions." Billboard, November 6, 1971. 
Hamlisch, Marvin and Edward Kleban. A Chorus Line: Vocal Score. New York: Edwin H. Morris \& Company, 1977.

Harnick, Sheldon. Foreword to Our Musicals, Ourselves: A Social History of the American Musical Theatre, by John Bush Jones. Hanover, MA: Brandeis University Press, 2003.

Harvey, Dennis. "A Chorus Line," Review of A Chorus Line, directed by Bob Avian, San Francisco. Variety, August 4, 2006.

Haun, Harry. “Company Man,” Playbill 95, no. 9 (1995): 47.

Hesburgh, Reverend Theodore. Forward to Chance and Circumstance: the Draft, the War, and the Vietnam Generation, by Lawrence M. Baskir and William A. Strauss. New York: Alfred A. Knopf, 1978.

Hill, Mike. After Whiteness: Unmaking an American Majority (New York: New York University Press, 2004), 3.

Hirsch, Foster. Harold Prince and the American Musical. Expanded ed. New York: Applause Theatre and Cinema Books, 2005.

Hischak, Thomas S. Boy Loses Girl: Broadway's Librettists. Lanham, MD: Scarecrow Press, 2002.

Horn, Barbara Lee. The Age of Hair: Evolution and Impact of Broadway's First Rock Musical. New York: Greenwood Press, 1991.

Ilson, Carol. Harold Prince: A Director's Journey. New York: Hal Leonard Corporation, 1989.

Johnson, Jonathan. Good Hair Days: A Personal Journey With the American Tribal Love-Rock Musical. Lincoln, NE: iUniverse, 2004.

Jones, John Bush. Our Musicals, Ourselves: A Social History of the American Musical. Hanover, MA: Brandeis University Press, 2003.

Kalem, T.E. "Dance of Life," Time, June 2, 1975 in Marlow, Joan and Betty Blake ed., New York Critics' Theatre Reviews. Vol. 36. New York: Critics' Theatre Reviews Inc., 1975.

--- "Defoliated." Time, October 17, 1977, in Marlow, Joan and Betty Blake ed,, New York Critics' Theatre Reviews. Vol. 38. New York: Critics' Theatre Reviews Inc., 1977.

Kerr, Walter. "Company: Original and Uncompromising." New York Times, May 3, 
1970, in New York Critics' Theatre Reviews. Vol. 31, ed. Joan Marlow and Betty Blake (New York: Critics’ Theatre Reviews Inc., 1970), 263.

Killen, Andreas. 1973, Nervous Breakdown: Watergate, Warhol, and the Birth of PostSixties America. New York: Bloomsbury Publishing, 2006.

Kirkwood, James et al. A Chorus Line: The Book of the Musical. New York: Applause, 1975.

Kirle, Bruce. Unfinished Show Business: Broadway Musicals as Works-in-Process. Carbondale, IL: Southern Illinois University Press, 2005.

Kittenplan, Susan. "High Kicks.” Vanity Fair, September 2006.

Knapp, Raymond. The American Musical and the Formation of National Identity. Princeton, NJ: Princeton University Press, 2005.

---. The American Musical and the Performance of Personal Identity.

Princeton, NJ: Princeton University Press, 2006.

Kois, Dan and Scott Brown. "Sunshine Supermen." Review of Hair, directed by Diane Paulus, New York. New York Magazine Online, April 1, 2009, accessed April 24, 2012, http://nymag.com/arts/theater/reviews/55815/.

Jack Kroll, “Broadway’s New Kick,” Newsweek, December 1, 1975.

---. “Defoliated." New York Times, October 6, 1977, in Marlow, Joan and Betty Blake ed, New York Critics' Theatre Reviews. Vol. 38. New York: Critics' Theatre Reviews Inc., 1977.

---. "The Kids on the Line," Newsweek, June 2, 1975, in Marlow, Joan and Betty Blake ed., New York Critics' Theatre Reviews. Vol. 36. New York: Critics' Theatre Reviews Inc., 1975.

Kurlansky, Mark. 1968: The Year That Rocked the World. New York: Random House, 2005.

Lampert-Gréaux, Ellen. “Tribal Revival.” Live Design, May 2009.

---. “The Ultimate Line Dance,” Live Design, December 2006.

Lahr, John. "Sour Ball: The Acid Thoughts of Stephen Sondheim and David Hare." Review of Company, directed by John Doyle, New York. The New Yorker, December 11, 2006.

Lancaster, John. Introducing Op Art. London: BT Batsford Limited, 1973. 
Lasch, Christopher. The Culture of Narcissism: American Life in an Age of Diminishing Expectations. New York: W.W. Norton, 1979.

Lawresnon, Helen. "A Weekend with Chief Michael Butler and His Inner Tribe." Esquire, November 1971.

Lundskaer-Nielsen, Miranda. Directors and the New Musical Drama: British and American Musical Theatre in the 1980s and 90s. New York: Palgrave Macmillan, 2008.

Mandelbaum, Ken. A Chorus Line and the Musicals of Michael Bennett. New York: St. Martin's, 1989.

--- "Company." Review of Company, directed by Scott Ellis, New York. Theatre Week, October 23, 1995.

Marks, Peter. "Dulling a Singular Sensation: Revived A Chorus Line Duplicates the Original, But Not Its Kick." Review of A Chorus Line, directed by Bob Avian, New York. Washington Post, October 9, 2006.

Masterworks Broadway. "A Chorus Line - Bob Avian.” Masterworks Broadway Website, mP3 file. http://www.masterworksbroadway.com/podcast/series/achorus-line (accessed April 24, 2013).

---. “A Chorus Line - Jonathan Tunick.” Masterworks Broadway Website, mP3 file, http://www.masterworksbroadway.com/podcast/series/a-chorus-line (accessed April 24, 2013).

McCarter, Jeremy. "Broadway Melody of 1975." Review of A Chorus Line, directed by Bob Avian, New York, New York, October 6, 2006.

Miller, Jonathan. Subsequent Performances. New York: Faber and Faber, 1986.

Miller, Timothy S. The Hippies and American Values, $2^{\text {nd }}$ ed. Knoxville, TN: University of Tennessee Press, 2011.

Mishkin, Leo. "Hair Explodes on Broadway." Review of Hair, directed by Tom O’Horgan, New York. New York Morning Telegraph, May 1, 1968.

Mitchell, Claudia A. and Jacqueline Reid-Walsh. Girl Culture: Studying Girl Culture - A Reader's Guide. Westport, CT: Greenwood Publishing, 2008.

Murray, Matthew. "A Chorus Line." Review of A Chorus Line, directed by Bob Avian., New York. Talkin' Broadway Reviews, June 29, 2008, http://www.talkinbroadway.com/world/ChorusLine2008.html (accessed February 23, 2013). 
O'Connor, John J. “The Theatre.” Wall Street Journal, May 1, 1968, in Marlow, Joan and Betty Blake ed. New York Critics' Theatre Reviews. Vol. 29. New York: Critics' Theatre Reviews Inc., 1968.

Olson, John. “Company - 25 Years Later.” Stephen Sondheim: A Casebook. ed. Joanne Gordon. New York: Garland Publishing, 1997: 47-68.

Pao, Angela C. No Safe Spaces: Re-casting Race, Ethnicity, and Nationality in American Theatre. Ann Arbor: University of Michigan Press, 2010.

Patinkin, Sheldon. No Legs, No Jokes, No Chance: A History of the American Musical Theater. Evanston, IL: Northwestern University Press, 2008.

Pender, Rick. "Thoughts Shared, Souls Bared: Company Returns to Broadway via John Doyle and 14 Actor-Musicians." The Sondheim Review 13, no. 3 (2007): 8-9.

Peterson, Amy T. and Ann T. Kellogg, eds. The Greenwood Encyclopedia of Clothing Through American History: 1900 to the Present. Westport, CT: Greenwood Press, 2008.

Prideaux, Tom. “That Play Is Sprouting Everywhere.” Life, April 17, 1970.

Rado, James and Gerome Ragni. Libretto to Hair: The American Tribal Love-Rock Musical. Tom O’Horgan Collection. Howard Gotlieb Archival Research Center at Boston University, Boston, MA.

Rich, Frank and Lisa Aronson. The Theatre Art of Boris Aronson. New York: Alfred A. Knopf, 1987.

Román, David. Performance in America: Contemporary U.S. Culture and the Performing Arts. Durham, NC: Duke University Press, 2005.

Rooney, David. “A Chorus Line.” Review of A Chorus Line, directed by Bob Avian., New York, Variety, October 6, 2006.

---. “Company.” Review of Company, directed by John Doyle, New York. Variety, December 4, 2006.

---. “Hair.” Review of Hair, directed by Diane Paulus, New York. Variety, April 1, 2009.

Rose, Lloyd. “Connoisseur’s World.” Connoisseur Magazine, February 1990.

Rothstein, Mervyn. “Back On the Line,” Playbill 25, no. 1 (2006): 10.

Rugg, Rebecca Ann. "What It Used to Be: Nostalgia and the State of the Broadway Musical." Theatre. 32.2 (2002): 44-55. 
Sandla, Robert. “Designer Sketchbook: Company,” TCI 30, no. 1 (1996): 62.

Savran, David. "Toward a Historiography of the Popular." Theatre Survey 45.2 (2004): 211-217.

Schjeldahl, Peter. "Can Hair Be Taught To Hate?" Review of Hair, directed by Tom O’Horgan. New York, New York Times, September 27, 1970.

Secrest, Meryle. Stephen Sondheim: A Life. New York: Alfred A. Knopf, 1998.

Shapiro, Howard. "Thirty-One Years Later, A Chorus Line is Sensational Again in Its Broadway Revival, Even With a Still-Unsettling Sense of Voyeurism.” Review of A Chorus Line, directed by Bob Avian, New York. Philadelphia Inquirer, October 8, 2006.

Simon, John. "Chorus Line Still Fresh in First Broadway Revival." Review of $A$ Chorus Line, directed by Bob Avian, New York, Bloomberg News Online, October 6, 2006, accessed March 3, 2013, http://www.bloomberg.com/apps/news?pid=newsarchive\&sid=aHUUhxigv2PA.

---. On Theatre: Criticism, 1974-2003. New York: Applause Theatre \& Cinema Books, 2005.

Somers, Michael. "Company." Review of Company, directed by John Doyle, New York. The Star-Ledger, November 30, 2006.

Sondheim, Stephen. Finishing the Hat: Collected Lyrics (1954-1981) with Attendant Comments, Principles, Heresies, Grudges, Whines, and Anecdotes. New York: Alfred A. Knopf, 2010.

Stasio, Marilyn. "The Roots of Hair." Cue, October 1-14, 1977.

Stempel, Larry. Showtime: A History of the Broadway Musical Theatre. New York: W. W. Norton, 2010.

Stevens, Gary and Alan George. The Longest Line: Broadway's Most Singular Sensation, A Chorus Line. New York: Applause, 1995.

Steyn, Mark. “Company \& Company,” New Criterion, November 1995.

Swain, Joseph P. The Broadway Musical: A Critical and Musical Survey. New York: Oxford University Press, 1990.

Swayne, Steve. How Sondheim Found His Sound. Ann Arbor: University of Michigan Press, 2007.

Thelen, Lawrence. The Show Makers: Great Directors of the American Musical Theatre. 
New York: Routledge, 2004.

Trynka, Paul, ed., Rock Hardware: 40 Years of Rock Instrumentation. London: Balafon Books, 1996.

Unger, Irwin and Debi Unger. Turning Point: 1968. New York: Charles Scribner's Sons, 1988.

Viagas, Robert et al. On the Line: The Creation of A Chorus Line. New York: William Morrow, 1990.

Vesser, H. Aram. "The New Historicism." The New Historicism Reader. ed. H. Aram Vesser. New York: Routledge, 1994: 1-32.

Vincentelli, Elisabeth. “An Amazing Hair Day.” Review of Hair, directed by Diane Paulus, New York. New York Post, April 1, 2009.

Warfield, Scott. "From Hair to Rent: Is 'Rock' a Four-Letter Word on Broadway." The Cambridge Companion to the Musical, $2^{\text {nd }}$ ed., ed. William A. Everett and Paul R. Laird. Cambridge: Cambridge University Press, 2008: 235-249.

Watt, Douglas. "Company Has Brilliant Fun with Couples in Manhattan." Daily News April 27, 1970, in New York Critics' Theatre Reviews. Vol. 31, ed. Joan Marlow and Betty Blake (New York: Critics' Theatre Reviews Inc., 1970), 263.

---. "Tell Me, Little Gypsy.” Daily News, May 22, 1975, in Marlow, Joan and Betty Blake ed., New York Critics' Theatre Reviews. Vol. 36. New York: Critics' Theatre Reviews Inc., 1975.

---. "Those Were the Days." Daily News, October 6, 1977, in Marlow, Joan and Betty Blake ed,, New York Critics' Theatre Reviews. Vol. 38. New York: Critics' Theatre Reviews Inc., 1977.

Wilcox, W. Bradford. “The Evolution of Divorce,” National Affairs 1 (2009): 81-94.

Wilson, Edwin. "Bring On the Dancing Girls." The Wall Street Journal, May 22, 1975, in Marlow, Joan and Betty Blake ed., New York Critics' Theatre Reviews. Vol. 36. New York: Critics' Theatre Reviews Inc., 1975.

Winer, Linda. "Bobby and Company Were Never So Together." Review of Company, directed by John Doyle, New York. Newsday, November 30, 2006.

---. "Chorus Still Kicking, but Not Quite So High." Review of $A$ Chorus Line, directed by Bob Avian, New York. Newsday, October 6, 2006.

---. “Company," Newsday October 6, 1995, in Marlow, Joan and Betty Blake ed., New 
York Critics' Theatre Reviews. Vol. 55. New York: Critics' Theatre Reviews Inc., 1995.

---. “A Joyous Broadway Hair Transplant.” Review of Hair, directed by Diane Paulus, New York. Newsday, April 1, 2009.

Wintz, Cary D. and Paul Finkelman, eds. The Encyclopedia of the Harlem Renaissance, Volume 2: K-Y. New York: Routledge, 2004.

Wolf, Matt. Sam Mendes at the Donmar: Stepping into Freedom. New York: Limelight Editions, 2003.

Wolf, Stacy. Changed for Good: A Feminist History of the Broadway Musical. New York: Oxford UP, 2011.

Wolfe, Tom. "The Me Decade and the Third Great Awakening." New York Magazine, August 23, 1976.

Wollman, Elizabeth L. The Theater Will Rock: A History of the Rock Musical, from Hair to Hedwig. Ann Arbor: University of Michigan Press, 2006.

Wontorek, Paul. "Scott Ellis Directs Company,” Theatre Week 9.8 (1995): 9.

Zadan, Craig. Sondheim \& Co. New York: Macmillan, 1974. 


\section{VITA}

Bryan M. Vandevender holds a BA in Theatre from North Central College in Naperville, Illinois and an MA in Performance Studies from the Tisch School of the Arts at New York University. His primary research interests include American musical theatre history, the notion of revival, the ethics of theatre criticism, dramaturgy, and pedagogy. Bryan is the recipient of the University of Missouri's Gregory Fellowship, the American Theatre and Drama Society's Graduate Student Fellowship, an MU Graduate Professional Council Travel Award, an MU Graduate School Dissertation Research Travel Award, a Larry Clark Travel Award, a Graduate Theatre Organization Travel Award, and a Catalyst Award. His publications have appeared in Studies in Musical Theatre, Theatre Journal, Theatre History Studies, and Media Ethics: Issues and Cases. He is a member of the Association for Theatre in Higher Education (ATHE), the MidAmerica Theatre Conference (MATC), the American Theatre and Drama Society (ATDS), and Song, Stage, and Screen.

Outside of his work in academe, Bryan is a director and dramaturg. He has worked as a director for the Normal Summer Music Theatre Program in Normal, Illinois since 2008. His productions for NSMT have included Thoroughly Modern Millie (2008), The Sound of Music (2009), Grease (2010), Into the Woods (2011), Les Misérables: School Edition (2012), Xanadu (2013), and Oliver! (2014). His other directing credits 
include Bus Stop, The Santaland Diaries, 8, Dog Sees God: Confessions of a Teenage Blockhead, Working, A Raisin in the Sun, and The Queer Monologues. Prior to his arrival at University of Missouri in 2008, Bryan was the Director of Performing Arts at Josephinum Academy in Chicago, Illinois. 